\title{
Das Problem des Skeptizismus bei Descartes und Locke
}

\section{Dissertation}

\author{
Zur Erlangung des Doktorgrades \\ der Philosophischen Fakultät \\ der Georg-August-Universität zu Göttingen
}

vorgelegt von

Suck-Young Won

aus Seoul, Korea

Göttingen 1999 
Für meine Eltern 
Danksagung

Dies ist die verbesserte und ergänzte Fassung der Arbeit, die im Juni 1997 von der philosophischen Fakultät der Universität Göttingen als Dissertation angenommen wurde.

Ich möchte an dieser Stelle all meinen Lehrern danken: Herrn Prof. Dr. W. Carl, Herrn Prof. Dr. K. Cramer, Herrn Prof. Dr. C. J. Classen und Herrn Prof. Dr. W. Sofsky. Ich darf auch nicht vergessen, meinem Freund P. Baumann, meiner Freundin A. Balestra, und meinen koreanischen Freunden - Chang-zun Kim, Sung-du Ahn, Sung-chul Ghim und ihren Familien -zu danken.

Seoul, im Herbst 1999

Suck-Young Won

\section{7 Göttinger philosophische Dissertation}

Referent:

Korreferent:
Prof. Dr. Wolfgang Carl

Prof. Dr. Konrad Cramer 
Erster Teil: Das Problem des Skeptizismus bei Descartes

Einleitung

I. Die erste Meditation

I.I. Descartes' Eingangsrede zur ersten Meditation

I. I. 1. Ein überraschender Eindruck

15

I. I. 2. Bestätigung des überraschenden Eindruckes

I. II. Das Vorhaben, alle eigenen Meinungen zu überprüfen 21

I. II. 1. Einschränkung des Vorhabens

I. II. 2. Wahrheit, Gewißheit und Methode $\quad 22$

I. II. 3. Zwei Probleme des Vorhabens

I. II. 4. Moores Lösung der Probleme $\quad 29$

I. III. Descartes' Vorhaben, sich aller eigenen Meinungen zu enthalten 31

I. III. 1. Die erste ratio dubitandi: Sinnestäuschung $\quad 31$

I. III. 2. Die zweite ratio dubitandi 3

I. III. 2. 1. Das Traumargument $\quad 34$

I. III. 2. 2. Kritik an Stroud $\quad 40$

I. III. 2. 3. Kritik an Wilson und Frankfurt $\quad 47$

I. III. 3. Die dritte ratio dubitandi: Gott 48

Fazit $\quad \mathbf{5 0}$

II. Die Motivationsfrage in den Regulae $\quad \mathbf{5 6}$

II. I. Descartes über die menschliche Erkenntnisfähigkeit:

Die Frage nach der Rechtfertigung und die Frage nach der Methode 56

II. I. 1. Antwort auf die Rechtfertigungsfrage: intuitus und deductio $\mathbf{5 8}$

II. I. 2. Neue Formulierung der Rechtfertigungsfrage:

Übergang zur Frage nach der Methode $\quad 62$

II. I. 3. Ursprung der Methode:

Antworten auf die Frage nach der Methode und nach der Rechtfertigung $\quad 67$

II. II. Die Motivation des Problems des Skeptizismus

II. II. 1. Die traditionelle Erklärung: Die Repräsentationstheorie $\quad 70$

II. II. 2. Williams' Erklärung: Der Begriff des Wissens $\quad 73$

II. II. 2. 1. Darstellung von Williams' Erklärung $\quad \mathbf{7 3}$

II. II. 2. 2. Probleme von Williams' Erklärung 76 
II. II. 2. 3. Exkurs zu den Regulae: Neue Formulierungen der

Rechtfertigungsfrage und der Frage nach der Methode

II. II. 2. 4. Zurück zu Williams: Kritik

II. II. 3. Mackies Erklärung: Die Repräsentationstheorie in einer anderen Version $\quad \mathbf{8 5}$

II. II. 3. 1. Exkurs zu den Reguale: Die Repräsentationstheorie Descartes' $\mathbf{8 5}$

II. II. 3. 2. Mackies Erklärung: Kritik 93

$\begin{array}{ll}\text { Fazit } & 97\end{array}$

III. Die Motivationsfrage von den Reguale bis zu den späteren Werken Descartes' 98

III. I. Die Frage nach der Methode der naturwissenschaftlichen

Untersuchung in den Regulae $\quad \mathbf{9 8}$

III. I. 1. Ein Vorbehalt

III. I. 2. Die bona mens und das ingenium $\quad \mathbf{1 0 0}$

III. I. 3. Die Methode der naturwissenschaftlichen Untersuchung in den Regulae 102

III. II. Übergang zu Descartes' Entwicklung von den

Regulae bis zu seinen späteren Werken 109

III. III. Neue unerhoffte Reichtïmer: Die Bedeutung der ersten Meditation 111

III. IV. Erklärung der Motivation $\quad \mathbf{1 1 8}$

III. IV. 1. Buchdahls Erklärung $\quad \mathbf{1 1 8}$

III. IV. 2. Descartes' Erklärung $\quad \mathbf{1 2 3}$

Fazit $\quad 130$

Zweiter Teil: Das Problem des Skeptizismus bei Locke $\quad 133$

$\begin{array}{ll}\text { Einleitung } & 133\end{array}$

I. Darlegung des Vorhabens

I. I. Ein erklärungsbedürftiges Phänomen (I) 135

I. II. Ein neues Problem

II. Versuche der Lösung des neuen Problems

II. I. Übergang zu dem neuen Problem

II. II. Erster Versuch der Lösung des neuen Problems:

II. II. 1. Lockes Ausgangsposition im analytisch-deskriptiven Projekt $\mathbf{1 4 5}$ 
II. II. 2. Die generelle Vorstellung der Substanz:

Relativierung von Lockes Position in II.VIII.1.

II. III. Zweiter Versuch der Lösung des neuen Problems

II. III. 1. Weitere Überlegung zur generellen Vorstellung der Substanz:

Bestätigung des Problems

II. III. 2. Relativierung von Lockes Position im Essay, II.XXIII.2.

155

II. III. 3. Relativierung von Lockes Position im Essay, IV.III.11.

159

Fazit

160

III. Erklärungen des fraglichen Phänomens

162

III. I. Ayers' Erklärung

162

III. I. 1. Darstellung von Ayers' Erklärung

163

III. I. 2. Qualitäten als dispositionale Eigenschaften

165

III. I. 3. Locke versus oder cum Descartes: Kritik an Ayers

173

III. II. Pragmatische Überlegungen zu dem erklärungsbedürftigen Phänomen

179

III. II. 1. Lockes pragmatische Erklärung

179

III. II. 2. Locke gegen seine eigene pragmatische Erklärung

182

III. II. 2. 1. Lockes Kritik an der Formtheorie: (RI) als Basis der Erklärung

182

III. II. 2. 2. Lockes Kritik an der Formtheorie: (RI) als Identitätskriterium

184

III. III. Das erklärungsbedürftige Phänomen (II)

189

III. IV. Lockes Kritik an dem Versuch, mit generellen Termini auf reale Essenzen zu referieren

Fazit 


\section{Vorwort}

Diese Arbeit ist durch zwei gegenläufige Überlegungen motiviert. Es wird in der Regel fast als eine Selbstverständlichkeit angesehen, Descartes in Verbindung mit dem Problem des Skeptizismus zu bringen. Ist dies aber wirklich eine Selbstverständlichkeit? Daß dieser Frage eine große Bedeutung zukommt, wird deutlich, wenn wir uns klar machen, daß es eine Zeit gab, in der Descartes das Thema des Skeptizismus überhaupt nicht interessiert hat. Dies war die Zeit der Regulae. Deshalb stellt sich, was das Problem des Skeptizismus bei Descartes angeht, zu allererst nicht die Frage, ob Descartes etwas auf den Skeptizismus entgegnet hat, und wenn ja, was, sondern eher die Motivationsfrage, warum er sich später für das Problem des Skeptizismus interessiert und sich damit beschäftigt hat. Man kann das Thema des Skeptizismus bei Descartes nicht angemessen behandeln, ohne zuerst oder zumindest zugleich die Motivationsfrage zu berücksichtigen. Im ersten Teil dieser Arbeit versuche ich, eine Antwort auf diese Frage zu geben. Dadurch wird die Bedeutung einer anderen Frage klar, nämlich der Frage, wie wir mit dem Problem des Skeptizismus bei Descartes umgehen müssen.

Während es fast selbstverständlich ist, Descartes in Verbindung mit dem Problem des Skeptizismus zu bringen, scheint dies bei Locke nicht der Fall zu sein. Kann man nun die Frage aufwerfen, warum das Problem des Skeptizismus Locke nicht interessiert hat? Diese Frage halte ich nicht für sinnvoll, da ich, anders als Stroud, der Meinung bin, daß die Beschäftigung mit dem Problem des Skeptizismus keine selbstverständliche und unabweisbare Aufgabe ist. Diese Frage ist aber sehr wichtig, - schließlich kann man Lockes Essay ohne Bezugnahme auf Descartes schwer verstehen. Zwar setzt er sich mit Descartes überall kritisch auseinander. Überall findet man aber auch das positive Erbe von Descartes. Warum hat dann ausgerechnet Descartes' Problem des Skeptizismus Locke nicht interessiert? Ist dem überhaupt so? Da ich dies nicht glaube, habe ich im zweiten Teil versucht zu zeigen, daß Locke, obwohl der Essay auf den ersten Blick den Eindruck mangelnden Interesses vermittelt, in Wirklichkeit doch das Problem des Skeptizismus bewußt oder unbewußt vor Augen hatte, als er den Essay schrieb. 


\section{Erster Teil: Das Problem des Skeptizismus bei Descartes}

\section{Einleitung}

Der Skeptizismus ist eine philosophische Position, die auf die Frage nach der Möglichkeit der Erkenntnis nur die Antwort zuläßt, daß diese Frage nicht entschieden werden kann, und es gibt bekanntermaßen viele Argumente, die dafür entwickelt worden sind. ${ }^{1}$ Als so charakterisierte Position scheint der Skeptizismus überall dort auftreten zu können, wo ein Wissensanspruch erhoben wird. Und oft, sogar sehr oft, werden Wissensansprüche erhoben. Trotzdem ist es nicht der Fall, daß all diejenigen, die einen Wissensanspruch erheben, am Skeptizismus Interesse zeigen und bereit sind, sich mit ihm auseinanderzusetzen. Eine Erklärung hierfür wäre, daß sie nicht wissen, daß es eine solche Position gibt. Diese Erklärung ist aber nicht ausreichend. Es ist nämlich nicht der Fall, daß sich all diejenigen, denen der Skeptizismus bekannt ist, für ihn interessieren und bereit sind, sich mit ihm auseinanderzusetzen. Nun kann es selbstverständlich erscheinen, an dieser Stelle zu fragen, woran dies liegt. Aber ist diese Frage wirklich selbstverständlich? Warum sollte das Phänomen der Nicht-Auseinandersetzung mit dem Skeptizismus erklärungsbedürftig sein?

Es gibt Autoren, die glauben, daß das Phänomen der Nicht-Auseinandersetzung mit dem Skeptizismus erklärungsbedürftig ist. Vor allem sind sie der Meinung, daß es nicht so einfach ist, wie oben geschildert, sondern kompliziert und erklärungsbedürftig. Unger behauptet z.B., daß man die skeptischen Argumente zwingend finde, ${ }^{2}$ wenn man mit ihnen konfrontiert werde. Stroud scheint dies auch nicht anders zu sehen. ${ }^{3}$ Aber trotzdem werden sie Ungers Meinung

\footnotetext{
1. Vgl. z.B. Sextus Empiricus, Grundriß der pyrrhonischen Skepsis. Wie Stroud richtig bemerkt hat, wurde der Skeptizismus in der Antike, vor allem für die Anhänger des Pyrrhon von Elis, als ein Lebensweg verstanden, der zur Sorglosigkeit und Ruhe der Seele führen sollte. Die Suche nach der Erkenntnis darüber, wie Dinge in Wirklichkeit sind, schien ihnen nur Sorge und Unruhe in der Seele zu verursachen, da jene Erkenntnis unerreichbar zu sein schien: Nicht Erkenntnis, sondern Meinungsverschiedenheit schien zu herrschen. So wurde die Enthaltung von Meinungen darüber, wie die Dinge in Wirklichkeit sind, als einziges Mittel angesehen, mit dessen Hilfe man zur Sorglosigkeit und Ruhe der Seele gelangen kann. Der Skeptizismus in der modernen Zeit und heute ist aber nicht ein Lebensweg, sondern eher eine These über die Bedingungen der Erkenntnis. Demgemäß muß man den Skeptizismus, wie Stroud richtig behauptet, nicht unbedingt auf Meinungen von allen Gegenstandsbereichen beziehen. Es ist nämlich möglich, daß Erkenntnis in einem Bereich möglich ist, während sie in einem anderen Bereich unmöglich ist. In dieser Arbeit wird hauptsächlich der Skeptizismus in bezug auf die Möglichkeit der Erkenntnis der physikalischen Außenwelt behandelt werden. Vgl. Stroud, The Significance of Philosophical Scepticism, Preface.

2. Unger sagt: "These arguments (Descartes'; d. Verf.) are exceedingly compelling. They tend to make sceptics of us all if only for a brief while.", Ignorance, S. 9.

3. Stroud sagt: "I think that when we first encounter the sceptical reasoning outlined in the previous chapter we find it immediately gripping. It appeals something deep in our nature and seems to raise a real problem about the human condition.", S. 39.
} 
nach so bereitwillig ignoriert, daß man ohne Bedenken weiter Wisssensansprüche erhebt, als ob nichts geschehen wäre. Wenn diese Schilderung Ungers zutrifft, ist jenes Phänomen in der Tat merkwürdig und einer Erklärung bedürftig. Da er seinerseits fest davon überzeugt ist, daß der Skeptizismus Recht hat, erklärt er das Phänomen folgendermaßen: "we don't connect the (sceptical; d. Verf.) arguments with enough other things of interest to hold our prolonged attention, not even our attention in pursuing our philosophical interests. ${ }^{14}$ Dies läßt vermuten, daß der Schwerpunkt der Aufgabe Ungers eher darin liegt, dem Skeptizismus, der ohnehin schon argumentative Überzeugungskraft besitzt, zusätzlich Wirkungskraft zu verleihen, als darin, direkt für den Skeptizismus zu argumentieren.

Stroud hingegen geht in die umgekehrte Richtung. Damit ist nicht gemeint, daß er das Phänomen, daß man von den skeptischen Argumenten zunächst beeindruckt ist und sie dann recht schnell ignoriert, für selbstverständlich hält. Auch er hält dieses Phänomen für erklärungsbedürftig. Aber anders als Unger scheint er dazu zu neigen, jenes Phänomen als ein Zeichen dafür anzusehen, daß die skeptischen Argumente irgendwie absurd oder unverständlich sind. Wenn sie trotzdem einen besonderen Eindruck auf uns machen, hat dies eigentlich nichts damit zu tun, daß sie zutreffend sind, sondern einfach damit, daß es uns noch nicht gelungen ist, ihre Absurdität und Unverständlichkeit ans Licht zu bringen. Dies ist der Grund dafür, daß Stroud das Problem der Widerlegung des Skeptizismus als ein rein strategisches Problem ansieht. ${ }^{5}$ Seine Betrachtung einiger repräsentativer Typen von Widerlegungsversuchen des Skeptizismus hat demgemäß den Charakter einer Strategieanalyse. Er führt sie nämlich durch, indem er sich nicht auf die Frage konzentriert, ob der Skeptizismus Recht hat oder nicht, sondern eher auf die Frage, warum die Anti-Skeptiker keinen Erfolg erzielen konnten, mit anderen Worten, welchen strategischen Fehler sie begangen haben. So gesehen kann man sagen, daß das zu erklärende Phänomen der NichtAuseinanderstzung mit dem Skeptizismus bei Ungers und Strouds Beschäftigung mit dem Problem des Skeptizismus eine bemerkenswerte Rolle gespielt hat.

Erfasst Ungers Schilderung unser Verhalten den skeptischen Argumenten gegenüber richtig, dann gibt es einen Unterschied bezüglich des Verhaltens der Menschen heute und zu Descartes' Zeit. ${ }^{6}$ Descartes nämlich fand, daß die skeptischen Argumente nicht nur überzeugende Kraft besäßen, ${ }^{7}$ sondern auch nachhaltig seien: Der Skeptizismus blühe. Aber er

\footnotetext{
${ }^{4}$. Unger, S. 9.

5. Vgl. Stroud, Kapitel VII, besonders, S. 200.

${ }^{6}$. Vgl. Popkin, The History of Scepticism from Erasmus to Spinoza, 1979, Kapitel II-VIII

${ }^{7}$. Vgl. Brief an Mersenne vom März 1636. Dies ist der Grund dafür, daß er in De Methodo darauf verzichtet hat, skeptische Argumente ausführlich zu entwickeln, obwohl er dies dafür notwendig fand, seine Beweise für den substantiellen Unterschied der Seele vom Körper und für die Existenz Gottes verständlicher zu machen. Die deutsche Übersetzung der Briefe zitiere ich nach folgender Ausgabe: René Descartes Briefe (1629-1650), übers. v. Fritz Baumgart.
} 
glaubte weder, daß dies ein Zeichen dafür sei, daß der Skeptizismus die richtige Position sei, noch, daß die skeptischen Argumente auf jeden Fall absurd seien. Wenn diese auf den ersten Blick den letzteren Eindruck vermitteln, so beruht dies nur darauf, daß sie nicht der Methode entsprechen, welche wir in unserem normalen Alltagsleben und in den Wissenschaften anwenden, um Erkenntnisse oder Überzeugungen zu erwerben. Dies besagt aber nicht, daß sie absurd sind. Eher das Gegenteil ist der Fall. Sie sind nämlich nach Descartes für den Aufbau der wichtigsten aller Wissenschaften notwendig, nämlich für den Aufbau der Metaphysik, die allen anderen Wissenschaften die Grundlagen liefern sollte. Der Grund dafür, daß der Skeptizismus trotzdem verfehlt ist, liegt nicht in seinen Argumenten, sondern vielmehr in der unvollständigen Entwicklung seiner Argumente. Wenn man sie nämlich richtig, d.h. radikal genug, entwickelt, liefert dies uns nach Descartes die Möglichkeit, die Existenz Gottes zu beweisen $^{8}$ und damit auch die Möglichkeit der Erkenntnis bezüglich der physikalischen Außenwelt überhaupt zu erweisen: Der Skeptizismus widerlegt sich durch seine eigenen Argumente. All dies zu zeigen, stellt Descartes sich als Aufgabe in den Meditationes. Zu diesem Zweck entwickelt Descartes in der ersten Meditation skeptische Argumente und versucht in der sechsten Meditation, sie zu widerlegen. So konnte die Widerlegung des Skeptizismus als das zentrale Thema in den Meditationes erscheinen, und seitdem ist es in der Diskussion über den Skeptizismus zur Tradition geworden, auf die erste Meditation zurückzugreifen. Unger und Stroud sind diesbezüglich keine Ausnahmen.

Wilson hält diese zentrale Stellung des Skeptizismus in der Interpretation der Meditationes für problematisch. Obwohl sie nicht bestreitet, daß die Widerlegung des Skeptizismus ein wichtiges Thema ist, ist dies ihrer Meinung nach dennoch weder das einzige noch das zentrale Thema. Es gibt bekanntermaßen auch andere Themen, die genauso wichtig sind: nämlich der Beweis der Existenz Gottes, die Unterscheidung der Seele vom Körper und die Ausarbeitung der Grundlagen der neuen Physik. ${ }^{9}$ Aber dies ist nicht der Grund dafür, daß sie die zentrale Betonung des Skeptizismus für problematisch hält. Es geht vielmehr um die Probleme besonders bei der Interpretation der ersten Meditation -, die auftreten, wenn man die skeptischen Argumente isoliert von den anderen Themen und allein mit Bezug auf das Thema des Skeptizismus interpretiert. Es gibt nämlich noch andere Funktionen, die Descartes den

\footnotetext{
${ }^{8}$. Descartes schreibt in einem Brief vom März 1638: "Obgleich die Pyrrhoniker nichts Sicheres auf Grund ihrer Zweifel gefolgert haben, so heißt das nicht, daß man es nicht könne. Und ich würde hier zu zeigen versuchen, wie man sich ihrer bedienen kann, um die Existenz Gottes zu beweisen, indem ich die Schwierigkeiten aufhelle, die ich in meinen Äußerungen darüber belassen hatte."(Baumgart, S. 114); "Bien que les Pyrrhoniens n'aient rien conclu de certain en suite de leurs doutes, ce n'est pas à dire qu'on ne le puisse. Et je tâcherai ici de faire voir comment on s'en peut servir pour prouver l'existence de Dieu, en éclaircissant les difficultés que j'ai laissées en ce que j'en ai écrit."(AT II, S. 38-39)

9 . Was Descartes' eigene Hinweise auf dieses letzte Thema betrifft, siehe die Briefe an Mersenne vom 11. November 1640 und vom 28. Januar 1641. Wilson scheint dazu zu neigen, dies als das zentrale Thema anzusehen.
} 
skeptischen Argumenten in der ersten Meditation zugeschrieben hat: "he (Descartes; d. Verf.) is also concerned to use this problem (of traditional scepticism; d. Verf.) to present convincingly an anti-empiricist metaphysics, a form of (rationalist) 'scientific realism"'. ${ }^{10}$ Diese Funktionen können nicht ans Licht gebracht werden, wenn man die skeptischen Argumente ohne Bezug auf die anderen Themen, nur als solche betrachtet. Eine Funktion, die Wilson dabei besonders wichtig findet, ist die, die dem Traumargument bezüglich der Grundlagen der Physik zukommt. In dieser Hinsicht ist es "not a barren exercise, which ultimately results in adding some fastidious bit of super-certainty to the normal assurance one already had about things seen, felt or calculated"'11, sondern ein realer Zweifel. Wir werden im ersten Kapitel dieses Teils sehen, in welcher Weise das Traumargument diese Funktion erfüllt.

Hatfield macht einen weiteren Schritt in diese Richtung, wenn er behauptet: "And although Descartes no doubt was pleased that his Meditations contained an answer to scepticism, answering the sceptics was the least of his concerns". ${ }^{12}$ Auch die Grundlagen der neuen Physik scheinen ihm kaum das zentrale Thema der Meditationes zu sein (S. 260). Seiner Meinung nach verlangt Descartes nämlich nach wie vor in den Meditationes einerseits keinen stärkeren Standard der Gewißheit als in der Mathematik und ist andererseits bereit, einen schwächeren Standard der Gewißheit in der Physik zu akzeptieren. Aus dieser Überlegung heraus sucht Hatfield die eigentliche Aufgabe der Meditationes anderswo, und er findet sie in der Metaphysik. Die Aufgabe soll darin bestehen, die Relation zwischen dem Verstand, der Natur und Gott neu aufzufassen. Dabei spielt die erste Meditation die rein methodologische Rolle, uns von sinnlichen Vorurteilen fernzuhalten, was uns auf die Verfolgung der metaphysische Diskussion vorbereiten sollte.

D.M. Clarke macht einen entscheidenden Schritt in diese Richtung, nämlich Descartes nicht so eng mit dem Problem des Skeptizismus in Verbindung zu bringen. ${ }^{13}$ Seiner Meinung nach hat nicht nur das Thema des Skeptizismus, sondern auch die Philosophie keine große Bedeutung für Descartes: "Rene Descartes is, in many ways, a victim of his own success as a philosopher."(S 3). Und er korrigiert die übliche Vorstellung über ihn als Philosophen, indem er ihn "as a practising scientist who also concerned himself with methodological, theological and metaphysical questions" beschreibt.

Nun lautet das Thema des ersten Teiles dieser Arbeit "Das Problem des Skeptizismus bei Descartes". Damit ist nicht nur vorausgesetzt, daß Descartes Interesse am Skeptizismus hatte,

\footnotetext{
${ }^{10}$. Wilson, Descartes, S. 8. Dazu vgl. Synopsis; AT VII, S. 12 und Descartes' Antwort auf Hobbes' Frage nach dem Grund der Entwicklung der skeptischen Argumente; AT VII, S. 171-2.

${ }^{11}$. Wilson, S. 8.

${ }^{12}$. Hatfield, Reason, Nature, and God in Descartes in Essays on the Philosohy and Science of Rene' Descartes, S. 261.

${ }^{13}$. Vgl. D.M. Clarke, Descartes' philosophy of science, Kapitel I.
} 
sondern auch, daß er ihn für problematisch hielt. Und wie wir zwar vorhin kurz bemerkt haben, aber in der Folge genauer betrachten werden, hatte Descartes in der Tat Interesse am Skeptizismus, fand ihn problematisch und hielt es deswegen für nötig, ihn zu widerlegen, und versuchte es auch. Aber warum all dies? Wie wir gesehen haben, ist die Auseinandersetzung mit dem Skeptizismus keine Selbstverständlichkeit für diejenige, die Wissensansprüche erheben. Descartes war hier keine Ausnahme. Es gab nämlich eine Zeit, in der der Skeptizismus für Descartes kein Thema war: die Zeit der Regulae. Warum hat er es später dann für nötig gehalten, sich mit dem Skeptizismus auseinanderzusetzen und ihn zu widerlegen? Eine angemessene Antwort auf diese Frage zu finden, ist die Aufgabe dieses Teils meiner Arbeit. Dadurch wird mit gezeigt werden, von welcher Bedeutung das Thema des Skeptizismus in den Meditationes und darüber hinaus bei Descartes ist. Trotzdem will ich hier darüber ein paar Bemerkungen machen, bevor ich näher auf mein Thema eingehe.

Ich bin der Meinung, daß das Problem des Skeptizismus und damit auch der Versuch der Widerlegung des Skeptizismus als das zentrale Thema der Meditationes und auch für Descartes im Allgemeinen angesehen werden sollte. Noch einmal: Es ist nicht für alle, die Wissensansprüche erheben, selbstverständlich, sich für den Skeptizismus zu interessieren und sich mit ihm auseinanderzusetzen. Dies gilt auch für Descartes. Ob sie dazu verpflichtet sind, und ob man ihnen deswegen einen Vorwurf machen kann, sind offene Fragen. Stroud behauptet, daß viele Philosophen durch ihre eigenen Erkenntnistheorien dazu verpflichtet seien. ${ }^{14}$ Ich bin nicht sicher, ob er damit Recht hat. Aber wenn man der Meinung ist, daß der Skeptizismus eine Bedrohung für die Möglichkeit der Erkenntnis ist und deswegen widerlegt werden sollte, und wenn man in der Folge den Versuch macht, ihn zu widerlegen, dann finde ich es überflüssig zu sagen, daß es kein wichtigeres Unternehmen als diesen Versuch gibt. Dies gilt auch für Descartes.

Woher kommt trotzdem die Tendenz bei einigen Kommentatoren wie Wilson, ${ }^{15}$ Hatfield und Clarke, das Thema des Skeptizismus von Descartes mehr oder weniger zu trennen?

Eine Antwort wäre diese: Obwohl die Frage, ob Descartes bei seinem Versuch der Widerlegung des Skeptizismus Erfolg hat oder nicht, eine völlig andere Frage ist, habe ich den Verdacht, daß sein Mißerfolg diese Kommentatoren zu ihrer Interpretation geführt hat. Sollte dies der Fall sein, irren sie sich.

\footnotetext{
${ }^{14}$. Stroud, Preface, viii-ix.

15. Obwohl ich mit ihr völlig einverstanden bin, daß Descartes sich nicht einfach mit dem traditionellen Problem des Skeptizismus beschäftigt, also mit der Rechtfertigung der Möglichkeit der Erkenntnis, sondern darüber hinaus auch mit dem Inhalt dieser Erkenntnis, finde ich es unglücklich, daß die Bedeutung des Problems des Skeptizismus bei Descartes in ihrer Interpretation dadurch zu gering eingeschätzt wird. Wilson findet nämlich die Funktion der skeptischen Argumente zuletzt hauptsächlich darin, "to leave us, provisionally, with a shadow of doubt or unease, particularly with reference to sense experience." S. 26.
} 
Eine andere Antwort wäre diese: Jene Interpreten haben ihrerseits eine bestimmte Vorstellung vom Problem des Skeptizismus, derzufolge es unabhängig und isoliert von anderen wissenschaftlichen Tätigkeiten betrachtet werden kann. Wenn dies der Fall ist, ist ihre Vorstellung von der Descartes' völlig verschieden.

Descartes meint, daß nicht alle sich mit dem Problem des Skeptizismus und den metaphysischen Problemen in De Methodo oder in den Meditationes beschäftigen müßten, und daß man sich, wenn überhaupt, nur einmal im Leben mit diesen Problemen beschäftigen müsse. Clarke glaubt, daß dies ein Zeichen dafür sei, daß Descartes diese Probleme gering schätze. ${ }^{16}$ Aber dies ist ein Mißverständnis. "Nur einmal" bedeutet nicht "niemals" und "nicht alle" bedeutet nicht "niemand". Vor allem ist die Rede von "nur einmal" und "nicht alle" kein Zeichen dafür, daß Descartes die Probleme für unbedeutend hält. Sie sind wichtig, wie Descartes an mehreren Stellen unmißverständlich sagt. Man sollte den Grund dafür, daß Descartes jenen Rat gegeben hat, eher anderswo suchen. Er liegt darin, daß Descartes glaubt, daß er die Probleme gelöst habe, und daß es ausreichend sei, daß er die Probleme gelöst habe. Sein Rat zielt darauf ab, einen Unterschied zwischen verschiedenen Leuten zu machen. ${ }^{17}$ Er rät nicht allen ohne Unterschied, sondern nur einigen Leuten, sich mit den erwähnten Problemen zu beschäftigen. Um den Grund dafür zu verstehen, müssen wir die Art und Weise betrachten, in der er zu jenen Problemen, besonders zum Problem des Skeptizismus, gekommen ist.

Es ist wichtig darauf hinzuweisen, daß sein Versuch, den Skeptizismus zu widerlegen, nicht aus dem Wunsch entstanden ist, Andere vor ihm zu schützen. ${ }^{18} \mathrm{Er}$ hat das Problem des Skeptizismus eher im Lauf seiner eigenen Suche nach der Wahrheit gefunden und es als das größte Hindernis erkannt, das jener Suche im Wege steht. Dies ist der Grund dafür, daß er es für notwendig gefunden hat, den Skeptizismus zu widerlegen. Und dies ist auch der Grund für ihn, zu glauben, daß er nicht der einzige sei, der das Problem erkennt und einen Lösungsversuch macht, denn er kann sich vorstellen, daß alle, die die Wahrheit suchen, sich ähnlich verhalten würden. Descartes zufolge hat es aber wenig Sinn, sich mit einem Problem zu beschäftigen, wenn man dazu nicht durch eigene Überlegungen, sondern dadurch geführt worden ist, daß man von anderen gelernt oder erfahren hat, daß es ein Problem ist. In diesem Fall ist es nämlich schwer, die Lösung nachzuvollziehen, die die anderen gefunden haben, geschweige denn sie selbst zu finden. ${ }^{19}$ Darauf beruht sein Rat.

\footnotetext{
${ }^{16}$. Vgl. D.M. Clarke, ebd.

${ }^{17}$. Dieser Punkt wird besonders deutlich in seinem Rat an Burman und Elizabeth. D.M. Clarke beruft sich darauf. Vgl. Ge spräch mit Burman, AT V, S. 165, Brief an Elizabeth vom 28. Juni 1643 und D.M. Clarke, S. $3 \mathrm{ff}$.

${ }^{18}$. Vgl. Williams, Descartes's Use of Skepticism, in The Skeptical Tradition, S. 338.

${ }^{19}$. Vgl. 6. Buch von De Methodo.
} 
Es ist die Aufgabe dieses Teils der Arbeit, die Wege zu verfolgen, auf denen Descartes dazu kam, sich mit dem Skeptizismus auseinanderzusetzen. Es geht hier nicht darum, seinen Widerlegungsversuch zu betrachten und zu bewerten, sondern nur darum zu verstehen, warum er einen solchen Versuch für nötig gefunden hat. Demgemäß gliedert sich dieser Teil in drei Kapitel. Im ersten Kapitel werde ich die erste Meditation interpretieren. Es geht dabei um die Frage, wie Descartes versucht, alle seine Meinungen in Frage zu stellen. Im zweiten Kapitel werde ich Descartes' Gedanken in der Zeit der Regulae verfolgen, indem die Überlegung angestellt wird, ob man die Motivation identifizieren kann, die Descartes zu der Beschäftigung mit dem Problem des Skeptizismus geführt hat. Im dritten Kapitel werde ich Descartes' Entwicklung von den Regulae bis zu seinen späteren philosophischen Werken verfolgen, indem dieselbe Überlegung angestellt wird. 


\section{Die erste Meditation}

\section{I. Descartes Eingangsrede zur ersten Meditation}

\section{I. 1. Ein überraschender Eindruck}

"Schon vor einer Reihe von Jahren habe ich bemerkt, wieviel Falsches ich in meiner Jugend als wahr habe gelten lassen und wie zweifelhaft alles ist, was ich hernach darauf aufgebaut, und daß ich daher einmal im Leben alles von Grund aus umstoßen und von den ersten Grundlagen an neu beginnen müsse, wenn ich endlich einmal etwas Festes und Bleibendes in den Wissenschaften ausmachen wolle. Indessen schien mir dies ein gewaltiges Unternehmen zu sein, und ich wartete daher das Alter ab, welches so reif sein würde, daß ihm unmöglich ein anderes nachfolgen könnte, das zur Erwerbung der Wissenschaften noch geeigneter wäre. .....Und da trifft es sich günstig, daß ich heute meinen Geist von allen Sorgen befreit habe, daß ich mir eine sichere Muße in einsamer Zurückgezogenheit verschafft habe: so will ich denn endlich ernsten und freien Sinnes zu diesem allgemeinen Umsturz meiner bisherigen Meinungen schreiten."(Buchenau, S. 11; Hervorhebung d. Verf.) ${ }^{20}$

Dies ist Descartes' Eingangsrede zur ersten Meditation. Sie ruft Überraschung hervor und damit auch das beunruhigende Gefühl, sofort darauf reagieren zu müssen. Dennoch ist schwer zu sehen, wie wir am besten und schnellsten darauf reagieren können. Jene Passage ist nämlich einerseits sehr allgemein formuliert und vermittelt andererseits den Eindruck, daß Descartes davon überzeugt ist, nicht nur zu wissen, sondern auch tun zu können, was nötig ist. Betrachten wir die Eingangsrede genauer.

Descartes stellt als Ziel der Meditationes heraus, die ersten Grundlagen anzugeben, auf denen etwas Gewisses und Bleibendes in den Wissenschaften gegründet werden kann. Er glaubt, daß dafür der Umsturz aller eigenen Meinungen eine notwendige Bedingung sei, und ist davon überzeugt, daß es möglich sei, diese zu erfüllen. Was dabei zunächst überrascht, ist nicht einfach die Überzeugung, alle eigenen Meinungen umstürzen zu können, obwohl dies allein schon überraschend genug ist. Es ist vielmehr seine Erklärung der Art und Weise, wie er überhaupt auf die Idee des Unternehmens gekommen ist, alle eigenen Meinungen umzustürzen. Zunächst die Frage: Was hat Descartes auf diesen Gedanken gebracht?

\footnotetext{
20. "Animadverti iam ante aliquot annos, quam multa, ineunte aetate, falsa pro veris admiserim, \& quam dubia sint quaecunque istis postea superextruxi, ac proinde funditus omnia semel in vita esse evertenda, atque a primis fundamentis_denuo inchoandum, si quid aliquando firmum \& mansurum cupiam in scientiis stabilire; sed ingens opus esse videbatur, eamque aetatem expectabam, quae foret tam matura, ut capessendis disciplinis aptior nulla sequeretur. ..... Opportune igitur hodie mentem curis omnibus exsolvi, securum mihi otium procuravi, solus secedo, serio tandem \& libere generali huic mearum opinionum eversioni vacabo." (AT VII, S. 17-18; Hervorhebung d. Verf.). Die deutsche Übersetzung der Meditationes zitiere ich nach folgender Ausgabe: Meditationen, übers. v. Buchenau.
} 
Descartes' Antwort auf diese Frage scheint einzig und allein in Erfahrungen zu liegen, die auch uns sehr vertraut sind: Viele Meinungen, die er sich früher angeeignet hat, haben sich später als falsch erwiesen, und deswegen sollten alle Meinungen, die er sich aufgrund jener Meinungen angeeignet hat, unsicher sein. Dies läßt uns zuerst annehmen, daß der Status der Meinung, auf die der Akt der eversio bezogen wird, darin besteht, daß sie falsch oder ungewiß ist. ${ }^{21}$ Wenn dem so ist, haben die oben genannten Erfahrungen ihn zum Gedanken geführt, daß es möglich ist, daß alle eigenen Meinungen falsch oder unsicher sind. Dies ist aber nicht nachvollziehbar. Obwohl solche Erfahrungen ausreichen, uns darauf aufmerksam zu machen, daß nicht alle unsere Meinungen wahr oder sicher sind, können sie uns doch nicht in dem Gedanken rechtfertigen, daß es möglich ist, daß sie alle falsch oder unsicher sind.

Würden wir nun gegen Descartes sagen, daß er den einfachen logischen Fehler begangen hat, aus der universalen Möglichkeit des Irrtums die Möglichkeit des universalen Irrtums abzuleiten? Wir können es. Aber trotzdem würden wir bemerken, nicht genug getan zu haben, auch wenn wir Recht haben. Die Situation nämlich, in der wir jetzt sind, scheint nicht Teil unseres Alltagslebens zu sein, in dem die Suche nach Wissen oft dadurch beendet wird, daß wir jemanden finden, der uns glaubwürdig Informationen über etwas liefern kann. Descartes hat nicht einfach die Möglichkeit offen gelassen, daß alle eigenen Meinungen falsch oder unsicher sind, sondern erweckt darüber hinaus den Eindruck, daß er davon überzeugt sei. Sonst hätte er es nicht als eine notwendige Bedingung für sein Ziel formulieren können, alle eigenen Meinungen umzustürzen. Er fügt noch hinzu, daß er sich lange Zeit darauf vorbereitet habe, dies zu tun, und daß er es nun tun werde. Damit versetzt Descartes uns in eine Prüfungssituation, in der der Prüfer, der über Wissen von etwas verfügt, prüft, ob wir Wissen haben, wenn wir behaupten, daß etwas der Fall sei. ${ }^{22}$ Obwohl wir von unseren Meinungen nur allgemein sagen können, daß es nicht der Fall ist, daß sie alle falsch oder unsicher sind, scheint uns dies nicht zu helfen, es sei denn, daß wir identifizieren, welche von ihnen wahr und sicher sind. Und dies ist schwer möglich, wenn nicht unmöglich.

Die bisherige Betrachtung zeigt, daß der überraschende Eindruck, den Descartes' Eingangsrede vermittelt, nicht aufgrund einer solchen Überlegung entsteht. Sie scheint eher dazu beizutragen, jenen Eindruck zu schwächen als zu verstärken, indem sie uns vom eigentlichen Thema "alle Meinungen" ablenkt und sich nur auf solche Meinungen konzentriert, auf welche Descartes' Irrtumserfahrungen zutreffen. Jener Eindruck rührt eher daher, daß wir wissen, daß es unter unseren Meinungen viele wahre Meinungen gibt, deren Wahrheit wir

\footnotetext{
${ }^{21}$.Was Descartes mit dem Terminus eversio meint, unter welchen Bedingungen der Umsturz einer Meinung stattfinden sollte, und wie er versucht, jene notwendige Bedingung zu erfüllen, sind Fragen, die wir in den auf diesem Abschnitt folgenden Abschnitten Schritt für Schritt beantworten werden. Aber bezüglich meiner Überlgung dieses Abschnittes sind sie alle irrelevant. Hier geht es nämlich nur darum zu überlegen, wie Descartes auf die Idee des Unternehmens gekommen ist, alle eigenen Meinungen umzustürzen.

${ }^{22}$. Vgl. Williams, Deciding to believe in ders., Problems of the Self, S. 146
} 
sicher sind, und daß wir immer in der Lage sind, sie zu identifizieren, wenn es nötig ist. Z.B. können wir an dieser Stelle auf Descartes reagieren, indem wir darauf hinweisen, daß "Ich habe zwei Hände. ${ }^{123}$ oder " 2 plus 2 ist 4" wahr ist, auch wenn wir zu Descartes' Gunsten annehmen, daß allein der Hinweis auf die universale Möglichkeit des Irrtums viele unserer Meinungen als unsicher erweisen kann. Wir können aus der bisherigen Betrachtung zwei Konsequenzen ziehen. Die erste ist die, daß die oben genannten Erfahrungen uns nicht zu der Vermutung führen, daß alle unsere Meinungen falsch oder unsicher sind. Die zweite ist die, daß der Grund dafür nicht darin liegt, daß wir allgemein glauben, daß es unter unseren Meinungen wahre und sichere Meinungen gibt, sondern vielmehr darin, daß wir darüber hinaus immer in der Lage sind, solche Meinungen anzugeben. Dies ist der eigentliche Grund dafür, daß Descartes' Eingangsrede einen überraschenden Eindruck vermittelt.

\section{I. 2. Bestätigung des überraschenden Eindruckes}

Ich habe aber Bedenken, ob eine solche Reaktion auf Descartes berechtigt ist. Er hat nämlich weder über uns noch über unsere Meinungen gesprochen, sondern bloß über sich selbst und seine eigenen Meinungen. Was hindert ihn denn daran, aufgrund seiner oben genannten früheren Erfahrungen auf den Gedanken zu kommen, daß es möglich sei, daß alle seine Meinungen falsch oder unsicher seien? Was hindert ihn daran, dadurch veranlaßt zu erwägen und nachzuprüfen, ob er in der Tat wahre Meinungen hat, deren er sicher ist? Es ist ja nicht unmöglich, daß er in der Tat herausgefunden hat, daß er keine solchen Meinungen hat. Ist dies gerade der Grund dafür, daß er im zweiten Teil von De Methodo sehr stark betont, daß sein Unternehmen eine rein private Angelegenheit sei? So erklärt er unmißverständlich, worum es bei seinem Unternehmen geht:

"Mein Unternehmen erstreckte sich nie weiter als auf den Versuch, meine eigenen Meinungen zu reformieren und auf einem Grund aufzubauen, der gänzlich meiner ist." (AT VI, S. 548; übers. v. d. Verf. $)^{24}$

Wenn dies der Fall wäre, wäre sein Unternehmen als rein privates nicht so interessant. ${ }^{25}$ Dies scheint aber nicht der Fall zu sein. Er sagt nämlich in seiner siebten Erwiderung Folgendes, indem er die Gesamtheit seiner Meinungen mit einem Korb von Äpfeln vergleicht:

\footnotetext{
${ }^{23}$. Vgl. Moore, Proof of external World in ders., Philosophical Papers

24. "Nunquam ulterius mea cogitatio provecta est, quam ut proprias opiniones emendare conarer, atque in fundo qui totus meus est aedificarem."

${ }^{25}$. Ist dies der Grund dafür, daß Descartes die Meditationes (natürlich auch De Methodo) in "ich-Form" verfaßt hat?
} 
"Wenn z.B. einer einen Korb mit Äpfeln hat und fürchtet, es könnten einige von den Äpfeln faul sein, und er sie aussondern will, damit nicht die übrigen schlecht werden, wie würde er das anstellen? Würde er nicht vor allem alle samt und sonders aus dem Korbe werfen, dann die einzelnen der Reihe nach durchsehen und nur die, die er als nicht verdorben erkennt, nehmen und sie wieder in den Korb legen und die anderen zurücklassen?" (Buchenau, S. 416) ${ }^{26}$

Obwohl Descartes hier anders als in der Eingangsrede der Meditationes den Terminus rejicere statt des Terminus' evertere verwendet, ist ohne weiteres klar, daß er die beiden Termini synonym verwendet. So verstanden zeigt das Beispiel im Zitat, daß es Descartes zufolge darum geht, sich einer Meinung zu enthalten: Die Pointe des Beispiels liegt nämlich darauf, den Korb zu entleeren.

Abgesehen davon schließt auch Descartes, wie wir im Zitat sehen können, nicht allein aufgrund seiner oben genannten Erfahrungen die Möglichkeit aus, daß er wahre oder sichere Meinungen hat. Daraus ergibt sich, daß seine Erfahrungen auch ihn nicht zu der Meinung führen konnten, daß alle seine Meinungen falsch oder unsicher sind. Trotzdem beharrt Descartes darauf, sich aller Meinungen und damit auch aller wahren Meinungen zu enthalten. Warum? Der von ihm im Zitat gegebene Grund dafür scheint sehr schwer nachvollziehbar zu sein. Obwohl es möglich ist, daß falsche Meinungen zur Bildung unsicherer Meinungen führen, so hat dies doch nichts mit den Meinungen zu tun, deren Wahrheit man sicher ist. Auch seine methodologische Begründung kann uns kaum davon überzeugen, und zwar nicht deswegen, weil es eine andere, bessere Alternative gibt, sondern vielmehr deswegen, weil es einfach keinen Grund gibt, aus dem man sich einer Meinung enthalten muß, deren Wahrheit man sicher ist.

Frankfurt behauptet aber erstens, daß die oben genannten Erfahrungen ausreichend dafür seien, uns zu der Frage zu führen, ob alle unsere Meinungen falsch oder unsicher seien, zweitens, daß es gemäß dem Ziel Descartes' (der Suche nach der Gewißheit) ein normales und vernünftiges Verfahren sei, sich aller Meinungen zu enthalten, und schließlich, daß darin keine Schwierigkeit bestehe. ${ }^{27}$ Frankfurt gibt keine Erklärung für die erste Behauptung. Aber wir haben schon gesehen, daß sie falsch ist. Seine Begründung für die zweite Behauptung will ich hier nicht betrachten. Sie ist genauso wie die Descartes' schwer nachvollziehbar. Aber dies ist nicht der Grund dafür, daß ich sie hier nicht betrachten will. Der Grund liegt eher in Folgendem. Die ersten beiden Behauptungen sind keine Konsequenzen, die er aus der Überlegung gezogen hat, ob, wie und wieweit Descartes' Verfahren und Unternehmen nachzuvollziehen sind, geschweige denn aus der Frage, wie Descartes in der Tat verfährt. Sie

\footnotetext{
26. "Si forte haberet corbem pomis plenam, \& vereretur ne aliqua ex pomis istis essent putrida, velletque ipsa auferre, ne reliqua corrumperent, quo pacto id faceret? An non in primis omnia omnino ex corbe rejiceret? ac deinde singula ordine perlustrans, ea sola, quae agnosceret non esse corrupta, resumeret, atque in corbem reponeret, aliis relictis?" (AT VII, S. 481)

${ }^{27}$. Vgl. Frankfurt, Demons, Dreamers, and Madmen, S. 17ff.
} 
sind eher zusätzliche Behauptungen, die er aufgestellt hat, nachdem er die Frage betrachtet und positiv entschieden hat, ob es überhaupt möglich ist, sich aller Meinungen zu enthalten. Damit gehen wir von der Frage, warum Descartes glaubt, daß er sich aller seiner Meinungen enthalten müsse, zur Frage über, ob dies möglich ist. Frankfurt behauptet, daß es möglich sei. Zur Begründung greift er auf Descartes' Theorie des Fällens eines Urteils in der vierten Meditation zurück. Das Fällen eines Urteils sei, so sagt er, eine reine Willenssache für Descartes, und demgemäß könne er sich allein mit Hilfe des Willens und ohne weiteres auf einmal aller seiner Meinungen und damit auch seiner wahren Meinungen enthalten. ${ }^{28}$ Es ist wahr, daß Descartes in der vierten Meditation das Fällen eines Urteils auf einen Willensakt zurückführt, und seine Formulierung kann eine Interpretation von der Art Frankfurts veranlassen. Trotzdem ist es nicht nur naiv, sondern auch verfehlt, seine Theorie so zu interpretieren. Dies würde in der Folge die absurde These erlauben, daß wir uns willkürlich eine Meinung aneignen, uns ihrer enthalten und sie auch für falsch halten können. ${ }^{29}$ Dies ist jedoch nicht der Fall.

Descartes führt das Fällen eines Urteils auf einen Willensakt zurück, aber weder ohne Ausnahmen noch ohne Einschränkung. Er führt nämlich das Fällen eines Urteils auf die Zusammenarbeit von Verstand und Willen zurück und betont, daß der Wille nur dem Verstand folgen sollte, obwohl er dem Willen den letzten Akt im Urteilen zuschreibt. Descartes' Verfahren in der ersten Meditation spiegelt dies am besten wieder. Descartes stellt sich in den Meditationes als eine Person dar, die sich einzig und allein die Suche nach der Wahrheit zur Aufgabe stellt und glaubt, daß dafür die radikale Anwendung der Methode des Zweifelns der richtige Weg sei: Wenn irgendein Grund angeführt wird, aus dem eine Meinung oder eine Klasse von Meinungen nicht sicher sein kann, muß sie aufgegeben werden. Aber während der radikalen Anwendung dieser Methode zeigt sich, daß die meisten eigenen Meinungen aufgegeben werden müssen, bis man auf die Aussagen trifft, die man nicht bezweifeln kann: "ut nunquam possimus de iis cogitare, quin vera esse credamus: ut quod ego, dum cogito, existam; quod ea, quae semel facta sunt, infecta esse non possint,..."(AT VII, S. 145) Diese Aussagen sind die Aussagen, die den Zweifel Descartes' beenden und einen Wendepunkt herbeifuihren. Dies kann zweierlei bedeuten. Es kann einen entscheidenden Mangel seiner Theorie ausmachen, da es bei solchen Urteilen überhaupt keine Funktion für den Willen gibt. Es kann aber auch bedeuten, daß seine Theorie nicht die absurde These erlaubt, daß der Willensakt gegen die Gründe oder Evidenzen ausgeübt werden kann, die man für oder gegen eine

\footnotetext{
${ }^{28}$. Frankfurt ist in der Tat vom Zitat (AT VII, S. 481) und von dieser Theorie so stark beeindruckt, daß er Descartes' Verfahren in der ersten Meditation mit Rekurs auf das Zitat interpretiert. Die skeptischen Argumente sind demnach nicht eingeführt worden, um die universale Enthaltung von allen Meinungen zu ermöglichen. Dies gilt deswegen, weil Frankfurt glaubt, daß man sich Descartes zufolge aller Meinungen einfach mit Hilfe des Willens auf einmal enthalten könne. Vgl. ebd.

${ }^{29}$. Diese These kann eine Debatte nicht nur über die Natur der Selbsttäuschung auslösen, sondern auch über die Ethik der Aneignung von Meinungen. Siehe Williams, Descartes, S. 177
} 
Aussage hat. Man kann den genannten Mangel relativieren, wenn man berïcksichtigt, wozu Descartes jene Theorie eigentlich eingeführt hat. Wie wir später sehen werden, kommt Descartes durch die radikale Anwendung der Methode des Zweifelns zu der Erkenntnis, daß die meisten Aussagen, mit denen wir in unserem Alltagsleben konfrontiert werden, nicht unbezweifelbar sind, und daß es trotzdem eine Tatsache ist, daß wir uns viele Aussagen von dieser Art aneignen. Woran liegt dies? Eine Antwort in funktionaler Hinsicht kann man in Descartes' Theorie des Fällens eines Urteils finden. ${ }^{30}$ Descartes scheint der Meinung zu sein, daß bezüglich des Fällens eines Urteils in jenen Fällen noch etwas anderes als der Verstand aktiv sein müsse, und er identifiziert dies als den Willen. So bietet seine Theorie ihm vor allem die Möglichkeit zu erklären, worauf falsche Urteile beruhen, und zu zeigen, daß die Möglichkeit für uns offen steht, Irrtümer zu vermeiden. Dies ist sehr wichtig für ihn, da er glaubt und zu beweisen versucht, daß Gott existiert und uns die Fähigkeit gegeben hat, die Wahrheit zu erkennen. ${ }^{31}$

Ich glaube, daß unsere bisherige Betrachtung zeigt, daß Descartes' Theorie des Fällens eines Urteils keinen Ansatzpunkt liefert, mit dessen Hilfe man behaupten kann, daß es möglich sei, sich auf einmal und allein mit Hilfe des Willens aller Meinungen zu enthalten.

\section{II. Das Vorhaben, alle eigenen Meinungen zu überprüfen}

\section{II. 1. Einschränkung des Vorhabens}

Bisher haben wir gesehen, daß die von Descartes in der Eingangsrede erwähnten Erfahrungen nicht dafür ausreichend sind, uns zu der Frage zu führen, ob alle unsere Meinungen falsch oder unsicher sind. Der Grund dafür ist vor allem der, daß es unter unseren Meinungen wahre gibt, deren wir sicher sind, und die wir angeben können. Sie reichen sogar eigentlich auch nicht aus, uns zur Frage zu führen, ob alle diejenige unserer Meinungen, für die wir die Möglichkeit des Irrtums anerkennen, falsch oder unsicher sind. Andererseits haben wir auch gesehen, daß dies auch für Descartes der Fall ist. Wenn Descartes behauptet, daß er sich aller seiner Meinungen

\footnotetext{
${ }^{30}$. Zu Descartes' pragmatischer Antwort siehe unten I. III. 3.

${ }^{31}$. Vgl. Williams, Descartes, S. 163f. Descartes sagt, "aliqua etiam sit in me facultas a Deo tributa ad illam(falsitatem; d. Verf.) emendandam". (AT VII, S. 80)
} 
enthalten müsse, um eine notwendige Bedingung seines Projektes zu erfüllen, und daß dies möglich sei, so beruht dies nicht darauf, daß er eine Theorie des Fällens eines Urteils vertritt, die dies einfach ohne Nachprüfung ermöglicht.

Wenn dem so ist, wie soll man dann Descartes verstehen, wenn er trotzdem einerseits behauptet, daß seine früheren Erfahrungen ihn zum Stellen der Frage geführt hätten, ob alle seine Meinungen falsch oder unsicher seien, und andererseits dazu, daß es möglich sei, sich ihrer zu enthalten? Ist dies bloß eine Übertreibung? Eine Übertreibung in welcher Hinsicht? Damit dieses Problem uns nicht daran hindert, Descartes' Unternehmen zu verfolgen, schränken wir es vorläufig nur auf alle solche Meinungen ein, für die wir die Möglichkeit des Irrtums anerkennen. Demnach geht es in seinem Vorhaben darum, sie nachzuprüfen, falsche oder unsichere unter ihnen zu finden und entweder auf sie zu verzichten oder sie durch andere wahre oder sichere Meinungen zu ersetzen. So eingeschränkt ist sein Unternehmen interessant genug, da es auch als solches ungewöhnlich ist. Ein Zeichen dafür wäre, daß wir es in unserem normalen Alltagsleben nicht in Angriff nehmen, obwohl wir ohne großes Bedenken anerkennen können, daß wir in unserem Alltagsleben eine wahre Meinung einer falschen vorziehen. Vor allem scheint Descartes eine richtige Erklärung dafür zu haben, daß wir es in unserem normalen Alltagsleben nicht in Angriff nehmen. Versuchen wir also Descartes' Vorhaben vorläufig mit dieser Einschränkung weiter zu verfolgen, um zu erfahren, warum wir nach Descartes in unserem Alltagsleben jenes Unternehmen nicht durchführen, und wie er es dann durchzuführen vorhat.

\section{II. 2. Wahrheit, Gewißheit und Methode}

Nach seiner Eingangsrede führt Descartes die Methode des Zweifelns ein:

"Dazu wird indessen nicht nötig sein, sie alle als falsch aufzuzeigen, denn das würde ich vielleicht niemals erreichen können; sondern da schon die gemeine Vernunft rät, in ebenso vorsichtiger Weise bei dem nicht ganz Gewissen und Unzweifelhaften wie bei dem offenbar Falschen die Zustimmung zurückzuhalten, so wird es hinreichen, sie alle zurückzuweisen, wenn ich in einer jeden irgendeinen Grund zum Zweifel antreffe."(Buchenau, S. 11)

\footnotetext{
32. "Ad hoc (ad generalem mearum opinoinum eversionem; d. Verf.) autem non erit necesse, ut omnes esse falsas ostendam, quod nunquam fortassis assequi possem; sed quia jam ratio persuadet, non minus accurate $a b$ iis quae non plane certa sunt atque indubitata, quam ab aperte falsis assensionem esse cohibendam, satis erit ad omnes rejiciendas, si aliquam rationem dubitandi in unaquaque reperero." (AT VII, S. 18)
} 
Descartes macht hier einen Themenwechsel von 'Wahrheit' zu 'Gewißheit'. Er behauptet nämlich, daß es nicht nötig sei, alle eigenen Meinungen als falsch zu erweisen, um alle eigenen Meinungen umzustürzen, sondern daß dafür ausreichend sei, lediglich Gründe dafür anzugeben, daß sie zweifelhaft sind. Damit wird die Gewißheit als das Kriterium dafür angegeben, ob man sich einer Meinung enthalten soll. Zunächst stellt sich die Frage, wie dieser Themenwechsel verstanden werden soll.

Die Wahrheit oder die Suche nach der Wahrheit ist das Zentralthema für Descartes. ${ }^{33}$ Trotzdem hat die Frage, was Wahrheit ist, ihn weder interessiert noch ihm Schwierigkeiten bereitet, und das nicht, weil er glaubt, daß die Frage keine wichtige sei, sondern deshalb, weil allen Menschen ohne Weiteres bekannt sei, was Wahrheit ist. Wahrheit ist ihm zufolge eine angeborene Idee:

"Ich selbst habe an ihr (der Wahrheit; d. Verf.) niemals gezweifelt, da es mir scheint, sie sei ein so transcendent deutlicher Begriff, daß es unmöglich ist, ihn nicht zu wissen: man hat wohl Mittel, eine Waage zu prüfen, bevor man sich ihrer bedient, man kann aber tatsächlich keine Mittel haben, um zu erfahren, was die Wahrheit ist, wenn man sie nicht von Natur kennen würde." (Brief an Mersenne vom 16. Oktober 1639; Baumgart, S. 173)) ${ }^{34}$

Aber daß eine Idee angeboren ist, heißt nicht, daß sie nicht definierbar, sondern nur, daß sie allen bekannt ist. Descartes erklärt deswegen weiter, daß die Idee der Wahrheit nicht nur angeboren, sondern auch einfach sei, so daß es nicht möglich sei, eine Definition zu geben (ebd.). Was man einzig tun kann, ist zu erklären, wie man den Terminus anwendet:

"Daher kann man denen, die die Sprache nicht verstehen, wohl quid nominis erläutern und sagen, daß das Wort Wahrheit in seiner eigentlichen Bedeutung die Übereinstimmung des Gedankens mit dem Gegenstand bezeichnet, daß es aber, wenn man es Dingen zuschreibt, die außerhalb des Gedanken sind, nur bedeutet, daß diese Dinge als Gegenstände für wirkliche Gedanken, sei es für unsere oder diejenigen Gottes, dienen können." (Baumgart, S. 173-4)

\footnotetext{
33. Hier eine Stelle, an der es am besten ausgedrückt ist. Descartes schreibt in seinem Brief an Mersenne vom 16. Oktober 1639 folgendermaßen: "Seit meinem letzten Brief habe ich mir die Zeit genommen, das Buch (De Veritate von Herbert de Cherbury; d. Verf.) zu lesen, das Sie mir liebenswürdigerweise geschickt hatten; und weil Sie meine Meinung darüber verlangt haben und es einen Gegenstand behandelt, über den ich mein ganzes Leben gearbeitet habe, ...."(Baumgart, S. 173); "Depuis mes dernières, j'ai pris le temps de lire le livre que vous m'avez fait la faveur de m'envoyer, et parce que vous m'en avez demandé mon sentiment et qu'il traite d'un sujet auquel j'ai travaillé toute ma vie.."(AT II, S. 596)

34. "pour moi, je n'en ai jamais douté, me semblant que c'est une notion si transcendentalement claire, qu'il est impossible de l'ignorer: en esset, on a bien des moyens pour examiner une balance avant que de s'en servir, mais on n'en aurait point pour apprendre ce que c'est que la vérité, si on ne la connaissait de nature.(AT II, S. 596-597)

35 . "Ainsi on peut bien expliquer quid nominis à ceux qui n'entendent pas a langue, et leur dire que ce mot vérité, en sa propre signification, dénote la conformité de la pensée avec l'objet, mais que, lorsqu'on l'attribue aux choses qui sont hors de la pensée, il signifie seulement que ces choses peuvent servir d'objets à des pensées véritables, soit aux nôtres, soit à celles de Dieu" (AT II. S. 597)
} 
"p" ist nur dann wahr, wenn p der Fall ist. Ein wichtiges Merkmal dieses Wahrheitsbegriffs ist die Unabhängigkeit der Wahrheit von uns. Wenn "p" wahr ist, ist "p" unabhängig davon wahr, ob es von uns erkannt wird oder nicht (um mit Descartes zu sprechen: es ist außerhalb des Gedankens). Zunächst stellt sich die Frage, wie wir Wahrheit erkennen können. Wir stellen uns nämlich keine solche Beziehung zu Wahrheiten vor, wie Gott sie haben kann:

I) (p)(p ---> Gott weiß, daß p): Deus omnisciens oder

II) (p)(Gott denkt, daß p ---> p): Cum Deus calculat, id fit.

Wir sind nämlich nicht in der Lage, alles, was in der Welt geschieht, ohne weiteres zu wissen, noch in der Lage, alles, woran wir denken, ohne weiteres in der Welt geschehen zu lassen. Weil dies so ist, müssen wir Menschen zur Suche nach der Wahrheit irgendeine Methoden finden und anwenden, die die Kluft zwischen uns und Wahrheiten in der physikalischen Welt überbrücken können. Dadurch erwerben wir Wissen oder Meinungen bezüglich der physikalischen Außenwelt. Was die Methoden zur Suche nach der Wahrheit betrifft, so gibt es ein wichtiges Merkmal dieser Methoden, in dem sie sich von anderen Methoden unterscheiden; ${ }^{36}$ Wenn ich z.B. ein Sammler ausschließlich von prähistorischen Töpfen bin, kann ich zum Sammeln die Methode wählen, daß ich zuerst ohne Unterschied viele Töpfe sammle und danach untersuche, welche von ihnen prähistorisch sind. Obwohl diese Methode aufwendiger ist als die Methode, von Anfang an gezielt nur prähistorische Töpfe zu sammeln, ist es nicht unmöglich, sie anzuwenden, und es kann unter Umständen sogar notwendig sein. Aber solche Alternativen sind bezüglich der Suche nach der Wahrheit undenkbar, wie Williams folgendermaßen richtig begründet:

"Since to believe something is to believe that it is true, to acquire a belief is already to assume an answer to the question of whether it is true. So a method which A uses as an enquirer to get into state (i) (if p, A believes that p, and if not p, A believes that not-p; d. Verf.) must be a method of acquiring beliefs which itself makes it likely that the beliefs A acquires by it will be true ones; or, equivalently, is such that he is unlikely to acquire beliefs by that method unless they are true" (S. 39).

Daraus folgt, daß die Voraussetzung für eine Methode der Aneignung von Meinungen gleichbedeutend mit einer Voraussetzung für wahre Meinungen ist.

Wie wir vorhin gesehen haben, stellt Descartes in der ersten Meditation die Gewißheit als die Voraussetzung dafür dar, sich eine Meinung anzueignen. Er will alle eigenen Meinungen nachprüfen und sich ihrer enthalten, wenn sie als zweifelhaft erwiesen werden. Dieses Verfahren scheint aber nicht ohne weiteres nachvollziehbar zu sein. Auch wir suchen nämlich

${ }^{36}$. Vgl. Williams, Descartes, Kapitel II, besonders S. 37-47. 
Wahrheit, aber stellen die Gewißheit nicht als die Voraussetzung für die Aneignung einer Meinung auf. Erinnern wir uns nämlich daran, daß Meinungen, die eine Person, z.B. ich, hat, nicht alle denselben, sondern verschiedenen Status haben. Es gibt viele unter ihnen, von denen ich nicht zögern werde zu sagen, daß ich ihrer Wahrheit sicher bin: z.B. "Ich habe zwei Hände" und "2 plus 2 ist 4" usw. Dagegen sind viele Meinungen der Art, daß ich die Möglichkeit des Irrtums nicht ausschließen kann. Dies zeigt einerseits, daß die meisten Methoden, von denen wir bei der Suche nach der Wahrheit Gebrauch machen, nicht in der Lage sind, uns solche Meinungen zu liefern, deren Wahrheit wir sicher sein können, und andererseits, daß wir trotzdem uns auch solche Meinungen aneignen, die nicht sicher sind. Warum eignen wir uns aber solche Meinungen an, auch wenn wir ihrer Wahrheit nicht sicher sind? Warum verzichten wir in solchen Fällen nicht lieber darauf, uns Meinungen anzueignen? Auf diese Frage hat Descartes seinerseits eine Antwort:

"Seit längere Zeit hatte ich bemerkt, daß es viele Meinungen gibt, denen wir, auch wenn sie sehr zweifelhaft sind, doch folgen müssen, als wären sie sicher und zuverlässig, insofern es sich um die Lebensführung handelt". (AT VI, S. 558; übers. v. d. Verf.) ${ }^{37}$

Es gibt viele Fälle in unserem normalen Alltagsleben, in denen von uns verlangt wird zu handeln, und dies zwingt uns dazu, uns auf Meinungen zu verlassen, auch wenn wir ihrer Wahrheit nicht sicher sind. ${ }^{38}$ Diese praktische Bedingtheit nämlich ist ein Grund dafür, daß die Methoden, die wir unter gegebenen Umständen verwenden, auf verschiedene Weise spezifiziert werden, je nachdem, worum es geht. Dies ist der Grund dafür, daß wir nicht glauben, daß, obwohl wir nicht beliebig Meinungen erworben haben, alle unsere Meinungen wahr sind, und es ist auch ein Grund dafür, daß ein und dieselbe Meinung von verschiedenen Personen mit verschiedener Überzeugungskraft angeeignet und von einigen für falsch, aber von anderen für wahr gehalten werden kann. So hält Descartes zu Recht dieselben pragmatischen Überlegungen für einen Grund dafür, daß wir in unserem normalen Alltagsleben nicht den Versuch unternehmen, nur wahre und sichere Meinungen zu erwerben. Wir müssen nämlich handeln.

Es sieht aber anders aus, wenn die Situation verändert betrachtet wird. Descartes tut dies, indem er zwischen Handeln und der Suche nach Wahrheit unterscheidet, und erklärt, daß es ihm einzig und allein um die Suche nach der Wahrheit geht:

\footnotetext{
${ }^{37}$. "Dudum observaveram permultas esse opiniones, quas, etsi valde dubiae sint $\&$ incertae, non minus constanter \& intrepide sequi debemus, quatenus ad usum vitae referuntur, quam si certae essent \& exploratae."; Siehe Entsprechende Stellen in den Meditationes, AT VII, S. 22 und in den Principia, AT VIII, S. 5.

${ }^{38}$. Vgl. das dritte Buch in De Methodo.
} 
"Aber da ich damals mich der Suche nach der Wahrheit, nicht der Lebensführung widmen wollte, glaubte ich, daß ich gerade das Gegenteil tun und alle solche Meinungen, in denen ich auch nur den minimalen Grund des Zweifelns finden konnte, zurückweisen mußte, als wären sie vollkommen falsch". (AT VI, S. 558; übers. v. d. Verf.)

Dadurch verschafft Descartes sich die Rahmenbedingung, unter der die Suche nach der Gewißheit eine vernünftige Methode zur Suche nach der Wahrheit sein kann.

Bevor wir fortfahren, will ich hier Folgendes bemerken. Erinnern wir uns zunächst daran, daß der Grund dafür, daß Descartes' Behauptung, alle seine Meinungen nachprüfen und sich ihrer enthalten zu können und zu müssen, einen überraschenden, übertriebenen und schließlich absurden Eindruck vermittelte, darin lag, daß wir wissen, daß wir Meinungen haben, deren Wahrheit wir sicher sind. Worauf ich nun aufmerksam machen will, ist Folgendes: Die Meinungen, deren Wahrheit wir sicher sind, unterscheiden sich von den aufgrund praktischer Überlegungen bedingt für wahr gehaltenen und angeeigneten Meinungen nicht nur dadurch, daß sie sicher sind, sondern auch darin, daß sie die Rahmenbedingung ausmachen, unter der praktische Überlegungen möglich sind. ${ }^{40}$

\section{II. 3. Zwei Probleme des Vorhabens}

Angenommen, daß Descartes durch die Unterscheidung zwischen Handeln und der Suche nach der Wahrheit und durch die Erklärung, daß es ihm allein und einzig um die Suche nach der Wahrheit geht, sich die Rahmenbedingung für sein Vorhaben gesichert hat, so daß unter dieser Bedingung die Suche nach der Gewißheit die richtige Methode zur Suche nach der Wahrheit ist, gibt es aber dennoch ein anderes Hindernis. Es geht um folgendes.

Wenn wir nachdenken und uns fragen, welche von unseren Meinungen der Möglichkeit des Irrtums ausgesetzt sind, werden wir sofort ratlos, wie wir mit dieser Frage umgehen sollen. Es ist wahr, daß es unter Umständen sehr sinnvoll ist, über eine Anzahl von Meinungen zu reden. Wir können nämlich sinnvoll fragen, wieviel verschiedene Meinungen bezüglich einer Sache vertreten werden, und wir zählen sie auf und geben die Anzahl als die von allen Meinungen über die Sache an. Manchmal ist dieses Verfahren sogar notwendig. Aber die Situation, in der wir uns befinden, sieht ganz anders aus, wenn wir unbestimmt über alle Meinungen reden, die wir haben. Eine Schwierigkeit, auf die ich vorhin hingewiesen habe, liegt darin, auf welche

\footnotetext{
39. "Sed quia tunc veritati quaerendae, non autem rebus agendis, totum me tradere volebam, putavi mihi plane contraium esse faciendum, \& illa omnia in quibus vel minimam dubitandi rationem possem reperire, tanquam aperte falsa esse rejicienda."

${ }^{40}$. Dies verstärkt den Grund dafür, Descartes' Unternehmen auf solche Meinungen einzuschränken, für die wir die Möglichkeit des Irrtums nicht ausschließen können.
} 
Weise wir unsere Meinungen numerisch identifizieren sollen, wie Stroud richtig bemerkt hat. ${ }^{41}$ Wenn z.B. jemand fragt, ob es meine Meinung ist, daß ich heute ins Kino gehen will, kann ich sagen, daß es meine Meinung ist. Wenn jemand mich fragt, ob es meine Meinung ist, daß ich heute einen Film sehen wolle, kann ich auch sagen, daß es meine Meinung ist. Sind dies eine Meinung oder zwei? Wenn ich sage, daß es eine Meinung ist, habe ich dadurch noch eine neue Meinung. Wenn ich sage, daß es zwei Meinungen sind, habe ich dadurch wiederum eine neue Meinung usw. Dies zeigt, daß der Versuch, alle unsere Meinungen vollständig aufzuzählen, hoffnungslos oder sinnlos ist. So gesehen scheint das Unternehmen alle die Meinungen nachzuprüfen, für die wir die Möglichkeit des Irrtums anerkennen, nicht realisierbar zu sein. Die Möglichkeit, sie aufzuzählen und zu identifizieren, scheint eine notwendige Bedingung dafür zu sein, aber diese Bedingung scheint nicht erfüllbar zu sein.

Aber ist dies ein ernsthaftes Problem? Descartes scheint dies nicht zu glauben. Zwar ist es auch ihm nicht unbekannt: "Nec ideo etiam singulae (opiniones; d. Verf.) erunt percurrendae, quod operis esset infiniti." (AT VII, S. 18). Er ist aber trotzdem davon überzeugt, sie alle nachprüfen und sich ihrer enthalten zu können. Wie dies geschieht, werden wir bald erfahren. Ein ernsthaftes Problem tritt aber in Wirklichkeit an anderer Stelle auf. Und dieses Problem wird zeigen, daß unser bisheriger Versuch, Descartes' Unternehmen nachvollziehbar zu machen, ein Fehlschlag ist. Das Problem ist folgendes.

Wie wir vorhin gesehen haben, ist Descartes' Unternehmen ein rein Privates. Descartes schränkte die Gegenstände seines Unternehmens völlig auf seine eigenen Meinungen ein und macht dementsprechend nur vom Personalpronomen der ersten Person Gebrauch. Trotzdem scheint er nicht zu glauben, daß das Ergebnis seines so ausgezeichneten Unternehmens auch nur privat bleiben werde. Er glaubt nämlich, daß der Erfolg oder der Mißerfolg seines Unternehmens eine Wirkung auf die gesamten Wissenschaften ausüben werde: Er behauptet, daß alle Wissenschaften unsicher blieben, wenn sein Projekt in den Meditationes keinen Erfolg erziele. Dies soll heißen, daß alle vorhandenen Wissenschaften in Frage gestellt würden, wenn es ihm in der ersten Meditation gelänge, alle seine Meinungen in Frage zu stellen. Dies wirft die interessante und wichtige Frage auf, ob und wie das Unternehmen bezüglich der eigenen Meinungen überhaupt eine Wirkung auf alle Wissenschaften ausüben kann. Wie sollten alle Wissenschaften dadurch in Frage gestellt werden, daß Descartes alle seine Meinungen in Frage stellt? Überlegen wir, wie ein solches Unternehmen aussehen kann. Diese Überlegung soll uns darauf aufmerksam machen, daß Descartes' Unternehmen einen besonderen Status haben muß, wenn es überhaupt möglich sein soll.

Vorhin haben wir die Überlegung angestellt, wie wir alle unsere Meinungen überprüfen könnten. Dabei habe ich ständig vom Personalpronomen der ersten Person Plural Gebrauch

\footnotetext{
${ }^{41}$. Vgl. Stroud, S. 5ff.
} 
gemacht und dieser Gebrauch war harmlos. Aber dies kann nun nicht mehr der Fall sein. Was jetzt $\mathrm{zu}$ untersuchen ist, ist nicht mehr die Art und Weise, wie man alle seine Meinungen überprüfen kann, sondern darüber hinaus, wie ein Unternehmen einer Person, alle ihre Meinungen zu überprüfen und eventuell zurückzuweisen, alle Wissenschaften betreffen kann. Wie ist es möglich, daß Descartes z.B. mich dadurch mich aller meiner Meinungen enthalten läßt, daß er sich aller seiner Meinungen enthält? Dies kann auf den ersten Blick ganz natürlich aussehen, wenn ich mich daran erinnere, daß ich meine Meinung korrigiert habe, weil man eine Meinung, die man früher für wahr gehalten hat, und die auch ich habe, später als falsch erwiesen hat. Aus diesem Grund muß hier noch einmal betont werden, daß dies gerade nicht das ist, was Descartes behauptet. Was Descartes behauptet, ist, daß alle meine Meinungen dadurch in Frage gestellt würden, daß er alle seine Meinungen in Frage stelle. Es ist keine schwierige Aufgabe zu zeigen, wie absurd dies ist.

Die Meinungen Descartes' können grob in zwei Klassen eingeteilt werden. Zur ersten Klasse gehören die Meinungen, die ich nicht habe oder haben kann, aus welchen Gründen auch immer. Zur zweiten Klasse gehören die Meinungen, die auch ich habe. Wenn Descartes jetzt eine seiner Meinungen der ersten Klasse überprüft, ist es selbstverständlich, daß ich nicht in der Lage bin zu beurteilen, ob diese Meinung wahr ist, noch in der Lage bin, seine Überprüfung zu verfolgen. Wenn dies selbstverständlich ist, ist es auch selbstverständlich, daß das Ergebnis seiner Überprüfung von Meinungen der ersten Klasse überhaupt nichts mit meinen eigenen Meinungen zu tun hat, geschweige denn mit Meinungen, die ich habe, aber Descartes nicht hat oder haben kann.

Wie würde es sich mit Meinungen der zweiten Klasse verhalten? Fragen wir uns zuerst, welche Meinungen ich gemeinsam mit Descartes haben könnte. Moore behauptet, daß dies Meinungen seien wie z.B. "Die Erde hat schon lange existiert, bevor ich geboren worden bin". Obwohl ich nicht weiß, woher er dies weiß, will ich hier annehmen, daß er Recht hat. Was wird Descartes tun, um diese seine Meinung zu überprüfen?

Als Naturwissenschaftler wird er eine Untersuchung anstellen und seine Meinung bewerten, je nachdem, zu welchem Ergebnis seine Untersuchung führt. Nehmen wir an, daß er in der Folge seiner Untersuchung herausgefunden hat, daß es fraglich ist, ob diese seine Meinung wahr ist, aus welchen Gründen auch immer. Kann er mich diese meine Meinungen einfach dadurch in Frage stellen lassen, daß er seine Gründe angibt, aus denen er diese seine Meinung in Frage gestellt hat? Dies ist nicht der Fall. Dies kann der Fall sein nur unter der Bedingung, daß seine Gründe auch mich überzeugen sollen. Wenn ich diese meine Meinung in Frage stelle, nachdem ich betrachtet habe, wie Descartes diese seine Meinung in Frage gestellt hat, heißt dies nicht, daß ich sie einfach dadurch in Frage stelle, daß ich betrachtet habe, wie er diese seine Meinung aus seinen Gründen heraus in Frage gestellt hat, sondern dadurch, daß seine Gründe mich überzeugen. 
Welche Konsequenzen kann man aus dieser Überlegung ziehen?

Die erste Konsequenz ist diese: Es ist möglich, daß es Descartes gelingt, alle seine Meinungen der zweiten Klasse in Frage zu stellen, aus Gründen, die ihn von der Fraglichkeit seiner Meinungen überzeugen.

Die zweite Konsequenz ist diese: Wenn es möglich ist, daß es Descartes gelingt, alle seine Meinungen der zweiten Klasse in Frage zu stellen, ist es auch möglich, daß Descartes mich alle meine Meinungen der zweiten Klasse dadurch in Frage stellen läßt, daß er alle seine Meinungen der zweiten Klasse in Frage stellt, wobei seine Gründe mich von der Fraglichkeit meiner Meinungen überzeugen.

Die dritte Konsequenz ist diese: Wenn seine Gründe mich überzeugen, und zwar nicht deswegen, weil es seine Gründe sind, sondern deswegen, weil es gute Gründe sind, dann ist es auch der Fall, daß diese Gründe ihn überzeugt haben, aber nicht deswegen, weil es seine Gründe sind, sondern weil es gute Gründe sind. Es ist fraglich, ob der Gebrauch des Personalpronomens der ersten Person einen besonderen Sinn hat bzw. welchen Sinn es in diesem Fall hat zu sagen, daß Descartes mich dadurch alle meine Meinungen der zweiten Klasse in Frage stellen läßt, daß er seine Meinungen der zweiten Klasse in Frage stellt.

Die letzte Konsequenz ist diese: Auch wenn es Descartes gelingt, alle Meinungen der zweiten Klasse in Frage zu stellen, ist es nicht der Fall, daß er dadurch alle meine Meinungen in Frage gestellt hat, geschweige denn Meinungen, die weder ich noch Descartes haben.

Sollen wir nun sagen, daß Descartes' Behauptung übertrieben ist, daß er alle Wissenschaften in Frage stellt, dadurch, daß er alle seine Meinungen in Frage stellt? Es sieht so aus.

\section{II. 4. Moores Lösung der Probleme}

Moore ist der Meinung, daß es methodologisch eine Möglichkeit gibt, die genannten zwei Probleme zu beseitigen. Das eine Problem war die Frage, wie man alle seine Meinungen nachprüfen und in Frage stellen kann. Das andere war die Frage, wie man alle Wissenschaften in Frage stellt dadurch, daß man alle seine Meinungen in Frage stellt. In seinem Aufsatz "A defence of common sense" stellt Moore eine Bedingung auf, ${ }^{42}$ bei deren Erfüllung er bereit ist zu akzeptieren, daß die Existenz der Außenwelt und damit automatisch alle Wissenschaften darüber in Frage gestellt werden. ${ }^{43}$ Diese Bedingung besteht darin, eine bestimmte Menge von Aussagen in Frage zu stellen. Ich will hier drei Aussagen nennen, die sich auf das Problem des Skeptizismus bezüglich der Außenwelt beziehen:

\footnotetext{
42. In Philosophical Papers, London, 1959.

43. Moore formuliert eine starke Position, die besagt, daß alle diese Aussagen falsch sind. Die skeptische Position, um die es hier geht, ist nicht die, sie für falsch zu halten, sondern sie in Frage zu stellen.
} 
I) Es gibt jetzt einen Körper, der meiner ist;

II) Es gibt viele Menschen, die mir ähnlich sind;

III) Die Erde hat schon lange existiert, bevor ich geboren worden bin. ${ }^{44}$

Der Grund dafür, daß Moore bereit ist zu akzeptieren, daß man die Existenz der physikalischen Außenwelt und damit auch alle Wissenschaften darüber in Frage stellt, wenn man diese Aussagen in Frage stellt, liegt darin, daß sie einerseits die Existenz der Außenwelt implizieren, und daß andererseits alle Menschen außer den Skeptikern sie nicht nur für wahr halten, sondern auch ihrer Wahrheit gewiß sind: Es sind nämlich Aussagen des "common sense". Wie problematisch Moores Auswahl von derartigen Aussagen auch sein mag und welche Probleme sie damit bereiten mag, ${ }^{45}$ so kann diese Idee Moores dennoch zumindest dazu dienen, uns eine Vorstellung davon zu geben, wie man alle Wissenschaften, die von der Präsupposition der Existenz der Außenwelt ausgehen, in Frage stellen kann. Es mag möglich sein, eine Menge von Aussagen zu finden, die in der Tat von der Art sind, daß es möglich ist, die Existenz der Außenwelt und damit auch alle Wissenschaften darüber in Frage zu stellen, dadurch, daß man sie in Frage stellt.

Nachdem Moore diese Bedingung aufgestellt hat, versucht er den Skeptizismus zu widerlegen. Dieser Versuch wird durch eine reductio ad absurdum gemacht. Seine Argumente sind einfach. Ich möchte hier nur zwei Argumente anführen.

Das erste ist dies: Wenn ein Skeptiker behauptet, daß diese Aussagen falsch oder fraglich seien, muß es wahr sein, daß er existiert und daß wir existieren, da er uns gegenüber diese Behauptung macht.

Das zweite Argument ist dies: Viele Skeptiker benutzen das Personalpronomen der ersten Person Plural "Wir", das die Existenz von anderen Menschen voraussetzt.

\footnotetext{
${ }^{44}$. Was den Gebrauch des Personalpronomens der ersten Person Singular in diesen Aussagen betrifft, ist zu bemerken, daß Moore damit nicht meint, daß alle Menschen wissen, daß Moore einen Körper hat, sondern, daß jeder Mensch weiß, daß er selbst einen Körper hat.

${ }^{45}$. Ich will hier nicht darauf eingehen, ob Moore Recht hat zu behaupten, daß es möglich sei, die Existenz der Außenwelt dadurch in Frage zu stellen, daß man alle diese Aussagen in Frage stelle. Er gibt keine Erklärung dafür, warum dies so sein soll. Vielleicht ist das ein Grund dafür, daß es schwer zu erkennen ist, nach welchem Kriterium er die Auswahl getroffen hat. Die Aussagen haben nämlich einen verschiedenen Status. Es scheint unmöglich zu sein, (I) für falsch zu halten, während es zwar schwer, aber nicht unmöglich ist, (II) für falsch zu halten. Aber es ist einfach möglich, (III) für falsch zu halten. Dieser Mangel mag aber harmlos sein, da Moore die skeptische Position nicht dadurch definiert, daß eine oder zwei von diesen Aussagen, sondern alle für falsch gehalten oder in Frage gestellt werden. Trotzdem glaube ich nicht, daß er Recht hat zu behaupten, daß es möglich sei, die Existenz der Außenwelt dadurch in Frage zu stellen, daß man alle diese Aussagen in Frage stelle. Es ist zwar schwer, aber nicht unmöglich, sich eine Situation vorzustellen, in der man alle diese Aussagen in Frage stellt, aber trotzdem viele andere Aussagen für wahr hält, die die Existenz der Außenwelt implizieren.
} 
Diesbezüglich will ich hier nur Folgendes bemerken, da ich im Fazit dieses Kapitels darauf zurückkommen werde, worauf Moore damit eigentlich hinaus wollte. Unabhängig davon, ob Moores Widerlegung erfolgreich ist oder nicht, trifft seine Darstellung der skeptischen Position und Widerlegung nicht auf Descartes zu. Descartes behauptet nämlich nicht, daß er vorhabe, alle Wissenschaften bezüglich der Außenwelt in Frage zu stellen, indem er die Aussagen in Frage stelle, von denen er annimmt, daß alle Menschen sie für wahr hielten. Er behauptet lediglich, daß er vorhabe, alle Wissenschaften bezüglich der Außenwelt in Frage stellen, indem er alle seine Meinungen in Frage stellt, ohne zu erwähnen, ob andere Menschen dieselbe Meinungen haben oder nicht. Demgemäß macht er nur von dem Personalpronomen der ersten Person Singular Gebrauch.

\section{III. Descartes' Vorhaben, sich aller eigenen Meinungen zu enthalten}

Versuchen wir nun zu verfolgen, ob und auf welche Weise Descartes alle seine Meinungen in Zweifel zieht, indem wir uns die oben genannten Besonderheiten dieses Vorhabens vor Augen führen.

\section{III. 1. Die erste ratio dubitandi: Sinnestäuschung}

"Alles nämlich, was ich bisher am ehesten für wahr angenommen, habe ich von den Sinnen oder durch Vermittlung der Sinne empfangen."(Buchenau, S. 11)

Die meisten seiner Meinungen sind einerseits solche, derer Wahrheit per sensus, nämlich per auditum a parentibus, praeceptoribus aliisque hominibus (AT V, S. 146) gerechtfertigt worden ist, und andererseits solche, derer Wahrheit a sensibus, nämlich aufgrund direkter Wahrnehmungen oder Beobachtungen gerechtfertigt worden ist. Die Strategie Descartes', alle seine Meinungen zu überprüfen, besteht zuerst darin, sie ihren Quellen nach zu überprüfen und darin eine ratio dubitandi zu finden.

Nachdem Descartes dies erklärt hat, schließt er ohne weiteres die Klasse von Meinungen, die er per sensus erworben hat, aus seinen weiteren Betrachtungen aus. Dies darf aber nicht so verstanden werden, als glaubte Descartes, daß alle Meinungen dieser Klasse ohne Unterschied und ohne weiteres für unsicher gehalten werden könnten. Damit würde er ihnen Unrecht tun. Obwohl er sie nämlich aufgrund von praktischen Überlegungen für wahr gehalten und sich angeeignet hat, heißt dies nicht, daß er sie sich beliebig angeeignet hat. Es heißt auch nicht, daß er bezüglich solcher Meinungen überhaupt nicht imstande ist, ihre Wahrheit festzustellen. Obwohl es viele von unseren per sensus erworbenen Meinungen gibt, von denen

\footnotetext{
46. "Nempe quidquid hactenus ut maxime verum admisi, vel a sensibus, vel per sensus accepi" (AT VII, S.
} 18) 
wir glauben, daß wir ihre Wahrheit nicht feststellen können, gibt es doch viele unter ihnen, von denen wir glauben, daß wir ihre Wahrheit feststellen können. Der Grund dafür, daß Descartes alle Meinungen dieser Klasse außer acht läßt, liegt eher darin, daß der Versuch der Feststellung ihrer Wahrheit per sensus prinzipiell darin besteht, ihnen denselben Status zu geben, den die Meinungen haben, die wir a sensibus erworben haben. Descartes' weitere Strategie besteht demnach darin zu sagen, daß die Klasse von Meinungen, die er per sensus erworben hat, aufgegeben werden kann, wenn gezeigt wird, daß er nicht sicher sein kann, ob die Meinungen, die er a sensibus erworben haben, wahr sind oder nicht:

"Auch wird es dazu nicht unumgänglich notwendig sein, sie alle einzeln durchzugehen, was eine endlose Arbeit wäre, sondern, da nach der Untergrabung der Grundlagen alles darauf Gebaute von selbst zusammenstïrzt, so werde ich den Angriff sogleich auf eben die Prinzipien richten, auf die sich alle meine sonstigen Meinungen stützten."(Buchenau, S. 11-12) ${ }^{47}$

Was Meinungen betrifft, die er a sensibus erworben hat, ist es überflüssig zu sagen, daß sie nicht alle wahr sind. Descartes erinnert sich an die Erfahrung, daß er gelegentlich eine falsche Meinung a sensibus gebildet hat. Wenn dem so ist, ist es ratsam, Meinungen nicht für wahr zu halten, allein aus dem Grund, daß er sie $a$ sensibus gebildet hat.

"Nun aber bin ich dahinter gekommen, daß diese (Sinne; d. Verf.) uns bisweilen täuschen, und es ist ein Gebot der Klugheit, niemals denen ganz zu trauen, die auch nur einmal uns getäuscht haben."( Buchenau, S. 12) (8 $^{4}$

Diese Erfahrungen können zwar zeigen, daß nicht alle Meinungen, die a sensibus erworben werden, wahr sind, aber nicht, daß alle Meinungen, die a sensibus erworben werden, falsch sind. Und die Erfahrung mit Irrtümern dieser Art und deren weitere Möglichkeit sind keine ernsthafte Gefahr für die Möglichkeit, wahre und sichere Meinungen a sensibus zu erwerben. Die Irrtümer, die dabei begangen worden sind, bestehen darin, daß man Meinungen unter schlechten äußeren Wahrnehmungsbedingungen erworben hat, und Descartes glaubt, daß er unter optimalen äußeren Wahrnehmungsbedingungen solche Irrtümer vermeiden und wahre Meinungen a sensibus erwerben könne sowie daß er optimale und schlechte äußere Bedingungen voneinander unterscheiden könne. Er sagt:

"Indessen mögen uns auch die Sinne mit Bezug auf zu kleine und entfernte Gegenstände bisweilen täuschen, so gibt es doch am Ende sehr vieles andere, woran man gar nicht zweifeln

\footnotetext{
47. "Nec ideo etiam singulae erunt percurrendae, quod operis esset infiniti; sed quia, suffosis fundamentis, quidquid iis superaedificatum est sponte collabitur, aggrediar statim ipsa principia, quibus illud omne quod olim credidi nitebatur." (AT VII, S. 18)

48. "hos (sensus; d. Verf.) autem interdum fallere deprehendi, ac prudentiae est numquam illis plane confidere, qui nos vel semel deceperunt." (ebd.)
} 
kann, wenn es gleich aus denselben Quellen geschöpft ist; so z.B. daß ich jetzt hier bin, daß ich, mit meinem Winterrocke angetan, am Kamin sitze,..."(ebd. $)^{49}$

49. "Sed forte, quamvis interdum sensus circa minuta quaedam \& remo tiora nos fallant, pleraque tamen alia sunt de quibus dubitari plane non potest, quamvis ab iisdem hauriantur: ut iam me hic esse, foco assidere, hyemali toga esse indutum..." (ebd.) 


\section{III. 2. Die zweite ratio dubitandi}

Obwohl Descartes der Meinung ist, daß wir unter optimalen Wahrnehmungsbedingungen wahre und sichere Meinungen erwerben können, gibt es ihm zufolge die Möglichkeit, daß man nicht sicher sein kann, ob sie in der Tat wahr sind, auch wenn sie a sensibus unter guten äußeren Bedingungen gebildet werden. Er kann sich nämlich darin irren zu glauben, daß er sich in optimalen Umständen befinde. Dies ist der Fall, wenn er träumt:

"Vortrefflich!--Als ob ich nicht ein Mensch wäre, der des Nachts zu schlafen pflegt, und dem dann genau dieselben, ja bisweilen noch weniger wahrscheinliche Dinge im Traume begegnen, wie jenen im Wachen! Wie oft doch kommt es vor, daß ich alle jene gewöhnlichen Begegnisse, wie daß ich hier bin, daß ich, mit meinem Rocke bekleidet, am Kamin sitze, mir während der Nachtruhe einbilde, während ich doch entkleidet im Bette liege! Aber jetzt schaue ich doch sicher mit wachen Augen auf dieses Papier, dies Haupt, das ich hin und her bewege, ist doch nicht im Schlaf, mit Vorbedacht und Bewußtsein strecke ich meine Hand aus und fühle das! Im Schlafe würde mir das doch nicht so deutlich entgegentreten! Als wenn ich mich nicht entsänne, daß ich auch sonst durch ähnliche Gedankengänge im Traume irregeführt worden bin! Denke ich einmal aufmerksamer hierüber nach, so sehe ich ganz klar, daß niemals Wachen und Traum nach sicheren Kennzeichen unterschieden werden können,--so daß ich ganz betroffen bin, und diese Betroffenheit selbst mich beinahe in der Meinung bestärkt, daß ich träume.

Sei es denn: wir träumen!"(Buchenau, S. 12-13)

Dieser Absatz ist von vielen Kommentatoren traditionell als das Traum-"Argument" aufgefaßt worden, obwohl Meinungsverschiedenheiten darüber bestehen, wogegen es gerichtet ist. Z.B. sind Moore und Stroud der Meinung, daß das Argument darauf abzielt, die Existenz der physikalischen Außenwelt in Frage zu stellen, während Frankfurt und Wilson die Ansicht vertreten, daß das Argument nicht hierauf, sondern darauf abzielt, in Frage zu stellen, ob die physikalischen Objekte die Eigenschaften besitzen, die wir wahrnehmen. Im folgenden will ich die These vertreten und zu rechtfertigen versuchen, daß der Absatz nicht als ein Argument, sondern als eine Illustration verstanden werden sollte. Um kurz vorzugreifen: Es scheint mir so zu sein, daß man, obwohl Descartes in dem letzten Satz des Absatzes ergo verwendet, diese Verwendung von ergo nicht stark lesen darf, sondern eher den Schwerpunkt darauf legen muß, daß Descartes den Satz mit "Age" und im Konjunktiv als Hortativ formuliert hat.

\footnotetext{
50. "Praeclare sane, tanquam non sim homo qui soleam noctu dormire, \& eadem omnia in somnis pati, vel etiam interdum minus verisimilia, quam quae isti vigilantes. Quam frequenter vero usitata ista, me hic esse, toga vestiri, foco assidere, quies nocturna persuadet, cum tamen positis vestibus iaceo inter strata! Atqui nunc certe vigilantibus oculis intueor hanc chartam, non sopitum est hoc caput quod commoveo, manum istam prudens \& sciens extendo \& sentio; non tam distincta contingerent dormienti. Quasi scilicet non recorder a similibus etiam cogitationibus me alias in somnis fuisse delusum; quae dum cogito attentius, tam plane video nunquam certis indiciis vigiliam a somno posse distingui, ut obstupescam, \& fere hic ipse stupor mihi opinionem somni confirmet.

Age ergo somniemus." (AT VII, S. 19)
} 
$\mathrm{Zu}$ diesem Zweck will ich zuerst den Absatz, der traditionellen Auffassung folgend, in der Form eines Argumentes wiedergeben und überlegen, was er als ein Argument leisten kann. Diese Überlegung soll zeigen, daß er als Argument aufgefaßt nicht die Kraft besitzen kann, die Existenz der physikalischen Außenwelt in Frage zu stellen, noch in Frage zu stellen, ob physikalische Objekte alle Eigenschaften besitzen, die wir wahrnehmen. Daraufhin werde ich versuchen, zu erklären, daß Descartes den Absatz mit Recht nicht als ein Argument, sondern als eine Illustration dargestellt hat.

\section{III. 2. 1. Das Traumargument}

Man kann jenen Absatz als ein Argument mit dem Ziel, die Existenz der physikalischen Außenwelt in Frage zu stellen, folgendermaßen rekonstruieren:

PI) Ich sitze jetzt mit Papieren in meiner Hand in meinem Zimmer;

PII) Ich erinnere mich an meine früheren Traumerfahrungen;

PIII) Es ist möglich, daß ich jetzt nur träume, daß ich mit Papieren in meiner Hand in meinem Zimmer sitze;

PIV) Es gibt kein Kriterium, mit dessen Hilfe ich jetzt entscheiden kann, ob ich jetzt träume oder nicht;

KI) Ich weiß nicht, ob ich jetzt nicht träume;

KII) Ich weiß nicht, daß ich jetzt mit Papieren in meiner Hand in meinem Zimmer sitze;

KIII) Ich weiß nicht, ob die physikalische Außenwelt existiert.

Seiner Rekonstruktion zufolge ist die von Descartes beabsichtigte Konklusion des Argumentes (KIII). Zu dieser Konklusion gelangt Descartes über (KII), und zu (KII) über (KI) mittels der oben eingeführten Prämissen. Es gibt daher drei Fragen zu betrachten. Die erste Frage ist die, ob Descartes' Übergang von (KI) zu (KII) korrekt ist. Die zweite Frage ist die, ob der Übergang von (KII) zu (KIII) korrekt ist. Die letzte Frage ist die, ob das auf (KI) führende Argument schlüssig ist. In diesem Abschnitt werden wir hauptsächlich die ersten beiden Fragen betrachten und die letzte Frage kurz, aber ausführlich im nächsten Abschnitt.

Hat Descartes Recht, (KII) zu behaupten, angenommen daß (KI) wahr ist? Es scheint so zu sein. Wenn ich nicht weiß, daß ich jetzt nicht träume, ist es möglich, daß ich jetzt nur träume, daß ich mit Papieren in meiner Hand in meinem Zimmer sitze, und bei dieser Möglichkeit kann ich nicht wissen, daß ich mit Papieren in meiner Hand in meinem Zimmer sitze. Obwohl es allgemein der Fall ist, daß die kontingenten Situationen, in denen wir uns im Traum zu befinden glauben, in Wirklichkeit nicht gegeben sind, liegt der Grund dafür, daß kein Wissen vorliegt, nicht schlechthin darin, daß es nicht wahr ist, daß ich mit Papieren in meiner Hand in meinem Zimmer sitze, während ich es träume. Es ist ja möglich, daß ich in Wirklichkeit mit Papieren in 
meiner Hand in meinem Zimmer sitze, während ich träume, daß ich mit Papieren in meiner Hand in meinem Zimmer sitze. Trotzdem werden wir auch in diesem Fall nicht sagen, daß ich weiß, daß ich mit Papieren in meiner Hand in meinem Zimmer sitze. Wir werden nur sagen, daß ich es träume. Der Grund dafür liegt darin, daß unser Wissen davon, daß wir wach sind, eine notwendige Bedingung für unser Wissen von der kontingenten Situation, in der wir uns befinden, ist. Wenn dem so ist, kann Descartes mit Recht von (KI) zu (KII) übergehen.

Gehen wir zu unserer zweiten Frage über. Angenommen daß (KI) und damit auch (KII) wahr sind, hat Descartes recht, (KIII) zu behaupten? Die Antwort auf diese Frage kann, wie wir bald sehen werden, verschieden ausfallen, je nach den verschiedenen Auffassungen des auf (KI) führenden Argumentes. Betrachten wir demgemäß unsere zweite Frage im Rekurs auf verschiedene Möglichkeiten, das auf (KI) führende Argument aufzufassen. Diese Überlegung will ich durchführen, indem ich mich mit Clarke, Walsh und Stroud auseinandersetze. Dies deswegen, weil ich denke, daß diese Auseinandersetzung uns am besten darauf vorbereiten kann, später ${ }^{51} \mathrm{zu}$ verstehen, warum jener Absatz des Traums nicht als ein Argument, sondern nur als eine Illustration aufgefaßt werden sollte, und wovon er eine Illustration sein sollte.

Stroud glaubt, daß (KIII) wahr ist, wenn (KII) wahr ist. Warum er dies glaubt, kann folgendermaßen erklärt werden. Er geht davon aus ${ }^{52}$, daß Descartes' Strategie, alle eigenen Meinungen bezüglich der physikalischen Außenwelt in Frage zu stellen, in zwei Schritten besteht. Der erste Schritt ist der, eine Situation auszuwählen, die derart optimale Bedingungen der Wahrnehmungen bildet, daß man sagen kann, daß man in jener Situation über die physikalische Außenwelt Bescheid wissen können muß, wenn es denn überhaupt möglich sein sollte, irgend etwas über die physikalische Außenwelt zu wissen. Die Situation, in der Descartes das Traumargument entwickelt, nämlich (PI), wird demgemäß von Stroud als eine Situation bewertet, die jene optimalen Bedingungen erfüllt, und dementsprechend als repräsentativ für alle Situationen derselben Art gilt. Der zweite Schritt besteht darin zu zeigen, daß es unmöglich ist, in jener Situation über die physikalische Außenwelt Bescheid zu wissen $((\mathrm{KII})$ ). Dies geschieht nach Stroud durch (PIII), (PIV) und (KI). Da jene Situation als repräsentativ für alle Situationen derselben Art anerkannt ist, folgt aus (KII) (KIII).

Das Problem liegt in der Frage, ob jene Situation in der Tat als repräsentativ zu verstehen ist, so daß sie dementsprechend die von ihr erwartete Rolle spielen kann. Thompson Clarke ist nicht dieser Meinung. ${ }^{53}$ Betrachten wir, warum nicht.

\footnotetext{
${ }^{51}$. Vgl. I.III.2.2.- I.III.3. dieser Arbeit.

52. Vgl. Stroud, S, 10. und Moore, Certainty in Philosophical Papers, S. 244.

${ }^{53}$. Vgl. Clarke, The legacy of skepticism, S. 764-765. Dazu vgl. Stroud, S. 264-269.
} 
Auch Clarke akzeptiert (PIII). (PIII) ist aber nach Clarke nicht irgendeine Möglichkeit, sondern eine genuine Möglichkeit, in dem Sinne, daß sie die Möglichkeit voraussetzt, daß ich später wach werde und erkenne, daß ich nur geträumt habe, daß ich mit Papieren in meiner Hand in meinem Zimmer sitze. Dementsprechend glaubt er, daß (PIII) als genuine Möglichkeit meine Meinung in Frage stellen kann, nämlich die Meinung, daß ich weiß, daß ich jetzt nicht träume, und damit auch meine Meinung, daß ich weiß, daß ich jetzt mit Papieren in meiner Hand in meinem Zimmer sitze. So ist er der Meinung, daß aus (PI) und (PIII) (KI) folgt, und aus (KI) (KII). Trotzdem glaubt er nicht, daß daraus (KIII) folgt. Der Grund dafür ist der Folgende: Um von (KI) über (KII) zu (KIII) überzugehen, muß man die Möglichkeit der späteren Erkenntnis davon ausschließen, daß ich wach werde und erkenne, in welcher Situation ich mich in Wirklichkeit befunden habe. Das entscheidende Problem dabei ist aber, daß dadurch die Möglichkeit des Traums -(PIII)- nicht mehr als genuine Möglichkeit im oben erklärten Sinne verstanden werden kann, während dies dafür notwendig ist, zu (KI) zu gelangen. Kurz gesagt, hindert uns die Möglichkeit des Traums als genuine Möglichkeit in bezug auf (PI) von Anfang an daran, (PI) als repräsentativ für alle Situationen aufzufassen, in denen optimale Bedingungen für unsere Wahrnehmungen vorliegen.

Wie gesagt, ist Stroud aber anderer Meinung. Um von (KI) über (KII) zu (KIII) überzugehen, braucht man Strouds Meinung nach nicht die Möglichkeit der späteren Erkenntnis davon vorauszusetzen, daß ich wach werde und erkenne, in welcher Situation ich mich in Wirklichkeit befunden habe:

"But there is another possibility at hand that seems to require no knowledge or discovery at all. I mean simply the possibility that I am dreaming now, whether I can ever come to discover that I am or not. The philosopher asks only whether it is possible that he is dreaming now, and how he can know he is not. The simple possibility that he is dreaming seems to involve no knowledge at all;"(S. 268; Hervorhebung d. Verf.)

Intuitiv versteht man, worauf eigentlich Clarke mit seiner Erklärung hinaus wollte, und ich denke, daß er recht hat. Doch meine ich, daß seine Erklärung in der oben vorgestellten Form uns nicht davon überzeugen kann, daß er recht hat. Vor allem ist in seiner Erklärung etwas enthalten, was eine Erwiderung wie die Strouds anregen und richtig erscheinen lassen kann. Was dieses "etwas" ist, kann folgendermaßen erklärt werden. Damit kommen wir zu der Frage, wie Clarke sich zu (PII) und (PIV) verhält.

Ohne Zweifel setzt die oben betrachtete Erklärung Clarkes voraus, daß (PII) wahr ist, da dies dafür notwendig ist, (PIII) als genuine Möglichkeit zu verstehen. (PII) ist entscheidend für seine Position. Trotzdem macht er in seiner Erklärung davon keinen expliziten Gebrauch, geschweige denn, daß er ihre Wichtigkeit in den Vordergrund stellt. Warum nicht? Die Antwort lautet folgendermaßen: Wie wir gesehen haben, akzeptiert er ohne weiteres (PIII). 
Damit kann er nicht umhin, in jeder gegebenen Situation die Möglichkeit des Traums als genuine Möglichkeit zuzulassen. Und dies führt ihn unvermeidlich dazu, (PIV), wenn auch halbherzig, zu akzeptieren. Damit sieht die Lage, in der er sich befindet, so aus: Auch wenn er (PII) akzeptiert, wird er dadurch, daß er (PIII) und damit auch (PIV) akzeptiert, dringend mit der Frage konfrontiert, ob und wie wir in einer gegebenen Situation wissen können, ob wir träumen oder nicht. In bezug auf die Entscheidung dieser Frage aber kann (PII) keine Rolle spielen.

Dasselbe Schicksal teilt aber auch seine Erklärung im Rekurs auf die Möglichkeit der späteren Erkenntnis des Wachwerdens. Sie kann uns nämlich überhaupt nicht helfen zu wissen, ob wir in einer gegebenen Situation träumen oder nicht. Gerade dies ist der Grund dafür, daß seine Erklärung eine Erwiderung wie die Strouds anregt und richtig erscheinen läßt. Sehen wir genauer, warum dem so ist.

Das einzige Mittel, das Clarke m.E. zur Entscheidung jener Frage liefert, ist "Abwarten". Wie lange aber und worauf soll man warten? Darauf gibt er uns keine Antwort. Kann das Abwarten uns wirklich helfen? Es scheint darauf anzukommen, ob wir Glück haben oder nicht. Wenn ich Glück habe, mit anderen Worten, wenn ich all diese Überlegungen in meinem Traum (zum Zeitpunkt t) anstelle, kann das Abwarten des Wachwerdens mir helfen, später (zum Zeitpunkt t') zu wissen, daß ich zum Zeitpunkt t nur geträumt habe. Wie verhält es sich aber, wenn ich kein Glück habe, mit anderen Worten, wenn ich all diese Überlegungen anstelle, während ich wach bin (zum Zeitpunkt t)? Kann das Abwarten mir auch in diesem Fall helfen, später (zum Zeitpunkt t') zu wissen, daß ich zum Zeitpunkt $t$ wach gewesen und zugleich zum Zeitpunkt t' wach bin? Wie lange und was soll ich denn abwarten? Soll ich bis zum Zeitpunkt t' abwarten, zu dem ich einschlafe und träume, daß ich erkenne, daß ich zum Zeitpunkt $t$ wach war? Aber wenn ich zum Zeitpunkt t' nur träume, daß ich zum Zeitpunkt t wach war, kann ich dadurch nicht wissen, daß ich zum Zeitpunkt $t$ wach war. Noch einmal: Wie lange und was soll ich denn abwarten? Die Situation, in der ich mich Clarkes Erklärung nach befinde, ist viel schlimmer, da ich mich in einer Situation befinde, in der ich nicht weiß, ob ich jetzt träume oder nicht. Deswegen kann ich, auch wenn das Abwarten zufällig Erfolg hat, - mit anderen Worten, auch wenn ich all dies im Schlaf getraümt habe, derart daß ich zum Zeitpunkt $\mathrm{t}^{\prime}$ wach geworden bin und weiß, daß ich zum Zeitpunkt t geträumt habe, - nicht sagen, daß ich in der Tat weiß, daß dies wirklich so ist. Um dies zu wissen, muß ich weiter abwarten. Wie lange aber und was soll ich denn abwarten? Ich glaube, daß man, wenn man Clarke folgt, keine Antwort auf diese Frage geben kann. So wird eine Erwiderung wie die Strouds gegen Clarke Erfolg haben.

Wie aber sieht es aus, wenn man (PII) explizit gebraucht und in den Vordergrund stellt, um den Übergang von (KI) über (KII) zu (KIII) zu verhindern? Ein Beispiel für dieses Vorgehen 
wäre Walsh. ${ }^{54}$ Er glaubt nämlich zu Recht, daß die Konklusion des Traumargumentes nicht als (KI) aufgefaßt werden darf, sondern als (KI') aufgefaßt werden muß:

(KI') Es ist möglich, daß ich immer träume.

In diesem Fall aber liegt das Problem, wie Walsh richtig gezeigt hat, darin, daß das Argument eine Prämisse, nämlich (PII), enthält, die mit $\left(\mathrm{KI}^{\prime}\right)$ nicht verträglich ist.

Aber Stroud hat auch etwas dagegen zu sagen. Um zu (KI) zu gelangen, benötigt man (PII) überhaupt nicht:

"I think he (Descartes; $d$. Verf.) need never have actually dreamt of anything before, and certainly needn't know that he ever has, in order to be worried in the way he is by the thought that he might be dreaming now." (S. 18.; Hervorhebung d. Verf.)

Ich bin der Meinung, daß nicht Stroud, sondern Walsh recht hat. Aber wie bei Clarke enthält auch Walshs Erklärung etwas, das eine Erwiderung wie die Strouds anregt und richtig erscheinen läßt.

Walsh denkt, daß (PIV) falsch sein sollte, da (PII) wahr ist:

"Were it really the case that, as Descartes put it, 'there exist no certain marks' by which to distinguish waking from dreaming, we could never formulate the premise that we sometimes think we are perceiving things when all the time we are dreaming."(S. 91)

Diese Behauptung ist aber nicht ohne Einschränkung richtig, wie wir bald sehen werden. Aber auch angenommen, daß sie ohne Einschränkung richtig ist, ist das Problem dabei, daß sie uns überhaupt nicht helfen kann zu wissen, ob wir in einer gegebenen Situation träumen oder nicht, da sie zu allgemein ist. Dies ist der Grund dafür, daß Stroud glaubt, daß er seine Position verteidigen kann, wenn er auf (PIII) und (PIV) zurückgreift. Um zu wissen, ob man träumt oder wach ist, muß man ein Kriterium haben, mit dessen Hilfe man entscheiden kann, ob man träumt oder wach ist. Aber da ein solches Kriterium fehlt, ist es unmöglich in einer gegebenen Situation zu wissen, ob man wach ist. Das besagt (KI). Da dieses Kriterium fehlt, können alle früheren Erfahrungen, vom Traum aus wach geworden $\mathrm{zu}$ sein, nichts anderes als Pseudoerfahrungen sein, auch angenommen, daß Descartes sie gemacht zu haben glaubt. Daraus folgt möglicherweise auch (KIII) bzw. (KI').

\footnotetext{
${ }^{54}$. Vgl. Walsh, Mataphysics, S. 91.

55 . Vgl. auch S. 15-177
} 
Hat Stroud recht, daß man ohne (PII) zu (KI) und damit auch zu (KIII) gelangen kann? Meine Antwort lautet "Nein". Da ich im nächsten Abschnitt vorhabe, diese Antwort näher zu rechtfertigen, will ich mich hier nur damit zufrieden geben, die wesentliche Problematik der Interpretation Strouds genau anzugeben.

Wir haben vorhin ein Merkmal des Traums darin gesehen, daß ich, wenn ich träume, damit nicht wissen kann, daß ich mit Papieren in meiner Hand in meinem Zimmer sitze, auch wenn dies der Fall ist. Dies ist der Grund dafür, daß man von (KI) zu (KII) übergehen kann.

Es gibt nun ein weiteres Merkmal von Träumen: Unser Wissen davon, daß wir geträumt haben, ist retrospektiv. Es ist nämlich nicht möglich zu wissen, daß ich träume, während ich träume. ${ }^{56}$ Es kann vor allem kein Mittel geben, mit dessen Hilfe ich wissen kann, daß ich träume, während ich träume. Keine Reflexion wie die über die äußeren Wahrnehmungsbedingungen, die mich daran hindert, aus der Möglichkeit des Irrtums bei der Meinungsbildung $a$ sensibus die Möglichkeit des universalen Irrtums zu folgern, kann mir nämlich dazu verhelfen zu wissen, daß ich jetzt träume, wenn ich jetzt träume. Aber daß unser Wissen davon, daß wir geträumt haben, retrospektiv ist, besagt nicht, daß unser Wissen davon, daß ich jetzt wach bin, auch retrospektiv ist. Ich kann nämlich ohne weiteres wissen, daß ich wach bin, wenn ich wach bin. Nicht mein Wissen davon nämlich, daß ich wach bin, wenn ich wach bin, sondern nur mein Wissen davon, daß ich geträumt habe, wenn ich geträumt habe, ist retrospektiv. Dies zeigt, daß (PII) wahr ist. Daraus folgert sich, daß (PIII) und (PIV) nicht ohne Einschränkung wahr sind. Dementsprechend kann die Antwort auf unsere dritte Frage, ob das auf (KI) führende Argument schlüssig ist, "Ja" und "Nein" lauten. Descartes kann nämlich mit dem Argument zu (KI) gelangen, wenn er es entwickelt, während er träumt, aber nicht, wenn er es entwickelt, während er wach ist. Diesen Punkt haben Clarke und Walsh übersehen. Sonst hätten sie (PIII) und damit auch (PIV) nicht so schlechthin, nämlich ohne Einschränkung, akzeptieren können.

Stroud aber begeht nicht denselben Fehler, den Clarke und Walsh begangen haben, da er (PII) nicht akzeptiert. Nehmen wir vorläufig an, daß Stroud recht hat, so daß man ohne (PII) zu (KI) gelangen kann. Kann man aber von hier aus zu (KIII) gelangen? Ich denke nicht. Dieser Übergang ist nämlich nur über (KII) möglich, aber die Möglichkeit des Übergangs von (KI) zu (KII) steht Stroud nicht offen, da er (PII) aus dem oben betrachteten Grund eliminiert hat. Es ist wichtig zu betonen, daß der entscheidende Grund dafür, daß wir früher Descartes recht gegeben haben, wenn er von (KI) zu (KII) übergeht, darin liegt, daß wir wissen, daß es unmöglich ist zu wissen, daß wir uns in einer kontingenten Situation befinden, wenn wir dies träumen. Dieses Wissen setzt aber unsere früheren Erfahrungen voraus, vom Traum aus wach

\footnotetext{
${ }^{56}$. Natürlich gibt es Fälle, in denen wir es wissen. Aber diese Fälle sind irrelevant.
} 
geworden zu sein. Ohne (PII) kann Strouds folgende von mir mit kursiver Schrift betonte Behauptung nicht verstanden werden:

"The only thought he needs is that it is now possible for him to be dreaming that he is sitting by the fire, and that if that possibility were realized he would not know that he is sitting by the fire." (S. 17; die letztere Hervorhebung d. Verf.).

So kann zwar die Konklusion, zu der Stroud ohne (PII) gelangen kann, nur (KI) sein, weder (KII) noch (KIII). Im nächsten Abschnitt werden wir diesen Punkt noch genauer und ausführlicher betrachten.

\section{III. 2. 2. Kritik an Stroud}

Es gibt zwei Fragen, die hier betrachtet werden sollen. Die eine Frage ist die, ob Stroud Recht hat. Die andere Frage ist die, ob seine Interpretation Descartes trifft. Versuchen wir die Fragen ihrer Reihenfolge nach zu betrachten.

Erinnern wir uns zuerst daran, daß bei Strouds Interpretation zwei Punkte eine entscheidende Rolle spielen.

Der erste Punkt ist der, daß Descartes verstehen kann, was Traum ist und was Wachsein ist, ohne Traumerfahrungen gemacht zu haben, jedenfalls so weit, daß er wissen kann, daß es nicht möglich ist zu wissen, daß er jetzt in seinem Zimmer mit Papieren in seiner Hand sitzt, wenn er es träumt. Der andere Punkt ist der, daß Stroud voraussetzt, daß wir ein Kriterium haben müssen, um zu wissen, ob wir zum gegebenen Zeitpunkt träumen oder nicht. Ich werde im Folgenden den zweiten Punkt zu widerlegen versuchen, indem ich mit Hilfe von Williams zu erklären versuche, wie wir wissen, daß wir wach sind, wenn wir wach sind. Diese Erklärung wird auch einen Grund dafür abgeben, daß der erste Punkt nicht akzeptabel ist.

Unter einem "Kriterium" verstehen wir ein kennzeichnendes oder unterscheidendes Merkmal für das Vorliegen eines Zustandes Z und wir entscheiden mit Hilfe des Kriteriums die Frage, ob Z vorliegt oder nicht. Das einfachste Beispiel wäre ein künstliches Kriterium, nämlich ein Meßgerät. Aber es ist wichtig zu sagen, daß hier nicht von einem solchen rein künstlichen Kriterium die Rede ist, sondern von einem anderen, nämlich einem Kriterium für sortale Unterscheidungen, das wir aufgrund unserer Beobachtungen von Merkmalen in der Welt aufstellen, weil wir glauben, daß diese Merkmale einen wesentlichen Unterschied zwischen Z 
und non-Z aufzeigen. ${ }^{57}$ Diese gewöhnliche Vorstellung von einem Kriterium führt leicht dazu zu glauben, daß wir immer in der Lage sein müssen, nicht nur zu sagen, daß Z erfüllt ist, wenn dem so ist, sondern auch zu sagen, daß $\mathrm{Z}$ nicht erfüllt ist, wenn dem so ist. Aber wie Williams richtig bemerkt hat, ${ }^{58}$ ist dies nicht immer der Fall. Es gibt nämlich viele Fälle, in denen wir zwar nicht sagen können, daß Z erfüllt ist, wenn dem so ist, aber in denen es für uns möglich ist zu sagen, daß Z nicht erfüllt ist, wenn dem so ist. Da es hier um Zustände des Subjektes geht, sind gute Beispiele dafür Tod und Leben, Trunkenheit und Nicht-Betrunkensein usw. Wir können nicht (bzw. nicht rational) sagen, daß wir tot oder volltrunken sind, wenn dies der Fall ist, aber dies nimmt uns nicht die Möglichkeit, rational zu sagen, daß wir nicht tot bzw. nicht volltrunken sind, wenn dies der Fall ist, ganz abgesehen davon, daß wir den Unterschied zwischen $\mathrm{Z}$ und non-Z herausstellen können.

Wozu gehört der Fall von Traum und Wachsein? Nach Stroud gehört er zu den ersten Fällen. Ich glaube, daß unsere Reflexion über den Fall der Sinnestäuschung uns leicht dazu verführen kann, Stroud zu folgen. Es ist auf den ersten Blick plausibel, daß unser Wissen von einer Sinnestäuschung retrospektiv ist. Dies ist aber nicht immer so. Nachdem wir Erfahrungen von Fällen von Sinnestäuschungen gemacht haben, sind wir in der Lage, den Fall der Sinnestäuschung und den Fall der Nicht-Sinnestäuschung, von einem neutralen Standpunkt aus zu betrachten, zu vergleichen und durch rationale Überlegungen ein Kriterium aufzustellen, mit dessen Hilfe es möglich ist, die Frage zu entscheiden, ob in einer gegebenen Situation eine Sinnestäuschung vorliegt oder nicht. Diese Fähigkeit ist von großer Bedeutung, weil sie uns die Möglichkeit gibt, falsche Urteile zu vermeiden. Wie verhält es sich aber mit dem Fall von Traum und Wachsein? Der Fall von Traum und Wachsein ist in gewisser Hinsicht dem Fall von Sinnestäuschung und Nicht-Sinnestäuschung ähnlich, nämlich in der Hinsicht, daß wir sowohl im Wachsein als auch im Traum rationale Überlegungen anstellen können, und in dieser Hinsicht ist der Traum von Tod und Volltrunkenheit verschieden. Ich glaube, daß dies ein Grund dafür ist, daß das Traumargument uns überzeugend erscheinen kann. Während es nämlich möglich ist zu wissen, daß Sinnestäuschung stattfindet, wenn dies der Fall ist, scheint es unmöglich zu sein zu wissen, ob wir träumen oder nicht (dies scheint um so mehr der Fall zu sein, wenn die Frage auftritt, während wir träumen), obwohl wir in beiden Fällen, nämlich im Fall des Traums und im Fall der Sinnestäuschung rationale Überlegungen anstellen können. Wenn man diese Ähnlichkeit des Falles von Traum und Wachsein und des Falles von Sinnestäuschung und Nicht-Sinnestäuschung für entscheidend hielte, wäre man geneigt zu denken, daß es nicht möglich ist zu wissen, ob wir träumen oder nicht. Denn um dies zu wissen, müssen wir von einem neutralen Standpunkt aus durch rationale Überlegungen und mit

\footnotetext{
57. Es ist eine offene und umstrittene Frage, ob man die Unterscheidung zwischen künstlichen und natürlichen Kriterien machen kann. Hierauf werden wir später zurückkommen.

${ }^{58}$. Vgl. Williams, Descartes, S. 310-311.
} 
Hilfe eines Kriteriums entscheiden können, ob wir träumen oder nicht. Dies scheint aber unmöglich zu sein, vor allem wenn diese Frage auftritt, während wir träumen. Wenn alles, was wir erfahren, während wir träumen, und alle rationalen Überlegungen, die wir anstellen, während wir träumen, von der Art sind, daß sie uns beurteilen lassen können, daß wir nicht träumen, ist überhaupt nicht klar, wie es uns möglich sein kann zu sagen, ob wir träumen oder nicht.

Dies ist aber kontraintuitiv und sogar absurd. Die Ähnlichkeit zwischen dem Fall von Traum und Wachsein und dem Fall von Sinnestäuschung und Nicht-Sinnestäuschung in der oben genannten Hinsicht ist nämlich nicht so entscheidend, daß beide Fälle gleichgesetzt werden müssen. Traum ist der Halluzination viel näher, insofern als das, was das betroffene Subjekt halluziniert, nur Umstände sind, in denen das Subjekt sich zu befinden glaubt, wobei seine Fähigkeit gleich bleibt, rationale Überlegungen anzustellen. In diesen Fällen liegt der Hauptgrund dafür, daß das betroffene Subjekt uns irrational zu sein scheint, nicht darin, daß das Subjekt durch die Halluzination unfähig wird, rationale Überlegungen anzustellen, sondern eher darin, daß diese Fähigkeit unter den genannten Umständen ausgeübt wird. Der Fall der Halluzination hat dann wie der des Traums mit dem Fall der Sinnestäuschung die Gemeinsamkeit, daß wir rationale Überlegungen anstellen können. Aber anders als im Fall der Sinnestäuschung können wir nicht von einem neutralen Standpunkt aus zwischen Halluzination und Nicht-Haluzination unterscheiden und beurteilen, ob wir in dem Halluzinationszustand sind, wenn dies der Fall ist. Trotzdem hindert dies uns überhaupt nicht daran, sagen zu können, daß wir nicht im Halluzinationszustand sind, wenn dies der Fall ist. Analoges gilt auch vom Fall des Traums.

Wie Williams richtig betont hat, halten wir den Fall des Traums nicht einfach für einen von diesen Fällen, sondern "it reflects features of dreaming, features which cannot of course be appealed to when we are dreaming, for no features can be rationally appealed to when dreaming, but which can be rationally appealed to at the only time when we can rationally appeal to anything, viz. when we are awake." (S. 313). Entscheidend ist nämlich, daß wir erklären können, was Wachsein ist und was Traum ist, und diese Erklärung kann nur vom Standpunkt des Wachseins aus gegeben werden. Die beiden oben genannten Merkmale des Traums, daß es z.B. unmöglich ist zu wissen, daß ich mit Papieren in meiner Hand in meinem Zimmer sitze, wenn ich dies träume, und daß ich nicht sagen kann, daß ich träume, wenn ich träume, sind solche Merkmale des Traums, die wir nur vom Standpunkt des Wachseins aus feststellen können, nachdem wir Traumerfahrungen gemacht und darüber nachgedacht haben, aber nicht umgekehrt.

Wenn die bisherige Überlegung zutreffend ist, können wir daraus die Konsequenz ziehen, daß die Rekonstruktion des Traumargumentes durch Stroud nicht schlüssig ist. In seiner Rekonstruktion ist nämlich vorausgesetzt, daß wir imstande sind zu verstehen, was Traum ist, 
zumindest zu wissen, daß es unmöglich ist zu wissen, in welcher kontingenten Situation wir uns befinden, während wir träumen, dadurch, daß wir träumen, daß wir uns in einer bestimmten kontingenten Situation befinden. Dieses Verständnis können wir nur vom Standpunkt des Wachseins aus haben. Soweit die erste Frage.

Versuchen wir nun zu zeigen, daß Descartes ebenfalls dieser Meinung ist, nämlich daß der Fall von Traum und Wachsein nicht dem Fall von Sinnestäuschung und Nicht-Sinnestäuschung entspricht, sondern eher dem Fall von Halluzination und Nicht-Halluzination. Wenn dies der Fall ist, kann dadurch nicht nur gezeigt werden, daß Descartes nicht durch das Traumargument die Existenz der physikalischen Außenwelt in Frage stellen wollte, sondern auch, daß er dies nicht für möglich hielt.

Zu diesem Zweck betrachten wir zuerst Descartes' Diskussion mit Hobbes. Descartes weist in der sechsten Meditation eine Behauptung zurück, die er in dem Absatz in der ersten Meditation gemacht hat, in dem das Traumargument eingeführt worden ist:

"so brauche ich nicht fernerhin zu fürchten, daß das von den Sinnen mir täglich Dargebotene falsch sei. So darf ich denn alle übertriebenen Zweifel dieser Tage als lächerlich zurückweisen. Dies gilt vorzüglich von dem allgemeinsten in Betreff des Traumes, welchen ich nicht vom Wachen zu unterscheiden vermochte. Jetzt nämlich merke ich, daß zwischen beiden der sehr große Unterschied ist, daß niemals meine Träume sich mit allen übrigen Erlebnissen durch das Gedächtnis so verbinden, wie das, was mir im Wachen begegnet."(Buchenau, S. 77) ${ }^{59}$

Zunächst ist die Frage: Was genau soll die Behauptung sein, die in der 1. Meditation gemacht wurde, die er aber jetzt für lächerlich hält, und warum? Wenn man wie Stroud jenen Absatz der ersten Meditation als ein Argument auffaßt, muß diese Behauptung (KI) sein, nämlich die These, daß Descartes nicht wissen kann, ob er jetzt träumt oder nicht. Dann muß der Grund dafür, daß Descartes sie jetzt als lächerlich zurückweist, der sein, daß er anders als in der ersten Meditation nun ein Kriterium gefunden hat, mit dessen Hilfe er sagen kann, daß er träumt, wenn dies der Fall ist, und daß er wach ist, wenn dies der Fall ist. Nennen wir dieses Kriterium "Kohärenz-Kriterium". Wenn dem so ist, ist es folgerichtig, folgende Erklärung Descartes' als ein Beispiel dafür zu verstehen:

"Denn in der Tat, wenn mir im Wachen plötzlich jemand erschiene und gleich darauf wieder verschwände, wie es in Träumen geschieht, und zwar so, daß ich weder sähe, woher er gekommen, noch wohin er gegangen, so würde ich dies nicht mit Unrecht eher für eine bloße

\footnotetext{
59. "non amplius vereri debeo ne illa, quae mihi quotidie a sensibus exhibentur, sint falsa, sed hyperbolicae superiorum dierum dubitationes, ut risu dignae, sunt explodendae. Praesertim summa illa de somno, quem a vigilia non distinguebam; nunc enim adverto permagnum inter utrumque esse discrimen, in eo quod nunquam insomnia cum reliquis omnibus actionibus vitae a memoria conjungantur, ut ea quae vigilanti occurrunt;" (AT VII, S. 89)
} 
Vorspiegelung oder für ein in meinem Gehirne erdichtetes Trugbild halten,--als urteilen, daß es ein wirklicher Mensch sei."(ebd. $)^{60}$

Wenn dem so ist, kann man wie Hobbes folgenden Einwand gegen Descartes erheben:

"Hier fragt es sich, ob es gewiß ist, daß ein Träumender, der zweifelt, ob er träumt oder nicht, nicht träumen könnte, daß sein Traum mit den Ideen vergangener Ereignisse in einer langen Reihe zusammenhängt. Kann er es, so kann das, was dem Träumenden Handlungen seines früheren Lebens $\mathrm{zu}$ sein scheinen, als wahr angesehen werden, genau wie wenn er wachte."(Buchenau, S. 176)

Auf diese Frage von Hobbes antwortet Descartes folgendermaßen:

"Unmöglich kann ein Träumender das, was er träumt, mit den Ideen vergangener Dinge wahrhaft verknüpfen, wenngleich er träumen kann, er verknüpfe es; denn wer bestreitet es, daß ein Schlafender sich täuschen kann? Ist er aber dann erst erwacht, so wird er seinen Irrtum mühelos erkennen."(ebd.) ${ }^{62}$

Wie Wilson richtig betont hat, ${ }^{63}$ vermittelt diese Antwort Descartes' den Eindruck, daß er dem wesentlichen Punkt von Hobbes' Einwand ausweicht. Was uns hier aber interessiert und viel wichtiger ist, ist die Art und Weise, wie Descartes auf Hobbes antwortet. Descartes erkennt nämlich nach wie vor die Möglichkeit an, daß wir in unserem Traum insofern getäuscht werden, daß wir während des Traums glauben, daß wir wach sind. Trotzdem erweckt er den Eindruck, daß dies kein ernsthaftes Problem ist, da er der Meinung ist, daß wir sagen können, daß wir nicht träumen, wenn dies der Fall ist. Er hält dies für selbstverständlich. Dies läßt uns zweifeln, ob (KI) die Konklusion ist, zu der Descartes in der Tat durch das Traumargument gelangen zu können glaubt. Und dies läßt uns weiter zweifeln, ob es richtig ist, die beiden oben zitierten Stellen aus der sechsten Meditation als Widerlegung des Traumargumentes zu verstehen, derart daß er nun ein Kriterium gefunden hat, mit dessen Hilfe er wissen könne, daß er träumt, wenn dies der Fall ist, und daß er wach ist, wenn dies der Fall ist. Gibt es eine Möglichkeit, diese Stellen anders zu verstehen und damit mit Descartes' Antwort auf Hobbes mehr Sinn zu verbinden? Ja. Diese Möglichkeit besteht darin, daß wir sie nicht unter Rekurs

\footnotetext{
60. "nam sane, si quis, dum vigilo, mihi derepente appareret, statimque postea dispareret, ut sit in somnis, ita scilicet ut nec unde venisset, nec quo abiret, viderem, non immerito spectrum potius, aut phantasma in cerebro meo effictum, quam verum hominem esse judicarem." (AT VII, S. 89-90)

61. "Quaero utrum sit hoc certum, quod quis, somnians se dubitare an somniet necne, non possit somniare cohaerere suum somnium cum ideis rerum longa serie praeteritarum. Si potest, ea quae somnianti videntur esse actiones vitae suae anteactae, possunt censeri pro veris, non minus quam si vigilaret." (AT VII, S. 195)

62. "Non potest somnians ea quae somniat cum ideis rerum praeteritarum revera connectere, quamvis somniare possit se connectere. Quis enim negat dormientem falli posse? Atqui postea experrectus errorem suum facile dignoscet." (AT VII, S. 196)

${ }^{63}$. Vgl. Wilson, S. 19-20.
} 
auf jenen Absatz des Traumargumentes in der ersten Meditation verstehen, sondern eher umgekehrt. ${ }^{64}$ Versuchen wir sie auf diese Weise zu verstehen.

Beginnen wir zu diesem Zweck mit der Frage, was Descartes mit dem Beispiel eigentlich zum Ausdruck bringen wollte, daß wir es für eine Sinnestäuschung halten werden, wenn wir während unseres Wachseins eine Person ohne irgendeine Verbindung mit anderen Ereignissen plötzlich erscheinen und dann sofort verschwinden sehen. Wenn man dieses Beispiel in Verbindung mit der Suche nach einem Kriterium versteht, mit dessen Hilfe es möglich ist zu sagen, ob man träumt oder nicht, muß es so verstanden werden, daß Descartes damit den Fall von Traum und Wachsein dem Fall von Sinnestäuschung und Nicht-Sinnestäuschung gleichsetzt. Aber wenn wir den Text des Beispiels vorsichtig lesen, finden wir, daß diese Lesart nicht richtig ist. Die Sinnestäuschung, von der dort die Rede ist, ist nicht ein Beispiel, um die Möglichkeit zu erklären, wie wir anhand des Kohärenz-Kriteriums feststellen können, daß wir träumen, wenn dies der Fall ist, und daß wir nicht träumen, wenn dies der Fall ist, sondern umgekehrt. Descartes sagt an dieser Stelle deutlich "ut sit in somnis". Um zu erklären, wie dies verstanden werden soll, halte ich es für einen richtigen Weg, zwei Fragen zu stellen und Descartes' Antworten auf diese zwei Fragen zu rekonstruieren: Woher hat Descartes das Kohärenz- Kriterium und warum glaubt er, daß wir mit Hilfe des KohärenzKriteriums uns dafür entscheiden können, daß die Erscheinung der Person in dem Beispiel eine Sinnestäuschung ist? ${ }^{65}$

Descartes' Antworten auf die beiden oben gestellten Fragen können folgendermaßen rekonstruiert werden. Wir wissen von Standpunkt des Wachseins aus, daß alles, was wir im Traum erfahren, nichts anderes als Phantasma sind, und daß das meiste, was als Phantasma in unserem Traum auftritt, die Eigenschaft hat, daß es das Kohärenz-Kriterium nicht erfüllt. Wenn dem so ist, kann etwas, das wir zwar im Wachsein erfahren, das aber das Kohärenz-Kriterium nicht erfüllt, nichts anderes als ein Phantasma sein.

Das Kohärenz-Kriterium ist nämlich ein Kriterium, das Descartes vom Standpunkt des Wachseins aus durch seine Reflexion über den Unterschied zwischen Traum und Wachsein herausgestellt hat, aber nicht ein Kriterium, mit dessen Hilfe wir sagen können, daß wir träumen, wenn dies der Fall ist, und daß wir nicht träumen, wenn dies nicht der Fall ist. Wenn

\footnotetext{
${ }^{64}$. In diesem Zusammenhang ist zu sagen, daß in der ersten Meditation nicht von discrimen, wovon in der sechsten Meditation eigentlich die Rede ist, sondern von indicium die Rede ist.

${ }^{65}$. Zuerst muß gesagt werden, daß die Sinnestäuschung im Beispiel nicht von der Art ist wie die, daß ein gerader Stock im Wasser geknickt erscheint, oder daß ein viereckiger Turm in einer großen Entfernung rund aussieht. Vielmehr geht es um eine Sinnestäuschung in Bezug auf die Existenz von etwas. Natürlich ist es eine interessante und wichtige, aber schwierig zu entscheidende Frage, wie wir unsere Erfahrung über die Person im Beispiel bewerten und beurteilen müssen, und ob und wieweit Descartes berechtigt ist zu behaupten, daß wir anhand des Kohärenz-Kriteriums uns dafür entscheiden könnten, daß die Person in der Tat nichts anderes als ein Phantasma ist. Lassen wir aber diese Frage außer acht. Der Punkt ist vielmehr der, daß Descartes der Meinung ist, daß wir diese Frage anhand des Kohärenz-Kriteriums entscheiden könnten.
} 
wir in der Tat dazu geneigt sind zu glauben, daß die Person im Beispiel nichts anderes als ein Phantasma sein sollte, dann scheint es mir so zu sein, daß es Descartes mit dem KohärenzKriterium und unter Rekurs auf die Traumerfahrung gelungen ist zu erklären, warum wir dies glauben.

Ich glaube, daß unsere bisherigen Überlegungen gezeigt haben, daß Descartes nicht die Ansicht haben kann noch hat, mit jenem Absatz des Traumarguments in der ersten Meditation alle seine Meinungen bezüglich der physikalischen Gegenstände der Außenwelt in Zweifel zu ziehen. Worauf wollte er dann mit diesem Absatz hinaus und wie stellt er alle eigenen Meinungen bezüglich der physikalischen Gegenstände der Außenwelt in Frage? Bevor ich darauf eingehe, will ich hier kurz, wie angekündigt, versuchen, noch zu zeigen, daß er jenen Absatz überhaupt nicht als ein Argument versteht. 


\section{III. 2. 3. Kritik an Wilson und Frankfurt}

Wie ich vorhin gesagt habe, sind Wilson und Frankfurt der Meinung, daß Descartes mit dem Traumargument zwar nicht alle Meinungen bezüglich der physikalischen Gegenstände der Außenwelt, aber einen Teil davon in Zweifel zieht. Die Hauptstïcke zu ihrer Auffassung des Traumarguments als Argument mit einer begrenzten Leistung haben diese Kommentatoren aus dem folgenden Abschnitt bezogen, der auf den erwähnten Absatz des Traumarguments folgt.

"Sei es denn: wir träumen! Mögen wirklich alle jene Einzelheiten nicht wahr sein, daß wir die Augen öffnen, den Kopf bewegen, die Hände ausstrecken; ja, mögen wir vielleicht gar keine solchen Hände, noch überhaupt einen solchen Körper haben:..... In gleicher Weise muß man, wenngleich sogar dieses Allgemeine: Augen, Haupt, Hände und dergleichen nur in der Einbildung vorhanden sein könnte, doch notwendig gestehen, daß wenigstens gewisse andere, noch einfachere und allgemeinere Dinge wirklich vorhanden sind.....

Von dieser Art scheinen zu sein die Natur des Körpers überhaupt und seine Ausdehnung, ferner die Gestalt der ausgedehnten Dinge ebenso die Quantität, d.h. ihre Größe und Zahl, ebenso der Ort, an welchem sie existieren, die Zeit, während welcher sie dauern und dergleichen."(Buchenau, S. 13-14)

Wenn man diesen Abschnitt in dem Sinne versteht, daß Descartes dort etwas erklärt, das durch die von ihm bisher entwickelten rationes dubitandi noch nicht in Zweifel gezogen werden kann, dann ist es ein kleiner Schritt, das Traumargument als ein Argument mit eingeschränkter Stärke zu verstehen, demgemäß Descartes zwar nicht alle eigenen Meinungen bezüglich der physikalischen Gegenstände der Außenwelt, aber einen Teil davon in Zweifel zieht. Demnach scheint er nämlich zu behaupten, daß das Traumargument nicht in der Lage sei, die Existenz von physikalischen Objekten in Zweifel zu ziehen, während es in der Lage sei in Frage zu stellen, ob physikalische Objekte alle Eigenschaften besitzen, die wir wahrnehmen. ${ }^{67}$ Aber die entscheidende Schwierigkeit dieser Interpretation liegt einfach darin zu erklären, in welchem konkreten Zusammenhang das Traumargument als ein Argument angesehen werden kann, das zwar nicht die Existenz von physikalischen Objekten in Frage stellt, dafür aber, ob sie alle Eigenschaften besitzen, die wir wahrnehmen.

All diese Schwierigkeiten entstehen, wie wir gesehen haben, nur daraus, daß man jenen Absatz des Traumarguments in der ersten Meditation als ein Argument auffaßt. Wenn aber nicht als Argument, wie soll man ihn dann verstehen? Wie ich oben gesagt habe, bin ich der

\footnotetext{
${ }^{66}$. "Age ergo somniemus, nec particularia ista vera sint, nos oculos aperire, caput movere, manus extendere, nec forte etiam nos habere tales manus, nec tale totum corpus;.......... Nec dispari ratione, quamvis etiam generalia haec, oculi, caput, manus, \& similia, imaginaria esse possent, necessario tamen saltem alia quaedam adhuc magis simplicia \& universalia vera esse fatendum est,........

Cuius generis esse videntur natura corporea in communi, eiusque extensio; item figura rerum extensarum; item quantitas, sive earumdum magnitudo \& numerus; item locus in quo existant, tempusque per quod durent, \& similia."( AT VII, S. 19-20)

${ }^{67}$. Vgl. Wilson, S. 24-5. und Frankfurt, Kapitel 6-8, insbesondere S. 70-71.
} 
Meinung, daß man ihn als eine Illustration verstehen sollte. Was für eine Illustration er ist, werden wir erfahren, wenn wir betrachten, auf welche Weise Descartes unsere Überzeugungen von der Außenwelt in Frage stellt.

\section{III. 3. Die dritte ratio dubitandi: Gott}

Halten wir zuerst zwei Fragen auseinander:

(FI) Können wir wissen, ob wir nicht träumen, wenn wir nicht träumen?

(FII) Leistet die Unterscheidung von Traum und Wachsein all das, worauf man damit hinaus wollte, vorausgesetzt, daß (FI) positiv beantwortet wird?

Descartes versucht die Existenz der physikalischen Außenwelt in Frage zu stellen, indem er nicht (FI), sondern (FII) stellt. Dies tut er in zwei Schritten.

Der erste Schritt besteht aus dem erwähnten Absatz des Traumarguments in der ersten Meditation. Er spielt dabei die Rolle einer Illustration, mit deren Hilfe Descartes uns zu dem Gedanken einlädt, daß es möglich ist, daß das, was man im Wachsein erfährt, dem ähnlich ist, was man im Traum erfährt, und zwar in der Hinsicht, daß direkte Gegenstände der Wahrnehmung im Wachsein Vorstellungen sind, die in einem sind, aber verschieden sind in der Hinsicht, daß die Vorstellungen, die man im Wachsein wahrnimmt, durch physikalische Objekte verursacht werden, während dies für die Traumvorstellungen nicht der Fall ist. Descartes setzt damit voraus, daß die Beziehung zwischen physikalischen Objekten und Wahrnehmungen eine kausale Beziehung ist, und daß die direkten Gegenstände, die wir im Wachsein wahrnehmen, Vorstellungen sind, die in uns sind..$^{68}$ Der zweite und entscheidende Schritt besteht darin, daß Descartes die Möglichkeit einführt, daß die angenommene kausale Beziehung zwischen physikalischen Objekten und Wahrnehmungen nicht besteht. Descartes sagt nämlich:

"Zu diesen Zweifelsgründen nun habe ich vor kurzem zwei von höchster Allgemeinheit hinzugefügt. Der erste war, daß nichts von dem, was ich jemals während des Wachens zu empfinden geglaubt habe, derart ist, daß ich es nicht auch irgend einmal im Schlafe zu empfinden meinen könnte. Da ich nun nicht annehme, daß das, was ich im Schlafe zu empfinden meine, von außer mir befindlichen Dingen kommt, so sah ich nicht recht ein, weshalb ich dies eher von dem annehmen sollte, was ich im Wachen zu empfinden meine."(Buchenau, S. 66) ${ }^{69}$

\footnotetext{
${ }^{68}$. Lassen wir die Fragen, die hier auftreten können, beiseite, nämlich die Fragen, welchen Anlaß Descartes hat, unsere Wahrnehmungen so zu interpretieren, und ob die angenommene kausale Beziehung zwischen physikalischen Gegenständen und Vorstellungen in der Tat bei Descartes eine entscheidende Rolle spielt, um zu seiner skeptischen Konklusion zu gelangen. Darauf werden wir im zweiten und dritten Kapitel zu sprechen kommen.

69. "Quibus etiam duas maxime generales dubitandi causas nuper adjeci: prima erat, quod nulla unquam, dum vigilo, me sentire crediderim, quae non etiam inter dormiendum possim aliquando putare me sentire;
} 
Meiner Meinung nach ist unsere Traumerfahrung eine notwendige Bedingung für die Möglichkeit, die Situation, in der wir zwar wach sind, aber jene kausale Beziehung nicht besteht, nachzuvollziehen, anders als Stroud glaubt. Dies ist der entscheidende Grund dafür, daß ich behaupte, daß jener Absatz des Traumarguments in der ersten Meditation als eine Illustration einer solchen Situation verstanden werden sollte. Dieser Punkt wird später durch meine Diskussion mit Mackie im letzten Abschnitt des nächsten Kapitels bestärkt werden.

Abgesehen davon, nennt Descartes zwei Möglichkeiten dafür, daß die Annahme der kausalen Beziehung zwischen physikalischen Objekten und Wahrnehmungen falsch ist, so daß er einen systematischen Fehler begeht zu glauben, daß er durch Wahrnehmungen Informationen über die physikalische Außenwelt bekommt. Die eine Möglichkeit ist die, daß Gott ihn täuscht, so daß er glaubt, daß eine kausale Beziehung besteht, obwohl es keine physikalische Außenwelt gibt. Diese Möglichkeit kann nach Descartes nicht einfach dadurch ausgeschlossen werden, daß, wie er glaubt, Gott gütig ist. Denn es ist möglich, daß sein Glauben daran, daß Gott gütig ist, falsch ist:

"Aber vielleicht hat Gott nicht gewollt, daß ich mich so täusche, heißt er doch der Allgütige?-Allein wenn es mit seiner Güte unvereinbar wäre, daß er mich so geschaffen, daß ich mich stets täusche, so schiene es doch ebensowenig dieser Eigenschaft entsprechend, daß ich mich bisweilen täusche."(Buchenau, S. 14)

Die andere Möglichkeit besteht darin, daß er so mangelhaft beschaffen ist, daß er sich ständig täuscht und glaubt, daß es die physikalische Außenwelt gibt. Descartes glaubt nun, daß es nicht möglich sei zu wissen, ob die physikalische Außenwelt existiere, es sei denn, daß diese beiden Möglichkeiten ausgeschlossen werden. Und da er in der ersten Meditation nicht in der Lage ist, sie auszuschließen, glaubt er in der Folge, daß er nicht wisse, ob die physikalische Außenwelt existiere.

cumque illa, quae sentire mihi videor in somnis, non credam a rebus extra me positis mihi advenire, non advertebam quare id potius crederem de iis quae sentire mihi videor vigilando."( AT VII, S. 77)

${ }^{70}$. "At forte noluit Deus ita me decipi, dicitur enim summe bonus; sed si hoc eius bonitati repugnaret talem me creasse ut semper fallar, ab eadem etiam videretur esse alienum permittere ut interdum fallar", (AT VII, S. 21) 


\section{Fazit}

Ich habe im letzten Abschnitt den Versuch unternommen darzustellen, wie Descartes alle seine Meinungen bezüglich der physikalischen Außenwelt in Frage gestellt zu haben glaubt. Er glaubt, daß er sich ihrer enthalten müsse, da er sich am Ende der ersten Meditation nicht in der Lage sieht, Bedingungen zu erfüllen, die er für die Möglichkeit seiner Erkenntnis der physikalischen Außenwelt für notwendig hält. Diese Bedingungen bestehen darin, jene im letzten Abschnitt genannten beiden Möglichkeiten auszuschließen, nämlich zum einen die Möglichkeit, daß es einen bösen Dämon gibt, der den Schein hervorruft, er nehme die physikalische Außenwelt wahr, obwohl diese nicht existiert. Zum anderen geht es um die Möglichkeit, daß Descartes von Natur aus so beschaffen sein könnte, daß er eine physikalische Außenwelt wahrzunehmen glaubt, obwohl sie nicht existiert. Nun ist die Frage die, wie wir damit umgehen können oder müssen. Die Betrachtung dieser Frage soll meinen Übergang zu dem Vorhaben des nächsten Kapitels verständlich machen.

Was unsere Frage nach der Art und Weise betrifft, wie man mit dem skeptischen Argument Descartes' und seiner skeptischen Konklusion umgehen kann und muß, meine ich, daß nichts, nicht einmal das Ignorieren des Problems, schlechter als dessen Trivialisierung oder Dramatisierung ist. Erinnern wir uns daran, wie Moore den Skeptiker zu widerlegen versucht hat. Wie wir gesehen haben, handelt es sich um eine reductio ad absurdum. Der erste Versuch sah so aus. Wenn ein Skeptiker behauptet, daß die von ihm ausgewählten Aussagen falsch oder fraglich seien, widerspricht er sich selbst. Er behauptet es nämlich uns gegenüber und setzt damit voraus, daß er und wir existieren. Der zweite Versuch sah so aus. Viele Skeptiker machen vom Personalpronomen der ersten Personen Plural Gebrauch und widersprechen dadurch sich selbst, denn sie setzen dadurch die Existenz von anderen Menschen voraus.

Was diese Versuche Moores betrifft, kann ich mir vorstellen, daß manche den Eindruck bekommen, daß Moore den Kernpunkt des Problems absichtlich umgeht: Moore trivialisiert das Problem- sogar in einer sehr groben Weise. Diesen Eindruck werden vor allem diejenigen bekommen, die geneigt sind, das Problem des Skeptizismus für ernst und wichtig zu halten. Einen ähnlichen Eindruck werden auch diejenigen bekommen, die der Meinung sind, daß jenes Problem ein Pseudoproblem ist. Für diese kann es nämlich unverständlich erscheinen, warum Moore überhaupt solche Versuche unternommen hat. Wenn Moore damit in der Tat beabsichtigt hat, den Skeptizismus zu widerlegen, wäre es viel besser gewesen, wenn er sich die Mühe gespart hätte und das Problem des Skeptizismus einfach ignoriert hätte. Oder wollte er damit ironisch auf die Skeptiker reagieren? 
Der oben erwähnte Eindruck und die darauf folgenden Reaktionen rühren selbstverständlich daher, daß sie Moores Ausführungen als Versuche aufgefaßt haben, den Skeptizismus zu widerlegen. Und dies scheint auf den ersten Blick von niemandem bestritten werden zu können. Aber trotzdem frage ich mich, ob dies eine vernünftige und produktive Umgangsweise mit Moore ist. Es ist undenkbar, daß er überhaupt nicht geahnt hat, welche Reaktion er mit seinen Versuchen hervorrufen würde. Da er sie aber trotzdem gemacht hat, scheint es mir so zu sein, daß die vernünftige und produktive Frage, auf die wir uns konzentrieren sollten, eher die ist, worauf er damit hinaus wollte, weniger die, was er damit erreichen kann. Sonst ist es ja möglich, daß man seine Versuche trivialisiert. Meiner Meinung nach haben Moores Versuche wenig mit der Widerlegung des Skeptizismus direkt zu tun. Und sie sind erst recht nicht eine grobe Trivialisierung des Problems. Wenn man sie als ironisch gemeint verstehen will, wäre es besser und richtiger, sie als Selbstironie zu verstehen, nicht als gegen die Skeptiker gerichtete Ironie. Warum dem so ist, kann folgendermaßen erklärt werden.

Nach meiner Meinung sind Moores Versuche Ausdruck für eine Schwierigkeit, mit der er bewußt oder unbewußt während seiner Beschäftigung mit dem Problem des Skeptizismus konfrontiert war. ${ }^{71}$ Diese Schwierigkeit bezieht sich auf die grundlegende Frage nach der Möglichkeit einer sinnvollen Diskussion über das Problem des Skeptizismus überhaupt. Wie wir gesehen haben, besteht der Kernpunkt seiner Versuche darin, auf die Absurdität hinzuweisen, welcher die Skeptiker bei dem Versuch ausgesetzt sind, ihr Problem als ein echtes Problem darzustellen. Ist es überhaupt möglich, das Problem des Skeptizismus als ein echtes Problem zu formulieren, ohne dabei triviale Wahrheiten zu ignorieren? Ist es nicht der Fall, daß die Diskussion über das Problem des Skeptizismus nur deswegen bisher geführt worden ist und werden kann, weil die Skeptiker stillschweigend geduldet haben, triviale Wahrheiten zu ignorieren? Aber sind die Skeptiker die Einzigen, die diesem Absurditätsverdacht ausgesetzt sind? Dies ist nicht der Fall. Die Antiskeptiker teilen das Schicksal mit den Skeptikern, wenn sie versuchen, den Skeptizismus zu widerlegen. Um ihn zu widerlegen, müssen sie selber in der Lage sein, den Skeptizismus als ein echtes Problem zu formulieren. Aber wenn sie dies versuchen, begehen sie denselben Irrtum, den die Skeptiker begehen. Ich glaube, daß diese Schwierigkeit Moore bewußt und unbewußt schwer belastet hat. Ich verstehe demgemäß Moores Versuche als eine verzweifelte Antwort auf diese Frage. Es geht nicht um die Widerlegung des Skeptizismus, sondern vielmehr um die Schwierigkeit, das Problem des Skeptizismus als ein echtes Problem $\mathrm{zu}$ formulieren. Wenn es keine Möglichkeit gibt, den Skeptizismus als ein echtes Problem zu formulieren, gibt es keine

\footnotetext{
${ }^{71}$. Wenn dies der Fall ist, ist der, der das Problem des Skeptizismus nicht verstanden hat, nicht Moore, sondern Stroud, der behauptet, daß Moore das Problem nie verstanden hat. Vgl. Stroud, Kapitel III.
} 
Möglichkeit, eine sinnvolle Diskussion darüber zu führen. Und dies gilt selbstverständlich für beide Parteien zugleich.

Es ist nun angebracht zu fragen, warum Moore dann nicht die einfache Lösung gewählt hat, den Skeptizismus zu ignorieren. Wollte er sich ironisch geben? Wir wissen, daß Moore auch später ähnliche Versuche unternommen hat, und es sind ihrer zu viele, als daß sie als "Ironie" bezeichnet werden können. Warum konnte Moore sich von dem Problem des Skeptizismus nicht befreien, obwohl er dessen Absurdität gesehen hat? Meiner Meinung nach ist es Moores Beitrag zur Diskussion über das Problem des Skeptizismus, daß er auf diese Problematik aufmerksam gemacht und sich darauf konzentriert hat, ohne irgendeinen Kompromiß gesucht zu haben. Was damit gemeint ist, ergibt sich aus folgender Betrachtung.

Die große Bedeutung der Problematik, auf die Moore aufmerksam gemacht hat, bemerken wir an Descartes. Es scheint so zu sein, daß es Descartes gelungen ist, die von Moore wieder aufgeworfene Problematik bezüglich der Möglichkeit der Formulierung des Problems des Skeptizismus überhaupt zu beseitigen. Es scheint Descartes nämlich gelungen zu sein, einen Standpunkt zu finden, von dem aus er das Problem des Skeptizismus formulieren kann, ohne dabei triviale Wahrheiten zu ignorieren: den Standpunkt des Ichs. Wie wir gesehen haben, behauptet er nicht, daß er alle Wissenschaften bezüglich der physikalischen Außenwelt in Frage stelle, indem er einige Aussagen in Frage stelle, von denen er annimmt, daß alle Menschen sie für wahr halten. Er macht nicht vom Personalpronomen der ersten Person Plural Gebrauch. Er behauptet lediglich, daß er alle Wissenschaften bezüglich der physikalischen Außenwelt in Frage stelle, indem er alle seine Meinungen bezüglich der physikalischen Außenwelt in Frage stelle. Aber diejenige Position, die daraus Nutzen zieht, scheint einzig und allein die der Skeptiker zu sein. Die Schwierigkeit oder die Absurdität, die Moore ans Licht gebracht hat, trifft mit voller Kraft allein uns, denn wir fragen uns, wie wir mit Descartes' skeptischem Argument umgehen können oder müssen.

Ignorieren ist besser als trivialisieren, wie es sich z.B. bei Mackie findet. Mackie macht nämlich die Entstehung des Problems des Skeptizismus ganz davon abhängig, daß man eine bestimmte Wahrnehmungstheorie vertritt, nämlich die Repräsentationstheorie. Mackie vermittelt den Eindruck, daß die Frage, ob eine Theorie eine Art Repräsentationstheorie ist, dadurch entschieden werden kann, ob die Theorie das Problem des Skeptizismus auftreten lassen kann oder nicht. ${ }^{72}$ Aber es ist sehr fraglich, ob Philosophen auf das Problem des Skeptizismus verfallen, wenn sie die Repräsentationstheorie vertreten. Wenn dies der Fall sein sollte, dann verfiele niemand auf das Problem des Skeptizismus, wenn er die Repräsentationstheorie nicht vertritt. Dies scheint mir absurd zu sein. Ich halte es für besser, daß man die Repräsentationstheorie von dem Problem des Skeptizismus trennt und sie als eine

\footnotetext{
${ }^{72}$. Mackie, Problems from Locke, S. 50. Auf diesen Punkt werden wir im nächsten Kapitel ausführlich zurückkommen.
} 
reine Hypothese behandelt, wobei das Problem des Skeptizismus außer Acht gelassen wird, wie Clarke es tut. ${ }^{73}$ Es ist wahr, daß Descartes die Repräsentationstheorie vertritt. Aber dennoch ist es, wie wir im nächsten Kapitel ausführlich sehen werden, nicht der Fall, daß sein skeptisches Argument sie voraussetzt. ${ }^{74}$ Entscheidend ist dabei nur seine Traumerfahrung. ${ }^{75}$

Wie können und müssen wir mit dem skeptischen Argument Descartes' umgehen? Können wir es einfach ignorieren? Meiner Meinung nach gibt es zwei Gründe dafür, daß wir dies nicht immer tun können. Ein Grund ist der, daß nicht zu leugnen ist, daß wir uns zumindest einmal im Leben Gedanken darüber gemacht haben, ob das Leben vielleicht nur ein Traum ist. Ein anderer Grund ist der, daß uns die Möglichkeit offen steht, uns das Argument Descartes' anzueignen: "Philosophi, si omnia Platonis et Aristotelis argumenta legerimus, de propositis autem rebus stabile judicium ferre nequeamus: ita enim non scientias videremur didicisse, sed historias."(AT X, S. 367). Vor allem scheint dies nicht so schwierig zu sein, denn wir wissen, wie viele Philosophen das Argument Descartes' als ein echtes Argument für den Skeptizismus verstanden haben. ${ }^{76}$

Dramatisierung ist schlimmer als ignorieren. Sie kann durch zweierlei Unzufriedenheit mit der Art und Weise formuliert werden, in der Descartes sein skeptisches Argument entwickelt hat. Die erste Unzufriedenheit ist die, daß Descartes sein Argument zwar radikal entwickelt hat, aber nicht radikal genug. Man könnte z.B. sagen, daß er die Möglichkeit, verrückt zu sein, nicht einfach hätte ausschließen dürfen, sondern ernsthaft hätte erwägen sollen. Mit anderen Worten hat er sein Argument nur so weit entwickelt, wie er ihm gewachsen ist: Dies ist aber willkürlich. ${ }^{77}$ Und in der Folge könnte man behaupten, daß Descartes' Versuch der Widerlegung des Skeptizismus sehr mangelhaft durchgeführt worden ist, so daß er dem Skeptizismus nicht gewachsen ist. Die andere Unzufriedenheit ist die, daß Descartes sein Argument in einer solchen Weise entwickelt hat, daß es ihm selbst von Anfang an die Möglichkeit nimmt, sein Projekt als Versuch der Widerlegung des Skeptizismus

\footnotetext{
73. Siehe D.M. Clarke, Kapitel II, besonders S. 25 ff.

${ }^{74}$. Daß dies auch für die traditionellen pyrrhonischen skeptischen Argumente nicht der Fall ist, hat Striker gezeigt. Siehe Striker, The Ten Tropes of Aenesidemus in The Skeptical Tradition.

75. Es ist überflüssig zu sagen, daß Descartes die Repräsentationstheorie nicht braucht, um Traumerfahrung zu erklären. Und es ist sehr fraglich, ob jemand, der keine Traumerfahrung gemacht hat, die Repräsentationstheorie und Descartes' skeptisches Argument verstehen kann.

${ }^{76}$. Wenn man das Argument Descartes' als ein echtes Argument für den Skeptizismus versteht, dann besteht die einzige Möglichkeit, den Skeptizismus zu widerlegen, darin, die Existenz Gottes zu beweisen, wie Descartes richtig gesehen hat.

77. Man scheint diesen Eindruck am besten bestätigen zu können, wenn man, wie Frankfurt, darauf aufmerksam macht, daß es für Descartes nicht nötig ist, auf die erste von den beiden Möglichkeiten hinzuweisen, sondern daß allein der Hinweis auf die zweite Möglichkeit ausreichend ist, die Existenz der physikalischen Außenwelt in Frage zu stellen. Also besteht die Absicht des Hinweises auf die erste Möglichkeit nicht darin, die Existenz der physikalischen Außenwelt in Frage zu stellen, sondern in dem rein strategischen Grund, sich die Möglichkeit zu bewahren, später die Existenz der physikalischen Außenwelt durch den Beweis der Existenz Gottes zu sichern. Aber daß dies ein Mißverständnis ist, zeigt sich an Descartes' Verfahren in De Methodo. Vgl. Frankfurt, S. 82.
} 
durchzuführen. Descartes scheint explizit die Möglichkeit der Erkenntnis von mathematischen Aussagen und damit auch implizit die Möglichkeit der Erkenntnis von logischen Aussagen dadurch in Zweifel zu ziehen, daß wir Irrtümer beim Rechnen und beim Schlußfolgern machen. ${ }^{78}$ Wenn dies der Fall wäre, würde es für Descartes unmöglich sein, sein Projekt durchzuführen. Was die Art und Weise betrifft, wie Descartes mathematische Aussagen in Frage stellt, ist es ein Mißverständnis zu glauben, daß er sie durch Rekurs auf die Möglichkeit des universalen Irrtums in Frage stellt. Dafür weiß Descartes zuviel, als daß es Überzeugungskraft haben kann. Das zeigt sich daran, wie er seine Meinungen bezüglich der physikalischen Außenwelt in Frage gestellt hat. Dieser Punkt wird noch plausibler, wenn wir im nächsten Teil Descartes' Grundposition in den Regulae diskutieren. Abgesehen davon liegt der Grund dafür, daß ich die erste Unzufriedenheit als Dramatisierung bezeichne, in Folgendem. Descartes erklärt in De Methodo:

"Nicht ahmte ich darin dennoch die Skeptiker nach, die zweifeln, nur um zu zweifeln, und nichts Anderes als Ungewißheit suchen."(AT VI, S. 556; übers. v. d. Verf.) ${ }^{79}$

Man kann diese Erklärung vielleicht als eine willkürliche Einschränkung seiner Beschäftigung mit dem Problem des Skeptizismus auf bestimmte Typen von Argumenten betrachten. Ein Beispiel dafür ist das Argument, das er in der ersten Meditation entwickelt hat. Aber dies ist nicht der Fall. Warum nicht, zeigt sich, wenn wir überlegen, warum Descartes das Argument für nötig befunden hat. Der Grund dafür, daß er sich nur damit beschäftigen will, und dafür, daß er glaubt, daß es widerlegt werden sollte, liegt darin, daß es die Möglichkeit von Erkenntnis zu bedrohen scheint, obwohl es zuläßt, daß wir die Fähigkeit haben, rational zu denken, und daß wir zwar Irrtümer begehen, aber daß wir sie auch vermeiden können. Dieser Grund spiegelt genau unsere Position in unserem normalen Alltagsleben wieder. Wir glauben nämlich in unserem Alltagsleben, daß wir zwar Irrtümer begehen, aber nicht immer, und in vielen Fällen in der Lage sind, sie zu vermeiden, und daß wir nicht verrückt sind. Erinnern wir uns dazu daran, wie stark wir gegen die Erklärung Descartes' in der Eingangsrede zur ersten Meditation reagiert haben und warum wir so stark reagiert haben.

Ich bin der Meinung, daß es Descartes gelungen ist, das Problem des Skeptizismus zu behandeln, wobei er es weder trivialisiert noch dramatisiert oder ignoriert hat. Dies ist der Grund dafür, daß es sich lohnt, sich mit dem Problem des Skeptizismus bei Descartes zu beschäftigen.

\footnotetext{
${ }^{78}$. Ayer interpretiert Descartes so. Vgl. Ayer, "cogito, ergo sum", in Analysis, Vol. 14, 1953-1954.

79. "Nec tamen in eo Scepticos imitabar, qui dubitant tantum ut dubitent, \& praeter incertitudinem ipsam nihil quaerunt."
} 


\section{Die Motivationsfrage in den Regulae}

\section{I. Descartes über die menschliche Erkenntnisfähigkeit: \\ Die Frage nach der Rechtfertigung und die Frage nach der Methode}

Descartes beginnt seine philosophischen Überlegungen mit der folgenden Äußerung:

"Nichts ist besser als der gesunde Verstand unter den Menschen verteilt: jeder glaubt nämlich, damit so gut versehen zu sein, daß selbst jene, die besonders unerfüllbare Begierden haben, und die die Natur bezüglich aller anderen Dingen niemals befriedigen kann, sich gewöhnlich nicht einmal wünschen, einen besseren Verstand zu haben, als sie wirklich haben. Es scheint nicht so zu sein, daß sich darin alle Menschen gleichermaßen täuschen, sondern eher so, daß das Vermögen, richtig zu urteilen und das Wahre vom Falschen zu unterscheiden( wir wollen das Vermögen passend den gesunden Verstand oder die richtige Vernunft nennen), von Natur in allen Menschen gleich ist. Und so entsteht die Meinungsverschiedenheit nicht daraus, daß die einen mehr Vernunft haben als die anderen, sondern nur daraus, daß wir unseren Gedanken nicht auf dieselbe Weise durchführen, oder daraus, daß wir nicht denselben Gegenstand betrachten. Es genügt nicht, daß uns natürliche Anlagen zur Verfügung stehen, sondern es ist entscheidend, sie richtig zu gebrauchen." (AT VI, S. 540; übers. v. d. Verf.) ${ }^{1}$

Wie wir hier sehen können, ist Descartes davon überzeugt, daß die bona mens allen Menschen gleichermaßen zuteil wird, also die Fähigkeit, richtig zu urteilen und die Wahrheit zu erkennen. Der von ihm angegebene Grund für seine Überzeugung mag zwar ironisch klingen, aber die Ernsthaftigkeit und die Festigkeit seiner Überzeugung können dadurch kaum beeinträchtigt werden. Es ist nämlich bekannt, daß diese Überzeugung der Anlaß war, den Discours de la Methode in französischer Sprache zu schreiben. ${ }^{2}$

Allen Menschen steht der Weg offen, zur Wahrheit zu gelangen, und er ist kein Vorrecht, das nur einige genießen. Dies ist der Grund dafür, daß ihn gerade die bona mens und nicht andere mögliche Wege zur Wahrheit interessiert. Descartes vertritt nämlich nicht die dogmatische Ansicht, daß die bona mens die einzige Möglichkeit ist, zur Wahrheit zu gelangen. Ein gutes Beispiel wäre etwa die Offenbarung, die er auch für eine solche Möglichkeit hält. ${ }^{3}$ Wenn diese ihn trotzdem nicht interessiert, liegt der Grund dafür nicht darin, daß sie ungeeignet wäre, sondern darin, daß es ihm zufolge von dem Willen Gottes abhängt, wem diese Offenbarung

\footnotetext{
1. "Nulla res aequabilius inter homines est distributa quam bona mens: ea enim unusquisque ita abundare se putat, ut nequidem illi qui maxime inexplebiles cupiditates habent, \& quibus in nulla unquam alia re natura satisfecit, meliorem mentem quam possideant optare consueverint. Qua in re pariter omnes falli non videtur esse credendum; sed potius vim incorrupte judicandi \& verum a falso distinguendi (quam proprie bonam mentem seu rectam rationem appellamus) natura aequalem omnibus nobis innatam esse. Atque ita nostrarum opinionum diversitatem, non ex eo manare quod simus aliis alii majore rationis vi donati, sed tantum ex eo quod cogitationem non per easdem vias ducamus, neque ad easdem res attendamus. Quippe ingenio pollere haud sufficit, sed eodem recte uti palmarium est."

2. Vgl. Curley, Descartes Against the Sceptics, S. 17.

${ }^{3}$. Vgl. AT X, S. 370 und S. 424.
} 
gegeben wird, und außerdem von dem Willen der Menschen abhängt, die Offenbarung für wahr zu halten. Der Weg, durch Offenbarung zur Wahrheit zu gelangen, kann dementsprechend nicht als repräsentativer Weg angesehen werden, der jedem Menschen zugänglich ist und den jeder einschlagen kann. Worum es bei Descartes geht, sind also nicht irgendwelche Fähigkeiten eines einzelnen Menschen, mit deren Hilfe er zur Wahrheit gelangen kann, sondern eine allgemeine und repräsentative Fähigkeit, von der sogar mit Recht angenommen wird, daß sie allen Menschen gleich zuteil wird. Mit dieser Überzeugung beginnt Descartes seine philosophische Überlegung.

Descartes sagt weiter in De Methodo (AT VI, S. 541 f.), daß er wie Andere auch von Kindheit an seine Studien verfolgt habe, weil er von Anderen davon überzeugt worden sei, daß er dadurch eine certa und evidenta cognitio von allem erlangen könne, was für das Leben nützlich sei. Die Vollendung seiner Studien hat aber für ihn weder Zufriedenheit mit seiner Gelehrsamkeit noch Hoffnung bezüglich der Zukunft mit sich gebracht, sondern Enttäuschung wegen seiner Unwissenheit und Unsicherheit. Diese Unwissenheit und Unsicherheit, die ihm seine Studien gebracht haben, repräsentieren nicht einfach seine persönliche Lage nach den Studien, sondern vielmehr die Lage der Wissenschaften seiner Zeit. Er sieht diese Lage nämlich so, daß überall Meinungsverschiedenheit herrscht, obwohl es eine einzige Wahrheit von einem und demselben Gegenstand geben muß, und daß man gegen diese Meinungsverschiedenheit machtlos bleibt. Aber wie wir in unserem Zitat sehen können, hält Descartes diese kritische Lage der Wissenschaften seiner Zeit nicht für ein Anzeichen der Unmöglichkeit von Erkenntnis, während sie für viele seiner Zeitgenossen als ein guter Grund für die Behauptung der Unmöglichkeit von Erkenntnis angenommen wurde. Für diese kritische Lage macht er nämlich nicht die bona mens als solche verantwortlich, sondern vielmehr den Umstand, daß man die bona mens falsch angewandt habe. Dennoch reicht diese kritische Situation aus, ihn darauf aufmerksam zu machen, daß allein der Besitz dieser Fähigkeit nicht den Erwerb von Erkenntnissen garantieren könne. So entsteht Descartes' Bedürfnis nach einer Methodenlehre. ${ }^{4}$

Ich werde der folgenden Betrachtung von Descartes' Gedanken in den Regulae zwei Fragen zugrunde legen. Descartes ist in der Zeit der Regulae davon überzeugt, daß wir die Fähigkeit besitzen, die Wahrheit zu erkennen. Die erste Frage ist die, wie er davon überzeugt sein kann, daß wir diese Fähigkeit haben. Die andere Frage ist die, wie wir unsere Fähigkeit gebrauchen müssen, um die Wahrheit zu erkennen, wenn unser Besitz der Fähigkeit allein nicht zum

\footnotetext{
${ }^{4}$. Vgl. Frankfurt, Demons, Dreamers, and Madmen, S. 5 f. Meiner Meinung nach ist es ein Irrtum von Frankfurt, wenn er Descartes' Unterscheidung zwischen der synthetischen Methode und der analytischen Methode nicht als einen methodologischen Kontrast zwischen der Philosophie der Zeit und seiner Philosophie, sondern einfach als einen Kontrast zwischen Gelehrten und Nichtgelehrten erklärt. Es ist irreführend zu sagen, daß Descartes die analytische Methode in den Meditationes verwandt hat, weil er Rücksicht auf ungelehrte Leser nehmen wollte.
} 
Erkennen des Wahren ausreicht. Die erste Frage ist eine Frage nach der Rechtfertigung seiner Überzeugung und die zweite Frage ist eine Frage nach der Methode. Da Descartes davon überzeugt ist, daß wir die Fähigkeit besitzen, zur Wahrheit zu gelangen, beschäftigt sich er in den Regulae nicht direkt mit der ersten Frage. Die Hauptaufgabe, die er sich in den Regulae stellt, ist nämlich die, auf die zweite Frage zu antworten. Aus diesem Grund können wir keine direkte Antwort von ihm auf die erste Frage erwarten. Trotzdem gibt es einige Passagen in den Regulae und in De Methodo, aus denen wir eine Antwort auf die erste Frage rekonstruieren können. Dies wird uns dabei helfen, eine Antwort auf die Motivationsfrage zu finden, warum sich Descartes später für das Problem des Skeptizismus interessiert und den Versuch für nötig gehalten hat, ihn zu widerlegen.

\section{I. 1. Antwort auf die Rechtfertigungsfrage: intuitus und deductio}

Wenn Descartes sagt, daß wir die Fähigkeit haben, die Wahrheit zu erkennen, meint er damit nicht einfach eine Fähigkeit, wahre Meinungen zu erwerben, sondern darüber hinaus eine Fähigkeit, zu wissen. Und Wissen definiert er so: omnis scientia est cognitio certa et evidenta (AT X, S. 362). ${ }^{5}$ Wenn dem so ist, muß unsere Rechtfertigungsfrage so formuliert werden: Wie kann Descartes seine Überzeugung rechtfertigen, daß wir die Fähigkeit haben, Wissen zu erwerben? Eine Antwort auf diese Frage können wir in seiner Erklärung über Intuition finden. Wie wir in der dritten Regel der Regulae sehen können, sind intuitus und deductio die zwei Handlungen der bona mens, durch die wir zur sicheren Erkenntnis gelangen können. Was intuitus ist, erklärt Descartes folgendermaßen:

"Unter Intuition verstehe ich nicht das schwankende Zeugnis der sinnlichen Wahrnehmung oder das trügerische Urteil der verkehrt verbindenden Einbildungskraft, sondern ein so müheloses und deutlich bestimmtes Begreifen des reinen und aufmerksamen Geistes, daß über das, was wir erkennen, gar kein Zweifel zurückbleibt, oder, was dasselbe ist: eines reinen und aufmerksamen Geistes unbezweifelbares Begreifen, welches allein dem Lichte der Vernunft entspringt und das, weil einfacher, deshalb zuverlässiger ist als selbst die Deduktion" (Gäber, S. $17-19)^{6}$

Diese Erklärung der Intuition läßt sich in vier Erklärungen aufspalten:

1) Intuition ist weder fluctuans sensuum fides noch male componentis imaginationis judicium fallax;

\footnotetext{
${ }^{5}$. Was er damit meint, werden wir im Verlauf dieses Kapitels erläutern.

${ }^{6}$.Die deutsche Übersetzung der Regulae zitiere ich nach der folgenden Ausgabe: Regeln, übers. von Gäbe. "Per intuitum intelligo, non fluctuantem sensuum fidem, vel male componentis imaginationis judicium fallax; sed mentis purae \& attentae tam facilem distinctumque conceptum, ut de eo, quod intelligimus, nulla prorsus dubitatio relinquatur; seu, quod idem est, mentis purae \& attentae non dubium conceptum, qui a sola rationis luce nascitur, \& ipsamet deductione certior est, quia simplicior" (AT X, S. 368).
} 
2) Intuition ist ein einfaches Begreifen der pura und attenta mens;

3) Was durch Intuition begriffen wird, ist sicher und unbezweifelbar;

4) Intuition ist einfacher und sicherer als Deduktion.

Was die erste Erklärung betrifft, ist es hier nicht nötig, näher zu betrachten, was fluctuans sensuum fides und male componentis imaginationis judicium fallax heißt. ${ }^{7}$ Die Erklärung (1) sagt nicht direkt, was Intuition ist, sondern nur, was sie nicht ist. Sie ist weder identisch mit sinnlicher Wahrnehmung noch mit Einbildung. Die Erklärung (2) scheint uns auf den ersten Blick positiv darüber zu informieren, was Intuition ist. Dies ist aber nicht der Fall. Es ist schwer zu verstehen, was die Einschränkung "rein" heißen soll, gesetzt den Fall, daß wir die andere Einschränkung "aufmerksam" verstehen, nämlich in dem psychologischen Sinne, daß wir uns auf den Gegenstand konzentrieren müssen, um den es geht. ${ }^{8}$ Dieses Verständnis der Beschränkung "aufmerksam" kann uns nicht helfen zu verstehen, was Intuition ist, weil dies eher eine Anforderung in bezug auf unsere Ausübung der Intuition darstellt. Wenn man unter der Einschränkung "rein" "nicht sinnlich" zu verstehen versucht, können wir sagen, daß die Einschränkung "rein" überflüssig ist, weil dies schon in (1) erwähnt worden ist. Vor allem ist es überhaupt nicht klar, was unter der bona mens, nämlich unter dem Subjekt des Aktes des Intuition, verstanden werden soll. Daraus folgt dann, daß diese Einschränkung auf eine andere Weise erklärt werden muß, damit sie einen Sinn haben kann und dazu beiträgt, eine positive Erklärung davon zu geben, was Intuition ist. Die einzige Möglichkeit dafür besteht darin, daß wir auf Descartes' negative Erklärung zurückgreifen, und annehmen, daß die Einschränkung "rein" ein Gegensatz zu fluctuans sensuum fides und male componentis imaginationis judicium fallax ist. Dies heißt aber nicht, daß wir eine positive Erklärung davon geben können, was Intuition ist, sondern wiederum nur, was sie nicht ist. Damit sind wir aber zu unserem Ausgangspunkt zurückgekehrt. Die Erklärung (3), daß Erkenntnis, die wir durch Intuition erwerben, sicher und unbezweifelbar ist, kann uns auch nicht helfen zu verstehen, was Intuition ist. Dieser Erklärung zufolge könnten wir mit ihr auch etwas Falsches zu etwas Wahrem machen. Die Erklärung (4) ist ebenfalls keine positive Bestimmung der Intuition, weil die Deduktion von Descartes mit Rekurs auf die Intuition erklärt wird, wie wir sehen werden.

Wenn meine bisherige Betrachtung zutrifft, dann scheint es so zu sein, daß Descartes uns mit dieser "Erklärung" der Intuition nicht helfen kann zu verstehen, was Intuition ist. Trotzdem kann dies seine Überzeugung nicht beeinträchtigen, daß allen Menschen die Fähigkeit zuteil wird, Erkenntnis zu erwerben, noch ihn hindern, auf unsere Rechtfertigungsfrage zu antworten. Diese Frage kann er nämlich beantworten, indem er auf die Tatsache zurückgreift, daß wir wissen,

\footnotetext{
${ }^{7}$. Vgl. Beck, The Method of Descartes, S. $52 \mathrm{ff}$.

${ }^{8}$. Vgl. die 9te Regel zu den perspicacites (AT X, S. 400 ff.)
} 
daß wir existieren, daß wir denken, daß ein Dreieck nur durch drei Seiten begrenzt wird, daß 2 plus 2 vier ist, usw. Dies ermöglicht ihm auch zu erklären, was Intuition ist. Was Intuition ist, kann man nämlich nur durch Rekurs auf Fälle von Erkenntnis erklären, die durch Intuition erkannt werden. Daran liegt es auch, daß man nur durch Analyse der Beispielsätze, die Descartes in seiner Erklärung der Intuition anführt, verstehen kann, welche Erkenntnis wir durch Intuition erwerben. Die ersten beiden Beispiele sind Aussagen über interne Zustände und über die eigene Existenz, das vorletzte ist die Definition des Dreieckes als eines mathematischen Gegenstandes, und das letzte ist eine einfache notwendigerweise wahre Aussage. Wir können dann sagen, daß "Intuition" ein terminus technicus ist, mit dem Descartes die Fähigkeit unseres Verstandes bezeichnen will, die Wahrheit der oben ausgezeichneten Typen von Aussagen zu erkennen, die dadurch charakterisiert werden können, selbstevident oder in ähnlicher Weise einleuchtend zu sein. ${ }^{9}$

Diese Tätigkeit, die Wahrheit einer selbstevidenten oder in ähnlicher Weise einleuchtenden einfachen Aussage unmittelbar zu erkennen, ist nicht die einzige Tätigkeit des Verstandes, die als "Intuition" bezeichnet wird. Wir können nämlich auch Verhältnisse zwischen einfachen Aussagen durch Intuition erkennen. Nachdem wir zum Beispiel durch Intuition die Wahrheit der einfachen Aussage erkannt haben, daß zwei plus zwei vier ist, und nachdem wir die Wahrheit der anderen einfachen Aussage erkannt haben, daß drei plus eins vier ist, können wir durch Intuition erkennen, daß die beiden Aussagen "identisch" sind. Diese Tätigkeit des Verstandes nennt Descartes Deduktion. Descartes sagt:

"worunter (unter Deduktion) wir all das verstehen, was aus etwas anderem sicher Erkanntem mit Notwendigkeit erschlossen wird. Aber das mußte so geschehen, weil das meiste zuverlässig gewußt wird, obgleich es selbst nicht evident ist, wofern es nur aus wahren und erkannten Prinzipien durch eine zusammenhängende und nirgendwo unterbrochene Tätigkeit des Denkens, welches das einzelne deutlich in der Intuition sieht, deduziert ist." (Gäbe, S. 19; Hervorhebung d. Verf. $)^{10}$

Obwohl dieser Erklärung der deductio psychologische Elemente beigemischt worden sind, ist dennoch das Entscheidende dabei die Rede von einer "Notwendigkeit". Was Descartes sagt, ist erstens, daß Prämissen, aus denen eine Konklusion geschlossen wird, selbstevident sein müssen oder aus anderen selbstevidenten Aussagen geschlossen worden sein müssen, und

\footnotetext{
9. Ich finde es am besten, die Aussagen, deren Wahrheit durch Intuition unmittelbar erkannt werden, so zu charakterisieren. Obwohl man sich darüber beklagen kann, daß dies zu vage ist, ist, was wir vermeiden müssen, eher, sie von Anfang an zu präzisieren. Es ist dabei auch wichtig zu bemerken, daß die Aussagen, deren Wahrheit durch Intuition erkannt werden, nicht auf den Bereich von einfachen notwendigen Aussagen beschränkt sind, die a priori erkannt werden. Vgl. Garber, Science and Certainty in Descartes: Critical and Interpretive Essays, S. 116

${ }^{10}$. "per quam (deductionem; d. Verf.) intelligimus, illud omne quod ex quibusdam alijs certo cognitis necessario concluditur. Sed hoc ita faciendum fuit, quia plurimae res certo sciuntur, quamvis non ipsae sint evidentes, modo tantum a veris cognitisque principiis deducantur per continuum \& nullibi interruptum cogitationis motum singula perspicue intuentis." (AT X, S. 369; Hervorhebung d. Verf.)
} 
zweitens, daß jeder Schritt der Deduktion durch Intuition durchgeführt werden muß, indem der Zusammenhang zwischen den Aussagen durch Intuition als notwendig erkannt wird. "Deduktion" ist also ein terminus technicus für eine Kette von Intuitionen. Der Unterschied zwischen Intuition und Deduktion liegt in Bezug auf ihre Funktion einfach darin, daß die Erkenntnis durch Deduktion durch unsere Erinnerungsfähigkeit unterstützt wird; in Bezug auf Gegenstände liegt er darin, daß die Aussagen, deren Wahrheit durch Deduktion erkannt wird, weder selbstevident noch einfach sind, während die Aussagen, die durch Intuition erkannt werden, selbstevident und einfach sind.

Wir können aus der bisherigen Überlegungen folgende Konsequenzen ziehen.

Erstens kann Descartes auf unsere Rechtfertigungsfrage ohne Schwierigkeiten (und nur) dadurch antworten, daß er auf Fälle von Erkenntnis hinweist. Dies tut er zuerst, indem er auf Fälle von Erkenntnis von selbstevidenten oder in ähnlicher Weise einleuchtenden Aussagen hinweist.

Zweitens ist seine Definition der Erkenntnis, die wir am Anfang dieses Abschnittes betrachtet haben, keine rein willkürliche und verbale. Es scheint sich eher so zu verhalten, daß Descartes die Definition der Erkenntnis aus der Analyse von ausgezeichneten Fällen von Erkenntnis gewonnen hat.

Drittens unterscheidet und spezifiziert er anhand dieser Fälle von Erkenntnis zwei Handlungen der bona mens, nämlich intuitus und deductio, mit Rekurs auf die Art und Weise, wie wir diese Erkenntnisse erwerben.

Viertens läßt er zwar die universale Möglichkeit des Irrtums bei der Deduktion offen, schließt aber die Möglichkeit des universalen Irrtums dadurch aus, daß er die Ursache des Irrtums nicht auf einen Mangel der Deduktion als solcher, sondern auf mangelhafte Anwendung zurückführt. Er sagt nämlich:

".., müssen wir daher beachten, daß wir auf doppeltem Wege zur Erkenntnis der Dinge kommen, durch Erfahrung nämlich oder durch Deduktion. Überdies müssen wir beachten, daß die Erfahrungen mit den Sachen häufig trügerisch sind, eine Deduktion oder reine Ableitung des einen aus dem anderen dagegen zwar verabsäumt werden kann, wenn man nicht aufpaßt, aber von einem Verstande, er mag der Vernunft noch so wenig mächtig sein, niemals verkehrt angestellt werden kann."(Gäbe, S. 11; Hervorhebung d. Verf.) ${ }^{11}$

\footnotetext{
11. "..,notandum est, nos duplici via ad cognitionem rerum devenire, per experientiam scilicet, vel deductionem. Notandum insuper, experientias rerum saepe esse fallaces, deductionem vero, sive illationem puram unius ab altero, posse quidem omitti, si non videatur, sed nunquam male fieri ab intellectu vel minimum rationali." (AT X, S. 364-365; Hervorhebung d. Verf.). Man muß dieses Zitat mit großer Vorsicht lesen. Der in ihm angegebene Gegensatz darf nicht als ein Gegensatz zwischen sinnlichen Wahrnehmungen und Deduktion verstanden werden, sondern als ein Gegensatz zwischen falschen Urteilen, die schlechthin aufgrund sinnlicher Wahrnehmungen gefällt werden, und Deduktion. Aus diesem
} 
Dies ist der Grund dafür, daß ich in meiner Interpretation der ersten Meditation nicht berücksichtigt habe, daß Descartes explizit die Möglichkeit der Erkenntnis von mathematischen Aussagen und damit auch implizit die Möglichkeit der Erkenntnis von logischen Aussagen aufgrund der Möglichkeit des universalen Irrtums beim Rechnen oder beim Schlußfolgern in Frage stellt. Es ist nämlich sehr schwer nachzuvollziehen, daß er diese seine grundsätzliche Überzeugung geändert haben sollte, aus welchen Gründen auch immer.

\section{I. 2. Neue Formulierung der Rechtfertigungsfrage:}

Übergang zur Frage nach der Methode

Wenn Descartes sagt, daß wir die Fähigkeit haben, Erkenntnis zu erwerben, scheint er damit nicht einfach zu meinen, daß wir eine Fähigkeit haben, mit der wir nur die Wahrheit von selbstevidenten oder in ähnlicher Weise einleuchtenden einfachen Aussagen oder die Wahrheit von Aussagen erkennen können, die aus selbstevidenten Wahrheiten unmittelbar erschlossen werden können. Wenn er nur dies gemeint hätte, wäre es zwar plausibel gewesen, aber wenig aufregend, und seine Kritik an den Wissenschaften seiner Zeit wäre hinfällig. Es ist nämlich kaum der Rede wert zu sagen, daß nicht alle Aussagen der Wissenschaften seiner Zeit falsch sind. Descartes meint viel mehr, nämlich daß wir auch die Wahrheit von solchen Aussagen erkennen können, die nicht selbstevident sind und nicht unmittelbar aus selbstevidenten und einfachen Aussagen erschlossen werden können (im Sinne der Erweiterung von Erkenntnissen oder des Aufbaus von sicheren Wissenschaften). Nur in diesem Zusammenhang können seine Betonung der Unentbehrlichkeit der Methode bei der Suche nach der Wahrheit und seine Kritik an den Wissenschaften seiner Zeit irgendeinen Sinn gewinnen. Demnach müssen wir die Frage nach der Rechtfertigung so umformulieren: Wie kann er seine Überzeugung rechtfertigen, daß wir die Fähigkeit haben, unsere Erkenntnis zu erweitern? Um diese Frage zu beantworten, gehe ich zuerst zu der Frage nach der Methode über, also zu der Frage, wie wir diese Fähigkeit gebrauchen müssen, um sichere Wissenschaften aufzubauen. Damit gehen wir von dem Problem der Erkenntnis der Wahrheit zu dem Problem der Gewißheit bei Descartes über.

Nachdem Descartes erklärt hat, daß die Suche nach der Wahrheit ohne Methode um nichts besser sei als sich keine Gedanken über die Wahrheit zu machen, erklärt er den Begriff der Methode:

Grund scheint es vernünftig zu sein, in diesem Zitat nur das zu berücksichtigen, was Descartes über Deduktion sagt. 
"Unter Methode aber verstehe ich zuverlässige und leicht zu befolgende Regeln, so daß, wer sich pünktlich an sie hält, niemals etwas Falsches für wahr unterstellt und, indem er keine geistige Mühe nutzlos verschwendet, sondern sein Wissen Stück für Stück ständig erweitert, die wahre Erkenntnis alles dessen erreicht, wozu er fähig ist.

Dies beides ist aber hier zu beachten: selbstredend nichts Falsches als wahr zu unterstellen und: eine umfassende Erkenntnis zu erreichen."(Gäber, S. 23) $)^{12}$

Die Nützlichkeit der Methode erkennen wir an drei Punkten:

1) Die Methode kann uns dabei helfen, Fehler (etwas Falsches als wahr anzunehmen) zu vermeiden und die Wahrheit zu erkennen.

2) Die Methode ist in pragmatischer Hinsicht nützlich.

3) Die Methode erweitert unsere Erkenntnis und zwar so weit, wie unsere Fähigkeiten reichen.

Konzentrieren wir uns hier nur auf den ersten Punkt. Da Descartes davon überzeugt ist, daß wir die Fähigkeit haben, Erkenntnis zu erwerben, weiß er auch, daß er nicht nur zeigen muß, wie wir die Fähigkeit anwenden müssen, um Erkenntnis zu erwerben, sondern auch, warum wir Irrtümer begehen. Die beiden Fragen, wie wir Erkenntnis erwerben können und wie wir Irrtümer vermeiden können, sind nur zwei verschiedene Seiten ein und derselben Frage. Wie ich in I.I.2. ausgeführt habe, ist es kein Zufall, daß Descartes in der vierten Meditation die Theorie des Urteils entwickelt, eine Kooperation von Willen und Verstand behauptet und das Fällen eines Urteils auf einen Willensakt zurückführt. Ein wesentliches Ziel dieses Versuches liegt darin zu erklären, worauf unsere falschen Urteile beruhen, und damit zu zeigen, daß es in unserer Macht steht, Irrtümer zu vermeiden. Für jemand wie Descartes, der bewiesen zu haben glaubt, daß Gott existiert und uns die Fähigkeit gegeben hat, Erkenntnis zu erwerben, ist die Tatsache problematisch und erklärungsbedürftig, daß wir Irrtümer begehen.

Die einfachste Antwort von Descartes auf die beiden Fragen ist die, daß wir etwas Falsches nicht als wahr annehmen dürfen. Wenn wir etwas Falsches als wahr annehmen, heißt dies, daß wir einen Irrtum begehen. Diese Antwort scheint aber auf den ersten Blick zu trivial zu sein. Vor allem wenn es z.B. nur um die Erkenntnis der Wahrheit von selbstevidenten Aussage geht, ist diese Antwort hinfällig. Die Wahrheit von selbstevidenten Aussagen wird nämlich durch Intuition unmittelbar erkannt, und die Gewißheit dieser Erkenntnis wird einerseits durch den einfachen Akt der Intuition und andererseits durch die Selbstevidenz der Aussage gesichert.

\footnotetext{
12. "Per methodum autem intelligo regulas certas \& faciles, quas quicumque exacte servaverit, nihil unquam falsum pro vero supponet, \& nullo mentis conatu inutiliter consumpto, sed gradatim semper augendo scientiam, perveniet ad veram cognitionem eorum omnium quorum erit capax.

Notanda autem hic sunt duo haec: nihil nimirum falsum pro vero supponere, $\&$ ad omnium cognitionem pervenire." (AT X, S. 371 f.). Vgl. De Methodo, AT VI, S. 541. Eine andere, mildere Version kann man in De Methodo finden. Dort schreibt Descartes: "Atque haec mihi Methodus in eo praecipue placebat, quod per illam viderer esse certus in omnibus me uti ratione, si non perfecte, saltem quam optime ipse possem" (AT VI, S. 552)
} 
So ist in diesem Fall die Möglichkeit ausgeschlossen, einen Irrtum zu begehen. Also muß seine Antwort auf andere Weise verstanden werden, damit sie einen angemessenen Sinn haben kann. Diese Möglichkeit besteht darin, sie mit Rekurs auf Fälle von Erkenntnis von nicht selbstevidenten Aussagen zu verstehen.

Wie wir oben gesehen haben, fällt die Gewißheit unserer Erkenntnis, wenn es um selbstevidente Aussagen geht, mit der Wahrheit der Aussagen zusammen. Dies läßt es als sinnlos erscheinen, über die Gewißheit unserer Erkenntnis und die Wahrheit der Aussagen getrennt zu sprechen. Wenn es aber um Erkenntnis von nicht selbstevidenten und komplexen Aussagen geht, sind wir nicht imstande, direkt über die Wahrheit von Aussagen zu sprechen, sondern wir können über die Wahrheit der Aussagen nur entscheiden mit Rekurs auf die Rechtfertigung für den Wahrheitsanspruch der Aussagen. Descartes scheint einen solchen Unterschied im Sinn zu haben, wenn er in der Exposition zur 7. Regel (AT X, S. 387) die beiden Termini certum und verum in folgender Weise differenziert:

"Die Beachtung dieser Vorschrift ist notwendig, um diejenigen Wahrheiten gewi $\beta$ zu machen, von denen wir oben gesagt haben, daß sie aus den ersten und an sich bekannten Prinzipien nicht unmittelbar deduziert werden. Dies nämlich geschieht manchmal über einen so weitläufigen Zusammenhang von Schlußfolgerungen, daß wir uns, wenn wir bei ihnen angelangt sind, nicht leicht an den ganzen Weg erinnern, der uns bis dahin geführt hat." (Gäbe, S. 41; Hervorhebung d. Verf.) ${ }^{13}$

So muß Descartes' Antwort, daß wir etwas Falsches nicht als wahr annehmen dürfen, so verstanden werden, daß wir eine unsichere Aussage nicht als wahr annehmen sollten. Ob eine nicht-selbstevidente Aussage sicher ist, hängt demnach davon $a b$, ob sie durch Intuition und durch Deduktion erkannt worden ist. Dies ist der Grund dafür, daß die Suche nach der Wahrheit von Aussagen, die nicht selbstevident sind, Descartes zur Suche nach Gewißheit führt.

"Und so weisen wir mit diesem Grundsatz alle jene bloß wahrscheinlichen Erkenntnisse zurück und beschließen, daß ausschließlich vollkommen Erkanntem, das nicht bezweifelt werden kann, Vertrauen zu schenken ist." (Gäbe, S. 7) ${ }^{14}$

Unsere bisherige Betrachtung bezieht sich nur auf die Frage, unter welcher Bedingung wir eine komplexe Aussage für wahr halten müssen. Es ist aber eine andere Frage, wie wir die

\footnotetext{
13. "Eorum, quae hic proponuntur, observatio necessaria est ad illas veritates inter certas admittendas, quas supra diximus a primis \& per se notis principiis non immediate deduci. Hoc enim fit interdum per tam longum consequentiarum contextum, ut, cum ad illas devenimus, non facile recordemur totius itineris, quod nos eo usque perduxit." (Hervorhebung d. Verf.)

${ }^{14}$. "Atque ita per hanc propositionem rejicimus illas omnes probabiles tantum cognitiones, nec nisi perfecte cognitis, \& de quibus dubitari non potest, statuimus esse credendum." (AT X, S. 362)
} 
Wahrheit einer komplexen Aussage entdecken können. ${ }^{15}$ Wenn es um Erkenntnis der Wahrheit einer komplexen Aussage geht, die nicht selbstevident und aus selbstevidenten Aussagen nicht unmittelbar deduktiv ableitbar ist, hängt die Möglichkeit unserer Erkenntnis der Wahrheit nach Descartes davon ab, ob wir die entsprechende Aussage auf Aussagen reduzieren können (Analysis), die selbstevident sind, oder deren Wahrheit wir aus anderen selbstevidenten Aussagen deduktiv ableiten können. Als Hilfsmittel dafür stellt er drei Regeln auf:

"Die zweite (Methode war die): Schwierigkeiten, die ich untersuchen würde, in so viele Teile zu zerlegen, wie es zur besseren Lösung beitragen könnte.

Die dritte: Alle Überlegungen, die ich zur Suche der Wahrheit anstellen würde, immer einer gewissen Ordnung nach zu entwickeln: dies natürlich dadurch, mit den einfachsten und für die Erkenntnis leichtesten Gegenständen zu beginnen und allmählich und gleichsam stufenweise zur Erkenntnis von schwierigeren und komplizierteren Gegenständen aufzusteigen; selbst solche Überlegungen, die ihrer Natur nach nicht in eine Reihenfolge eingebettet werden könnten, in Ordnung zu halten.

Die letzte: Bei der Suche nach Lösungen und bei der Zerlegung einer Schwierigkeit in Teile alles Betreffendes so vollständig aufzuzählen und Übersicht zu schaffen, daß ich sicher wäre, nichts auszulassen."(AT VI, S. 550; übers. v. d. Verf.) ${ }^{16}$

Was diese Methode betrifft, sind folgende Bemerkungen zu machen.

Erstens ist sie so allgemein formuliert worden, daß man vielleicht kritisieren kann, daß man damit nichts anfangen könne. Aber es ist wichtig zu sehen, daß Descartes weder mit seiner Methodenschrift (d.h. dem ersten Buch von De Methodo) noch mit den darauf folgenden drei Abhandlungen beabsichtigt hat, irgendeine bestimmte Methode darzustellen. ${ }^{17} \mathrm{Er}$ scheint eher der Ansicht zu sein, daß es nicht möglich ist, sie darzustellen. In dieser Hinsicht hat er recht, wie Williams richtig sagt: "But it is not just a matter of one work or a particular set of essays failing to explain fully the Method - no purely abstract treatment could. It is very much part of

\footnotetext{
${ }^{15}$. Garber behauptet mit Recht: "Thus a given item of knowledge is certain not by the virtue of the way we discover it (e.g., by using Cartesian Method), but by the way in which justify it (i.e., by presenting it as the product of intuition and deduction)." Garber, S. 118.

16. "Alterum, ut difficultates quas essem examinaturus, in tot partes dividerem, quot expediret ad illas commodius resolvendas.

Tertium, ut cogitationes omnes quas veritati quaerendae impenderem, certo semper ordine promoverem: incipiendo scilicet a rebus simplicissimis \& cognitu facillimis, ut paulatim \& quasi per gradus ad difficiliorum \& magis compositarum cognitionem ascenderem; in aliquem etiam ordinem illas mente disponendo, quae se mutuo ex natura sua non praecedunt.

Ac postremum, ut tum in quaerendis mediis, tum in difficultatum partibus percurrendis, tam perfecte singula enumerarem \& ad omnia circumspicerem, ut nihil a me omitti essem certus"

17. Siehe seinen Brief an Mersenne vom März 1636: Descartes erklärt hier, warum sein Buch nicht mit "Lehrbuch der Methode", sondern mit "Gespräch über die Methode" betitelt werden soll. Siehe außerdem seinen Brief an einen Unbekannten vom 27. April 1637(?) und seinen Brief an Pater Vatier vom 22. Februar 1638: Descartes begründet hier, warum er glaubt, daß man die Methode für die Suche nach der Wahrheit nicht lehren könne, indem er den Unterschied zwischen analytischer Methode und synthetischer Methode (deren Funktion darin liegt, die durch die Methode der Analysis gefundene Wahrheit darzustellen) hervorhebt. Vgl. AT VII. S. 155-156.
} 
his (Descartes'; d. Verf.) outlook that actual exposure to intellectual problems is necessary to give any content to such maxims; the words gain meaning only from the experience of dealing with scientific questions themselves". ${ }^{18}$ Um z.B. die Wahrheit einer komplexen Aussage in der Geometrie oder Arithmetik zu erkennen, müssen wir sie Schritt für Schritt auf einfachere Aussagen zurückführen. Dieses Verfahren ist kein einfaches Verfahren, sondern ein trial-anderror-Verfahren. Was uns dabei helfen kann, sind Ordnung und Übersicht. So gesehen liegt Descartes' Intention eher darin, die Notwendigkeit einer Methode bei allen wissenschaftlichen Untersuchungen zu betonen, als irgendeine konkrete Methode zu lehren. Und wie sie im Einzelnen aussehen soll, ist eine Frage, die je nach Objekt und Person entschieden werden muß. ${ }^{19}$

Zweitens: Descartes' Behauptung, daß es keine Methode in dem Sinne geben könne, daß wir ex vi formae eine sichere Erkenntnis erwerben können, muß im Zusammenhang mit dem ersten Punkt verstanden werden. Jene Behauptung ist nämlich häufig so mißverstanden worden, als hätte er den Anspruch des Syllogismus auf Wahrheitsbegründung mit dem auf Wahrheitsfindung verwechselt. Dies ist aber nicht der Fall. Er scheint sich völlig dessen bewußt zu sein, da er nirgends leugnet, sondern vielmehr anerkennt, daß der Syllogismus zur Erklärung dessen, was wir erkannt haben, nützlich ist. Der Kernpunkt seiner Kritik liegt eher darin, daß die Betonung der Formen des Schlusses in dem Sinne sinnlos ist, als wir uns beim Gebrauch von Syllogismen auf Intuition und Deduktion verlassen müssen. ${ }^{20}$

Drittens darf die zweite Regel nicht einfach als identisch mit dem Verfahren der Analyse in der Chemie verstanden werden. Sie soll eher als eine apriorische Übersicht über alle Bedingungen verstanden werden, unter denen ein Problem gestellt und damit auch gelöst werden kann.

Viertens darf die enumeratio oder inductio bei Descartes nicht als identisch mit dem induktiven Schlußverfahren bei Bacon verstanden werden. In den meisten Fällen wird sie nur in dem neutralen Sinn eines "check-up" aller Bestandteile eines Verfahrens verwendet. ${ }^{21}$

\section{I. 3. Ursprung der Methode:}

Antworten auf die Frage nach der Methode und nach der Rechtfertigung

\footnotetext{
${ }^{18}$. Williams, Descartes, S. 33

19. Vgl. AT X, S. 319-392.

20. Weil Intuition und Deduktion uns als einzige zu sicherer Erkenntnis führen können, müssen wir uns gegenseitig von dem überzeugen können, was wir zu wissen glauben (Vgl. AT X, S. 363), wenn wir es in der Tat wissen. Andererseits können wir weder Geometer und Arithmetiker noch Philosophen sein einfach dadurch, daß wir Beweise oder Argumente auswendig lernen. Wir müssen vielmehr durch diese beiden $a c$ tiones die Argumente selbst nachvollziehen können und wir können sie nachvollziehen. Vgl. AT X, S. 367. und Descartes' Kritik am Syllogismus, AT VI, S. 549 und AT X, S. 405 f.

${ }^{21}$. Auf diese letzten beiden Punkte werden wir im dritten Kapitel zurückkommen.
} 
Descartes erwähnt an einigen Stellen, ${ }^{22}$ daß er diese Methode aus der Geometrie und Arithmetik entliehen hat. Hier werden wir kurz versuchen, auf die Frage nach der Methode und auf die Rechtfertigungsfrage zu antworten, indem wir Descartes' Erklärung über den Ursprung seiner Methode betrachten. Descartes führt hinzu folgendes aus:

"Es besitzt nämlich der menschliche Geist etwas irgendwie Gotterfülltes, worein die ersten Samen nützlicher Gedanken so gestreut sind, daß sie oft, so sehr sie auch vernachlässigt und durch in die Quere geschossene Studien erstickt sein mögen, eine wildwachsende Frucht hervorbringen. Das erleben wir in den einfachsten Wissenschaften, in der Arithmetik und der Geometrie. Man bemerkt nämlich recht gut, daß die alten Geometer sich einer gewissen Analysis bedient haben, die sie auf die Lösung aller Probleme ausdehnten,...Und eben jetzt ist eine Spielart der Arithmetik, Algebra genannt, im Schwange, um das bezüglich der Zahlen zu leisten, was die Alten bezüglich der Figuren schufen."(Gäbe, S. 25; Hervorhebung v. Verf.) ${ }^{23}$

Die Antwort auf die Frage nach der Methode zum Aufbau der sicheren Wissenschaften, die wir aus diesem Zitat rekonstruieren können, ist diese: Wir müssen die bona mens ihrer Natur nach richtig gebrauchen. ${ }^{24}$ Gerade dies soll Descartes mit den beiden Phrasen aliquid divini und spontaneam frugem im Sinne haben. Diese Antwort ist aber zu vage und veranlaßt uns deswegen zu zwei weiteren Fragen. Die erste Frage ist die, was es heißen soll, die bona mens ihrer Natur nach richtig anzuwenden. Die zweite ist die Rechtfertigungsfrage, wie er die Überzeugung rechtfertigen kann, daß es so möglich ist, sichere Wissenschaften aufzubauen. Auf diese beiden Fragen antwortet Descartes zugleich, indem er auf die beiden vorhandenen sicheren Wissenschaften, nämlich Arithmetik und Geometrie zurückgreift, die er als realisierte Möglichkeit der sicheren Wissenschaften betrachtet.

Wenn Descartes sagt, daß er die Methode aus den beiden Wissenschaften "entliehen" habe, darf dies aber nicht so verstanden werden, daß er dies deswegen getan habe, weil jene Wissenschaften diese Methode benutzen, sondern weil sie sich durch diese Methode als Realisierung der Möglichkeit sicherer Wissenschaften erweisen, genauer gesagt, weil die Methode, die jene beiden Wissenschaften verwenden, als eine bloße Darstellung des richtigen Gebrauchs der bona mens (ihrer Natur nach) verstanden werden kann. ${ }^{25}$ In diesem Sinne ist die Methode nicht nur ein Mittel, mit dessen Hilfe wir zur Wahrheit gelangen können, sie drückt vielmehr "the innermost essence of mind: and the problem as the nature and limits of

\footnotetext{
22. Am deutlichsten in De Methodo, AT VI, S. 550.

23. "Habet enim humana mens nescio quid divini, in quo prima cogitationum utilium semina ita jacta sunt, ut saepe, quantumvis neglecta et transversis studiis suffocata, spontaneam frugem producant. Quod experimur in facillimis scientarum, Arithmetica \& Geometria: satis enim advertimus veteres Geometras analysi quadam usos fuisse, quam ad omnium problematum resolutionem extendebant....Et jam viget Arithmeticae genus quoddam, quod Algebram vocant, ad id praestandum circa numeros, quod veteres circa figuras faciebant." (AT X, S. 373; Hervorhebung d. Verf.)

${ }^{24}$. Vgl. Beck, Method, S. 20 und 31.

25. Wie wichtig es ist, diesen Punkt richtig zu verstehen, werden wir in meiner Auseinandersetzung mit Buchdahl im dritten Kapitel sehen.
} 
knowledge" aus: "Since in the method we have a complete analysis of the mind, in determining that method we necessarily also determine the measure and scope of mind"16

Der grundsätzliche Gedanke ist hier der, der der ersten Regel in den Regulae zugrunde liegt, nämlich daß alle Wissenschaften so eng miteinander verbunden sind, daß sie einander beeinflussen können. Dieser Gedanke führte Descartes zu der Erkenntnis, daß Arithmetik und Geometrie nichts anderes als eine oder zwei Formen der "Mathesis universalis" sind, deren Gegenstand dadurch charakterisiert wird, "ordo" und "mensura" unterzogen zu werden. Diese Erkenntnis ermöglichte es ihm in der Folge, die analytische Geometrie zu erfinden: Figuren durch Zahlen und Gleichungen zu beschreiben sowie geometrische Aussagen in algebraische Aussagen und umgekehrt zu übersetzen.

\section{II. Die Motivation des Problems des Skeptizismus}

Obwohl man Descartes' großen Beitrag zur Mathematik durch seine Erfindung der analytischen Geometrie kaum überschätzen kann, kann dies doch prinzipiell daran nichts ändern, daß seine Überzeugung, wir hätten die Fähigkeit, sichere Wissenschaften aufzubauen, als solche nicht der Betrachtung wert ist. Diese Überzeugung kann nämlich durch das Vorhandensein von Arithmetik und Geometrie ohnehin gerechtfertigt werden. Meint Descartes mehr? Falls ja, was? Wie kann er dies rechtfertigen? Gerade hier ist die Stelle, an der er sich der Frage zuwendet, was Erkenntnis ist und wie groß der Umfang unserer Erkenntnis ist:

"Nichts Nützlicheres aber gibt es hier zu untersuchen, als was die menschliche Erkenntnis sei und wieweit sie sich erstrecke. Daher fassen wir eben dieses jetzt in einer einzigen Frage zusammen, von der wir glauben, daß sie als erste vermittels der bereits dargelegten Regeln zu untersuchen ist. Dies muß jeder von denen, die auch nur ein wenig die Wahrheit lieben, einmal im Leben tun, da doch in der Untersuchung dieser Frage die wahren Instrumente des Wissens und die ganze Methode enthalten sind."(Gäber, S. 53; Hervorhebung d. Verf.) ${ }^{27}$

\footnotetext{
${ }^{26}$. Kemp Smith, Studies in Cartesian Philosophy, S. 23 f. zitiert nach: Beck, Method, S. 21.

27. "At vero nihil hic utilius quaeri potest, quam quid sit humana cognitio \& quousque extendatur. Ideoque nunc hoc ipsum unica quaestione complectimur, quam omnium primam regulas jam ante traditas examinandam esse censemus; idque semel in vita ab unoquoque ex iis, qui tantillum amant veritatem, esse faciendum, quoniam in illius investigatione vera instrumenta sciendi \& tota methodus continentur." (AT X, S. 397-8; Hervorhebung d. Verf.) Es ist fast überflüssig zu sagen, welchen großen Einfluß Descartes mit
} 
Meiner Meinung nach sind diese beiden Fragen und die Art und Weise, in welcher Descartes sie zu beantworten versucht, von entscheidender Bedeutung bezüglich unserer Motivationsfrage. Gehen wir nun zu dieser Frage über. Ich will hier drei Erklärungen (die miteinander in engem Zusammenhang stehen) von Descartes' Motivation, sich mit dem Problem des Skeptizismus zu beschäftigen, kritisch betrachten. Die erste Erklärung ist die traditionelle, Descartes' Motivation in der Repräsentationstheorie zu suchen. Die zweite Erklärung ist von Williams mit Rekurs auf den Begriff der objektiven Erkenntnis gegeben worden, und die dritte von Mackie mit Rekurs auf die Repräsentationstheorie in einer anderen Version. Ich halte alle diese drei Erklärungen für Fehlschläge, und bin der Meinung, daß sie im ganzen und großen darauf beruhen, daß man den beiden Fragen und der Art und Weise, in welcher Descartes sie zu beantworten versucht hat, nicht genügend Aufmerksamkeit gewidmet hat.

II. II. 1. Die traditionelle Erklärung: Die Repräsentationstheorie

Um zu betrachten, worin die traditionelle Erklärung besteht, und um zu zeigen, daß und warum sie ein Fehlschlag ist, will ich mich hier mit Williams auseinandersetzen, und zwar nicht bloß, weil die Auseinandersetzung mit Williams dafür geeignet ist. Vielmehr kann diese einerseits ans Licht bringen, warum Williams es für nötig gehalten hat, Descartes' Motivation mit Rekurs auf den Begriff des Wissens zu erklären, obwohl er sich prinzipiell der traditionellen Erklärung mit Rekurs auf die Repräsentationstheorie anschließt. Andererseits kann uns die Auseinandersetzung mit Williams darauf aufmerksam machen, wie nötig ein Versuch ist, Descartes' Repräsentationstheorie als solche zu verstehen.

Williams geht davon aus, daß in Descartes' skeptischem Argument die kausale Auffassung der Wahrnehmung die entscheidende Rolle gespielt habe: Ihrzufolge impliziert jedes Wahrnehmungsurteil eine Aussage der Art, daß es Dinge außerhalb von uns selbst gibt, die unsere Wahrnehmungen kausal bewirken. ${ }^{28}$ Descartes' Strategie besteht demnach darin, diese Aussage in Frage zu stellen, um alle eigenen Meinungen bezüglich der physikalischen Außenwelt in Frage zu stellen. Danach sagt Williams folgendes:

dieser Fragestellung und der Art und Weise, in der er in den Regulae auf diese Frage zu antworten versucht hat, auf seine Nachfolger in der Philosophie der Neuzeit ausgeübt hat.

${ }^{28}$. Daß dies aber nicht der Fall ist, wird später in meiner Auseinandersetzung mit Mackie gezeigt werden. 
"Descartes himself never in fact doubts the causal conception of perception: he regards the causal element as straightforwardly part of the concept of perception, in the sense of that term in which we perceive such things as tables. He also believes, in fact, though he does not use the belief at this stage, that eyerything 'outside myself' is known only through the medium of ideas, which represent reality, and are themselves the immediate objects of the mind's cognition (to Gibieuf, 19 January 1642: VII 474, K 123; III Rep.: VII 181, HR2 678 ); it is ideas that, in perception, are caused by external objects. This goes beyond a minimal causal conception of perception and in carrying this weight of philosophical theory seems indeed open to grave doubt. On the other hand, it seems equally hard to deny that some causal element is part of the concept of perception." (Descartes, S. 59; Hervorhebung d. Verf.)

Williams' Position läßt sich folgendermaßen kurz zusammenfassen:

a) Descartes hat keinen Zweifel an der kausalen Auffassung der Wahrnehmung;

b) Diese Auffassung liegt der Repräsentationstheorie Descartes' zugrunde, in deren

Rahmen Descartes die Wahrnehmungstheorie formuliert; Ihrzufolge sind

Vorstellungen, die durch physikalische Gegenstände verursacht werden, direkte

Objekte in mir und die einzige Informationsquelle über die physikalische

Außenwelt sind: Vorstellungen repräsentieren physikalische Gegenstände;

c) (b) ist problematisch;

d) Descartes macht aber von der Repräsentationstheorie keinen Gebrauch, um zu seiner

skeptischen Konklusion zu gelangen;

e) Es ist nicht zu leugnen, daß Wahrnehmungen eine kausalen Aspekt aufweisen. ${ }^{29}$

Beginnen wir mit (e). Ich bin mit Williams völlig einverstanden, daß Wahrnehmungen irgendein kausales Element enthalten. Wir werden später sehen, daß auch Descartes dieser Ansicht ist, wie Williams in (a) behauptet. Ich stimme Williams auch in Bezug auf (b) zu. Descartes erklärt nämlich die Wahrnehmung in der Tat im Rahmen der Repräsentationstheorie, die dadurch charakterisiert wird, daß Vorstellungen, die durch physikalische Gegenstände verursacht werden, direkte Gegenstände in mir und die einzige Informationsquelle über die physikalische Außenwelt sind: Vorstellungen repräsentieren physikalische Gegenstände.

Hat aber Williams Recht mit (c)? Es kommt m.E. darauf an, wie die oben ausgezeichneten Vorstellungen weiter interpretiert werden. ${ }^{30}$ Williams nennt als Grund für (c), daß jene ausgezeichnete Vorstellung über den Minimalsinn der kausalen Auffassung der Wahrnehmung hinausgehe. Aber in welcher Hinsicht und warum? Williams gibt zwar an dieser Stelle darüber keine weitere Auskunft, aber es gibt eine andere Stelle, die uns weiterhilft. Er sagt nämlich: "Any representational theory of perception is faced with the question of how we know, or what reason we have to believe, that anything exists at all outside experience" (S. 240). Diese Behauptung ist nichts anderes als die bekannte traditionelle Diagnose der Problematik der Repräsentationstheorie. So schließt sich Williams an die traditionellen Erklärung mit Rekurs auf

\footnotetext{
${ }^{29}$. Der Grund dafür, daß Williams hier das kausale Element der Wahrnehmung als "minimal" etc. qualifiziert, liegt, so vermute ich, darin, daß das Kausalprinzip eigentlich ein Prinzip ist, das sich nur auf Beziehungen zwischen Ereignissen bezieht.

${ }^{30}$. Vgl. II.II.3.1. dieser Arbeit.
} 
die Repräsentationstheorie an. Diese zeichnet sich dadurch aus, Vorstellungen einen bestimmten Status zu verleihen, nämlich den Status, daß sie von physikalischen Gegenständen ontologisch distinkt sind, und es ist fast überflüssig zu sagen, daß die traditionelle Auffassung die Problematik der Repräsentationstheorie gerade in dem ausgezeichneten ontologischen Status der Vorstellungen sieht, da diese uns angeblich von der physikalischen Außenwelt völlig abschneiden. ${ }^{31}$ So wird die Motivation Descartes', sich mit dem Problem des Skeptizismus zu beschäftigen, erklärt.

Nun ist aber das entscheidende Problem dabei, daß überhaupt nicht klar ist, wie man jenen ontologischen Status der Vorstellungen verstehen soll. So weit ich sehen kann, bietet die traditionelle Erklärung mit Rekurs auf die Repräsentationstheorie uns keine Hilfe. Vielleicht ist es eine Ironie, daß gerade Ryle, der die traditionelle Erklärung vertritt, dieses Problem zu bestätigen scheint, wenn er sagt: "They (Vorstellungen mit jenem ontologischen Status; d. Verf.) belong where 'phlogiston' belongs and where `substantial forms' belong, namely to the folklore of philosophy.'132 Daraus ergibt sich: Wenn Williams kritisch behauptet, 'Vorstellung' mit jenem ontologischen Status gehe über den Minimalsinn der kausalen Auffassung der Wahrnehmung hinaus, so beruht seine Behauptung nicht darauf, daß ihm klar ist, warum dies so ist. Sie beruht eher darauf, daß er ohne weiteres unterstellt, daß die Repräsentationstheorie aus dem oben genannten Grund das Problem des Skeptizismus auftreten lasse, und darauf, daß er glaubt, daß wir uns in diesem Fall entscheiden müßten, eher auf die Repräsentationstheorie, die nichts anderes als eine Analyse der Wahrnehmung anhand von "commonsense judgements" sei, zu verzichten, als auf "commonsense judgements". ${ }^{33}$

So gesehen besteht die einzige Möglichkeit, jenen ontologischen Status der Vorstellungen zu verstehen, darin, ihn vom Standpunkt der skeptischen Konklusion aus zu betrachten. Dies bedeutet, daß wir bereits ein Verständnis der skeptischen Konklusion haben müssen, um jenen ontologischen Status zu verstehen, nicht umgekehrt. Daraus ergibt sich, daß die traditionelle Erklärung mit Rekurs auf die Repräsentationstheorie kein Ergebnis des Versuchs ist, sie als solche zu verstehen und zu interpretieren, sondern ein Ergebnis der unbegründeten Verbindung der Repräsentationstheorie mit dem Problem des Skeptizismus. Gerade dies ist der Grund dafür, daß ich die traditionelle Erklärung mit Rekurs auf die Repräsentationstheorie als Interpretation dieser Theorie für einen Fehlschlag halte, und zwar um so mehr, wenn wir

\footnotetext{
31. Siehe Yolton, Perceptual Acquaintance from Descartes to Reid, S.3-6. Yolton liefert eine Übersicht über diese traditionelle Auffassung der Repräsentationstheorie, die bei Thomas Reid ihren Ursprung hat. Diesen so ausgezeichneten Status der Vorstellungen will ich im Folgenden "den ontologischen Status der Vorstellungen" nennen.

${ }^{32}$. Ryle, John Locke on the Human Understanding in Locke and Berkeley, S. 23.

33. "if some commonsense judgements which we ordinarily believe with a high degree of conviction are said to imply some very general or philosophical proposition Q, and Q is doubtful, then we should regard this as a ground for criticizing the supposed implication, not for criticizing our ordinary judgements on the strenght of the doubtfulness of Q." Williams, S. 59.
} 
berücksichtigen, daß Descartes in den Regulae und in Le Monde die Repräsentationstheorie ohne Verbindung mit dem Problem des Skeptizismus entwickelt hat. Dagegen wird man vielleicht einwenden, daß dies kein Grund dafür sei, die beiden Themen voneinander zu trennen, sondern eher ein Grund dafür, sie miteinander zu verbinden. Es ist, so könnte man sagen, gerade ein Zeichen dafür, daß er später eingesehen hat, daß die Repräsentationstheorie das Problem des Skeptizismus auftreten läßt, und dies ist der Grund dafür, daß er sich in den Meditationes die Aufgabe stellt, das Problem zu überwinden. ${ }^{34}$ Dieser Einwand aber enthält eine petitio principii.

Davon abgesehen scheint Williams der Meinung zu sein, daß die traditionelle Auffassung und ihre Kritik an Descartes hinfällig sein könne. Es gibt zwei Gründe dafür an. Ein Grund ist (d), daß Descartes nicht explizit von der Repräsentationstheorie Gebrauch macht, um zu seiner skeptischen Konklusion zu gelangen. Dabei spielt nämlich nur die kausale Auffassung der Wahrnehmung eine Rolle. Ein anderer Grund ist der, daß Williams, wie wir gesehen haben, auch der Ansicht ist, daß im Begriff der Wahrnehmung ein kausales Element enthalten ist. Daraus ergibt sich auch, daß Descartes' skeptischem Argument anders als oben nicht einfach mit der Behauptung begegnet werden kann, daß man in diesem Fall eher auf die kausale Auffassung der Wahrnehmung verzichten müsse, als auf "commonsense judgements". So stellt sich nach Williams eine neue Frage:

"The real question is whether the minimal sense in which some causal element is undeniably part of the concept of perception is enough for Descartes comprehensibly to deploy it, in the hyperbolical doubt, against all our ordinary perceptual judgements together." (ebd.)

Dieser Frage nähert sich Williams, indem er die Motivation, die Descartes dazu geführt hat, mit Rekurs auf den Begriff des Wissens verständlich zu machen versucht: "Knowledge does have a problematical character, and does have something in it which offers a standing invitation to scepticism" (S. 64). Wir werden im nächsten Abschnitt betrachten, wie er dies zu erklären versucht.

\section{II. 2. Williams' Erklärung: Der Begriff des Wissens}

II. II. 2. 1. Darstellung von Williams' Erklärung

\footnotetext{
${ }^{34}$. Williams sagt an der auf die oben zitierte Stelle (S. 240) direkt folgenden Stelle: "Descartes's answer to this,... ,depends on God."
} 
Williams geht davon aus, daß Wissen Wissen von etwas ist, das unabhängig von unserem Denken und Vorstellen irgendwie existiert: "it is knowledge of a reality which exists independently of that knowledge, and indeed,...,independently of any thought or experience. Knowledge is of what is there anyway" (S. 64.). Nehmen wir an, daß zwei Menschen, A und $\mathrm{B}$, behaupten, daß sie Wissen von derselben Welt hätten. Jeder hat seine eigenen Mittel, durch die er es erworben hat, und seine eigene Art und Weise, in welcher er es konzipiert und formuliert hat. Nennen wir all dies ihre Repräsentationen der Welt. Nun ist es nicht schwer, sich die Möglichkeit vorzustellen, daß A's Repräsentation und B's Repräsentation voneinander verschieden sind. Wenn aber A's Repräsentation und B's Repräsentation in der Tat Wissen darstellen, scheint es so zu sein, daß es eine Möglichkeit geben muß, einerseits zu verstehen und erklären, warum sie voneinander verschieden sind, obwohl sie Repräsentationen von ein und derselben Welt sind, und andererseits, wie sie miteinander in Beziehung stehen. Um eine solche Erklärung zu geben oder um eine gegebene Erklärung zu verstehen, muß es offenbar möglich sein, einen Standpunkt einzunehmen, von dem aus eine neue Repräsentation der Welt (RIII) zu formulieren ist, in der A, B und ihre Repräsentationen enthalten sind. Wenn dies so ist, ist leicht einsichtig, daß dieser Prozeß weiter geführt werden muß, da RIII seinerseits wiederum nichts anderes als eine Repräsentation der Welt ist. Und es ist auch leicht vorstellbar, daß der Prozeß kein Ende hat, da es unendlich viele mögliche Repräsentationen geben kann. Wenn nun Wissen Wissen von etwas ist, das unabhängig von unserem Denken und Vorstellen irgendwie existiert, dann muß es möglich sein, eine endgültige Repräsentation der Welt in bezug auf alle möglichen Repräsentationen (Williams nennt sie die "absolute conception") zu formulieren: eine Repräsentation unabhängig von jeder besonderen Repräsentation zu formulieren und so zu erklären, wie Wissen überhaupt möglich ist. Aber diese Forderung konfrontiert uns mit einem grundlegenden Dilemma:

"On the one hand, the absolute conception might be regarded as entirely empty, specified only as 'whatever it is that these representations represent'. In this case, it no longer does the work that was expected of it, and provides insufficient substance to the conception of an independent reality; it slips out of the picture, leaving us only with a variety of possible representations to be measured against each other, with nothing to mediate them. On the other hand, we may have some determinate picture of what the world is like independent of any knowledge or representation in thought; but then that is open to the reflection, once more, that that is only one particular representation of it, our own, and that we have no independent point of leverage for raising this into the absolute representation of reality". (S. 65)

Kurz gesagt, besteht das Dilemma nach Williams in Folgendem:

D1) Die "absolute conception" bleibt völlig leer und kann deswegen ihre vorgesehene Rolle überhaupt spielen;

D2) Jede von uns für diese Funktion gebildete Repräsentation der Welt ist keine "absolute conception"und kann deswegen jene Rolle nur begrenzt spielen. 
Nun fragt sich Williams, ob und wie man einen Ausweg aus diesem Dilemma finden kann, um zu zeigen, daß Wissen möglich ist. Seiner Meinung nach gibt es drei Versuche, ganz abgesehen von der Frage, ob sie Erfolg haben können. ${ }^{35}$

Der erste Versuch besteht darin, die "absolute conception" von dem Begriff des Wissens zu trennen. In diesem Fall ist die Rede von einem "Dilemma" selbst hinfällig. Ich will ihn hier beiseite lassen, nicht deswegen, weil ich ihn uninteressant finde, sondern deswegen, weil dies Williams' Meinung nach nicht der Weg ist, den Descartes eingeschlagen hat.

Der zweite Versuch besteht darin, eine "absolute conception" zu entwickeln. Dafür ist es nötig, einen absoluten Standpunkt zu erreichen, von dem aus sie formuliert werden kann. Williams versteht das Projekt von Descartes in den Meditationes als Versuch dieser Art, nämlich als Versuch, die "absolute conception" als solche zu entwickeln und $\mathrm{zu}$ rechtfertigen. Das Problem, das Williams dabei sieht, ist das, daß Descartes mit seinem Projekt gescheitert ist. Sein Erfolg ist nämlich völlig auf den Erfolg des Beweises der Existenz Gottes angewiesen; dieser Beweis ist aber nicht schlüssig.

Welche Implikation kann dies für uns haben? Soll dies heißen, daß Wissen nicht möglich ist? Kann es nicht andere Möglichkeiten geben, die "absolute conception" als solche zu entwickeln und rechtfertigen? Diese Fragen stellt Williams nicht. Ich meine, daß er, sogar mit Recht, glaubt, daß der Versuch von Descartes der einzige mögliche sei, jene Konzeption zu gewinnen.

Der letzte Versuch, den Williams vorschlägt, ist der, die Definition des Wissens so zu variieren, daß Wissen nicht die "absolute conception", sondern lediglich ihre Möglichkeit voraussetzt: "we can preserve the connection (between knowledge and the possibility of an absolute conception; d. Verf.), and seek to detach the idea of an absolute conception from considerations of certainty." (S. 212). Es ist wichtig darauf hinzuweisen, daß dieser Vorschlag von Williams nicht so verstanden werden darf, als wollte er damit das Problem des Skeptizismus völlig davon abhängig machen, welchen Begriff des Wissens wir akzeptieren, wobei unsere Entscheidung dieser Frage beliebig getroffen werden könne. Er beruht eher auf einer Reflexion auf die Art und Weise, wie wir die "absolute conception" bei unseren wissenschaftlichen Tätigkeiten zu erreichen versuchen. Diese Reflexion zeigt nach Williams, daß sie in sich keine Gewißheit enthalten weder "as the point from which such enquiry must set out, nor as a point which we must suppose it to have already reached, nor need we think that our present physical conceptions are adequate or unshakeable." (S. 247). Die "absolute conception" ist demnach "not something transcendental, but is an historical product of consciousness in the world." (S. 246.). Wenn wir Williams folgend annehmen, daß Wissen nicht die "absolute conception", sondern lediglich ihre Möglichkeit voraussetzt, folgt daraus,

\footnotetext{
${ }^{35}$. Vgl. Williams, S. 211-2.
} 
daß es nicht mehr nötig ist, die "absolute conception" als solche zu entwickeln, um zu zeigen, daß Wissen möglich ist. Was aber gezeigt werden muß, ist ihre Möglichkeit, mit anderen Worten: daß der oben angeführte Prozeß, der nur schrittweise vollzogen werden kann und bei dem kein Ende abzusehen ist, sich einer "absolute conception" annähert. Wie kann aber diese Möglichkeit gezeigt werden? Darauf antwortet Williams, daß der Prozeß so durchgeführt werde, daß jede neu formulierte Repräsentation immer größere Erklärungskraft besitze. Williams glaubt, daß dies dagegen spricht, daß jener Prozeß hinfällig ist (S. 247.). Aber angenommen, daß (D1) dadurch überwunden werden kann, gibt es auch eine Möglichkeit, (D2) zu überwinden? "Are not all our concepts ours, including thoses of physics?" (S. 244). Auf diese Frage antwortet Williams so: "Of course: but there is no suggestion that we should try to describe a world without ourselves using any concepts, or without using concepts which we, human beings, can understand. The suggestion is that there are possible descriptions of the world using concepts which are not peculiarly ours, and not peculiarly relative to our experience" (ebd.).

\section{II. 2. 2. Probleme von Williams' Erklärung}

Die im letzten Abschnitt betrachtete Erklärung von Williams wirft jedoch Probleme auf. Was den Begriff des Wissens betrifft, kann man zuerst folgende beide Fragen stellen. Die eine Frage ist die, ob und wie wir diesen Begriff verstehen können. Was bedeutet "etwas", das unabhängig von unserem Denken und Vorstellen irgendwie existiert? Was kann man darunter verstehen? Wenn dies nicht klar ist, ist auch nicht klar, was "Wissen" davon heißen soll. Die andere Frage ist die, ob jene Erklärung in der Tat unseren Begriff des Wissens richtig repräsentiert, angenommen, er sei verständlich. Wie wir gesehen haben, geht Williams ohne weiteres davon aus, daß dieser Begriff des Wissens nicht nur verständlich ist, sondern auch eben der Begriff ist, den wir haben. Lassen wir kurz diese Fragen beiseite und nehmen wir an, daß dies selbstverständlich ist. Beginnen wir Williams folgend mit dem oben angeführten Begriff des Wissens.

Wissen ist Wissen von etwas, das unabhängig von unserem Denken und Vorstellen irgendwie existiert. Wenn dies so ist, sind (D1) und (D2) nichts anderes als eine logische Konsequenz aus dem Begriff des Wissens. Nun ist die Frage, die mich interessiert, die, welche Implikationen dies hat. Williams scheint der Meinung zu sein, daß sie ein Problem aufwerfen: nämlich ein Dilemma, demzufolge Wissen unmöglich zu sein scheint. Ist dies aber in der Tat so? Warum sollen sie ein Problem oder ein Dilemma darstellen, wenn sie eine logische Konsequenz aus dem Begriff des Wissens sind, den wir haben? Wenn man nämlich von dem 
Begriff des Wissens ausgeht und feststellt, daß Wissen nicht möglich ist, warum soll dies ein Problem sein? Ich sehe keinen Grund dafür. Nun findet Descartes aber zweifellos den Skeptizismus problematisch. Allein dies reicht aus um zu zeigen, wie problematisch Williams' Versuch ist, Descartes' Motivation zur Beschäftigung mit dem Problem des Skeptizismus mit Rekurs auf den ausgezeichneten Begriff des Wissens zu erklären. Wir müssen demnach eher mit der Frage beginnen, unter welcher Bedingung der Skeptizismus als Problem betrachtet werden kann, um das Problem des Skeptizismus bei Descartes und seine Motivation richtig zu verstehen. Selbstverständlich kann sich diese Frage nicht einfach dadurch beantworten lassen, daß man auf einen Begriff des Wissens zurückgreift, der seinerseits inhaltlich ungeklärt und hinsichtlich seiner eigenen Möglichkeit offen ist.

Unter welcher Bedingung ist der Skeptizismus problematisch? Ich glaube, daß es nicht schwierig ist, darauf eine Antwort zu geben. Sie lautet nämlich einfach: Der Skeptizismus ist problematisch, weil erwiesen wird, daß Wissen, das man zu haben glaubt, in Wirklichkeit kein Wissen ist. Wenn der Skeptizismus uns problematisch erscheint, liegt der Grund dafür nicht darin, daß er viele Meinungen in Frage stellt, an denen wir aus praktischen Überlegungen heraus festhalten. In Bezug auf solche Meinungen lassen wir nämlich die Möglichkeit des Irrtums offen. Der Grund liegt eher darin, daß der Skeptizismus gerade solche Erkenntnisse sämtlich in Frage stellt, deren Wahrheit wir für sicher halten und die den Rahmen bilden, innerhalb dessen praktische Überlegungen überhaupt möglich sind: nämlich Erkenntnisse wie "Ich habe zwei Hände". So gesehen kann der Begriff des Wissens nur im Hinblick auf Fälle von Wissen erklärt und verstanden werden, die wir zu haben glauben. Dies führt uns zu der Ausgangsposition von Descartes in den Regulae zurück. Lassen wir für einen Augenblick das Problem des Skeptizismus und die Motivationsfrage außer Acht und betrachten seine Ausgangsposition in den Regulae.

\section{II. 2. 3. Exkurs zu den Regulae: Neue Formulierungen der Rechtfertigungsfrage und der Frage nach der Methode}

Erinnern wir uns zuerst an die Frage, wie Descartes seine Überzeugung rechtfertigen kann, daß wir die Fähigkeit haben, Erkenntnis zu erwerben. Wir haben gesehen, daß er sie dadurch rechtfertigen konnte, daß er auf Fälle von Erkenntnis hinwies. Als Fälle von Erkenntnis führte er dort zuerst nur solche Aussagen an, die selbstevident oder in ähnlicher Weise einleuchtend sind. Er gab sich aber nicht einfach damit zufrieden. Er hat nämlich die Erkenntnisfähigkeit nicht nur als eine Fähigkeit identifiziert, ausgezeichnete Erkenntnisse zu erwerben, sondern auch als eine rein mentale Fähigkeit, die darüber hinaus als Fähigkeit zu Intuition und Deduktion spezifiziert und differenziert wurde. Wir haben gesagt, daß diese Fähigkeit zu mehr in die Lage 
versetzen muß als nur die ausgezeichneten Fälle von Erkenntnis zu erwerben. Sonst wäre Descartes' Überzeugung nicht der Betrachtung wert. Dies wäre auch der Fall, wenn sie darüber hinaus als die Fähigkeit verstanden würde, sichere Wissenschaften aufzubauen. Sie konnte nämlich auch allein mit Rekurs auf die Existenz von Geometrie und Arithmetik gerechtfertigt werden.

Gerade an dieser Stelle erklärt Descartes, daß er sich der Frage zuwenden müsse, was Erkenntnis ist und wie weit ihr Umfang ist. Er geht nämlich weder davon aus, daß Wissen Wissen von etwas ist, das unabhängig von unserem Denken und Vorstellen irgendwie existiert, wie "a reality, which is there anyway", noch geht er davon aus, daß dies möglich ist. Vielmehr fragt er zuerst, was Erkenntnis ist und wie weit ihr Umfang ist. Er ist völlig davon überzeugt, daß die Frage dadurch beantwortet werden kann, daß alle unsere Erkenntnismittel erschöpfend aufgezeigt werden ("perspectis deinde illis omnibus quae proxime sequuntur post intellectus puri cognitionem, inter caetera enumerabit quaecumque alia habemus instrumenta cognoscendi praeter intellectum" (AT X, S. 395)), und daß dies keine schwierige Aufgabe ist. Wie kann oder soll Descartes vorgehen, um dies zu tun? Obwohl er sich dazu nicht explizit geäußert hat, legt sein früheres Verfahren nahe, daß er auf Fälle von Erkenntnis hinweist, die aus anderen Erkenntnisquellen stammen, und sie wiederum mit Rekurs auf die Art und Weise identifiziert, differenziert und spezifiziert, in der jene Quellen zur Erkenntnis beitragen. Haben wir Fälle von Erkenntnis, die aus anderen Erkenntnisquellen als aus der bona mens stammen? Die Antwort ist natürlich "Ja". Wir wissen nämlich, daß es physikalische Gegenstände gibt:

"Man muß sich also erstens vorstellen, daß alle äußeren Sinne, soweit sie leibliche Organe sind, obgleich wir sie den Objekten durch eine Handlung, durch eine Ortsbewegung nämlich, zuwenden, dennoch nur passiv im eigentlichen Sinne wahrnehmen, in der gleichen Art, wie das Wachs seine Figur vom Siegel empfängt. Auch darf man nicht glauben, dies sei nur als Analogie gemeint, sondern man muß sich vorstellen, daß die äußere Gestalt des empfindenden Körpers wirklich vom Objekt ganz auf dieselbe Weise verändert wird wie die der Oberfläche des Wachses vom Siegel." (Gäbe, S. 77; Hervorhebung d. Verf.) ${ }^{36}$

Hier geht Descartes schlechthin davon aus, daß wir wissen, ${ }^{37}$ daß es physikalische Gegenstände gibt. Was er tut, ist, anhand dieses Wissens Bedingungen zu erklären, unter

\footnotetext{
36. "Concipiendum est igitur, primo, sensus omnes externos, in quantum sunt partes corporis, etiamsi illos applicemus ad objecta per actionem, nempe per motum localem, proprie tamen sentire per passionem tantum, eadem ratione qua cera recipit figuram a sigillo. Neque hoc per analogiam dici putandum est; sed plane eodem modo concipiendum, figuram externam corporis sentientis realiter mutari ab objecto, sicut illa, quae est in superficie cerae, mutatur a sigillo." (AT X, S. 412; Hervorhebung d. Verf.)

37. Ich habe hier mit Absicht von dem Terminus "Wissen" statt von dem Terminus "Voraussetzen" Gebrauch gemacht. Während der Gebrauch des Terminus "Wissen" nur eine rein epistemologische Implikation hat, ist dies nicht immer der Fall, wenn man von dem Terminus "Voraussetzen" Gebrauch macht. Ein gutes Beispiel dafür kann man bei Carnap finden. Er behauptet nämlich, daß man Existenzfragen nur innerhalb eines Sprachsystems sinnvollerweise stellen und beantworten könne, wobei entscheidend einerseits ist, daß die Frage, welches Sprachsystem eingeführt werden soll, aus rein pragmatischen Überlegungen heraus entschieden wird, und andererseits, daß mit der Einführung eines Sprachsystems,
} 
denen es möglich ist. Eine notwendige Bedingung dafür ist die, daß physikalische Gegenstände im Raum gegeben sind. Dies zeigt Descartes' Betonung der Passivität sinnlicher Wahrnehmungen deutlich. Eine andere notwendige Bedingung dafür sind unsere subjektiven Bedingungen der Erkenntnis. Er spezifiziert sie nach ihrer jeweiligen Funktion als bona mens, sensus, memoria und imaginatio. ${ }^{38}$

Wenn aber Descartes' Überzeugung, daß wir die Fähigkeit haben, Erkenntnis zu erwerben, die aus anderen Erkenntnisquellen als aus rein intellektuellen stammt, eine Überzeugung wäre, die durch Hinweis auf die oben genannten Fälle von Erkenntnis gerechtfertigt werden kann, wäre sie wiederum wenig gehaltvoll. Hier muß also mehr gemeint sein. Was könnte gemeint sein? Nehmen wir vorläufig an, daß Descartes meint, daß es möglich sei, sichere Naturwissenschaften aufzubauen. Dann muß unsere Frage nach der Methode so umformuliert werden: Wie müssen wir verfahren, um sichere Naturwissenschaften aufzubauen? Unsere Rechtfertigungsfrage lautet dann: Wie kann Descartes seine Überzeugung rechtfertigen? Im Folgenden will ich nur versuchen, eine Teilantwort auf die Frage nach der Methode zu geben.

Die Überlegungen, die Descartes angesichts dieser Frage anstellt, könnten die sein, warum es nur Arithmetik und Geometrie gelungen ist, sich als sichere Wissenschaft zu etablieren, während dies anderen Wissenschaften nicht gelungen ist. Er scheint den Grund dafür in der Unterschiedlichkeit der Gegenstände der beiden Wissenschaften einerseits und der anderen Wissenschaften andererseits gesehen $\mathrm{zu}$ haben. Er glaubt aber nicht, daß diese Unterschiedlichkeit der Gegenstände uns daran hindern kann, andere sichere Wissenschaften aufzubauen. In seiner Erwiderung auf den zweiten Einwand führt Descartes den Umstand, daß er in den Meditationes nicht die synthetische, sondern die analytische Methode benutzen mußte, auf die Unterschiedlichkeit der Gegenstände von Geometrie und Arithmetik einerseits und Philosophie andererseits zurück. Er sagt:

"Ich meinerseits bin in den Meditationen ausschließlich den Weg der Analysis gegangen, weil er mir zur Belehrung als der wahre und der beste erschien, während die Synthesis, die zweifellos das ist, was Ihr von mir verlangt, wenngleich man bei den Gegenständen der Geometrie recht daran tut, sie auf die Analysis folgen zu lassen, doch für die metaphysischen Gegenstände nicht so recht passen dürfte.

Denn der Unterschied ist der, daß die Grundbegriffe, die zum Beweise der geometrischen Sätze vorausgesetzt werden, von jedem zugegeben werden, weil sie mit der sinnlichen

ein Gegenstandsbereich vorausgesetzt wird, in Bezug auf den die Existenzfragen gestellt und beantwortet werden. Dagegen ist die ontologische Frage, was existiert, für Descartes eine rein epistemologische Frage. Dies ist ein Grund dafür, daß Descartes das Problem des Skeptizismus für sinnvoll und ein reales Problem hält, während dies für Carnap nicht der Fall ist. Vgl. Carnap, Empiricism, Semantics and Ontology, in Meaning and Necessity.

${ }^{38}$. Darauf werden wir später unten in II.II.3.1. zurückkommen. 
Anschauung übereinstimmen, so daß es im wesentlichen bei ihr darauf ankommt, die richtigen Konsequenzen zu ziehen,..

Ganz im Gegenteil macht bei den metaphysischen Gegenständen nichts so große Mühe, als die ersten Begriffe klar und distinkt zu erfassen. Wenn sie auch aus ihrer eigenen Natur heraus ebenso bekannt oder gar bekannter sind als die von den Geometern betrachteten, werden sie doch, weil ihnen viele Vorurteile der Sinne entgegenstehen, an die wir uns von Jugend auf gewöhnt haben, nur von sehr Aufmerksamen und solchen, die sich bemühen, den Geist von den körperlichen Dingen nach Möglichkeit abzuziehen, vollkommen erkannt; und wenn sie ganz allein hingestellt würden, könnten kritisch verlangte Leute sie leicht leugnen."(Buchenau, S. 141-142; Hervorhebung d. Verf. $)^{39}$

Die Grundbegriffe der Geometrie werden von jedem verstanden, weil sie mit seinen sinnlichen Anschauungen übereinstimmen. Ihre anderen Begriffe werden durch Definitionen wiederum aus den Grundbegriffen abgeleitet. So gibt es kein Verständnisproblem bezüglich der Begriffe, mit denen Aussagen formuliert werden, um deren Beweis es geht. So kann man, nachdem man ein Problem gelöst hat, dessen Beweis nach dem synthetischen Verfahren darstellen. Aber die Situation sieht anders aus, wenn es um metaphysische Probleme geht. Die Grundbegriffe der Metaphysik sind noch nicht so klar und deutlich erfaßt worden, so daß nicht nur die Probleme, sondern auch ihre Lösung schwer verstanden werden können. Dies hat Descartes genötigt, seine Metaphysik nicht einfach nach der Synthesis, sondern eher nach der Analysis darzustellen. Dies spiegelt m.E. den Gedanken wider, den Descartes in den Regulae bezüglich des Unterschiedes zwischen der Mathematik und Naturwissenschaften geäußert hat. Er scheint nämlich zu glauben, daß für den Aufbau sicherer Naturwissenschaften am dringendsten erforderlich sei, neue Grundbegriffe für physikalische Gegenstände zu entwickeln. In diesem Zusammenhang ist es interessant zu sehen, daß Descartes sich bis zur elften Regel in den Regulae über die Tätigkeit der Intuition der bona mens, einfache Begriffe zu erfassen, überhaupt nicht geäußert hat. Alle Beispielsätze, mit deren Hilfe Descartes in der dritten Regel die Intuition erklärt, betreffen nicht einfache Begriffe, sondern einfache Aussagen. Dies kommt daher, daß alle Beispielsätze, außer den beiden Sätzen "Ich denke" und "ich existiere", mathematische Sätze sind, die in einfachen Begriffen formuliert sind, und daß Descartes es für unnötig hält, gesondert zu erklären, daß wir sie durch Intuition erfassen. Erst in der zwölften

\footnotetext{
39. "Ego vero solam Analysim, quae vera \& optima via est ad docendum, in Meditationibus meis sum sequutus; sed quantum ad Synthesim, quae procul dubio ea est quam hic a me requiritis, etsi in rebus Geometricis aptissime post Analysim ponatur, non tamen ad has Metaphysicas tam commode potest applicari.

Haec enim differentia est, quod primae notiones, quae ad res Geometricas demonstrandas praesupponuntur, cum sensuum usu convenientes, facile a quibuslibet admittantur. Ideoque nulla est ibi difficultas, nisi in consequentiis rite deducendis; ...

Contra vero in his Metaphysicis de nulla re magis laboratur, quam de primis notionibus clare et distincte percipiendis. Etsi enim ipsae ex natura sua non minus notae vel etiam notiores sint, quam illae quae a Geometris considerantur, quia tamen iis multa repugnant sensuum praejudicia quibus ab ineunte aetate assuevimus, non nisi a valde attentis \& meditantibus, mentemque a rebus corporeis, quantum fieri potest, avocantibus, perfecte cognoscuntur; atque si solae ponerentur, facile a contradicendi cupidis negari possent." (AT VII, S. 156-157; Hervorhebung d. Verf.)
} 
Regel tritt Descartes' Erklärung über die Tätigkeit der Intuition auf, einfache Begriffe von physikalischen Gegenständen zu erfassen. Dies ist der erste Schritt, von dem Descartes glaubt, daß man ihn unternehmen müsse, um sichere Naturwissenschaften aufzubauen: physikalische Gegenstände nicht nach ihrer Existenz, sondern nach unserer Erkenntnis neu zu konzeptualisieren. Nach Descartes gibt es drei Arten von einfachen Begriffen: "vel pure intellectuales, vel pure materiales, vel communes" (AT X, S. 419).

Die einfachen Begriffe, die rein intellektuell sind, sind die, die wir durch Intuition ohne Hilfe von sinnlichen Wahrnehmungen erfassen. Derartige Begriffe sind z.B. Erkenntnis, Zweifel usw. Die einfachen Begriffe, die wir mit Bezug auf materielle Gegenstände durch Intuition erfassen, sind z.B. Gestalt, Ausdehnung, Bewegung. Die einfachen Begriffe, die "gemeinsam" sind, sind diejenigen, die wir sowohl mit Bezug auf materielle Gegenstände als auch auf immaterielle Dinge durch Intuition erfassen, z.B. existentia, unitas, duratio, similia. Hierzu gehören auch die communes notiones, die unseren deduktiven Schlüssen zugrunde liegen.

"Hierher sind auch jene Gemeinbegriffe zu rechnen, die gleichsam die Verbindungsglieder sind, um andere einfache Naturen miteinander zu verbinden, und auf deren Evidenz. alles beruht, was wir im folgernden Denken erschließen, nämlich diese: was einem Dritten gleich ist, ist untereinander gleich, ebenso: was nicht auf gleiche Weise auf dasselbe Dritte bezogen werden kann, besitzt auch unter sich einen Unterschied usw. Und zwar können diese allgemeinen Naturen sowohl vom reinen Verstand erkannt werden, als auch von ihm, sofern er die Bilder dessen, was materiell ist, intuitiv erfaßt." (Gäber, S. 89; Hervorhebung d. Verf.) ${ }^{40}$

Dazu sind folgende Bemerkungen nötig.

Erstens werden die einfachen materiellen Begriffe nicht durch die Sinne, sondern durch die Intuition der bona mens erfaßt. Die bona mens wird in bezug auf physikalische Gegenstände sowohl urteilend als auch intuitiv erfassend tätig. ${ }^{41}$

Zweitens werden alle einfachen Begriffe durch Intuition direkt (notiones per se notae) erfaßt, d.h. sie sind durch Rekurs auf andere Begriffe weder definierbar noch erklärbar. ${ }^{42}$

Drittens sind alle hier angegebenen einfachen materiellen Begriffe nur quantitative Begriffe.

Viertens meint Descartes mit "einfachen materiellen Begriffen" nur reale einfache Begriffe, die wir durch Analyse von physikalischen Gegenständen abstrahieren. ${ }^{43}$

\footnotetext{
${ }^{40}$. "Huc etiam referendae sunt communes illae notiones, quae sunt veluti vincula quaedam ad alias naturas simplices inter se conjugendas, \& quarum evidentia nititur quidquid ratiocinando concludimus. Hae scilicet: quae sunt eadem uni tertio, sunt eadem inter se; item, quae ad idem tertium eodem modo referri non possunt, aliquid etiam inter se habent diversum, \&c.Et quidem hae communes possunt vel ab intellectu puro cognosci, vel ab eodem imagines rerum materialium intuente." (AT X, S. 419-420; Hervorhebung d. Verf.)

${ }^{41}$. Vgl. Walsh, Metaphysics, S. 40.

${ }^{42}$. In den Regulae übt Descartes starke Kritik an den Metaphysikern seiner Zeit. Eine Kritik ist die an dem Syllogis mus (AT X, S. 405 f), wie wir in II. I. 2. gesehen haben. Eine andere Kritik ist die an denjenigen Metaphysikern, die sich darum bemühen, einfache Begriffe mit Rekurs auf andere Begriffe zu definieren und zu erklären (AT X, S. 426). Und gerade diesen Versuch hält Descartes für völlig sinnlos und überhaupt nicht nützlich.
} 
Fünftens dürfen die communes notiones nicht als allgemeine Aussagen verstanden werden, die wir als Obersatz in einem Syllogismus verwenden. Sie müssen eher als Gesetz des Schliessens verwandt werden in dem Sinne, daß wir ihre Wahrheit durch Intuition nur an konkreten Fällen erfassen. ${ }^{44}$

\section{II. 2. 4. Zurück zu Williams: Kritik}

Descartes zielt mit seiner Konzeptualisierung von physikalischen Gegenständen nicht einfach darauf $\mathrm{ab}$, diese und damit auch die Naturphänomene nur unter dem Aspekt der Extension, Ausdehnung und Bewegung usw. zu betrachten. ${ }^{45}$ Er glaubt nämlich darüber hinaus, daß allein mit Hilfe von ausgezeichneten Begriffen zu beschreiben sei, wie physikalische Gegenstände in Wirklichkeit sind. Nun hat eine Unterscheidung dieser Art (die Unterscheidung von primären und sekundären Qualitäten), wie sie auch immer aussehen mag, ohne Zweifel die Implikation, daß nicht alle subjektiven Bedingungen der Erkenntnis eine verläßliche Grundlage für eine objektive Auffassung von physikalischen Gegenständen sind. Wie wir gesehen haben, ist Williams der Meinung, daß diese Unterscheidung durch die Suche nach dem Wissen von etwas, das unabhängig von unserem Denken und Vorstellen irgendwie existiert, veranlaßt worden sei, und daß sie eben aus demselben Grund weiter zu dem Gedanken führt, ob vielleicht keine von ihnen eine verläßliche Grundlage für jene objektive Auffassung liefern könne. Dies meint er mit (D2). Aber dies ist ein Irrtum. Warum dies so ist, kann folgendermaßen näher erklärt werden.

Wie wir gesehen haben, geht Descartes nicht von einem ausgezeichneten Begriff des Wissens aus, sondern davon, daß wir wissen, daß es physikalische Gegenstände gibt, die unabhängig von uns und unserem Denken gegeben sind. Worin soll dieses Wissen bestehen? Es ist nicht Wissen von der Existenz von etwas, das unabhängig von uns und unserem Denken irgendwie existiert, sondern Wissen von der Existenz von physikalischen Gegenständen, die im Raum zwar von uns und unserem Denken unabhängig gegeben sind, die wir aber gemäß unseren subjektiven Bedingungen der Erkenntnis in räumlicher Beziehung als von uns und von unserem Denken unabhängig gegebene Individuen zu identifizieren und von uns und voneinander zu

\footnotetext{
${ }^{43}$. Vgl. AT X, S. 418. Descartes hält den Begriff "Figur" für einen materiellen einfachen Begriff, aber nicht den Begriff "Grenze", der ein noch abstrakterer Begriff als der Begriff "Figur" ist, weil der Begriff "Grenze" nicht nur auf materielle Gegenstände, sondern auch auf andersartige Gegenständen angewandt werden kann.

${ }^{44}$. Dies ist der Grund dafür, daß Descartes erstens sein Cogito-Argument zwar als Schluß, aber nicht als einen Syllogismus auffassen will, und daß er zweitens dadurch die Kritik der pyrrhonischen Skeptiker vermeiden will, nämlich die, daß alle Beweise, wenn sie eine überflüssige Prämisse enthalten, nicht schlüssig sind. Vgl. Sextus Empiricus, Grundriß, 144-66. Curley, Descartes, S. 25-34.

${ }^{45}$. Vgl. unten II.II.3.1.
} 
unterscheiden in der Lage sind. Das heißt, daß unser Wissen von der Existenz von physikalischen Gegenständen von vornherein vorschreibt, worum es geht, wenn es um objektive Erkenntnis der physikalischen Gegenstände geht. Gerade daraus erklärt sich, warum Descartes die beiden Fragen, was Erkenntnis ist und wie weit ihr Umfang ist, zu Recht als Fragen betrachtet, die nur dadurch beantwortet werden können, daß alle Erkenntnismittel aufgezeigt werden. Die Suche nach objektiver Erkenntnis ist nichts anderes als die Suche nach objektiver Erkenntnis der physikalischen Gegenstände, die als unter unseren subjektiven Bedingungen der Erkenntnis stehend verstanden werden; sie ist nicht die Suche nach der Erkenntnis von etwas, das über unsere subjektiven Bedingungen der Erkenntnis hinaus geht und irgendwie existiert. Sie ist nicht "novum aliquod genus entis inveniri" (AT X, S. 438). Wenn es etwas gibt, das über unsere subjektiven Bedingungen hinaus gehen sollte, ist Descartes' Position die, daß wir nicht in der Lage sind, es zu erkennen. Denn dafür "(nos; d. Verf.) vel novo aliquo sensu instructos esse oporteret, vel mente divina" (S. 439). Dies ist der Grund dafür, daß Descartes der Beschäftigung mit den beiden Fragen, was Erkenntnis ist und wie weit ihre Umfang ist, eine große Bedeutung zuschreibt, obwohl sie nicht direkt dazu beitragen kann, Erkenntnisse von physikalischen Gegenständen zu erwerben. Die Erkenntnis, die dadurch erworben wird, schreibt nämlich vor, worauf unsere Untersuchung gerichtet werden soll und worauf nicht.

Descartes' Überlegung zur Möglichkeit der Unterscheidung zwischen der Erscheinung physikalischer Gegenstände und ihrer wirklichen Beschaffenheit muß in diesem Zusammenhang gesehen werden. Sie ist nämlich keine Überlegung der Art, wie physikalische Gegenstände in Wirklichkeit beschaffen sind, wobei sie völlig unspezifiziert als "etwas" verstanden werden, das irgendwie existiert. Es ist eher eine Überlegung darüber, ob andere (sekundäre) Qualitäten referentielle Bedeutung haben, wobei die referentielle Bedeutung der (primären) Qualitäten von Anfang an nicht dafür in Frage kommt, die physikalischen Gegenstände räumlich als Individuen zu identifizieren und von uns und voneinander zu unterscheiden. (D1) ist deshalb nicht haltbar. Die Qualitäten, die notwendig sind, um physikalische Gegenstände als Individuen räumlich zu identifizieren, müssen von Anfang an in der Formulierung der "absolute conception" enthalten sein. Unser Wissen von der Existenz von physikalischen Gegenständen im oben erklärten Sinne setzt demnach weder die "absolute conception" in ihrer endgültigen Fassung noch deren Möglichkeit voraus, sondern es verhält sich eher umgekehrt. Jenes Wissen ist nämlich eine notwendige Bedingung für den Versuch, die "absolute conception" zu entwickeln und zu formulieren. Wenn A und B den Versuch machen, eine neue Repräsentation der Welt zu formulieren, durch die erklärt werden kann, warum ihre Repräsentationen voneinander verschieden sind und in welcher Beziehung sie miteinander stehen, muß vorausgesetzt werden, daß A und B wissen, daß ihre Repräsentationen Repräsentationen ein und derselben Welt sind. Für dieses Wissen ist es notwendig, daß A und B zumindest mit denselben subjektiven 
Bedingungen der Erkenntnis ausgestattet sind. Daraus ergibt sich auch, daß wir beim Versuch der Formulierung der "absolute conception" nur von uns zur Verfügung stehenden Begriffen Gebrauch machen. Dies tun wir nicht deswegen, weil es kein Gebot gibt, daß wir die "absolute conception" nur mit Hilfe von Begriffen beschreiben dürfen, die nicht unsere sind, wie Williams behauptet. Wir können nichts anderes tun und brauchen auch nichts anderes zu tun. Eben dies ist auch der Grund dafür, daß, wenn man eine Überlegung zur Möglichkeit von (D2) anstellt, man (D2) nicht in der Weise überwinden kann, wie Williams dies für möglich hält. Natürlich ist es eine offene Frage, ob es irgendwann möglich sein wird, die "absolute conception" in ihrer vollständigen Fassung zu formulieren. Descartes scheint davon überzeugt zu sein, daß es möglich ist. Die Unterscheidung von primären und sekundären Qualitäten ist Descartes' erster Schritt in dem Versuch, die "absolute conception" zu formulieren. Entscheidend ist dabei aber zu bemerken, daß er sich des hypothetischen Charakters seines Unternehmens bewußt ist. Er sagt nämlich:

"Sie sollen gar nicht glauben, wenn Sie nicht mögen, daß die Sache sich so verhält, aber was wird Sie daran hindern, eben diesen Hypothesen beizutreten, wenn in die Augen fällt, daß sie die Wahrheit nicht beeinträchtigen, sondern alles nur weit klarer machen." (Gäbe, S. 77) ${ }^{46}$

Aus der bisherigen Betrachtung ergibt sich, daß der Versuch von Williams, die Motivation, die Descartes zum Problem des Skeptizismus geführt hat, mit Rekurs auf den von ihm ausgezeichneten Begriff des Wissens zu erklären, schwer nachvollziehbar ist. Dagegen wird man vielleicht einwenden, daß ich damit Williams Unrecht tue. Was Williams zu erklären versucht, ist, so könnte man sagen, nur die Motivation, aus der heraus Descartes sich in den Meditationes mit dem Problem des Skeptizismus beschäftigt hat. Angenommen, daß dies der Fall ist, scheint es mir so zu sein, daß sich seine Erklärung eben deswegen als um so unzureichender, sogar als uninteressant erweist. Sie setzt dann nämlich voraus, daß Descartes erst nach den Regulae den ausgezeichneten Begriff des Wissens akzeptiert hat. In diesem Fall aber ist in Bezug auf die Motivationsfrage nicht die Frage relevant, wie der Begriff des Wissens Descartes zur Beschäftigung mit dem Problem des Skeptizismus geführt hat, sondern eher die, warum Descartes nach den Regulae jenen Begriff des Wissens akzeptiert hat.

\section{II. 3. Mackies Erklärung: Die Repräsentationstheorie in einer anderer Version}

Wir haben gesehen, daß die traditionelle Erklärung mit Rekurs auf die Repräsentationstheorie auf ein schwerwiegendes Problem stößt. Es bleibt nämlich völlig unklar, wie der ontologische

\footnotetext{
46. "Neque credetis, nisi lubet, rem ita se habere; sed quid impediet, quominus easdem suppositiones sequamini, si appareat, nihil illas ex rerum veritate minuere, sed tantum reddere omnia longe clariora" (AT X, S. 412).
} 
Status der Vorstellungen verstanden werden soll. Die einzige Möglichkeit, ihn zu verstehen, besteht demnach darin, ihn mit Rekurs auf die skeptische Konklusion zu verstehen, die unabhängig davon vollzogen werden muß. Dies ist der Grund dafür, daß ich die traditionelle Auffassung für einen Fehlschlag halte. Ich habe keinen Zweifel daran, daß auch Mackie dieses Problem gesehen hat. Daher erklärt sich nämlich, daß er sich zuerst bemüht, die Repräsentationstheorie ohne Bezug auf das Problem des Skeptizismus verständlich zu machen, und dann zu zeigen, wie man davon ausgehend zu dem Problem des Skeptizismus kommt. Bevor ich aber auf die Auseinandersetzung mit Mackie eingehe, will ich zuerst betrachten, warum Descartes es überhaupt für nötig gehalten hat, eine Wahrnehmungstheorie anzubieten. Dieser Versuch wird uns einen guten Ansatzpunkt liefern, mit dessen Hilfe wir zur Auseinandersetzung mit Mackie übergehen können.

\section{II. 3. 1. Exkurs zu den Regulae: Die Repräsentationstheorie Descartes'}

Um herauszufinden, warum Descartes es überhaupt für nötig gehalten hat, eine Wahrnehmungstheorie zu entwerfen, betrachten wir die Frage, in welcher Weise er sie in den Regulae einführt:

"Man muß sich also erstens vorstellen, daß alle äußeren Sinne, soweit sie leibliche Organe
sind, obgleich wir sie den Objekten durch eine Handlung, durch eine Ortsbewegung nämlich,
zuwenden, dennoch nur passiv im eigentlichen Sinne wahrnehmen, in der gleichen Art, wie das
Wachs seine Figur vom Siegel empfängt. Auch darf man nicht glauben, dies sei nur als
Analogie gemeint, sondern man muß sich vorstellen, daß die äußere Gestalt des empfindenden
Körpers wirklich vom Objekt ganz auf dieselbe Weise verändert wird wie die der Oberfläche
des Wachses vom Siegel. Dies muß nicht nur angenommen werden, wenn wir einen Körper
als gestaltet oder hart oder rauh usw. ertasten, sondern auch, wenn wir mit dem Tastsinn
Wärme oder Kälte und Ähnliches wahrnehmen; ebenso bei den anderen Sinnen, nämlich daß
das erste Undurchsichtige im Auge auf diese Weise eine Figur empfängt, die ihr von dem
verschieden gefärbten Licht eingedrückt wird, und daß die erste für das Objekt unpassierbare
Haut der Ohren, der Nase und der Zunge auf eben die Weise eine neue Figur vom Ton, vom
Duft und vom Geschmack annimmt."(Gäbe, S. 77$)^{47}$ Die so auf die Sinne übertragenen Figuren werden durch den sensus communis weiter auf die phantasia übertragen:

\footnotetext{
47. "Concipiendum est igitur, primo, sensus omnes externos, in quantum sunt partes corporis, etiamsi illos applicemus ad objecta per actionem, nempe per motum localem, proprie tamen sentire per passionem tantum, eadem ratione qua cera recipit figuram a sigillo. Neque hoc per analogiam dici putandum est; sed plane eodem modo concipiendum, figuram externam corporis sentientis realiter mutari ab objecto, sicut illa, quae est in superficie cerae, mutatur a sigillo. Quod non modo admittendum est, cum tangimus aliquod corpus ut figuratum, vel durum, vel asperum, \&c., sed etiam cum tactu percipimus calorem, vel frigus, \& similia. Item in aliis sensibus, nempe primum opacum, quod est in oculo, ita recipere figuram impressam ab illuminatione variis coloribus induta; \& primam aurium, narium, \& linguae cutem, objecto imperviam, ita novam quoque figuram mutuari a sono, odore, \& sapore." (AT X, S. 412-413)
} 
"Drittens muß man sich vorstellen, daß der Gemeinsinn gleichfalls die Rolle eines Siegels spielt, um eben diese Figuren oder Ideen, die von den äußeren Sinnen rein und ohne Körper ankommen, in der Phantasie oder Einbildungskraft gleich wie im Wachs abzudrücken, ferner daß diese Phantasie ein wirklicher Teil des Körpers ist und von solcher Größe, daß seine verschiedenen Abteilungen sich mit mehreren voneinander verschiedenen Figuren bekleiden können und sie gewöhnlich längere Zeit aufbewahren. In diesem Fall ist sie gerade das, was man das Gedächtnis nennt.

Viertens muß man sich vorstellen, daß die bewegende Kraft bzw. die Nerven selbst im Gehirn entspringen, in dem sich die Phantasie befindet, von der sie verschiedenartig bewegt werden wie der Gemeinsinn vom äußeren Sinn.....Von hier aus läßt auch sich verstehen, wie die Bewegungen anderer Lebewesen alle entstehen können, obwohl man ihnen überhaupt keine Erkenntnisse, sondern nur eine rein körperliche Phantasie zubilligt; ebenso auch, wie in uns alle jene Handlungen zustande kommen, die wir ohne jeden Beistand der Vernunft ausführen.

Fünftens schließlich muß man sich vorstellen, daß diejenige Kraft, mit der wir die Dinge im eigentlichen Sinne erkennen, rein geistig ist ...." (Gäber, S. 79-81) (8) $^{48}$

Wie wir sehen können, sind in dieser skizzenhaften physio-psychologischen Erklärung drei Themen miteinander verbunden: die Unterscheidung von primären und sekundären Qualitäten, eine Wahrnehmungstheorie und die Spezifizierung und Differenzierung unserer Erkenntnisfähigkeiten. Betrachten wir zuerst das letzte Thema näher und dann die beiden ersten Themen zusammen.

Was Descartes' Spezifizierung und Differenzierung unserer Erkenntnisfähigkeiten betrifft, ist folgendes zu bemerken.

Die einzige Fähigkeit, Erkenntnis zu erwerben, und damit zugleich die einzige Fähigkeit, Irrtümer zu begehen, ist die bona mens. Sensus, imaginatio und memoria, als körperliche Instanzen, sind keine Fähigkeiten, Erkenntnis zu erwerben, sondern nur Hilfsmittel, zu denen die vis cognoscens der bona mens greifen muß, je nachdem von welcher Art die Gegenstände sind, die sie betrachtet. Wenn es um sinnliche Gegenstände geht, wird sie sich an die imaginatio und den sensus wenden, während sie allein tätig wird und sein muß, wenn es um nicht sinnliche Gegenstände geht. ${ }^{49}$ In diesem Fall ist der Gebrauch der körperlichen

\footnotetext{
48. "Tertio concipiendum est, sensum communem fungi etiam vice sigilli ad easdem figuras vel ideas, a sensibus externis puras et sine corpore venientes in phantasia vel imaginatione veluti in cera formandas, atque hanc phantasiam esse veram partem corporis et tantae magnitudinis, ut diversae eius portiones plures figuras ab invicem distinctas induere possint, illasque diutius soleant retinere; tuncque eadem est quae memoria appellatur.

Quarto concipiendum est, vim motricem sive ipsos nervos originem suam ducere a cerebro, in quo phantasia est, a qua illi diversimode moventur, ut sensus communis a sensu externo,.... Atque ex his intelligere licet, quomodo fieri possint omnes aliorum animalium motus, quamvis in illis nulla prorsus rerum cognito, sed phantasia tantum pure corporea admittatur; item etiam, quomodo fiant in nobis ipsis operationes illae, quas peragimus absque ullo ministerio rationis.

Quinto denique concipiendum est, vim illam, per quam res proprie cognoscimus, esse pure spiritualem....." (AT X, S. 414-5)

49. Vgl. AT X, S. 398 und S. 415 f. ( 8te und 12te Regel), und Beck, Method, S. 29 f. Man kann die Frage stellen, wie die bona mens lang andauernde Überlegungen bezüglich nicht-physikalischer Themen anstellen kann, da memoria eine körperliche Instanz ist und als körperliche Instanz dabei Descartes'
} 
Instanzen nicht nur nutzlos, sondern vielmehr hinderlich. Im ersten Fall nennt Descartes sie ingenium und im zweiten Fall intellectus purus. Descartes' Erklärung darf aber nicht so verstanden werden, als ob die drei Tätigkeiten, nämlich uns an etwas zu erinnern, uns etwas einzubilden und etwas wahrzunehmen, selbständige Tätigkeiten der körperlichen Instanzen, nämlich von imagiatio, memoria und sensus wären, so daß die erkennende Kraft der bona mens sich bloß als eine zusätzliche Tätigkeit an diese selbständigen Tätigkeiten der körperlichen Instanzen wendet, wenn es nötig ist. Was Descartes meint, ist eher, daß diese drei körperlichen Instanzen erst in der Verbindung mit der bona mens ihre entsprechenden Tätigkeiten als solche ausüben und dementsprechende Bezeichnungen bekommen können. ${ }^{50}$ Sonst sind sie nichts anderes als bloße mechanische Funktionen, die zwar ein gewisses Verhalten verursachen können, aber nicht mit Bewußtsein verbunden sind. Descartes glaubt, daß alle Bewegungen bei Tieren von solcher Art sind und daß es auch gewisse Verhaltensweisen bei Menschen gibt, die von dieser Art sind.

Was die ersten beiden Themen betrifft, ist es wichtig, ihren Zusammenhang zu verstehen.

Es ist zu bemerken, daß mit den Figuren oder Ideen, die von physikalischen Gegenständen zuerst den sensus externi eingeprägt und dann über den sensus communis weiter zur phantasia oder imaginatio geleitet werden, nicht Bilder im wörtlichen Sinn, sondern geometrische Figuren sind. Wenn wir z.B. verschiedene Farben an verschiedenen physikalischen Gegenständen wahrnehmen, ist das, was von diesen durch den oculus über den sensus communis weiter zur phantasia oder imaginatio geleitet wird, nur dementsprechend verschiedene Figuren. Diese sind rein physikalisch, wie imaginatio, eine physikalische Instanz ist. Daraus kann man folgende zwei Konsequenzen ziehen.

Die eine Konsequenz ist die, daß es in Descartes' physio-psychologischer Erklärung der Wahrnehmungen nicht einfach darum geht, diese irgendwie zu erklären, sondern vielmehr darum, sie unter der Voraussetzung zu erklären, daß physikalische Gegenstände einzig und allein aus (sozusagen) primären Qualitäten bestehen.

Die andere Konsequenz ist die, daß Descartes mit seiner Unterscheidung von primären und sekundären Qualitäten nicht einfach darauf abzielt, physikalische Gegenstände nur unter dem Aspekt der Extension, Ausdehnung und Bewegung usw. zu betrachten, sondern eher darauf, daß ihnen in Wirklichkeit nur primäre Qualitäten zukommen.

Meinung nach nicht nur nicht helfen kann, sondern vielmehr hinderlich ist (AT X, S. 416-7). Ich glaube, daß Descartes später auf diese Frage gestoßen ist. Er unterscheidet nämlich später zwei verschiedene Erinnerungskräfte. Er schreibt im Brief an Mersenne vom 6. August 1640: "Außerdem glaube ich, daß es neben dem körperlichen Gedächtnis, dessen Eindrücke durch diese Gehirnfalten erklärt werden können, in unserem Begriffsvermögen noch eine Art von Gedächtnis gibt, das nicht von den Organen des Körpers abhängt und vollständig geistig ist und sich bei den Tieren nicht findet".

${ }^{50}$. In diesem Sinne kann die bona mens als Bewußtsein verstanden werden. 
Wie Perler richtig bemerkt hat, scheint aber Descartes den Terminus "Idee" ab 1641 nicht mehr zur Bezugnahme auf physikalische Entitäten in der imaginatio zu verwenden, sondern nur noch zur Bezugnahme auf geistige Entitäten. ${ }^{51}$ Und er ist zu Recht der Meinung, daß dies viele (der Hauptadressat von Perler ist Reid) veranlaßt hat, die Repräsentationstheorie Descartes' so zu interpretieren, daß sie den Skeptizismus zur Folge haben sollte (S. 7 und 11). Dies geschieht bekanntermaßen dadurch, Ideen in einer Wahrnehmungssituation einerseits als von physikalischen Gegenständen ontologisch distinkte geistige Bilder und andererseits als direkte Gegenstände unserer Wahrnehmungen aufzufassen. Perler glaubt aber zu recht, daß dies ein Irrtum sei. Es gibt zwar auch seiner Meinung nach einige Textstellen bei Descartes, die auf den ersten Blick eine solche traditionelle Interpretation veranlassen und ermutigen könnten. Aber er ist doch der Meinung, daß jene Textstellen anders interpretiert werden können, und vor allem der Meinung, daß es auch viele andere Textstellen gibt, die die traditionelle Interpretation ausschliessen (S. 11-15). Dadurch macht Perler es sich zur Hauptaufgabe, Descartes' Repräsentationstheorie so zu interpretieren, daß sie keine Implikation des Skeptizismus hat, indem er neue Analyse jener problematischen Textstellen anzubieten versucht. In meiner folgenden Betrachtung über Perlers Versuch will ich nicht auf alle Einzelheiten eingehen, sondern mich nur auf zwei Punkte konzentrieren, die mir wichtig zu sein scheinen.

Der erste Punkt ist der, das Problem des Skeptizismus von der Repräsentationstheorie zu trennen. $\mathrm{Zu}$ diesem Zweck stellt Perler sich die grundsätzliche Frage, warum Descartes den Terminus "Idee" ab 1641 nur zur Bezugnahme auf geistige Entitäten verwendet (S.23-37). ${ }^{52}$ Perler glaubt, daß man dafür "mindestens fünf Gründe in den späteren Werken, insbesondere in den Meditationes" finden könne (S. 33). Von den fünf Gründen will ich hier nur einen nennen, den ich für relevant für unsere Diskussion halte. Es ist der folgende Grund:

"Würden wir nur über die Entitäten in der Zirbeldrüse verfügen, wäre durch den methodischen Zweifel jedes Fundament für eine sichere Erkenntnis von der wahrnehmbaren Welt in Frage gestellt. Um nun ein solches Fundament zu gewährleisten, führt Descartes die geistigen Ideen ein. Ihre Existenz ist selber dann unbezweifelbar, wenn die Zuverlässigkeit des ganzen physiologischen Wahrnehmungsprozesses in Frage gestellt wird. Bereits die Strategie des methodischen Zweifels legt also nahe, daß es zusätzlich zu den körperlichen Entitäten geistige Entitäten geben muß, die zwar in Relation zu den körperlichen "Bildern" stehen können, jedoch von diesen distinkt sind."(S. 34)

Hier sagt Perler, daß Descartes` Einführung der geistigen Entitäten (Bilder) im Kontext der ersten Meditation durch seine skeptische Konklusion erzwungen worden ist. So hat die

\footnotetext{
51. Vgl. Perler, Repräsentation bei Descartes, S. 32

${ }^{52}$. Wie Perler richtig betont hat, darf dies zuerst nicht so verstanden werden, als wollte Descartes damit auf die oben betrachtete physio-psychologische Erklärung verzichten. Dies ist überhaupt nicht der Fall.
} 
Einführung der geistigen Bilder eigentlich nichts mit der Repräsentationstheorie Descartes' als solcher zu tun. In dieser Hinsicht stimme ich Perler völlig zu.

Der zweite Punkt ist der Folgende. Perler weiß, daß Reid, wenn dieser behauptet, daß die Repräsentationstheorie zum Skeptizismus führe, dies nicht deswegen behauptet, weil die radikale Anwendung der Methode des Zweifels Descartes am Ende dazu zwingen sollte, geistige Bilder als direkte Gegenstände unserer Wahrnehmungen anzunehmen, sondern eher deswegen, weil Descartes' Repräsentationstheorie als solche es unvermeidbar macht, die geistigen Bilder als direkte Gegenstände aufzufassen. Um zu zeigen, daß dies nicht der Fall ist, wendet Perler sich hauptsächlich an Descartes' Erklärung der Äquivokation des Terminus der "Idee" (AT VII, 8). Er versucht ihrzufolge, Ideen einerseits im materiellen Sinn als intentionale Akte des Geistes und andererseits im objektiven Sinn als den Inhalt der intentionalen Akte zu interpretieren, vermittels dessen die physikalischen Gegenstände als intentionale Gegenstände uns direkt gegeben sind ( $\$ 6-\S 7$ und $\S 21) .{ }^{53}$ Die Unterscheidung zwischen den Ideen im objektiven Sinn und physikalischen Gegenständen ist demnach "nichts anderes als die Unterscheidung zwischen dem Gegenstand, wie er an sich ist und wie er für uns ist" (S. 316). Der Fehler, den Reid begangen hat, ist nach Perler der, daß er Ideen im objektiven Sinn nicht erkenntnistheoretisch, sondern ontologisch verstanden hat (S. 317). Auch in dieser Hinsicht stimme ich Perler völlig zu. Wenn man nämlich die Passagen in den Meditationes, in denen es um Descartes' Explikation der Repräsentationstheorie geht, ohne Verbindung mit dem Problem des Skeptizismus liest, heißt "Ideen haben" in einer Wahrnehmungssituation nichts anderes als "physikalische Gegenstände direkt wahrnehmen". ${ }^{54}$

Woran liegt es aber eigentlich, daß jemand wie Reid Ideen als geistige Bilder in einer Wahrnehmungssituation angenommen hat? Liegt es daran, daß er zu schnell vom Dualismus zu

\footnotetext{
53. Yolton geht auch in diese Richtung. Aus diesem Grund schlägt er perceptual acquaintance als passende englische Übersetzung für idea vor. Vgl. Perceptual acquaintance from Descartes to Reid, Vorrede, Einleitung, Kapitel I und V.

${ }^{54}$. Es gibt doch eine Stelle, an der Perler uns große Schwierigkeiten bereitet, seine Position einheitlich darzustellen. Perler gibt nämlich an einer Stelle eine Erklärung darüber, wie Descartes zur skeptischen Konklusion gelangt: "Der Zweifel geht von der Situation aus, in der die Gegenstände zunächst nur relational betrachtet werden. Der Meditierende weiß, daß ihm die Gegenstände als so-und-so beschaffene Gegenstände gegeben sind, er weiß aber nicht, ob sie unabhängig von dieser Relation auch existieren. Deshalb darf er nicht einfach von der Feststellung,die Gegenstände als mir gegebene Gegenstände existieren`zur Behauptung,die Gegenstände existieren` übergehen." (S. 112). Diese Erklärung spricht eindeutig gegen den oben betrachteten zweiten Punkt. Auch gegen den ersten Punkt spricht sie insofern, als der Repräsentationstheorie, wie diese auch immer interpretiert werden mag, ein unentbehrlicher Anteil daran zugeschrieben worden ist, Descartes mit dem Problem des Skeptizismus zu konfrontieren. Trotzdem denke ich, daß man jenes Zitat (S. 112) nicht so stark lesen darf. Wenn man nämlich Perler fragt, wie die Existenz von physikalischen Gegenständen bei Descartes bewiesen wird, die durch die Methode des Zweifels in Frage gestellt worden ist, lautet seine Antwort "durch den Existenzbeweis Gottes" (seine Fußnote 33 auf der S. 91). Dies zeigt, daß er doch nicht der Meinung ist, daß das Problem des Skeptizismus auf der Repräsentationstheorie Descartes' als solcher beruht.
} 
der Behauptung übergegangen ist, daß alle Gegenstände des Geistes deswegen, weil der Geist immateriell ist, geistige Entitäten sein müssen (Perler, S. 7-11)? Liegt es daran, daß er dadurch veranlaßt einige Textstellen bei Descartes mißinterpretiert hat (Perler, §4-§8)? Liegt es daran, daß er durch die Rezeption der Repräsentationstheorie Descartes' von Locke, Malebranche usw. beeinflußt worden ist (Perler, S. 317-321)? Mehr als diese drei Gründe hat Perler in seinem Buch nicht berücksichtigt. Ich will hier nicht darauf eingehen, ob Perler damit recht hat. Was ich statt dessen betrachten will, ist ein anderer Grund, der meiner Meinung nach eher eine Interpretation von der Art Reids veranlassen und ermutigen kann, den aber Perler überhaupt nicht berücksichtigt hat. Worin dieser Grund besteht und warum dieser viel entscheidender ist, kann folgendermaßen erklärt werden.

Es gibt ein theoretisches Problem in Descartes' Repräsentationstheorie, das die traditionelle Interpretation von der Art Reids veranlassen und ermutigen kann. Das Problem tritt mit der Frage nach dem ontologischen Status der sekundären Qualitäten auf, z.B. nach dem der Farbe oder der Hitze. Wie wir vorhin gesehen haben, setzt Descartes voraus, daß physikalische Gegenstände nur primäre Qualitäten besitzen. Obwohl diese unsere Farbwahrnehmungen verursachen, haben sie Farben nicht als ihre realen Eigenschaften. Trotzdem ist die Existenz der Farbe als des Inhalts unserer Wahrnehmungen unleugbar. Was ist ihr ontologischer Status? Darauf gibt Perler keine präzise Antwort:

"Hitze und Kälte sind nämlich keine realen Eigenschaften im Gegenstand....,daß Sinneseigenschaften etwas sind, was im Wahrnehmenden (und nur im Wahrnehmenden) existiert."(S. 56; Hervorhebung d. Verf.)

"Es gibt keine Hitze und keine Farbe im zu erkennenden Gegenstand, sondern nichts anderes als Materieteilchen, die den Erkennenden derart affizieren, daß er eine Sinneswahrnehmung von Hitze und Farbe hat." (S. 72; Hervorhebung d. Verf.)

Was meint Perler genau unter "der Wahrnehmende" bzw. "der Erkennende"? Ich denke, daß darunter nichts anderes als "der Geist" verstanden werden kann. Wenn dem so ist, sollte die Farbe als ein rein geistiges Bild (Phänomen) angenommen werden. Dabei ist das Problem, daß wir, wenn wir physikalische Gegenstände wahrnehmen, ihre Farben nicht isoliert von ihren anderen primären Qualitäten wahrnehmen können. Wir nehmen sie alle zusammengesetzt und zugleich als an physikalischen Gegenständen Seiendes wahr. Wenn dem so ist, tritt die Frage auf, warum nur die Farbe, nicht auch die primären Qualitäten, die wir an physikalischen Gegenständen mit der Farbe in der ausgezeichneten Weise wahrnehmen, für geistige Phänomen gehalten werden sollten. Ich denke, daß gerade dieses Problem der entscheidende Anlaß zur traditionellen Interpretation gewesen ist, alle Ideen Descartes' in einer Wahrnehmungssituation als geistige Bilder zu verstehen. Dieses Problem besteht weiter, auch 
angenommen, daß es Perler gelungen ist, alle Textstellen bei Descartes, die eine Interpretation von der Art Reids veranlassen und ermutigen können, Descartes' Intention nach zu relativieren, und auch angenommen, daß allein der Dualismus nicht einfach zur Annahme führen kann, daß die direkten Gegenstände geistige Entitäten (Bilder) sind. So ist jenes Problem viel entscheidender. Aber, wie gesagt, hat Perler leider dieses Problem nicht betrachtet.

$\mathrm{Ob}$ die Interpretation aller Ideen als geistige Bilder in einer Wahrnehmungssituation -durch jenes Problem veranlaßt - die Repräsentationstheorie Descartes' adäquat wiedergibt, ist natürlich eine andere Frage, die wir negativ beantworten müssen. Damit beabsichtige ich nicht, die Existenz jenes Problems zu leugnen. Die Frage ist aber die, welche Bedeutung jenes Problem in der Repräsentationstheorie Descartes' eigentlich besitzt. Versuchen wir diese Frage zu beantworten.

$\mathrm{Zu}$ diesem Zweck ist es zunächst nötig, noch einmal darauf aufmerksam zu machen, daß die Grundlage zur Einführung der Wahrnehmungstheorie bei Descartes nichts anderes als die Unterscheidung von primären und sekundären Qualitäten ist. Dementsprechend geht es in Descartes' Wahrnehmungstheorie, wie wir vorhin gesehen haben, nicht einfach darum, die Wahrnehmungen irgendwie zu erklären, sondern vielmehr darum, die Wahrnehmungen, insbesondere die von sekundären Qualitäten unter der Voraussetzung von primären und sekundären Qualitäten zu erklären. Daraus ergibt sich, daß Descartes mit dieser Unterscheidung nicht einfach darauf abzielt, physikalische Gegenstände nur unter dem Aspekt von primären Qualitäten zu betrachten, sondern eher darauf, ihnen in Wirklichkeit nur primäre Qualitäten zuzuschreiben. Gerade dies erklärt wiederum, warum Descartes es für nötig gehalten hat, eine Wahrnehmungstheorie neu zu entwickeln. Wegen der ausgezeichneten Unterscheidung treten nämlich besonders die Frage nach der Ursache der Wahrnehmungen von sekundären Qualitäten einerseits und die Frage nach ihrem ontologischen Status andererseits auf. Und gerade deswegen braucht Descartes viel dringender als je sonst eine Erklärung, wie überhaupt die Wahrnehmungen von sekundären Qualitäten zustande kommen können. Descartes' Erklärung zielt darauf ab, die Wahrnehmungen von sekundären Qualitäten einerseits auf die kausalen Wirkungen von physikalischen Gegenständen -wobei vorausgesetzt wird, daß diese einzig und allein aus primären Qualitäten bestehen,- und andererseits auf unsere spezifischen subjektiven Bedingungen der Erkenntnis zurückzuführen. Dabei tritt nun das oben betrachtete Problem auf, das die Interpretation von der Reids Art ermutigen kann. Wird dieses Problem Descartes dazu führen, dem Skeptizismus zu verfallen? Meine Antwort ist negativ. Die Unterscheidung von primären und sekundären Qualitäten ist nämlich unter der Voraussetzung gemacht worden, daß wir wissen, daß physikalische Gegenstände existieren, wie ich in meiner Auseinandersetzung mit Williams gezeigt habe. Deshalb kann die Existenz von physikalischen Gegenstände überhaupt nicht in Frage kommen, 
auch in dem Fall, daß Descartes zu allerletzt sich dazu gezwungen finden wird anzuerkennen, daß es unmöglich ist, jenes Problem zu lösen, ohne von physikalischen Gegenständen distinkte geistige Bilder als direkte Gegenstände unserer Wahrnehmungen anzunehmen. Dies kann ihn höchstens zum Gedanken führen, auf die Unterscheidung von primären und sekundären Qualitäten verzichten zu müssen. Aber ob jenes Problem so zu lösen sei oder nicht, ist selbst eine offene Frage, die sehr von dem Erfolg "of a certain programm of physical explanation" (Mackie, S. 23) abhängt und deswegen erst nach Descartes entschieden werden kann.

In diesem Zusammenhang sehe ich die Möglichkeit, die Rolle und den Status der "Idee" zu verstehen. Die Möglichkeit dazu ergibt sich, wenn wir fragen, worauf Descartes mit dem Gebrauch des Terminus' "Idee" hinaus wollte. Die Antwort liegt in der Unterscheidung von primären und sekundären Qualitäten. Obwohl die Differenz der beiden Ausdrücke "Es scheint mir so und so zu sein" und "Es ist so und so" geeignet ist, den Unterschied zwischen der Erscheinung der physikalischen Gegenstände und ihrer wirklichen Beschaffenheit zum Ausdruck zu bringen, sind sie doch nicht dazu geeignet, die Unterscheidung von primären und sekundären Qualitäten zum Ausdruck zu bringen.

\section{II. 3. 2. Mackies Erklärung: Kritik}

Mackie aber hält die direkt realistische Ansicht im letzten Abschnitt für problematisch. Er ist nämlich der Ansicht, daß sie die Implikation habe, daß Wahrnehmungen überhaupt unproblematisch sind. Er behauptet:

"I suspect that the direct realist's insistence that it is tables that we see, not ideas, and that we are not shut up in a private picture gallery, is meant to carry the implication that perception is unproblematic. In the sense of 'see' on which he insists, I can see a table only if the table is there, and he may conclude from this that seeing is a self-guaranteeing mode of awareness, something which, when we do it, leaves no room for sceptical doubts, not even for selective scepticism about the outside existence of, say, colours-as-we-see-them. ${ }^{165}$

Aus diesem Grund schlägt er vor, vorgestellte Gegenstände als intentionale Gegenstände der Vorstellung aufzufassen, die er wiederum folgendermaßen charakterisiert:

\footnotetext{
${ }^{55}$. Mackie, Problems from Locke, S. 43. Man kann vielleicht sagen, daß, was Mackie hier sagt, nichts mit Descartes zu tun hat, sondern nur mit Locke. Aber dies ist nicht der Fall. Das Verfahren von Mackie besteht darin, daß er zuerst eine Repräsentationstheorie aufstellt, die seiner Meinung nach nachvollziehbar ist, und versucht, sie dann Locke zuzuschreiben.
} 
"There is a construction with such verbs as 'see' such that in 'I see a horse' the phrase 'a horse' is somewhat like an internal accusative; what in terms of this construction I see is necessarily exactly as I see it, but the statement does not entail that what I see should be there, independently of my seeing it... They are mind-dependent: they exist only in and by being perceived, that is, as contents of states of perceptual awareness" (S. 47-8)

Mackie behauptet also, daß die direkt realistische Ansicht besage, daß ich z.B. nur dann einen Menschen sehen könne, wenn es in der Tat einen Menschen vor mir gibt. ${ }^{56}$ Ich denke, daß er damit völlig Recht hat. Dies ist nämlich in der Tat eine wichtige Explikation der direkt realistischen Auffassung. Was aber nicht nachvollziehbar ist, ist, daß er daraus die Schlußfolgerung zieht, daß die realistische Auffassung damit behauptet, daß Wahrnehmungen unproblematisch sind. Ich kann nicht einsehen, welchen Zusammenhang es zwischen beidem gibt. Ist es nicht wahr, daß ich nur dann einen Menschen sehen kann, wenn es vor mir in der Tat einen Menschen gibt? Und damit auch, daß ich keinen Menschen sehen kann, wenn es vor mir keinen Menschen gibt? Aber warum soll dies heißen, daß Wahrnehmungen unproblematisch sind? Übrigens wird niemand, der jene Ansicht vertritt, behaupten, daß Wahrnehmungen unproblematisch sind. Wenn nämlich der Anlaß für Mackie, alle Gegenstände unserer Wahrnehmungen ununterschieden als intentionale Gegenstände aufzufassen, in der Möglichkeit des Irrtums der oben angeführten Art besteht, habe ich Bedenken, ob dieser Weg zur Erklärung von Irrtum taugt. Er verwehrt uns nämlich eher die Möglichkeit, Irrtum zu erklären, da der besondere Status von Gegenständen, die wir irrtümlicherweise wahrzunehmen glauben, in Differenz zu physikalischen Gegenständen als intentionale Gegenstände aufgefaßt werden. Lassen wir aber diese Probleme beiseite und nehmen wir Mackie folgend an, daß Vorstellungen intentionale Gegenstände sind.

Als derart charakterisierte Theorie setzt die Repräsentationstheorie von Mackie voraus, daß es in einer direkten Wahrnehmungssituation sinnvoll ist, von "Vorstellungen von einzelnen Individuen" zu reden, z.B. von Vorstellungen von einem Tisch, von einem Pferd, usw. Sie setzt auch die Möglichkeit voraus, zwischen dem Fall, daß z.B. meine Vorstellungen von einem Tisch in der Tat einen physikalischen Gegenstand repräsentieren, und der Situation, in der dies nicht der Fall ist, zu unterscheiden. Mackie glaubt, daß dieser Unterschied mit Hilfe des kausalen Elements der Wahrnehmung gemacht werden könne. Lassen wir die Frage beiseite, in welcher Weise dies geschieht, und nehmen wir an, daß es dabei kein Problem gibt.

Nun ist Mackie der Meinung, daß die so ausgezeichnete Repräsentationstheorie das Problem des Skeptizismus auftreten läßt: "perhaps there are no things that correspond at all

\footnotetext{
${ }^{56}$. Es geht hier nicht um die Frage, ob der physikalische Gegenstand, den ich sehe, in der Tat ein Mensch, nicht ein Automat ist, sondern um die Frage, ob ich seine Existenz durch direkte Wahrnehmung erkenne.
} 
systematically to our experiential content as a whole" (S. 50). ${ }^{57}$ Es ist wichtig darauf hinzuweisen, daß er damit nicht einfach meint, daß das Problem des Skeptizismus sinnvoll sei, und daß deswegen der Versuch gemacht werden solle, ihn zu widerlegen, sondern vielmehr, daß die Repräsentationstheorie wegen ihrer so ausgezeichneten theoretischen Eigentümlichkeiten notwendigerweise mit dem Problem des Skeptizismus konfrontiert werde. Gerade dies leuchtet mir aber nicht ein, und deshalb setze ich mich mit Mackie auseinander. Versuchen wir also zuerst, uns darüber zu verständigen, wie er den Übergang von der Repräsentationstheorie zu der universalen skeptischen Frage erklärt.

Seiner Meinung nach wird der Übergang in zwei Schritten gemacht. Der erste Schritt besteht darin, folgende Frage zu stellen: "Is this inference (von Vorstellungen von Individuen zu ihren Ursachen; d. Verf.) not then exposed to the stock objections against an argument from an effect to a supposed cause of a type which is never directly observed?" (S. 50). Der zweite Schritt besteht darin, alle so gestellten einzelnen Fragen zu summieren, so daß sie die universale skeptische Frage bilden. Mackie behauptet nämlich: "If separate, piecemeal statements of the form 'This fully objective material thing causes and is represented by this idea' were admitted, it would be impossible to refuse the mere summation or intergration of these to yield the all-at-once thesis" (S. 52). Damit aber stößt Mackie auf ein schwerwiegendes Problem. Welches Problem es ist und warum es entsteht, kann folgendermaßen erklärt werden.

Wie wir gesehen haben, setzt die Repräsentationstheorie von Mackie voraus, daß es sinnvoll ist, von "Vorstellungen von Individuen" zu reden. Mackie scheint diese Redeweise für selbstverständlich zu halten. ${ }^{58}$ Er glaubt vor allem, daß man an ihr festhalten werde und könne, auch wenn der erste Schritt gemacht worden ist. Er glaubt darüber hinaus, daß man daran weiter festhalten könne, nachdem der zweite Schritt gemacht worden ist: Er glaubt nämlich, daß wir das so gestellte Problem des universalen Skeptizismus dadurch beseitigen können, daß wir kausale Zusammenhänge zwischen Vorstellungen und physikalischen Gegenständen als ihren Ursachen herausstellen, indem wir dafür von kausalen Zusammenhängen zwischen Vorstellungen ausgehen. ${ }^{59}$

Die oben genannte Redeweise ist aber alles andere als selbstverständlich. Sie ist nämlich nur dann sinnvoll, wenn man annimmt, daß Ursachen von Vorstellungen, wenn man sie aus Vorstellungen von Individuen mit Hilfe kausaler Annahmen erschließen zu können glaubt, in Wirklichkeit Individuen sind, wenn man also annimmt, daß Ursachen von Vorstellungen von

\footnotetext{
57. Dies ist der Grund dafür, daß Mackie glaubt, daß seine Auffassung der Vorstellungen als intentionaler Gegenstände eine Repräsentationstheorie sei.

58. Es ist erstaunlich, daß Mackie manchmal den Eindruck vermittelt, daß der kausale Zusammenhang sie ohne weiteres sinnvoll machen könne, vor allem, wenn er behauptet, daß das Problem des Skeptizismus mit Hilfe des kausalen Zusammenhanges entkräftet werden könne.

${ }^{59}$. Vgl. Mackie, S. 64-66.
} 
Individuen die Qualitäten besitzen, die dafür notwendig sind, um sie als Individuen zu identifizieren und voneinander zu unterscheiden. ${ }^{60}$

Wenn nun die von Mackie als erster Schritt dargestellte Frage unter dieser Bedingung gestellt und verstanden wird, dann kann die Frage nach "a supposed cause of a type which is never directly observed" nur als eine Frage von der Art verstanden werden, ob meine Vorstellungen z.B. von einem Tisch in einer direkten Wahrnehmungssituation in der Tat einen physikalischen Gegenstand repräsentieren oder nicht. Wenn die Frage aber so verstanden wird, kann sie empirisch entschieden werden. Ihre Entscheidung hat nichts mit dem Problem des Skeptizismus zu tun. Aus diesem Grund muß sie anders verstanden werden, damit das Problem des Skeptizismus auftreten kann. Aber wie? Die Antwort scheint darin zu liegen, "a supposed cause...never directly observed" als etwas zu verstehen, das über unsere subjektiven Bedingungen der Erkenntnis überhaupt hinausgeht. Einen Ausdruck dieser Möglichkeit kann man bei Bennett finden: "If we stand back and try to focus on the relation between sensory states as a whole and the objective realm as a whole, asking en bloc whether the former are ever reliable guides to the latter". ${ }^{61}$ Dagegen könnte man vielleicht einwenden, daß dies eher ein Beweis dafür ist, daß der erste Schritt nur im Rahmen der Repräsentationstheorie sinnvoll ist, da in der Erklärung von Bennett die Unterscheidung zwischen Vorstellungen und ihren Ursachen entscheidend ist. Dies ist aber ein Mißverständnis. Die Unterscheidung, auf der die Repräsentationstheorie basiert, ist nicht die Unterscheidung zwischen Vorstellungen en bloc und ihren Ursachen en bloc, sondern die Unterscheidung zwischen Vorstellungen von Individuen und ihren Ursachen als Individuen. Gerade dies ist der Kernpunkt der Kritik von Bennett an Locke, ${ }^{62}$ den Mackie nicht verstanden hat. Er liegt nicht darin, daß Locke irrtïmlicherweise glaubt, daß die en bloc gestellt Frage sinnvoll sei. Bennett behauptet, anders als Mackie unterstellt, nirgends, daß sie sinnlos sei, sondern nur, daß sie nicht ohne weiteres verständlich sei. Sie enthält nämlich zwei Termini, die nicht ohne weiteres verstanden werden können, die Termini "etwas" und "Vorstellungen en bloc". Der erste Terminus kann deswegen nicht ohne weiteres verstanden werden, weil er über unsere subjektiven Bedingungen der Erkenntnis hinausgeht, der zweite deswegen nicht, weil in der Repräsentationstheorie nur von "Vorstellungen von Individuen" die Rede ist. ${ }^{63}$ Demgemäß liegt der Kernpunkt von Bennetts Kritik an Locke darin, daß Locke irrtümlicherweise glaubt, daß sie als Gesamtheit aller einzelnen Fragen aufgefaßt werden könne. Diesen Fehler begeht also auch Mackie. ${ }^{64}$

\footnotetext{
${ }^{60}$. Dies ist eine andere wichtige Explikation der direkt realistischen Ansicht.

${ }^{61}$. Bennett, Locke, Berkeley, Hume, S. 67-8.

${ }^{62}$. Ich will hier die Frage nicht entscheiden, ob diese Kritik an Locke richtig ist.

${ }^{63}$. Damit ist selbstverständlich nicht gemeint, daß in der Repräsentationstheorie kaum von Vorstellungen von Farbe usw. die Rede ist.

${ }^{64}$. Daraus ergibt sich, daß Williams denselben Fehler begangen hat. Er macht nämlich keinen Unterschied zwischen den beiden kausalen Fragen.
} 
Gibt es dann irgendeine Möglichkeit, die en bloc gestellte Frage zu verstehen? Descartes hat eine solche Möglichkeit vorgestellt. Sie besteht, wie wir im ersten Kapitel gesehen haben, darin, die Frage mit Rekurs auf Traumerfahrung zu verstehen.

\section{Fazit}

Die bisherige Betrachtung zeigt, daß man weder mit Rekurs auf den Begriff des Wissens noch mit Rekurs auf die Repräsentationstheorie die Motivation ans Licht bringen kann, die Descartes zu dem Problem des Skeptizismus geführt hat. Demnach müssen wir die Repräsentationstheorie von dem Problem des Skeptizismus trennen. Die Motivation muß also an anderer Stelle liegen. Andererseits haben wir Descartes' Gedanken in den Regulae noch nicht ausreichend betrachtet. Was wir bisher betrachtet haben, bezieht sich nur auf seine neue Konzeptualisierung der physikalischen Gegenstände. Es bleibt noch die Frage offen, wie man nach Descartes in naturwissenschaftlichen Untersuchungen verfahren soll. Darum wird im nächsten Kapitel gehen. 
III. Die Motivationsfrage von den Regulae bis zu den späteren Werken Descartes'

Erinnern wir uns daran, daß wir im letzten Kapitel Descartes' Position in den Regulae dahingehend interpretiert haben, daß es möglich ist, sichere Naturwissenschaften aufzubauen. Wenn nämlich Descartes einfach nur der Überzeugung wäre, daß wir die Fähigkeit haben, Erkenntnis von kontingenten Wahrheiten zu erwerben, so wäre diese Überzeugung kaum der Rede wert. Danach haben wir uns zuerst der Frage nach der Methode zugewandt, wobei diese als die Frage neu formuliert wurde, wie man verfahren muß, um sichere Naturwissenschaften aufzubauen. Descartes' Unterscheidung von primären und sekundären Qualitäten haben wir dementsprechend im Rahmen dieses Projektes betrachtet und als den Versuch interpretiert, eine konzeptuelle Bedingung der Möglichkeit dafür zu erfüllen, daß Beweisen in den Naturwissenschaften derselbe Status zukommt wie in der Mathematik. Dabei habe ich in Auseinandersetzung mit Williams und Mackie gezeigt, daß man darin keinen Ansatz für die Erklärung der Motivation finden kann, die Descartes zu dem Problem des Skeptizismus geführt hat. Deshalb habe ich vorgeschlagen, den Rest der Regulae hinsichtlich der ersten Frage zu betrachten, um zu sehen, ob wir dort einen Ansatz für eine mögliche Erklärung jener Motivation finden können. Danach werden wir Descartes' Entwicklung von den Regulae bis zu seinen späteren Werken verfolgen, um eine Antwort auf die Motivationsfrage zu geben.

\section{I. Die Frage nach der Methode der naturwissenschaftlichen Untersuchung in den Regulae}

Bevor ich auf die Frage eingehe, wie man nach Descartes verfahren muß, um sichere Naturwissenschaften aufzubauen, will ich hier zwei Überlegungen vorausschicken. Die eine Überlegung bezieht sich auf Descartes' Überzeugung von der Möglichkeit, sichere Naturwissenschaften aufzubauen, und die andere auf das Verhältnis zwischen der bona mens und dem ingenium. Diese Überlegungen werden dazu beitragen, die Frage nach der Methode der naturwissenschaftlichen Untersuchung von einem neutralen Standpunkt aus zu betrachten.

\section{I. 1. Ein Vorbehalt}


Sollte Descartes' Überzeugung die sein, daß es möglich ist, sichere Naturwissenschaften aufzubauen? Was diese Frage betrifft, gibt es einige Interpreten, die behaupten, daß dem so sei. Was soll man aber unter "sicheren Naturwissenschaften" verstehen? Jene Interpreten antworten auf diese Frage, daß Descartes hier Euklids Geometrie als Vorbild vor Augen habe, und behaupten weiter, daß der Anlaß dazu in nichts anderem liege, als daß er durch Arithmetik und Geometrie sehr stark beeindruckt gewesen sei. In diese Richtung scheint Buchdahl zu gehen, wenn er bemerkt: "It was clearly very tempting to seek the foundations and the basic statements of science among propositions possessing a priori strength - a temptation to which not a few philosophers and quite a number of scientists yielded, and still yield."'

Diese Auffassung kann in der Tat sehr überzeugend erscheinen, wenn man Folgendes berücksichtigt.

Erstens: Obwohl Descartes Arithmetik und Geometrie als einzig sichere Wissenschaften seiner Zeit betrachtet hat, scheint er dennoch nicht zu glauben, daß sie die einzigen Wissenschaften sind, die sicher sein können. Er sagt, daß er nicht in dieser Weise mißverstanden werden dürfe:

"Nunmehr darf man aus alledem vollends schließen, nicht zwar, daß allein Arithmetik und Geometrie gelernt werden dürfen, sondern nur, daß, wer den richtigen Weg zur Wahrheit sucht, mit keinem Gegenstand umgehen darf, über den er nicht eine den arithmetischen oder geometrischen Beweisen gleiche Gewißheit gewinnen kann." (Gäber, S. 13) ${ }^{2}$

Zweitens sagt Descartes an einigen Stellen unmißverständlich, ${ }^{3}$ daß er seine Methoden aus der Geometrie und Arithmetik entliehen habe. Dies könnte dafür sprechen, daß er die Geometrie zum Vorbild für die Naturwissenschaften nimmt.

Schließlich kann die Unterscheidung von primären und sekundären Qualitäten als Versuch verstanden werden, physikalische Gegenstände nach dem Modell der Geometrie zu konzeptualisieren.

Falls diese Auffassung zutrifft, muß Descartes mit "sicheren Naturwissenschaften" solche Wissenschaften meinen, in denen alle Naturphänomene aus einer bestimmten Menge von Postulaten und Axiomen mittels deduktiver Verfahren abzuleiten sind. "Descartes portrays philosophical knowledge as a deductive system in which all claims to knowledge arise through small, certain steps from self-evident beginnings", ${ }^{4}$ faßt Hatfield zusammen.

\footnotetext{
1. Buchdahl, Metaphysics and the Philosophy of Science, S. 24.

2. "Jam vero ex his omnibus est concludendum, non quidem solas Arithmeticam \& Geometriam esse addiscendas, sed tantummodo rectum veritatis iter quaerentes circa nullum objectum debere occupari, de quo non possint habere certitudinem Arithmeticis \& Geometricis demonstrationibus aequalem." (AT X, S. 366)

3. Am deutlichsten in De Methodo AT VI, S. 550.

${ }^{4}$. Hatfield, Science, Certainty, and Descartes in PSA 1988, S. 251. Siehe auch S. 250 und 252. Mit "philosophical knowledge" ist gemeint "the explanations of natural phenomena" (vgl. S. 255). Und mit "selfevident beginnings" sind "basic principles" gemeint (ebd.)
} 
Wie überzeugend diese Auffassung auch sein mag, so möchte ich hier dennoch vorsichtig sein und vorschlagen, die Frage, worin Descartes' Überzeugung besteht, offen zu lassen, und uns nur auf die Frage zu konzentrieren, welche Methode Descartes für naturwissenschaftliche Untersuchungen für angemessen hält und welchen Status er der naturwissenschaftlichen Erkenntnis zuspricht. Es gibt dafür folgende zwei Gründe.

Der eine Grund ist dieser: Wenn Buchdahl Recht hat, ist wichtig zu sehen, daß sie nicht nur Descartes und andere Philosophen, sondern auch uns als Interpreten trifft. Wir haben nämlich gesehen, wie vorbehaltlos wir seine Überzeugung neu formuliert haben als die, daß es möglich ist, sichere Naturwissenschaften aufzubauen.

Der andere Grund ist dieser: Wenn wir großen Wert darauf legen, daß Descartes die Mathematik hoch einschätzt, und daraus die Konsequenz ziehen, daß er davon überzeugt ist, $\mathrm{da}$ es möglich ist, sichere Naturwissenschaften nach dem Modell der Mathematik aufzubauen, müssen wir auch berücksichtigen, daß er sich bewußt war, daß es einen Unterschied zwischen beiden Wissenschaften gibt, obwohl dies bei ihm nicht immer einen klaren Ausdruck finden konnte. Er bemerkt nämlich an vielen Stellen, daß die Mathematik sehr leicht und sogar nichts anderes als ein Übungs- und Vorbereitungsmittel für andere Wissenschaften (Naturwissenschaften) ist. ${ }^{5}$ Worauf er eigentlich damit hinaus wollte, kann erst durch eine Betrachtung seiner Vorstellungen zum Verfahren naturwissenschaftlicher Untersuchungen ans Licht gebracht werden.

\section{I. 2. Die bona mens und das ingenium}

Es ist bekannt, daß Descartes die Regulae nicht vollendet hat. Wie wir am Ende der zwölften Regel erfahren, hatte er eigentlich den Plan, 36 Regeln anzuführen. Die ersten zwölf Regeln, die wir bisher betrachtet haben, beziehen sich hauptsächlich auf Erkenntnis von selbstevidenten oder ähnlich einleuchtenden Aussagen und auf Aussagen, die daraus erkannt werden können. In den darauf folgenden zwölf Regeln geht es darum zu zeigen, wie man das ingenium anwenden kann oder soll, um Probleme in der Mathematik zu lösen, und in den letzten zwölf Regeln, die leider nicht geschrieben worden sind, sollte es eigentlich darum gehen zu zeigen, wie man das ingenium anwenden muß, um Probleme in den Naturwissenschaften zu lösen. Diesem Plan liegt der Gedanke zugrunde, daß man sowohl für naturwissenschaftliche Untersuchungen als auch für mathematische Untersuchungen auf die sensus und die imaginatio angewiesen ist. Obwohl die bona mens einzig und allein die Fähigkeit ist, Erkenntnis zu erwer-

\footnotetext{
${ }^{5}$. Siehe Brief an Mersenne vom 27 Juli 1638.
} 
ben, ${ }^{6}$ heißt dies nicht, daß andere körperliche Instanzen ohne Bedeutung sind. Sie sind genauso wie die bona mens eine wichtige Gabe, die für die Erkenntnis der entsprechenden Gegenstände notwendig ist. Dies ist eine wichtige Grundposition von Descartes, an der er in seinen späteren Werken prinzipiell weiter festhält.

In seinem Aufsatz "Ingenium, Memory Art, and the Unity of Imaginative Knowing in the Early Descartes"17 vertritt Sepper die interessante These, daß die in den Regulae exponierte Position eine Übergangsstation zwischen Descartes' früherem Werk (gemeint ist das Compendium musicae) und seinen späteren Werken sei. Sepper beruft sich auf den Titel der Regulae, nämlich auf "Regulae ad directionem ingenii", "a set of rules for the direction of imagination" (S. 147) oder "the embodied power that treats of imagines" (S. 154). So spielt in den Regulae die imaginatio bei der kognitiven Tätigkeit eine positive und zentrale Rolle. Sepper findet darin eine Gemeinsamkeit zwischen den Regulae und dem Compendium musicae. Trotzdem gibt es seiner Meinung nach in den Regulae einen wichtigen Punkt, der Descartes' Position in den Regulae von der im Compendium musicae unterscheidet. Es besteht darin, daß in den Regulae die vis cognoscens allein der bona mens zugeschrieben wird, wobei die Möglichkeit besteht, daß sie allein tätig ist. Dies bildet eine wichtige Gemeinsamkeit zwischen den Regulae und Descartes' späteren Werken. Trotzdem gibt es nach Sepper einen wesentlichen Unterschied zwischen ihnen, und er besteht darin, daß, während die bona mens in den späteren Werken die zentrale Rolle in allen kognitiven Tätigkeiten übernimmt, die imaginatio immer mehr ihre Rolle verliert.

Was diese These von Sepper problematisch macht, ist, daß er diese Veränderung (besonders zwischen den Regulae und den Meditationes) nicht einfach chronologisch darstellt, sondern als ein Zeichen für eine Positionsänderung interpretiert. Er zieht nämlich daraus diese Konsequenz: "Imagination, after all, is unreliable and even deceptive" (S. 142). Diese Schlußfolgerung ist aber falsch und beruht auf einem Mißverständnis. Anders als er glaubt, beruht Descartes' Distanzierung von der imaginatio in den Meditationes nicht auf einer Positionsänderung, die zur Folge hat, der imaginatio ihre Aufgabe bei der kognitiven Tätigkeit abzustreiten, sondern bloß auf der Verschiedenheit der Themen in den Meditationes und in den Regulae. Es geht nämlich in den Regulae um die Methodenlehre für die Erweiterung der Erkenntnis in der Mathematik und den Naturwissenschaften. Und dabei ist man, wie gesagt, nach Descartes auf die imaginatio, oder besser gesagt, auf das ingenium angewiesen. Dies

\footnotetext{
${ }^{6}$. Obwohl Descartes in der zwölften Regel (AT X, S. 422-3) das Fällen eines Urteils zwar thematisiert, aber nicht so ausführt wie in der vierten Meditation, wo er Urteilen auf die Kooperation von Willen und Verstand zurückführt, ist doch die Idee, daß die bona mens im Prinzip einzig und allein die Fähigkeit ist, Erkenntnis zu erwerben, eine andere wichtige Grundposition von ihm, an der er auch in seinen späteren Werken weiter festhält.

${ }^{7}$. In Essays on the Philosophy and Science of René Descartes
} 
läßt von selbst verstehen, daß die imaginatio, besser gesagt, das ingenium, das zentrale Thema bildet. Aber dies kann und darf in den Meditationes nicht der Fall sein, da das Thema in den Meditationes ein metaphysisches ist. Wenn es um metaphysische Themen geht, ist Descartes' Position die, daß die bona mens allein tätig sein muß. In diesem Fall ist die Anwendung der körperlichen Fähigkeiten nicht nur nicht hilfreich, sondern eher hinderlich. Wenn Descartes an vielen Stellen betont, daß die Einführung der ersten Meditation notwendig gewesen sei, um uns von sinnlichen Vermögen abzuwenden, liegt der Grund dafür nicht darin, daß sie als solche unnütz oder trügerisch seien, sondern darin, daß sie für metaphysische Überlegungen nicht geeignet sind. ${ }^{8}$ Da Sepper diesen wichtigen Punkt übersehen hat, ist verständlich, daß es ihm unverständlich erscheint, daß Descartes nach wie vor den Meditationes betont, daß man körperliche Fähigkeiten zur Hilfe nehmen muß, wenn es um Mathematik und Naturwissenschaft geht." "In his scientific work and even in his mature philosophical writings Descartes frequently resorted to images. .......Are such "facts" about imagination in Descartes isolated and aberrant, or do they reveal something deeply ingrained in his thought?" (S. 142).

III. I. 3. Die Methode der naturwissenschaftlichen Untersuchung in den Regulae

Gehen wir nun darauf ein, welches Verfahren Descartes in den Regulae im Prinzip als angemessen für naturwissenschaftliche Untersuchungen erachtet und welchen Status er der naturwissenschaftlichen Erkenntnis zuspricht. Obwohl, wie gesagt, die Regulae nicht vollendet worden sind, gibt es dennoch einige Stellen, die ausreichend sind, um diese Fragen zu beantworten. Ich meine folgende Stellen:

"So verfahren alle Astrologen, die in Unkenntnis der Natur des Himmels, ja sogar ohne vollkommene Beobachtung der Himmelsbewegungen hoffen, deren Wirkungen angeben zu können,....,so auch jene Philosophen, die die Erfahrung mißachten und dann glauben, daß die Wahrheit aus ihrem eigenen Gehirne entspringe, wie Minerva aus dem des Jupiter." (Gäber, S. $29)^{10}$

Kurz zusammengefaßt:

(a) Man muß genügende Beobachtungen von Naturphänomenen machen, bevor man sie zu erklären versucht.

\footnotetext{
${ }^{8}$. Das beste Beispiel dafür kann man in der zweiten Meditation finden, in der Descartes es für hinfällig hält, mit Hilfe der imaginatio auf die Frage zu antworten, was ich bin.

${ }^{9}$. Siehe Brief an Mersenne vom 13. November 1639 und Brief an Elisabeth vom 28. Juni 1643.

${ }^{10}$. "Ita faciunt omnes Astrologi, qui non cognita coelorum natura, sed ne quidem motibus perfecte observatis, sperant se illorum effectus posse designare....Ita etiam Philosophi illi, qui neglectis experimentis veritatem ex proprio cerebro, quasi Jovis Minervam, orituram putant." (AT X, S. 380)
} 
Ein Beispiel dafür wäre folgendes:

"Wer aber bedenkt, daß am Magneten nichts erkannt werden kann, was nicht aus gewissen einfachen und an sich selbst bekannten Naturen besteht, der ist nicht unschlüssig, was er tun soll, sammelt erstens sorgfältig alle Erfahrungen, deren er über diesen Stein habhaft werden kann, und versucht dann zweitens daraus zu deduzieren, von welcher Beschaffenheit diejenige Vereinigung von einfachen Naturen ist, die zur Erzeugung der Effekte, die ihm die Erfahrung am Magneten gezeigt hat, notwendig ist. Hat er dies einmal gefunden, so kann er kühn behaupten, er habe die wahre Natur des Magneten durchschaut, soweit sie vom Menschen und aufgrund der gegebenen Experimente entdeckt werden konnte." (Gäber, S. 101; Hervorhebung d. Verf. $)^{11}$

\section{Mit anderen Worten:}

(b) Man muß davon ausgehen, daß es nichts an Magneten gibt, das nicht aus gewissen einfachen und an sich selbst bekannten Naturen besteht;

(c) Man muß zuerst genügende Beobachtungen von Magneten machen und dann versuchen, eine Hypothese über die Natur von Magneten aufzustellen, indem man jene Phänomene aus der Hypothese deduktiv abzuleiten versucht;

(d) Wenn die Natur der Magneten auf diese Weise erforscht wird, kann man sagen, daß man die wahre Natur der Magneten erkannt hat, soweit sie von Menschen und aufgrund der gegebenen Beobachtungen entdeckt werden kann.

Descartes betont zuerst in (a) zu Recht, daß man mit Beobachtung anfangen und ausreichende Daten sammeln muß. Aber allein Beobachtung und Sammeln von Daten können nicht zur Erklärung der Phänomene führen, es sei denn, daß man eine gewisse Einsicht in die Natur des Problems hat, mit anderen Worten in die Bedingungen, unter denen das Problem gelöst werden kann. ${ }^{12}$ Wir müssen dann eine Hypothese über die aktuelle Figur und die Bewegungen von gewissen elementaren Partikeln angesichts unserer Beobachtungen von magnetischen Phänomenen aufstellen, wobei es möglich sein muß, die Phänomene aus der Hypothese abzuleiten. Dieses Verfahren ist also nichts anderes als das sogenannte "hypothetisch-deduktive". Was dabei entscheidend ist, ist die Forderung, daß die Hypothese nur in Begriffen der Kinematik ausgedrückt werden soll, wie man in (b) sehen kann. Descartes' Kritik an Astrologen, Physikern und Philosophen soll auch in diesem Zusammenhang verstanden werden, nämlich als ein Kontrast zwischen dem Verfahren der deduktiven Theoretisierung

\footnotetext{
11. "Sed qui cogitat, nihil in magnete posse cognosci, quod non constet ex simplicibus quibusdam naturis $\&$ per se notis, non incertus quid agendum sit, primo diligenter colligit illa omnia quae de hoc lapide habere potest experimenta, ex quibus deinde deducere conatur qualis necessaria sit naturarum simplicium mixtura ad omnes illos, quos in magnete expertus est, effectus producendos; qua semel inventa, audacter potest asserere, se veram percepisse magnetis naturam, quantum ab homine \& ex datis experimentis potuit inveniri." (AT X, S. 427; Hervorhebung d. Verf.)

12. Dies bringt Descartes in der achten Regel der Regulae (AT X, S. 393-4) auf den Punkt am Beispiel der Frage, wie man verfahren muß, um die Brechungslehre zu entdecken. Dafür ist die Einsicht entscheidend, daß man sie weder durch Beobachtung noch durch ein rein mathematisches Postulat entdecken kann.
} 
aufgrund von ausreichenden Daten einerseits und dem auf unzureichende Beobachtung gestützten nicht-deduktiven Verfahren andererseits.

Bevor ich weiter darauf eingehe, welchen Status Descartes naturwissenschaftlicher Erkenntnis zuschreibt, werde ich mich hier mit Hatfield auseinandersetzen, um einige Mißverständnisse bezüglich Descartes' Grundkonzepts der Naturwissenschaften auszuräumen. Zu diesem Zweck betrachten wir zuerst folgende Stelle:

"Damit wir uns aber auch der Einbildungskraft als Hilfsmittels bedienen, ist zu beachten, daß man, sooft etwas Unbekanntes aus etwas schon vorher Erkanntem deduziert wird, darum noch keine neue Gattung des Seins entdeckt.....Wenn in Magneten etwa irgendeine Gattung des Seins steckt und unser Verstand bisher keine erkannt hat, die ihr ähnlich wäre, so dürfen wir nicht hoffen, sie jemals durch schlußfolgerndes Denken zu entdecken, sondern dazu müßten wir mit einem neuen Sinn oder mit göttlichem Geiste ausgerüstet sein. Alles aber, was hier von der menschlichen Erkenntniskraft geleistet werden kann, werden wir für erreicht halten, wenn wir diejenige Vereinigung schon bekannter Dinge oder Naturen deutlich erfassen, die eben die Wirkungen hervorbringt, wie sie am Magneten in Erscheinung treten." (Gäber, S. $119)^{13}$

Descartes sagt damit also Folgendes:

(e) Die imaginatio als Hilfsmittel zu benutzen, heißt nicht, eine neue Gattung des Seins entdecken zu wollen;

(f) Wenn die Natur der Magneten aus etwas besteht, das über unsere Fähigkeiten der Erkenntnis hinaus geht, ist es unmöglich, sie zu erkennen;

(f') Dafür bräuchten wir nämlich andere Erkenntnisfähigkeiten;

(g) Wenn etwas herausgefunden wird, das aus schon bekannten Dingen besteht und aus dem die magnetischen Phänomene kausal erklärt werden können, ist dies als Natur der Magneten zu betrachten.

Descartes sagt in (e), daß seine Forderung, von der imaginatio Gebrauch zu machen, nicht so mißverstanden werden dürfe, als ob er damit meine, daß man mit Hilfe der imaginatio irgend etwas als Ursache zu finden versuchen solle, das über unsere Erkenntnisfähigkeit hinausgeht. $\mathrm{Zu}$ wieviel verpflichtet Descartes (f)? Wird damit von ihm ernsthaft die Möglichkeit erwogen, daß die Natur des Magneten etwas ist, das über unsere Erkenntnisfähigkeit hinaus geht? Hatfield geht in diese Richtung und behauptet, daß dies sich aus dem Charakter eines wichtigen Projektes der Regulae verstehe, nämlich des Projektes, die Restriktionsfrage zu beantworten, wie weit der Umfang unserer Erkenntnis ist: "He (Descartes; d. Verf.) left open the possibility that nature contains powers or agencies which lie beyond human

\footnotetext{
${ }^{13}$. "Ut autem etiam imaginationis utamur adjumento, notandum est, quoties unum quid ignotum ex aliquo alio jam ante cognito deducitur, non idcirco novum aliquod genus entis inveniri, .. si in magnete aliquod sit genus entis, cui nullum simile intellectus noster hactenus perceperit, non sperandum est nos illud unquam ratiocinando cognituros, sed vel novo aliquo sensu instructos esse oporteret, vel mente divina; quidquid autem hac in re ab humano ingenio praestari potest, nos adeptos esse credemus, si illam jam notorum entium sive naturarum mixturam, quae eosdem, qui in magnete apparent, effectus producat, distinctissime percipiamus." (AT X, S. 438-9)
} 
comprehension. The fact that he should leave open this possibility - a possibility he would later foreclose - may be understood by considering the aim of the Rules. That work took as its object of investigation the conditions for application of the "knowing power", rather than the natures of the things to be known". ${ }^{14}$ Wenn der Inhalt des Vordersatzes von (f) demnach als eine reelle Möglichkeit betrachtet wird, was soll dann unter der Suche nach der Natur des Magneten im Sinne von (g) verstanden werden? Hatfield versteht die Suche nach der Natur des Magneten im Sinne von (g) als eine sinnvolle Alternative zur Suche nach der Natur im Sinne des Vordersatzes von (f), wobei er den Unterschied zwischen beidem darin sieht, daß letztere darauf abzielt, Phänomene aus Ursachen zu erklären, während erstere nur darauf abzielt, die Phänomene zu retten. Vor allem glaubt Hatfield, daß Descartes dieser Meinung sei. Nun scheint (d) auf den ersten Blick dafür zu sprechen. Obwohl Descartes im Hauptsatz von "vera natura" spricht, schränkt er sie dennoch sofort durch den darauf folgenden Nebensatz ein, daß sie nichts anderes als "vera natura" für die Menschen sein könne. Trotzdem finde ich Hatfields Interpretation irrefuihrend, ${ }^{15}$ und sie wirft vor allem zwei schwerwiegende Probleme auf.

Das erste Problem ist folgendes: Nehmen wir an, daß die Natur des Magneten im Sinne von (g) in der Tat eine echte Alternative zu der Natur im Sinne des Vordersatzes von (f) ist: nämlich im Sinne eines Operationalismus, demgemäß das Kriterium für die Wahrheit einer physikalischen Theorie lediglich in der Frage besteht, welche Forschungsmethode am ökonomischsten die Phänomene vorhersagt. Wenn Descartes dieser Meinung gewesen wäre, seine Position dazu klar und seine Bereitschaft deutlich wäre, sich mit (g) zufrieden zu geben, wäre seine Konfrontation mit dem Problem des Skeptizismus in seinen späteren Werken unerklärlich. Dafür ist nämlich fundamental, daß er einen Realismus und eine Konzeption von der Welt vertritt, die eine durch eine realistische Naturwissenschaft spezifizierte Konzeption von physikalischen Gegenständen umfaßt, wie wir später sehen werden. ${ }^{16}$

Das andere Problem, das mit dem ersten eng verbunden ist, ist dieses: Wenn der Inhalt des Vordersatzes von (f) als eine echte Möglichkeit betrachtet wird, kann die Suche nach der Natur im Sinne von (g), anders als Hatfield glaubt, nicht als eine Alternative dazu betrachtet werden. Wie in unserer Auseinandersetzung mit Williams und Mackie gezeigt worden ist, enthält der Inhalt des Vordersatzes von (f) die Implikation des universalen Skeptizismus. In

\footnotetext{
${ }^{14}$. Hatfield, Science, S. 252-3.

15. Sie führt Hatfield in der Tat am Ende sogar zu der fatalen Konsequenz, daß er Descartes eine absurde Position zuschreibt: "Descartes was quite willing to trade scope for power in the Rules; he was willing to limit scope of the knowledge attained, in oder to be assured what he did attain possesed certainty.", Hatfield, Science, S. 253.

${ }^{16}$. In dieser Hinsicht hat Williams völlig Recht, wenn er sagt: "any view which loses touch with realism in these matters is more deeply opposed to the Cartesian outlook than any which retains the realist connection -even if that latter abondons, as it must, all the characteristic Cartesian beliefs in God, in dualism and in the search for certainty". Williams, Descartes, S. 249.
} 
diesem Fall kann der Operationalismus nicht als Alternative zu der Suche nach der Natur im Sinne des Vordersatzes von (f) verstanden werden.

Abgesehen davon ist es nicht der Fall, daß Descartes den Inhalt des Vordersatzes von (f) als eine echte Möglichkeit betrachtet. Ohne Zweifel ist es ein wichtiges Projekt der Regulae, die Restriktionsfrage zu beantworten, wie weit der Umfang der Erkenntnis ist. Dennoch ist es ein Fehler von Hatfield, daß er es als ein Projekt versteht, das von einem neutralen Standpunkt aus unternommen worden ist: Descartes möchte nämlich wissen, was die Menschen wissen können und was nicht. Wie unsere bisherige Betrachtung der Regulae deutlich zeigt, ist die Restriktionsfrage eher eine, die ihrerseits von einer festen Überzeugung aus und anderen gegenüber mit einem kritischen Charakter gestellt worden ist: Warum haben wir bis jetzt darin versagt, die Naturwissenschaften aufzubauen, obwohl es uns prinzipiell möglich ist? Wie man in der sechsten Regel und an vielen anderen Stellen in den Regulae erfahren kann, ist Descartes' Vorstellung von den Naturwissenschaften zu eng damit verbunden, Naturphänomene aus Ursachen zu erklären, als daß er die Suche nach der Natur im Sinne von (g) als eine echte Alternative zu der Suche nach der Natur im Sinne des Vordersatzes von (f) betrachten und sich damit zufrieden geben könnte. ${ }^{17}$ Dazu ist noch zu bemerken, daß die richtige Lesart der beiden Einschränkungen in (d) ("von Menschen und aufgrund der gegebenen Beobachtungen") die ist, die zweite Einschränkung als Explikation der ersten aufzufassen, in dem Sinne, daß uns als Menschen nur begrenzte Beobachtungen zur Verfügung stehen.

Wenn dem so ist, kann man fragen, worauf Descartes denn mit (f) und (g) hinaus wollte. Die richtige Antwort auf diese Frage ist die, daß er Gilbert kritisieren wollte, der sich, um die Anziehungskraft des Magneten zu erklären, auf die Existenz der sympathetischen Relation und der beseelten Form berufen hat, was Descartes' Meinung nach völlig unverständlich und dunkel ist. ${ }^{18}$

Gehen wir nun $\mathrm{zu}$ der Frage über, welchen Status Descartes in den Regulae der naturwissenschaftlichen Erkenntnis zuschreibt. Wenn wir z.B. anhand einer bestimmten Menge von Daten mittels des hypothetisch-deduktiven Verfahrens in Begriffen der Kinematik eine Hypothese über die innere Struktur eines Magneten aufgestellt haben, welchen Status wird Descartes dieser Hypothese dann zusprechen? Seine Antwort auf diese Frage können wir in Folgendem vermuten:

\footnotetext{
${ }^{17}$. Wie wir gesagt haben, zielt er mit der Unterscheidung von primären und sekundären Qualitäten nicht einfach darauf ab, Naturphänomene zu retten, sondern darüber hinaus darauf, zu erklären, wie die physikalischen Gegenstände in Wirklichkeit beschaffen sind.

${ }^{18}$. Vgl. Buchdahl, S. 85 .
} 
"Von den Problemen dagegen werden die einen vollkommen verstanden,..; Die anderen schließlich werden nicht vollkommen verstanden.......Und es ist zu beachten, daß wir unter die Probleme, die vollkommen verstanden werden, nur diejenigen setzen, in denen wir dreierlei deutlich erfassen, nämlich durch welche Zeichen das Gesuchte erkannt werden kann, wenn es unterläuft, was genau genommen dasjenige ist, woraus wir es deduzieren müssen, und wie bewiesen werden muß, daß dies voneinander so abhängt, daß das eine auf keine Weise verändert werden kann, solange das andere unverändert bleibt" (Gäber, S. 103-105) ${ }^{19}$

Hier macht Descartes bezüglich des Status der Probleme einen wichtigen Unterschied zwischen der Mathematik und den Naturwissenschaften. Mit der Bezeichnung "die vollständig verstandenen Probleme" meint er solche, die die folgenden Bedingungen erfüllen:

1) Das Problem ist zu identifizieren;

2) Bekannt sind die Prämissen (aufgrund derer das Problem durch Deduktion gelöst werden kann);

3) $\mathrm{Zu}$ beweisen ist die logische Abhängigkeit zwischen den Prämissen und dem Problem.

Probleme, die diese drei Bedingungen erfuillen, sind Probleme, denen wir in der Mathematik begegnen. Die "unvollständig verstandenen Probleme" sind dagegen solche, denen man in den Naturwissenschaften begegnet, und ihr Unterschied von "vollständig verstandenen Problemen" soll nach Descartes darin liegen, daß sie (2) und (3) nicht erfüllen können. Woran liegt es, daß der naturwissenschaftlichen Erkenntnis nicht derselbe Status wie der mathematischen Erkenntnis zugeschrieben werden kann? Descartes gibt darüber in den Regulae aus dem oben genannten Grund keine Auskunft. ${ }^{20}$ Auf diese Frage werden wir später zurückkommen.

\footnotetext{
19. "Ex quaestionibus autem aliae intelliguntur perfecte, etiamsi illarum solutio ignoretur,..; aliae denique non perfecte intelliguntur.... Notandumque est, inter quaestiones quae perfecte intelliguntur nos illas tantum ponere, in quibus tria distincte percipimus, nempe, quibus signis id quod quaeritur possit cognosci, cum occuret, quid sit praecise, ex quo illud deducere debeamus, et quomodo probandum sit, illa ab invicem ita pendere, ut unum nulla ratione possit mutari, alio immutato;" (AT X. S. 429)

${ }^{20}$. Vgl. AT X, S. 430-431. Diese Stelle muß man sehr vorsichtig lesen. Sonst würde man Descartes eine absurde Position zuschreiben. Damit meine ich folgendes. Descartes vermittelt hier den Eindruck, als wäre er der Meinung, daß unvollständige Probleme problemlos vervollständigt werden könnten, indem man (2) einfach dadurch erfüllt, daß man die "Data" beliebig einschränkt, wobei die Möglichkeit, (3) zu erfüllen, überhaupt nicht in Frage käme. Diese Erklärung ist an sich harmlos. Sie kann aber irreführend sein, wenn man sie wie Hatfield liest, und sie von vornherein in Verbindung mit der Vorstellung bringt, daß Descartes' Ziel darin liegt, sichere Naturwissenschaften nach dem Modell der Mathematik aufzubauen. In diesem Fall müßte Descartes' Intention der Einschränkung der Data so verstanden werden: "he (Descartes; d. Verf.) was willing to limit the scope of the knowledge attained, in order to be assured that what he did attain possessed certainty" (Hatfield, Science, S. 253). Könnte man die Lösung eines naturwissenschaftlichen Problems immer in der Form eines Konditionalsatzes wiedergeben, so wäre die Position Descartes absurd. Noch absurder wäre seine Position, wenn er, wie Hatfield meint, Gewißheit als Selbstzweck betrachtete (Vgl. Hatfield, S, 254). Beides ist aber nicht der Fall. Es ist nur ein Mißverständnis, das, wie gesagt, hauptsächlich darauf beruht, daß man Descartes' Erklärung von vornherein in Verbindung mit jener fraglichen Vorstellung gebracht hat. Zu erklären, warum dies so ist, ist keine schwierige Aufgabe. Es ist sehr wichtig zwei Fragen auseinanderzuhalten. Es ist eine Frage, wie man nach Descartes verfahren muß, um Naturphänomene zu erklären. Es ist eine andere Frage, welchen Status Descartes einer gegebenen Erklärung zuschreibt. Jene Erklärung Descartes' bezieht sich in erster Linie auf die erste Frage, nicht auf die zweite, anders als Hatfield unterstellt. Wenn man sie so versteht,-ohne Bezugnahme auf die zweite Frage-, drückt sie weder mehr noch weniger als das sogenannte hypothetisch-deduktive Verfahren aus. Daß man
} 
in naturwissenschaftlichen Untersuchungen "Data" irgendwie einschränken muß, ist zwar problematisch, aber notwendig. Daß man (3) ohne weiteres als erfüllt annimmt, kann als unberechtigt erscheinen, ist aber an sich harmlos. Die Frage, ob und wieweit diese beiden Punkte in der Tat harmlos sind, hängt völlig davon ab, welchen Status man der daraus folgenden Erklärung zuschreibt. Wenn Descartes, wie Hatfield richtig behauptet, jene Erklärung in der Form eines Konditionalsatzes zum Ausdruck bringt, tut er dies nicht deswe gen, weil er Gewißheit als Selbstzweck um jeden Preis will, sondern eher deswegen, weil er es für unvermeidbar hält, die Gültigkeit jener Erklärung auf die berücksichtigten Data einzuschränken. So erweisen sich die beiden Punkte bei Descartes als harmlos. Auf dieses Thema werden wir später in der Auseinandersetzung mit Buchdahl zurückkommen. 


\section{II. Übergang zu Descartes' Entwicklung von den Regulae bis zu seinen späteren Werken}

Nun sind, wie gesagt, die Regulae nicht vollendet worden. Ein Grund dafür könnte darin liegen, daß Descartes später auf den Gedanken gekommen ist, daß es wenig Sinn hat, nur eine ausführliche Abhandlung über die Methode zu schreiben. In diesem Fall ist es nämlich unvermeidbar, daß sie einen abstrakten und allgemeinen Charakter besitzt, so daß ihre Nützlichkeit schwer zu erweisen wäre. Er scheint somit zur Erkenntnis gekommen zu sein, daß der einzige und beste Weg, seine Methode als richtig zu erweisen, schlechthin darin besteht zu zeigen, daß eine methodengeleitete wissenschaftliche Untersuchung Erfolg hat:

"Denn wie man aus dem ersehen kann, was ich darüber (seine Methode; d. Verf.) sage, besteht sie mehr in Praxis denn in Theorie, und ich nenne die folgenden Abhandlungen Versuche mit dieser Methode (Dioptrik, Meteorologie und Geometrie; d. Verf.), weil ich behaupte, daß die Dinge, die sie enthalten, nicht ohne Methode gefunden werden können, und daß man durch die Versuche erkennen kann, was diese wert ist." (Brief an Mersenne vom März 1637; Baumgart, S. 77). ${ }^{21}$

Einen anderen und wichtigeren Grund nennt Descartes an anderer Stelle, aber in einer metaphorischen Redeweise, die er später sehr häufig verwendet. Nachdem er eingeräumt hat, daß er mit dem Schreiben der Regulae aufgehört habe, sagt er folgendes:

"während ich daran arbeitete, erwarb ich ein wenig mehr Kenntnisse, als ich beim Beginn hatte; und wenn ich mich dem anpassen wollte, war ich gezwungen, einen neuen Plan zu machen, der etwas größer als der erste war, wie etwa jemand, der ein Gebäude als seinen Wohnsitz begonnen hat und währenddem nicht erhoffte Reichtïmer erwarb und dadurch seine Lage derart änderte, daß das begonnene Gebäude viel zu klein für ihn geworden wäre; man würde ihn nicht tadeln, wenn man ihn ein anderes, seinem Vermögen gemäßeres Bauwerk von neuem beginnen sähe." (Brief an Mersenne vom 15. April 1630; Baumgart, S.43 )22

Wenn man Descartes' Erklärung berücksichtigt, die er vor der eben zitierten Stelle gegeben hat, ist man geneigt zu vermuten, daß das "neue Bauwerk " das Werk "Le Monde" sein sollte. In diesem Falle sollte mit "unerhofften Reichtïmern" Descartes' Konzept einer universalen Physik gemeint sein. Abgesehen von der Frage, ob das Wort "unerhoffte Reichtümer" dafür ein geeigneter Ausdruck sein kann, bekommt man aber im Lauf des Briefes den Eindruck, daß

\footnotetext{
${ }^{21}$. "Car comme on peut voir de ce que j'en dis, elle consiste plus en pratique qu'en théorie, et je nomme les traités suivants des Essais de cette Méthode, parce que je prétends que les choses qu'ils contiennent n'ont pu être trouvées sans elle, et qu'on peut connaître par eux ce qu'elle vaut" (AT I, S. 349)

22. "c'est que pendant que j'y travaillais, j'acquérais un peu plus de connaissance que je n'en avais eu en commençant, selon laquelle me voulant accommoder, j'étais contraint de faire un nouveau projet, un peu plus grand que le premier, ainsi que si quelqu'un ayant commencé un bâtiment pour sa demeure, acquérait cependant des richesses qu'il n'aurait pas espérées et changeait de condition, en sorte que son bâtiment commencé fût trop petit pour lui, on ne le blâmerait pas si on lui en voyait recommencer un autre plus convenable à sa fortune."(AT I, 1377-138)
} 
man, anders als man anfangs vielleicht dachte, nicht so einfach sagen kann, daß das, was mit "unerhofften Reichtïmern" gemeint ist, einzig und allein Descartes' Konzept der universalen Physik sei. Dort kommen nämlich auch andere Themen vor, die Descartes zwar in der Zeit der Regulae nicht interessierten, aber danach großes Interesse bei ihm geweckt haben. Vor allem gibt es schon in seinem Brief an P. Gibieuf vom 18. Juli 1629 einen Hinweis auf seinen ersten Entwurf der Meditationes. ${ }^{23}$ Nun bin ich der Meinung, daß die Überlegung, was mit "unerhofften Reichtümern" gemeint sein soll und wie Descartes dazu gekommen ist, uns helfen kann, die Bedeutung der ersten Meditation zu erkennen und einen Ansatz für die Antwort auf die Motivationsfrage zu geben. Demnach werde ich im Folgenden zuerst jene Überlegung durchführen und dann zur Motivationsfrage übergehen.

Bevor wir aber darauf eingehen, ziehen wir aus unseren bisherigen Betrachtungen zusammenfassend folgende Konsequenzen. Erstens versteht Descartes unter Naturwissenschaften den Versuch, Naturphänomene aus Ursachen zu erklären. Zweitens ist er davon fest überzeugt, daß der beste Weg dazu das hypothetisch-deduktive Verfahren sei, wobei die dabei aufgestellten Hypothesen allein in Begriffen der Kinematik formuliert werden sollen. Drittens scheint Descartes der Hypothese oder der daraus entstandenen Erkenntnis nicht denselben Grad an Gewißheit zuzuschreiben, wie der Erkenntnis in der Mathematik. Viertens zeigt diese Betrachtung, daß die von Buchdahl und Hatfield vertretene These fraglich ist, die ich zu Beginn dieses Abschnittes vorgestellt habe. Wenn sie Recht hätten, hätten wir in den Regulae zumindest ein Zeichen dafür finden können müssen, daß Descartes mit voller Absicht den Versuch macht, Postulate und Axiome aufzustellen, aus denen alle Naturphänomene mittels deduktiver Verfahren abzuleiten sind. Aber wie wir gesehen haben, ist davon kaum die Rede, sondern sein Interesse bezieht sich eher auf die Erklärung einzelner Naturphänomene, und das Verfahren, das von ihm dafür als geeignet angesehen wird, ist das hypothetisch-deduktive Verfahren. Das liegt auch nicht daran, daß die letzten zwölf Regeln nicht geschrieben worden sind. Sie sollten nämlich nur, wie wir dem Ende der zwölften Regel entnehmen können, die Regeln enthalten, die zeigen, wie wir das hypothetisch-deduktive Verfahren am besten anwenden sollen. ${ }^{24}$

\footnotetext{
${ }^{23}$. Descartes schreibt im Brief an Mersenne vom März 1637, daß er vor ungefähr acht Jahren einen Anfang der Metaphysik auf lateinisch geschrieben habe, die die vorzubringenden Zweifel enthalte, anders als das vierte Buch von De Methodo.

${ }^{24}$. Wir werden auf diesen Punkt später ausführlich zurückkommen.
} 


\section{III. Neue unerhoffte Reichtümer: Die Bedeutung der ersten Meditation}

Was meint Descartes mit den "neuen unerhofften Reichtümern"? Meint er damit nur "die universale Physik" und "die Metaphysik"? Angenommen, daß dies der Fall ist: wie konnte er dazu kommen? Den Versuch, auf diese Fragen zu antworten, will ich machen, indem ich mich mit Wilson und Hatfield auseinandersetze.

Wie ich in der Einleitung dieses Teils erwähnt habe, geht die leitende Fragestellung dieser Arbeit, nämlich die Frage nach der Motivation, die Descartes zum Problem des Skeptizismus geführt hat, davon aus, daß das Problem des Skeptizismus bei ihm ein ernsthaftes Problem ist und sein Versuch der Widerlegung des Skeptizismus dementsprechend ein wichtiges Ziel der Meditationes ist, sogar das wichtigste. Dabei habe ich auch eine andere Interpretation der ersten Meditation genannt, die den skeptischen Argumenten nur eine rein methodologische Funktion zuschreibt. Dieser Interpretation, die zuerst von Wilson vertreten wurde, und zur Zeit weit verbreitet ist, liegt der Gedanke zugrunde, daß das Problem des Skeptizismus für Descartes keine Bedeutung, oder höchstens eine sehr geringere Bedeutung hat. Aus diesem Grund halte ich es für nötig, mich zuerst mit Wilson und Hatfield auseinanderzusetzen, der auch ein Fürsprecher dieser Interpretation ist. Wenn sie nämlich damit Recht haben, ist es wenig überraschend zu sagen, daß sich die leitende Frage und damit auch die Interpretation der ersten Meditation im ersten Kapitel von Anfang an als hinfällig erweist. Außerdem wird diese Auseinandersetzung uns nicht nur auf die Bedeutung der Beschäftigung mit jener Frage aufmerksam machen, sondern auch eine optimale Ausgangsposition für die leitende Frage schaffen.

$\mathrm{Zu}$ diesem Zweck halten wir uns zuerst folgende Stellen vor Augen, an denen alle neue Themen vorkommen, die man bei Descartes in der Zeit der Regulae noch nicht finden konnte:

"Aber alle Schwierigkeiten der Physik, bezüglich derer ich, wie ich Ihnen berichtet habe, zu einem Entschluß gekommen bin, sind derart verkettet und hängen so stark voneinander $a b$, daß es mir unmöglich sein würde, eine zu erklären, ohne sie alle zusammen zu erläutern; was ich nicht früher und bündiger als in der Abhandlung machen könnte, die ich vorbereite." (Brief an Mersenne vom 15. April 1630; Baumgart, S. 45 $)^{25}$

\footnotetext{
25. "Mais toutes les difficultés de physique touchant lesquelles je vous ai mandé que j'avais pris parti, sont tellement enchaînées, et dépendent si fort les unes des autres, qu'il me serait impossible d'en démontrer une, sans les démontrer toutes ensemble; ce que je ne saurais faire plus tôt ni plus succinctement que dans le traité que je prépare."(AT I, S. 140-141) In dem Brief an Mersenne vom 13. November 1629 schrieb Descartes, daß er sich entschlossen habe, alle Phänomene der Natur und nicht nur einzelne Phänomene zu erklären zu versuchen. Vgl. AT I, S. 70. Diese Abhandlung ist Le Monde.
} 
An dieser Stelle erklärt Descartes seinen Entschluß, sich mit einer universalen Physik zu beschäftigen. ${ }^{26}$

"Was Ihre theologische Frage anbelangt, so scheint sie mir, wenn sie auch die Fähigkeit meines Geistes überschreitet, doch nicht außerhalb meines Berufes zu liegen, da sie nicht an das von der Offenbarung Abhängige rührt, was ich eigentlich Theologie nenne; sondern sie ist viel eher metaphysisch und muß durch die menschliche Vernunft geprüft werden. Nun schätze ich aber, daß alle, denen Gott den Gebrauch dieser Vernunft gegeben, verpflichtet sind, sie hauptsächlich zu dem Versuch zu verwenden, ihn und sich selbst zu erkennen." (Brief an Mersenne vom 15. April 1630; Baumgart, S. 48) ${ }^{27}$

Descartes vertritt hier die folgende These:

(A) Man muß mit der Vernunft versuchen, Gott und sich selbst zu erkennen.

Descartes sagt außerdem an der folgenden Stelle:

"Damit jedenfalls habe ich versucht, meine Studien zu beginnen; und ich sage Ihnen, daß ich niemals die Grundlagen der Physik zu finden verstanden haben würde, wenn ich sie nicht auf diesem Wege gesucht hätte....wenigstens glaube ich, gefunden $\mathrm{zu}$ haben, wie man die metaphysischen Wahrheiten beweisen kann, und zwar auf eine Art, die augenscheinlicher als die geometrischen Beweise ist; ich sage dies gemäß meinem Urteil, denn ich weiß nicht, ob ich die anderen davon werde überzeugen können. Die in diesem Lande verbrachten ersten neun Monate habe ich an nichts anderem gearbeitet, und ich glaube, Sie haben mich schon früher davon sprechen hören, daß ich den Plan gefaßt hatte, etwas schriftlich niederzulegen; aber ich halte es nicht für ratsam, dieses zu tun, ehe ich nicht zuerst gesehen habe, wie die Physik aufgenommen werden wird......... Ich werde es aber nicht unterlassen, in meiner Physik mehrere metaphysische Fragen zu berühren, und besonders folgende: $\mathrm{Da} ß$ die mathematischen Wahrheiten, die Sie ewige nennen, von Gott gestiftet worden sind und gänzlich von ihm abhängen, eben so wie alles übrige Geschaffene. .. Fürchten Sie bitte nicht, überall zu versichern und zu veröffentlichen, daß Gott diese Gesetze in der Natur eingerichtet hat, so wie ein König Gesetze in seinem Königreich stiftet." (Brief an Mersenne vom 15. April 1630; Baumgart, S. 48-49) ${ }^{28}$

\footnotetext{
${ }^{26}$. Buchdahl findet eine mögliche Erklärung dafür in der zweiten der vier Regeln von De Methodo: "There is a fundamental lesson implied in this procedure, a lesson which still has relevance for contemporary discussions. Logicians often say that hypotheses have to be 'guessed' in the light of the data. Now whilst there is some truth in this, it is usually added that the guessing is 'inspired' and 'informed'. It is carried out in the light of a complicated network of background knowledge ...This is the reverse of the usual account of scientific method, according to which we pass from the data to hypothesis and then only seek for an explanatory mechanism which might account for the hypothesis. What is true is that the physical theory injected into the situation is at this initial stage only approximate; more precise and accurate accounts will have to awaite adequate formulation of the laws for which we are still searching. In short, the procedure is one which employs the method of 'leap-frogging'. Buchdahl, S, 139. und AT X, S. 435-6.

27. "Pour votre question de théologie, encore qu'elle passe la capacité de mon esprit, elle ne me semble pas toutefois hors de ma profession, parce qu'elle ne touche point à ce qui dépend de la révélation, ce que je nomme proprement théologie; mais elle est plutôt métaphysique et se doit examiner par la raison humanine. Or j'estime que tous ceux à qui Dieu a donné l'usage de cette raison, sont obligés de l'employer principalement pour tâcher à le connaître, et à se connaître eux-mêmes."(AT I, 143-144)

${ }^{28}$. C'est par là que j'ai tâché de commencer mes études; et je vous dirai que je n'eusse jamais su trouver les fondements de la physique, si je ne les eusse cherchés par cette voie.....; au moins, pensé-je avoir trouvé comment on peut démontrer les vérités métaphysiques, d'une façon qui est plus évident que les
} 
Diesen Absatz fasse ich folgendermaßen auf:

(B) 1) Ich habe begonnen, rationale Theologie sowie mich selbst zu studieren;

2) Dadurch habe ich die Grundlagen der Physik gefunden;

3) Dadurch habe ich auch erkannt, wie die metaphysischen Wahrheiten augenscheinlicher als die geometrischen Wahrheiten bewiesen werden können;

4) Ich werde meine Metaphysik nicht in die Öffentlichkeit bringen, bevor ich erfahre, wie meine Physik aufgenommen wird;

5) Es ist in der Behandlung der Physik unvermeidbar, die Metaphysik mit zu behandeln, da Gott die Gesetze der Natur geschaffen hat.

Im Brief an Mersenne vom 6. Mai 1630 radikalisiert Descartes (B 5), indem er ewige Wahrheiten von Gottes Willen abhängig macht. Er sagt, daß

"sie (ewige Wahrheiten; d. Verf.) nur wahr oder möglich sind, weil Gott sie als wahr oder möglich erkennt, daß sie dagegen von Gott nicht als insofern wahr erkannt sind, als sie etwa unabhängig von ihm wahr wären....

Er (Gott) deswegen, weil er etwas will, dieses auch erkennt, und daß allein deswegen etwas wahr ist."(Baumgart, S. 52)

Kurz:

(C) Gott erkennt Wahrheiten einfach dadurch, daß er will, daß sie Wahrheiten sind:

Ewige Wahrheiten (bzw. auch alle anderen Wahrheiten) sind demnach nur insofern wahr (bzw. möglich), als Gott es so wollte.

Wenn man der ersten Meditation nur eine rein methodologische Funktion zuschreibt, treten zunächst zwei Fragen auf, nämlich die, worauf sie abzielt und wozu sie dienen soll. Nach der Antwort von Wilson und Hatfield zielt sie darauf ab, die Leser von sinnlichen Vorurteilen fernzuhalten. Dies soll nach Wilson dazu dienen, die Leser besser dazu in die Lage zu versetzen, sich mit den in den Meditationes enthaltenen Grundlagen der neuen Physik vertraut zu machen. Hatfields Antwort auf die zweite Frage geht darüber hinaus: Die erste Meditation dient dazu, die Leser besser dazu in die Lage zu versetzen, sich mit der neuen Metaphysik Descartes' vertraut zu machen. In diese Richtung scheint Descartes auf den ersten Blick zu gehen, wenn er im Brief an Mersenne vom März 1637 die Notwendigkeit der Einführung der

démonstrations de géométrie; je dis ceci selon mon jugement, car je ne sais pas si je le pourrai persuader aux autres. Les neuf premiers mois que j'ai été en ce pays, je n'ai travaillé à autre chose, et je crois que vous m'aviez déjà ou $\in$ parler auparavant que j'avais fait dessein d'en mettre quelque chose par écrit; mais je ne juge pas à propos de le faire, que je n'aie vu premièrement comment la physique sera re $\div$ ue......Mais je ne laisserai pas de toucher en ma physique plusieurs questions métaphysiques, et particulièrement celle-ci: Que les vérités mathématiques, lesquelles vous nommez éternelles, ont été établies de Dieu et en dépendent entièrement, aussi bien que tout le reste des créatures........Ne craignez point, je vous prie, d'assurer et de publier partout, que c'est Dieu qui a établi ces lois en la nature, ainsi qu'un roi établit des lois en son royaume." (AT I, S. 144-145) 
skeptischen Argumente für die metaphysischen Beweise der Existenz Gottes und des substanziellen Unterschied der Seele vom Körper folgendermaßen erklärt:

"Aber ich konnte diesen Gegenstand (den Beweis der Existenz Gottes und den substantiellen Unterschied der Seele vom Körper; d. Verf.) nicht besser behandeln als durch die ausfuihrliche Erläuterung der Falschheit oder Unsicherheit, die sich in allen von den Sinnen oder der Einbildungskraft abhängigen Urteilen finden, um hierauf zu zeigen, welches die nur von der reinen Urteilskraft abhängigen sind und wie sehr diese offenbar und sicher sind." (Baumgart, S. $78)^{29}$

Ist die erste Meditation in der Tat nichts anderes als ein "warming-up" für die Leser? ${ }^{30}$ Eine positive Antwort scheint an vielen Stellen bei Descartes Unterstützung zu finden. Hierzu gehören die Synopsis der ersten Meditation (AT VII, S. 12) und die Erwiderung auf den Einwand von Hobbes (ebd. S. 171-2). Trotzdem halte ich diese Lesart für problematisch. Warum, kann folgendermaßen erklärt werden.

Der entscheidende Anlaß Wilsons zu ihrer methodologischen Interpretation liegt darin, daß sie das Hauptziel der Meditationes darin sieht, dem Leser die Grundlagen seiner neuen Physik zu vermitteln. Es ist wahr, daß Descartes in seinem Brief an Mersenne vom 18. März 1647 (AT III, 297-8), auf den Wilson sich auch beruft, sagt, daß in den Meditationes die Grundlagen der neuen Physik verborgen seien. ${ }^{31}$ An dieser Stelle ist aber problematisch, daß sie überhaupt nicht in der Lage ist, Descartes' Ansicht über die Beziehung zwischen der Metaphysik und der Physik (in B2, 4, 5 und C) ans Licht zu bringen. Damit meine ich folgendes. Wie wir sehen können, ist dort nicht einfach von der universalen Physik und der Metaphysik die Rede, sondern auch von ihrer besonderen Beziehung zueinander. ${ }^{32}$ So soll auch diese besondere Beziehung zu jenen unerhofften Reichtïmern gerechnet werden. Diesen Punkt aber kann Wilsons Lesart überhaupt nicht ans Licht bringen. Dies ist nämlich nur dann möglich, wenn man berücksichtigt, wie er zu den metaphysischen Themen gekommen ist und wie er sie ausgearbeitet hat.

Dies läßt es interessant erscheinen, Hatfield zu betrachten. Er glaubt nämlich, daß die Betonung von Descartes' Entwicklung hin zu metaphysischen Themen eher für die methodologische Interpretation spreche als dagegen. Hatfield findet die Motivation, die Descartes zur

\footnotetext{
29. "Mais je ne pouvais mieux traiter cette matière, qu'en expliquant amplement la fausseté ou l'incertitude qui se trouve en tous les jugements qui dépendent du sens ou de l'imagination, afin de montrer ensuite quels sont ceux qui ne dépendent que de l'entendement pur, et combien ils sont évidents et certains." (AT I, S. 350)

${ }^{30}$. Beide Interpreten, besonders Hatfield, betonen diesen Punkt sehr stark. Vgl. Hatfield, Reason, Nature, and God in Descartes in Essays on the Philosophy and Science of Rene Descartes, S. 262.

${ }^{31}$. Vgl. Wilson, Descartes, S. 2-3.

${ }^{32}$. In seiner Vorrede für die französische Ausgabe der Principia sagt er, daß die Metaphysik die Wurzel eines Baumes sei, dessen Stamm die Physik und dessen Zweige alle anderen Wissenschaften seien. Die Vorrede zitiere ich nach folgender Ausgabe: Die Prinzipien der Philosophie, Übers. v. Buchenau, Hamburg: Felix Meiner, 8. Auflage, 1992. Vgl. S. XLII.
} 
Beschäftigung mit der Metaphysik, besser gesagt, mit der metaphysischen Theologie geführt hat, in seinem Brief an Mersenne vom 18. Dezember 1629 (AT I, S. 85-86) ausgesprochen. Hier beklagt er sich darüber, daß es fast unmöglich sei, eine neue Philosophie (Naturphilosophie) zu vertreten, ohne den Anschein zu erwecken, daß sie gegen den Glauben verstoße. Worauf aber legt Descartes diese Klage fest? Eines kann man nicht leugnen: daß sie eine Motivation für die Beschäftigung mit der Metaphysik gewesen sein kann. Kann dies noch mehr bedeuten? Hatfield gibt sich nicht einfach damit zufrieden, sondern zieht daraus eine weitere Konsequenz, nämlich die, daß damit den Meditationes von Anfang an ein strategisches Ziel zugeschrieben worden ist: "I shall be attributing to Descartes an intellectual strategy that, I claim, allowed him to attack the intellectual basis for one aspect of what he considered to be the overly close relation between theology and metaphysics" (Reason, S. 261). So stehen neue Physik gegen alte Physik und neue Metaphysik gegen alte Metaphysik. Demnach setzt er sich zur Aufgabe zu zeigen, wie Descartes mit seiner Doktrin der Abhängigkeit ewiger Wahrheiten von Gottes Willen sein strategisches Ziel erreichen kann. Dies wirft aber zwei Probleme auf. Das eine Problem ist das, daß Hatfield in seiner Betrachtung über die Metaphysik Descartes' (B 3) und damit auch (C) außer Acht läßt. In der Metaphysik Descartes' ist aber nicht einfach von der Metaphysik als solcher, sondern auch von ihrem Status die Rede: ihre Wahrheiten sind viel augenscheinlicher und gewisser als die der Mathematik. ${ }^{33}$ (C) liefert mit Rekurs auf die Abhängigkeit der mathematischen Wahrheiten vom Willen Gottes den Grund, warum dies so ist. Das andere Problem ist viel ernsthafter als das erste und das von Wilson. Die Situation sieht demnach nun so aus, als ob Hatfield, um die methodologische Interpretation der ersten Meditation $\mathrm{zu}$ rechtfertigen, die Bedeutung der gesamten Meditationes aufs Spiel setzen wollte. Ich habe große Bedenken, ob und wie es von dieser Perspektive aus überhaupt möglich ist, den Meditationes irgendeine ernsthafte Bedeutung zu geben, da sie in diesem Fall nichts mehr als ein Werkzeug für einen gegebenen Zweck sein können.

Meiner Meinung nach ist es, um die erste Meditation richtig zu bewerten und zu interpretieren, entscheidend zur Kenntnis zu nehmen, daß Descartes aus einem reinen Zufall in der Metaphysik die Grundlagen seiner Physik gefunden hat. (A) und (B) bringen dies unmißverständlich zum Ausdruck. Dies stellt Descartes' Situation so dar, daß er sich, aus welchen Gründen auch immer, aber unabhängig von seiner Entscheidung für die Beschäftigung mit der universalen Physik, eines Tages dazu entschieden hat, sich mit der Metaphysik zu beschäftigen, und dann dadurch zufällig dazu gekommen ist, darin die Grundlagen seiner Physik zu finden. Dies schließt natürlich nicht die Möglichkeit aus, daß die Motivation, die ihn zur Beschäftigung mit der metaphysischen Theologie geführt hat, zu Beginn

\footnotetext{
${ }^{33}$. Diese Behauptung kann man in den Meditationes häufig finden.
} 
einzig und allein auf dem oben genannten strategischen Grund beruht. Wenn aber jene Möglichkeit besteht, dann muß die Frage nach der Art und Weise um so dringlicher und interessanter werden, in der er sich mit den metaphysischen Themen beschäftigt hat, derart daß dadurch ein von ihm unerwartetes Ergebnis zustande gekommen ist. Diese Frage bleibt offen, wenn man der Anwendung der Methode des Zweifelns nur eine methodologische Funktion zuschreibt. Dies ist auch der Fall, wenn man der Metaphysik nur eine strategische Funktion zuschreibt. Um die Frage zu beantworten, muß man Descartes' Erklärung der Notwendigkeit der Anwendung der Methode des Zweifelns in der Metaphysik sehr ernst nehmen. Dies kann folgendermaßen näher begründet werden.

Wie wir in (A) und (B 1) sehen können, sagt Descartes nicht einfach, daß die Beschäftigung mit Gott es ihm ermöglicht habe, die Grundlagen der Physik zu finden, sondern darüber hinaus, daß auch die Beschäftigung mit dem "Ich" es ihm ermöglicht habe. Dabei ist es wichtig darauf hinzuweisen, daß, obwohl der Gegenstand "Gott" für ihn ein neues Thema ist, der andere Gegenstand, nämlich das "Ich", kein neues Thema für ihn ist. Wir haben bereits gesehen, daß er sich dem "Ich" bereits in den Regulae zugewandt hatte, und das Ergebnis aus dieser Zuwendung kennen wir, nämlich seine Methodenlehre und seine Antwort auf die Restriktionsfrage. Obwohl dies seinen Zeitgenossen nicht bekannt gewesen sein mag, da die Regulae nicht publiziert worden sind, konnte es ihnen dennoch nicht vollkommen entgehen, da sich ein deutlicher Hinweis dazu in dem biographischen Abschnitt von De Methodo findet, nämlich der Hinweis, daß er sich zweimal dem "Ich" zuwendet. Wenn nun Descartes sagt, daß nicht die Beschäftigung mit "Gott" allein, sondern auch mit dem "Ich" es ihm ermöglicht habe, die Grundlagen der Physik zu finden, heißt dies, daß es einen Unterschied der Art und Weise seiner Beschäftigung mit dem "Ich" geben muß, aufgrund dessen er zu verschiedenen Ergebnissen kommen konnte. Die Antwort auf diese Frage liegt in der radikalen Anwendung der ersten Methode in De Methodo, nämlich in der Anwendung der Methode des Zweifelns. So muß die erste Meditation als solche und für sich ernst genommen werden. Descartes' Doktrin von Gott in (C) muß auch in diesem Zusammenhang gelesen werden. Sie ist nämlich nicht etwas, das Descartes entworfen hat, um sein strategisches Ziel zu erreichen.

Zusammengefaßt: Mit "unerhofften neuen Reichtïmern" meint Descartes nicht einfach die universale Physik und die Metaphysik, sondern vielmehr ihre besondere Beziehung zueinander, den besonderen Status der metaphysischen Wahrheiten den mathematischen Wahrheiten gegenüber, sowie die Abhängigkeit der mathematischen Wahrheiten von dem Willen Gottes. Die Bedeutung der ersten Meditation liegt gerade darin, daß sie Descartes die Grundlage dafür liefert. 


\section{IV. Erklärung der Motivation}

Was hat aber Descartes zur Anwendung der Methode des Zweifelns geführt? Wenn Descartes' Doktrin von Gott in (C) dabei eine Rolle gespielt hat, warum? Um eine Antwort auf diese Frage zu finden, ist es nötig, sich ein richtiges Bild von Descartes' Entwicklung zu machen. Damit meine ich folgendes.

Wenn man Descartes nur aus seinen späteren Werken, nämlich aus De Methodo, aus den Meditationes und den Principia kennt, wenn man also das Problem des Skeptizismus nur mit Rekurs auf diese Werke zu verstehen versucht, ist die Gefahr sehr groß, ein falsches Bild zu bekommen. Dort wird nämlich zuerst die Existenz der Außenwelt in Frage gestellt; daraufhin tritt die Frage nach der Essenz der physikalischen Gegenstände (die in De Methodo fehlt) auf, und erst später kommt die Frage nach den grundlegenden Naturgesetzen zur Sprache (die in den Meditationes fehlt). Dies führt zu der Annahme, daß Descartes' Motivation, sich mit dem Problem des Skeptizismus zu beschäftigen, in einem direkten Zusammenhang mit der Frage nach der Existenz der Außenwelt gesehen werden muß. Beispiele für diese Annahme finden wir bei Williams und Mackie. Da Descartes gesagt hat, daß kein Mensch mit gesundem Verstand solche Gedanken hat; ${ }^{34}$ scheint es von Anfang an aussichtslos zu sein, eine solche Motivation zu finden oder nachzuvollziehen. Dies kann in die umgekehrte Richtung führen, in die Wilson und Hatfield gegangen sind. Aber, wie gesagt: diese Interpretation beruht auf derselbe Annahme, daß man, um Descartes' Beschäftigung mit dem Problem des Skeptizismus nachzuvollziehen, eine Motivation finden können muß, die direkt erklären kann, wie die Existenz der Außenwelt fraglich werden kann. Diese Annahme aber ist falsch.

Abgesehen davon gibt es allerdings ein Problem bei Descartes, das meiner Meinung nach indirekt nachvollziehen lassen kann, warum und wie Descartes zu dem Problem des universalen Skeptizismus gekommen ist. Zu diesem Zweck will ich hier zuerst Buchdahls Auffassung diskutieren, da sie uns einen guten Ansatz für die Diskussion über die Verbindung von Physik und Metaphysik liefert. Daraufhin werde ich versuchen zu erklären, was Descartes zur Beschäftigung mit dem Problem des Skeptizismus geführt hat.

\section{IV. 1. Buchdahls Erklärung}

Die erste und allgemeine Aufgabe, die Buchdahl sich in seinem Buch "Metaphysics and the Philosophy of Science" stellt, ist die, den logischen Status der Naturgesetze zu analysieren. ${ }^{35}$ Der Anlaß dazu besteht darin, daß Naturgesetze gewöhnlich von dem Anspruch auf

\footnotetext{
${ }^{34}$. Siehe die Synopsis der sechsten Meditation, AT VII, S. 16.

${ }^{35}$. Siehe Buchdahl, Kapitel I und II, besonders S. 26-49.
} 
Notwendigkeit begleitet werden, während niemand sie für immun gegenüber Falsifikation halten würde. Dies zeigt nach seiner Meinung, daß der Status der Notwendigkeit, der den Naturgesetzen zugesprochen wird, nicht mit demjenigen identisch sein kann, den wir in der Logik finden. Was soll man dann darunter verstehen? Woher kommt dieser Anspruch? Buchdahl versucht auf diese Fragen zu antworten, indem er drei repräsentative Modelle, nämlich "the formal and apriori group", "the nomothetic group" und "the systemic group" vorstellt, die seiner Meinung nach im Hintergrund jenes Anspruches stehen. ${ }^{36}$ Was uns dabei interessiert, sind die ersten beiden Modelle. Betrachten wir sie hier nur kurz.

Was Buchdahl unter dem ersten Modell versteht, haben wir schon am Anfang dieses Kapitels gesehen: Die Gleichstellung von Naturwissenschaften mit Mathematik und Logik. Dabei nimmt man als grundlegende Gesetze solche Naturgesetze an, die durch Merkmale wie Apriorität, Notwendigkeit und Unbezweifelbarkeit zu charakterisieren sind. Wie wir gesehen haben, ist es schwer zu entscheiden, ob Descartes in den Regulae dieses Modell vor Augen hatte. Dagegen spricht, daß er dort kein Interesse an der universalen Physik zeigt; einerseits entsteht Descartes' Interesse an der universalen Physik, wie wir gesehen haben, erst nach den Regulae, und andererseits beginnt er damit zugleich, bezüglich ihrer grundlegenden Gesetze den Anspruch auf Apriorität und Notwendigkeit zu erheben, wie wir bald sehen werden.

Was das zweite Modell charakterisiert, ist die Annahme der Existenz von notwendigen Gesetzen in der Welt. Entscheidend dabei ist, daß jene Annahme als eine notwendige Bedingung für die Möglichkeit des induktiven Verfahrens überhaupt angesehen wird, und zwar in dem Sinne, daß über ihre Gültigkeit nicht empirisch entschieden werden kann. Gegeben diese Annahme, besteht das Ziel aller Naturwissenschaften darin, jene Gesetze zu entdecken. Buchdahl ist der Meinung, daß diese Vorstellung der Naturwissenschaftler von den meisten Philosophen geteilt werde. ${ }^{37}$ Wie wir in (B 5) gesehen haben, trifft dies auch für Descartes zu.

Wie Descartes nach diesen Modellen die Physik mit der Metaphysik in Verbindung gebracht haben soll, kann man folgendermaßen erklären. ${ }^{38}$

Wenn wir Le Monde (Kapitel I-V) betrachten, ${ }^{39}$ sehen wir, daß Descartes nicht nur sein endgültiges Konzept der Essenz der physikalischen Gegenstände als Ausdehnung vorstellt, also nicht nur das Konzept der physikalischen Welt als eines homogenen, unbegrenzt ausgedehnten, dreidimensionalen Dinges vorstellt, sondern auch seine drei grundlegenden Naturgesetze darstellt, ohne sie durch eine Schöpfungstheorie mit Gott in Verbindung zu bringen. ${ }^{40}$

\footnotetext{
${ }^{36}$. Natürlich sind sie miteinander eng verbunden.

${ }^{37}$. Vgl. Buchdahl, S. 39 und 44.

${ }^{38}$. Vgl. Buchdahls eigene Version, S. 147-154.

39. Die deutsche Übersetzung von Le Monde zitiere ich nach folgender Ausgabe: Die Welt oder Abhandlung über das Licht, Übers. v. Tripp, Weinheim: VCH, Acta humaniora, 1989.

${ }^{40}$. Dies geschieht erst später im siebten Kapitel.
} 
Dabei behauptet er zuerst, daß diese Gesetze aus Vernunftgründen erschlossen worden seien (S. 17). So könnte man nun behaupten, daß Descartes damit den Anspruch auf apriorische Wahrheit der Gesetze erhebt, und daß dies zeigt, daß Descartes dem ersten Modell anhängt. Man muß jedoch jene Stelle vorsichtig lesen. Es ist nämlich möglich, daß Descartes damit nicht mehr zum Ausdruck bringen wollte, als daß die Gesetze als "conceptual foundations" nicht durch induktive Verfahren gefunden, sondern als Einschränkungen angenommen werden, innerhalb derer hypothetisch-deduktive Verfahren durchgeführt werden können. In diesem Fall hat dies nichts mit dem ersten Modell zu tun, da dies nämlich von jedem naturwissenschaftlichen System gilt. Um zu erfahren, wie und wo dieses Modell bei Descartes ins Spiel kommt, muß man genau fragen, wo und wie Descartes anfängt, den Gesetzen den Status zuzuschreiben, den alle Wahrheiten aus Vernunftgründen zu beanspruchen pflegen, nämlich den Status der "apriorischen Wahrheit" (im Sinne der Notwendigkeit) ${ }^{41}$. Descartes schreibt ihnen nämlich diesen Status nicht allein aufgrund der Behauptung $\mathrm{zu}$, daß sie aus Vernunftgründen abgeleitet worden seien, sondern erst, nachdem er sie aus der Unveränderlichkeit Gottes abzuleiten versucht hat. ${ }^{42}$ Dies ist deswegen nötig, weil alle Wahrheiten gleichermaßen von dem Willen Gottes abhängig sind, wie wir in III.III. dieser Arbeit gesehen haben. Also kommt erst hier das erste Modell bei Descartes ins Spiel, wenn es überhaupt ins Spiel kommen soll. Die Konsequenz, die ich aus dieser Betrachtung ziehen will, ist die, daß allein die Aufstellung der grundlegenden Gesetze bei Descartes nichts mit dem Anspruch auf Notwendigkeit zu tun hat. Dieser Anspruch kommt erst später durch die Verbindung mit der Metaphysik zustande.

Dagegen kann man vielleicht einwenden, daß es bei der Ableitung der Gesetze aus der Unveränderlichkeit Gottes nicht darum geht, den Gesetzen den Status der "apriorischen Wahrheit" oder "Unbezweifelbarkeit" zuzuschreiben (dies ergibt sich nämlich schon daraus, daß sie aus Vernunftgründen geschlossen worden sind), sondern vielmehr darum, ihnen objektive Gültigkeit zuzuschreiben. Dies wirkt auf den ersten Blick sehr überzeugend. Descartes beginnt das siebte Kapitel von Le Monde nämlich so:

"Aber ich will es nicht länger aufschieben, Ihnen zu sagen, mit welchem Mittel die Natur allein die Unordnung des Chaos entwirren kann, wovon ich gesprochen habe, und welches die Gesetze sind, die Gott ihr auferlegt hat." ( Tripp, S. 45; Hervorhebung d. Verf.) ${ }^{43}$

Descartes' Versuch, die oben erwähnten Gesetze aus der Unveränderlichkeit Gottes abzuleiten, folgt auf die zitierte Stelle. Dies legt nahe, daß hier von objektiver Gültigkeit die

\footnotetext{
${ }^{41}$. Dafür verwendet dort Descartes auch den Terminus "Unbezweifelbarkeit".

${ }^{42}$. Siehe das 7. Kapitel von Le Monde.

43. "Mais je ne veux pas differer plus long-temps à vous dire, par quel moyen la Nature seule pourra déméler la confusion du Chaos dont j'ay parlé, \& quelles sont les Lois que Dieu luy a imposées."(AT XI, S. 36)
} 
Rede ist, und zwar nicht nur hinsichtlich der drei Gesetze ${ }^{44}$ sondern auch hinsichtlich aller mathematischen Wahrheiten. ${ }^{45}$ Es geht also um objektive Gültigkeit aller apriorischen Wahrheiten. Dafür scheinen auch (B 4 und 5) und (C) zu sprechen. Allerdings gibt es hier eine Unklarheit. Damit meine ich folgendes.

Um die objektive Gültigkeit der mathematischen Wahrheiten zu belegen, ist es für Descartes nicht erforderlich, die mathematischen Wahrheiten selbst direkt aus der Unveränderlichkeit Gottes abzuleiten. Dafür reicht es nämlich allein aus zu zeigen, daß Gott unveränderlich und gütig ist, wobei die mathematischen Wahrheiten selbst lediglich aus Vernunftgründen abzuleiten sind. Die Situation sieht aber anders aus, wenn es um die drei grundlegenden Gesetze geht. Auch wenn Descartes behauptet, daß er sie aus Vernunftgründen abgeleitet habe, ist nicht klar, ob und wie dies geschieht, so daß wir akzeptieren könnten, daß sie a priori wahr sind. Ich glaube nicht, daß Descartes davon so überzeugt ist, wie er selbst behauptet. So nehme ich an, daß er, um ihre Wahrheit zu erweisen, es für nötig gehalten hat, sie zusätzlich aus der Unveränderlichkeit Gottes a priori abzuleiten. Natürlich wirft dies wiederum die Frage auf, ob Descartes davon überzeugt ist, daß er sie aus der Unveränderlichkeit Gottes a priori abgeleitet hat. Lassen wir aber diese Frage hier beiseite ${ }^{46}$ und nehmen wir vorläufig an, daß dies der Fall ist.

Abgesehen davon zeigt das zweite Modell in Descartes' Annahme der Existenz der notwendigen Naturgesetze, daß Gott der Schöpfer der Welt ist, wobei er nicht nur mathematische, sondern auch alle Naturgesetze geschaffen hat. Descartes' Ableitung der Gesetze aus der Unveränderlichkeit Gottes hat die Funktion, ihnen objektive Gültigkeit zu sichern. So werden die Merkmale "apriori" "unbezweifelbar" und "notwendig" für die grundlegenden Gesetze verwendet, um sie im Unterschied zu allgemeinen induktiven Aussagen zu charakterisieren.

Buchdahl versucht deren Problematik ans Licht zu bringen, indem er analysiert, unter welchen Bedingungen wir eine Aussage als Gesetzaussage akzeptieren. Daraus ergibt sich, daß bezüglich unserer Entscheidung der Frage, ob eine Aussage als Gesetzaussage mit Anspruch auf Notwendigkeit akzeptiert werden soll oder nicht, einzig und allein die Frage entscheidend ist, ob sie folgende zwei Kriterien erfüllt oder nicht:

\footnotetext{
${ }^{44}$. Das erste Gesetz ist dieses: Daß jeder einzelne Teil der Materie solange immer im selben Zustand verharrt, wie das Zusammentreffen mit anderen ihn nicht zwingt, ihn zu ändern (AT XI, S. 38;Tripp, S. 47). Das zweite Gesetz besagt: Wenn ein Körper einen anderen anstößt, kann er ihm keine Bewegung übertragen, wenn er nicht gleichzeitig ebensoviel von seiner eigenen verliert; und ihm auch keine davon entziehen, ohne daß die seinige sich ebensoviel vermehrt (AT XI, S. 41; Tripp, S. 49). Das dritte: Wenn sich ein Körper bewegt, obgleich seine Bewegung sich meistens in gekrümmter Linie vollzieht, und er niemals eine andere als in irgendeiner Form kreisförmige vollziehen könnte,..., strebt dennoch jeder seiner Teile für sich immer danach, die seine geradlinig fortzusetzen (AT XI, S. 43-44; Tripp, S. 53).

${ }^{45}$. Siehe das Ende des 7. Kapitels von Le Monde.

${ }^{46}$. Diese Frage werden wir später behandeln.
} 
"The statement must satisfy certain conventional inductive criteria (using 'inductive' in a broad sense), e.g. absence of falsification under severe testing. Moreover, it must display a number of logical, functional, structural and systemic characteristics. ${ }^{147}$

"The statement emerges after the deployment of certain 'consolidative devices,...., involving additional methodological principles like those of `simplicity' and `symmetry'." (S. 38)

So ist das einzige entscheidende Kriterium bei der Entscheidung der oben genannten Frage eigentlich ein empirisches. Nennen wir dieses Kriterium "das Falsifikationskriterium". Den Status der Gesetze, die dieses Kriterium erfüllen, nennt Buchdahl, Johnson folgend, "nomical necessity" im Gegensatz zu dem der ontologischen Notwendigkeit (S. 29). Daraus ergibt sich nach Buchdahl, daß die Annahme der Existenz notwendiger Gesetze in der Natur überhaupt keine Rolle spielt, ganz abgesehen davon, daß sie die notwendige Bedingung für das induktive Verfahren ist. So weit das zweite Modell.

Wenn einigen Gesetzen trotzdem im Unterschied zu anderen Gesetzen der besondere Status zugeschrieben worden ist, a priori wahr zu sein, so liegt dies nicht daran, daß sie in der Tat $a$ priori wahr und notwendig sind. Noch liegt es daran, daß sie noch nicht falsifiziert worden sind. Es liegt vielmehr daran, daß sie als einfache Prinzipien zur fundamentalen Sprache eines naturwissenschaftlichen Systems gehören, so daß der Verzicht auf sie oder ihre Modifikation nur dann vorstellbar ist, wenn man durch die Entdeckung eines entscheidenden Mangels des Systems gezwungen worden ist, das ganze System durch ein ganz anderes neues System zu ersetzen. In dieser Hinsicht nennt Buchdahl den Status jener Gesetze "functional a priori" im Unterschied zu logischer Notwendigkeit (S. 33). Nennen wir dies "das ökonomischfunktionelle Kriterium".

Aus dieser Betrachtung zieht Buchdahl die Konsequenz, daß die gewöhnliche Charakterisierung der Naturgesetze durch "Apriorität" oder "Notwendigkeit" nichts anderes als ein Ergebnis einer rein philosophischen Analyse der Gesetze ist (S. 38).

Was diese Erklärung von Buchdahl betrifft, so habe ich hier nicht vor, auf die Frage einzugehen, ob sie richtig ist oder nicht. Was ich aber problematisieren will, ist seine Behauptung, daß Descartes zu denjenigen Philosophen gehört, die die oben genannten beiden Modelle vor Augen haben. Meiner Meinung nach ist dies nicht der Fall. Und auch wenn dies der Fall wäre, wäre seine Position viel komplexer und vernünftiger. Kurz vorgreifend will ich

\footnotetext{
${ }^{47}$. Natürlich ist hiermit nicht gemeint, daß alle Naturgesetze ohne Unterschied einzig und allein durch induktive Verfahren aufgestellt werden. Buchdahl stimmt nämlich mit Recht der Ansicht zu, daß es in jedem naturwissenschaftlichen System besondere Gesetze gibt, die nicht durch induktive Verfahren aufgestellt, sondern als Beschränkungen (conceptual foundations) ohne weiteres angenommen werden, innerhalb derer induktive Verfahren durchgeführt werden. Solche Gesetze sind z.B. das Gesetz der inertia. Es geht hier also um die Frage, in Abhängigkeit wovon solche Einschränkungen als auch andere Naturgesetze, die innerhalb dieser Einschränkungen durch induktive Verfahren aufgestellt werden, als Gesetz akzeptiert werden können. Siehe Buchdahl. S. 147-155.
} 
zwei Bemerkungen machen. Descartes sagt in (B 4), daß er es nicht für ratsam hält, die Abhandlung über die Metaphysik zu veröffentlichen, ehe er nicht gesehen habe, wie seine "Physik" aufgenommen wird. Dies besagt unmißverständlich, daß Descartes das Falsifikationskriterium für das entscheidende Kriterium der Wahrheit seiner Physik hält. Es geht ihm um deren Erklärungspotential und nicht um metaphysische Überlegungen, von denen angenommen wird, daß daraus die Grundlagen der Physik abzuleiten sind. ${ }^{48}$ Wie wir sehen werden, vertritt Descartes, anders als Buchdahl glaubt, auch nicht die Ansicht, daß die Annahme der Existenz von notwendigen Gesetzen in der Natur eine notwendige Bedingung für die Möglichkeit ist, hypothetisch-deduktive Verfahren anzuwenden.

\section{IV. 2. Descartes' Erklärung}

Ich möchte nun versuchen, Descartes' Position dazu noch klarer darzustellen und daraus eine Antwort auf die Motivationsfrage zu entnehmen. Zu diesem Zweck betrachten wir zuerst folgende Stelle:

"da es aber wenig Menschen gibt, die meine Geometrie verstehen können, und da Sie (Mersenne; d. Verf.) wünschen, daß ich Ihnen meine Meinung darüber (über De Methodo; d. Verf.) berichte, so schickt es sich nach meiner Ansicht durchaus, Ihnen zu sagen, daß sie derart ist, daß ich mir nichts über sie hinaus wünsche, und daß ich mit der Dioptrik und den Meteoren nur versucht habe, davon zu überzeugen, daß meine Methode besser als die übliche ist; ich behaupte aber, es durch meine Geometrie bewiesen zu haben." (Brief an Mersenne vom Ende Dezember 1637?; Baumgart, S. 91; Hervorhebung d. Verf.). ${ }^{49}$

Wie wir hier vermuten können, hält Descartes nach wie vor daran fest, daß die naturwissenschaftliche Erkenntnis nicht denselben Status der Gewißheit besitzen kann wie die mathematische Erkenntnis. Er spricht nämlich lediglich von der Überzeugung von der

\footnotetext{
${ }^{48}$. Wenn Wilson Recht hat, soll dies vermuten lassen, daß er seine metaphysischen Überlegungen nicht veröffentlicht hätte, wenn er die Möglichkeit gehabt hätte, seine Physik ( in Le Monde ) zu veröffentlichen und erfahren hätte, daß sie von den Lesern richtig aufgenommen worden ist. Aber aus einem bekannten Grund, nämlich dem Fall Ga lilei, konnte und wollte er sie nicht veröffentlichen, und dies war der Grund dafür, daß er stattdessen De Methodo veröffentlicht hat, in der seine universale Physik durch metaphysische Überlegungen über ihre Grundlagen ersetzt worden ist. So gesehen kann man sagen, daß die Meditationes als zweite Wahl publiziert worden sind, allererst und hauptsächlich mit der Absicht, die Leser mit seiner neuen Physik, bzw. deren Grundlagen vertraut zu machen. Sie sind sozusagen eine metaphysische Version der Physik.

49. "mais parce qu'il y a peu de gens qui puissent entendre ma géométrie, et que vous désirez que je vous mande quelle est l'opinion que j'en ai, je crois qu'il est à propos que je vous dise qu'elle est telle, que je n'y souhaite rien davantage; et que j'ai seulement tâché par la Dioptrique et par les Météores de persuader que ma méthode est meilleure que l'ordinaire, mais je prétends l'avoir démontré par ma géométrie."(AT I, S. 478) Eine parallele Stelle kann man in seinem Schreiben an Picot finden. Vgl. Die Prinzipien der Philosophie, XLII-XLIII.
} 
Tüchtigkeit seiner Methode, wenn es um die Dioptrik und die Meteoren geht, während er von dem Beweis der Tüchtigkeit spricht, wenn es um die Geometrie geht. Betrachten wir folgende Stellen, indem wir uns diesen Punkt vor Augen hatten:

"Sie fragen mich, ob ich das, was ich über die Brechung geschrieben habe, als Beweis ansehe; und ich glaube, daß es das ist, zumindest in dem Maße, in dem es in dieser Angelegenheit unmöglich ist, einen Beweis zu erstellen, ohne zunächst die Prinzipien aus der Metaphysik (was ich eines Tages zu tun hoffe, aber was bisher noch nicht getan wurde) abzuleiten und in dem Maße, in dem andere Fragen der Mechanik oder der Optik oder der Astronomie oder jeder anderen Angelegenheit, die nicht rein geometrisch oder arithmetisch ist, jemals bewiesen worden sind. Aber von mir geometrische Beweise in einer Angelegenheit zu fordern, die von der Physik abhängt, heißt, von mir das Unmögliche zu verlangen. Und wenn jemand nur die Beweise der Geometrie Beweise nennt, dann müßte dieser behaupten, daß Archimedes niemals irgend etwas in der Mechanik bewiesen hätte, noch Vitellion in der Optik, noch Ptolemäus in der Astronomie etc. und dies wird nicht behauptet. In diesen Angelegenheiten ist man zufriedengestellt, wenn die Autoren - nachdem sie einige Dinge vorausgesetzt haben, die offenkundig der Erfahrung nicht widersprechen - von dort aus konsistent fortfahren und keinen Fehler der Logik begehen, selbst wenn ihre Annahmen nicht völlig der Wahrheit entsprechen." (Brief an Mersenne vom 17 oder 27 Mai 1638) $)^{50}$

Hier sind folgende Punkte festzuhalten:

(E) 1) Damit der Beweis über die Brechung denselben Status wie ein geometrischer Beweis hat, ist es nötig, die grundlegenden Naturgesetze aus der Metaphysik abzuleiten;

2) Dies ist Descartes zwar noch nicht gelungen, aber er hofft, daß es ihm irgendwann gelingen wird;

3) Es ist unmöglich, einen Beweis in den Naturwissenschaften zu liefern, der denselben Status wie geometrische Beweise besitzt;

4) Die Frage, ob in den Naturwissenschaften etwas als ein Beweis akzeptiert werden soll oder nicht, wird gewöhnlich eher anhand des Falsifikationskriteriums entschieden;

5) Da Descartes' Argument das Falsifikationkriteium erfüllt, ist es als Beweis anzuerkennen.

\footnotetext{
50. "Vous demandez si je tiens que ce que j'ai écrit de la réfraction soit démonstration; et je crois qu'oui au moins autant qu'il est possible d'en donner en cette matière, sans avoir auparavant démontré les principes de la Physique par la Métaphysique (ce que j'espère faire quelque jour, mais que ne l'a point été par cidevant), et autant qu'aucune autre question de Mécanique, ou d'Optique, ou d'Astronomie, ou autre matière qui ne soit point purement Géométrique ou Arithmétique, ait jamais été démontrée. Mais d'exiger de moi des démonstrations Géométriques en une matière qui dépend de la Physique, c'est vouloir que je fasse des choses impossibles. Et si l'on ne veut nommer démonstrations que les preuves des Géomètres, il faut donc dire qu'Archimède n'a jamais rien démontré dans le Mécaniques, ni Vitellion en l'Optique, ni Ptolomée en l'Astronomie, etc., ce qui toutesfois ne se dit pas. Car on se contente, en telles matières, que les Auteurs, ayant presupposé certaines choses qui ne sont point manifestement contraires à l'expérience, ayant au reste parlé conséquemment et sans faire de Paralogisme, encore même que leurs suppositions ne suiffent pas exactement vraies."(AT II, 141-142) Zitiert nach Williams. Vgl. Williams, S. 257-8.
} 
Zunächst ein Problem, das (E 1), (E 2) und (E 3) aufwerfen. Wenn nämlich Descartes (E 3) behauptet, heißt dies, daß er es für unmöglich hält, die Bedingung in (E 1) zu erfüllen, die grundlegenden Gesetze aus der Metaphysik abzuleiten. Aber wenn er in der Tat so denkt, wie kann er darauf hoffen, daß er irgendwann jene Bedingung erfüllt, wie wir in (E 2) sehen können? Kann man dieses Rätsel lösen? Die einzige Möglichkeit dafür liegt darin, daß der Grund dafür, daß Descartes (E 3) behauptet, anderswo liegt. Und dies ist in der Tat der Fall. Dies ergibt sich nämlich daraus, daß Descartes,- selbst wenn es ihm gelingt, die grundlegenden Gesetze aus der Unveränderlichkeit Gottes abzuleiten, wie er in den Principia behauptet, ${ }^{51}$ dennoch nach wie vor nicht die Bereitschaft zeigt, der naturwissenschaftlichen Erkenntnis denselben Status der Gewißheit wie der mathematischen Erkenntnis zuzuschreiben. Hier (Principia iv 205-206; AT VIII, S. 327-328) stellt er ihren Stellenwert zwar über den der moralischen Gewißheit, die, wie wir gesehen haben, zur Begründung der Handlungen ausreichend ist, aber bei ihm keinen großen Anspruch beinhaltet, setzt ihn aber nicht dem Standard der Gewißheit gleich, den die mathematische Erkenntnis und die der Existenz der Außenwelt besitzt. ${ }^{52}$ Woran dies liegt, ist keine schwer zu beantwortende Frage.

Wie Williams richtig betont hat ${ }^{53}$ ist es sehr wichtig, bei Descartes zweierlei auseinanderzuhalten, nämlich den Versuch, die grundlegenden Gesetze aus der Unveränderlichkeit Gottes abzuleiten, und den Versuch, einzelne Naturphänomene zu erklären.

Mit anderen Worten: Auch wenn die erste Aufgabe erledigt worden ist, legt dies zwar Einschränkungen dessen fest, ${ }^{54}$ was in der Welt geschehen kann, kann aber weder bestimmen, welche Mechanismen in der Welt existieren, noch von sich aus die Erkenntnis ermöglichen, welche Mechanismen in der Welt existieren. Dies ist nämlich eine andere Frage, die anders beantwortet werden muß. Wie sie beantwortet werden muß und welche Schwierigkeiten dabei entstehen sind, erklärt Descartes folgendermaßen:

"Aber ich muß auch bekennen, daß die Macht der Natur so umfangreich und weit ist, und jene Prinzipien so einfach und allgemein sind, daß ich fast keine Wirkung mehr beobachten kann, von der ich nicht erkenne, daß sie aus ihnen auf verschiedene Weisen abgeleitet werden kann, und daß nichts mir gewöhnlich schwieriger erscheint, als jene Modi zu bestimmen, von denen sie abhängig ist. Um sie zu bestimmen, kann ich nichts anderes tun, als wiederum andere Experimente zu suchen, die derart sind, daß darauf eine jeweils verschiedene Wirkung folgen wird, je nachdem, ob sie auf diese oder eine andere Weise erklärt wird." (AT VI, S. 576; übers. v. d. Verf. und Hervorhebung d. Verf. $)^{55}$

\footnotetext{
51. Siehe ii. 36-54, AT VIII. S. 61-68. Vgl. das 7. Kapitel von Le Monde. Le Monde ist nicht veröffentlicht worden.

52. Vgl. die Principia, iii 43 und 44, AT VIII. S. 99.

${ }^{53}$. Siehe Williams, S. 260-261.

${ }^{54}$. Vgl. Buchdahl, S. 152 und 154.

55 . "Sed confiteri me etiam oportet, potentiam Naturae esse adeo amplam \& diffusam, \& principia haec adeo esse simplicia \& generalia, ut nullum fere amplius particularem effectum observem, quem statim variis modis ex iis deduci posse non agnoscam; nihilque ordinarie mihi difficilius videri, quam invenire quo ex his
} 
Descartes sagt hier also Folgendes:

(F) (1) Es gibt verschiedene Möglichkeiten, ein und dieselbe Wirkung aus grundlegenden Gesetzen abzuleiten;

(2) Die Schwierigkeit liegt darin zu entscheiden, welche von ihnen die richtige ist;

(3) Worauf wir uns bei der Entscheidung dieser Frage einzig verlassen müssen, sind wiederum weitere Beobachtungen und Experimente.

Es ist wichtig zuerst darauf hinzuweisen, daß mit "ableiten" in (F 1) nicht eine rein logische Ableitung gemeint ist. Wie das Wort "rursus" in (F 3) deutlich macht, besteht Ableitung in der Anwendung hypothetisch-deduktiver Verfahren. ${ }^{56}$ Die richtige Lesart ist demnach die, daß jedes gegebene Phänomen auf mehr als eine Weise erklärt werden kann, auch wenn das hypothetisch-deduktive Verfahren im Rahmen der Einschränkungen durchgeführt wird, die durch die kinematischen Begriffe und die grundlegenden Gesetze der physikalischen Theorie gesetzt worden sind. Dies ist der eigentliche Grund für (E 3). Daher kommt, daß ein Beweis mittels hypothetisch-deduktiver Verfahren keinen Anspruch auf den Standard der Gewißheit erheben darf, den die mathematische Erkenntnis besitzt (B 3, 4 und 5).

Descartes glaubt trotzdem, daß es einen Mechanismus gebe, der den Phänomenen zugrunde liege, und ist einerseits fest davon überzeugt, daß es prinzipiell möglich sei, diesen Mechanismus zu entdecken, und andererseits davon, daß diese Möglichkeit darin bestehe, die Alternativen mit Hilfe von weiteren Experimenten zu verringern, wie man an (F 3) sieht. ${ }^{57}$ Gerade in dieser Überzeugung sehe ich eine Möglichkeit, eine Antwort auf die Frage nach der Motivation zu finden, die Descartes zur Beschäftigung mit der metaphysischen Theologie und damit auch mit dem Problem des Skeptizismus geführt hat. Um dies zu tun, betrachten wir zuerst folgende Stelle.

"Wenn man auch vielleicht auf diese Weise erkennt, wie alle Naturkörper haben entstehen können, so darf man daraus doch nicht folgern, daß sie wirklich so gemacht worden sind. Denn derselbe Künstler kann zwei Uhren fertigen, die beide die Stunden gleich gut anzeigen und äußerlich ganz sich gleichen, aber innerlich doch aus sehr verschiedenen Verbindungen der Räder bestehen, und so hat unzweifelhaft auch der höchste Werkmeister, Gott, alles Sichtbare

modis inde dependeat. Hinc enim aliter me extricare non possum, quam si rursus aliqua experimenta quaeram, quae talia sint, ut eorum idem non sit futurus eventus, si hoc modo quam si illo explicetur." ( Hervorhebung d. Verf)

56. Vgl. Buchdahl, S. 22.

${ }^{57}$. Es ist immer möglich, vom gegenwärtigen Zustand der Forschung aus dieselben Phänomene auf mehr als eine Weise zu erklären. Wie wir gesehen haben, ist dies wiederum der Grund dafür, daß Descartes nach wie vor der naturwissenschaftlichen Erkenntnis nicht denselben Status der Gewißheit zuspricht wie der mathematischen Erkenntnis. Diese Betrachtung bestätigt unsere Formulierung der Überzeugung Descartes', daß es prinzipiell möglich ist, Phänomene aus Ursachen zu erklären. Trotzdem ist dies ein Zeichen dafür, daß er sich weit vom Operationalismus entfernt hat. 
auf mehrere verschiedene Arten hervorbringen können. Ich gebe diese Wahrheit bereitwilligst zu, und ich bin zufrieden, wenn die von mir erklärten Ursachen derart sind, daß alle Wirkungen, die sie hervorzubringen vermögen, denen gleich sind, die wir in den Erscheinungen bemerken. Dies wird auch für die Zwecke des Lebens genügen, weil sowohl die Medizin und Mechanik, wie alle anderen Künste, welche der Hilfe der Physik bedürfen, nur das Sichtbare und deshalb zu den Naturerscheinungen Gehörige zu ihrem Ziel haben." (Principia iv 204; Buchenau, S. 246) ${ }^{58}$

Wie wir hier deutlich sehen können, schließt Descartes nicht ohne weiteres die Möglichkeit aus, daß die Phänomene (wie in (F 1)) durch eine große Anzahl willkürlicher Mechanismen zustande kommen. Daraus ergibt sich die Möglichkeit, daß eine Hypothese, die durch hypothetisch-deduktive Verfahren aufgestellt und durch in (F 3) angegebene Verfahren weiter präzisiert worden ist, nicht den wahren Mechanismus aufzeigt. Dies ist der erste Punkt.

Der zweite Punkt ist der entscheidende, daß Descartes darin keinen Widerspruch sieht, daß es uns trotzdem gelingt, einzig und allein anhand der beiden Kriterien von Buchdahl, nämlich anhand des Falsifikationskriteriums und des ökonomisch-funktionellen Kriteriums, verschiedene naturwissenschaftliche Systeme aufzubauen, und daß sie dadurch mehr oder weniger zu unserem Wohl beitragen, je nach ihrer Fähigkeit, Naturphänomene vorauszusagen.

Was den ersten Punkt betrifft, ist die Beobachtung wichtig, daß die Unmöglichkeit, Naturphänomene aus ihren wahren Ursachen zu erklären, nicht darin besteht, daß die Ursachen über unsere Erkenntnisfähigkeit hinausgehen. ${ }^{59}$ Diese Unmöglichkeit besteht, auch, wenn die physikalischen Gegenstände nur die Qualitäten besitzen, die wir wahrnehmen, unabhängig von der Frage, welche von ihnen sie in Wirklichkeit besitzen. Dies ist der Grund dafür, daß diese Unmöglichkeit Descartes nicht zu dem Problem des Skeptizismus führt.

Der zweite Punkt zeigt, daß Descartes die Annahme der Existenz von notwendigen Gesetzen nicht als notwendige Bedingung für die Möglichkeit einer naturwissenschaftlichen Untersuchung ansieht. Er läßt nämlich damit die Möglichkeit völlig offen, daß eine naturwissenschaftliche Untersuchung prinzipiell nicht über den Operationalismus hinausgeht. Dies heißt, daß er anerkennt, daß sie logisch unabhängig von der Entscheidung der Frage nach der Existenz von

\footnotetext{
${ }^{58}$.Die deutsche Übersetzung der Principia zitiere ich nach folgender Ausgabe: Prinzipien, übers. v. Buchenau. "At quamvis forte hoc pacto intelligatur, quomodo res omnes naturales fieri potuerint, non tamen ideo concludi debet, ipsas revera sic factas esse. Nam quemadmodum ab eodem artifice duo horologia fieri possunt, quae, quamvis horas aeque bene indicent, \& extrinsecus omnino similia sint, intus tamen ex valde dissimili rotularum compage constant: ita non dubium est, quin summus rerum opifex omnia illa, quae videmus, pluribus diversis modis potuerit efficere. Quod equidem verum esse libentissime concedo, satisque a me praestitum esse putabo, si tantum ea quae scripsi talia sint, ut omnibus naturae phaenomenis accurate respondeant. Hocque etiam ad usum viate sufficiet, quia \& Medicina, \& Mechanica, \& caeterae artes omnes, quae ope Physicae perfici possunt, ea tantum quae sensilia sunt, ac proinde inter naturae phaenomena numeranda, pro fine habent." (AT VIII, S. 327)

59. In den Principia iv 203, AT VIII, S. 326 wird dieser Punkt unmißverständlich zum Ausdruck gebracht. Siehe die obige Diskussion von Hatfield.
} 
notwendigen Gesetzen durchgeführt werden kann. Dieser Punkt zeigt sich am besten an der auf obiges Zitat folgenden Stelle:

"Und damit niemand glaube, daß Aristoteles mehr geleistet habe oder habe leisten wollen, so erklärt derselbe im I. Buche seiner Meteorologie im Eingang des 7. Kapitels ausdrücklich, daß er über das den Sinnen nicht Wahrnehmbare glaube genügende Gründe und Beweise beizubringen, sobald er nur zeige, daß das Wahrnehmbare nach seinen Voraussetzungen so hätte entstehen können. ${ }^{160}$

Descartes wollte damit auf folgendes hinaus. Auch wenn die Möglichkeit besteht, daß die Phänomene durch eine große Anzahl willkürlicher Mechanismen zustande kommen, und auch wenn es deshalb möglich ist, daß die Hypothese, die durch hypothetisch-deduktive Verfahren aufgestellt und durch das in (F 3) angegebene Verfahren weiter präzisiert worden ist, nicht den wirklichen Mechanismus aufzeigt, ist Descartes' Meinung nach seine Physik besser als die aristotelische. Der Grund dafür liegt darin, daß seine Physik seiner Meinung nach die beiden Kriterien von Buchdahl besser erfüllt als die aristotelische. Worauf wir hier aufmerksam machen müssen, ist, daß Descartes keinen Grund zeigt, daraus die Konsequenz zu ziehen, daß dies ein Beweis dafür ist, daß seine Physik uns den Ursachen der Phänomene näher bringt. Dies unterscheidet Descartes von Williams. Wie wir gesehen haben, vertritt Williams die Ansicht, daß die beiden Kriterien zugleich diejenigen seien, nach denen wir beurteilen können, ob ein naturwissenschaftliches System uns der "absolute conception" näher bringt, und daß man deswegen das Problem des Skeptizismus überwinden, besser gesagt, vermeiden könne. ${ }^{61}$ Descartes teilt aber diese Ansicht nicht, und ich glaube, daß dies daran liegt, daß er glaubt, daß sie dogmatisch ist.

Dies stellt auch Buchdahls Erklärung in Frage, wie Descartes Physik und Metaphysik miteinander in Verbindung bringt. Man kann nämlich keinen Grund dafür finden, daß Descartes den Versuch für nötig halten muß, seinen Grundgesetzen eine metaphysische Gewißheit zu verschaffen. Vielleicht kommt daher der Eindruck, daß es, wenn wir betrachten, wie Descartes die grundlegenden Gesetze aus der Unveränderlichkeit Gottes ableitet, ${ }^{62}$ zweifelhaft wird, ob er selbst in der Tat glaubt, sie daraus streng a priori abgeleitet zu haben. ${ }^{63}$ Deswegen bin ich geneigt, dies eher als Zeichen dafür zu verstehen, daß er Schwierigkeiten hat, ihren besonderen Status zu charakterisieren, nämlich den Status, daß sie nicht durch

\footnotetext{
${ }^{60}$. "Et ne quis forte sibi persuadeat, Aristotelm aliquid amplius praestitisse, aut praestare voluisse, ipsemet in primo Meterorologicorum, initio capitis septimi, expresse testatur, de iis quae sensui non sunt manifesta, se putare sufficientes rationes \& demonstrationes afferre, si tantum ostendat ea ita fieri posse, ut a se explicantur."; Vgl. AT VI, S. 576.

${ }^{61}$. Descartes aber sieht darin anders als Williams kein Problem des Skeptizismus.

${ }^{62}$. Siehe die Principia, ii. 36-54. AT VIII. S. 61-68. Vgl. das 7. Kapitel von Le Monde.

${ }^{63}$. Vgl. Williams, S. 268-270.
} 
induktive Verfahren aufgestellt, sondern als Einschränkungen (conceptual foundations) angenommen werden, innerhalb derer hypothetisch-deduktive Verfahren angewandt werden. Wenn dem so ist, welchen Anlaß kann es dann für Descartes geben, das Problem des universalen Skeptizismus aufzuwerfen? Meine Antwort auf diese Frage ist folgende. Es steht außer Zweifel, daß Descartes sich nicht mit einem Operationalismus zufrieden gibt. Wie gesagt, ist er von Anfang an der Meinung oder hat die Hoffnung, daß es prinzipiell möglich ist, Naturphänomene aus ihren Ursachen zu erklären. Das hypothetisch-deduktive Verfahren führt uns Schritt für Schritt dazu, wie wir aus (F 3) erfahren. Trotzdem ist es auch wahr, daß Descartes nicht die Möglichkeit ausschließt, daß die Phänomene durch eine große Anzahl willkürlicher Mechanismen zustande kommen können, so daß es möglich ist, daß eine Hypothese nicht den wirkliche Mechanismus aufzeigt. So betrachtet er diese Möglichkeit als eine reelle und keine metaphysische Möglichkeit. Daraus ergibt sich, daß seine Überlegung zu dieser Möglichkeit keinen direkten Anlaß zu dem Problem des Skeptizismus geben kann. Der Anlaß dazu besteht eher in der rein metaphysischen Frage nach dem Sinn unserer wissenschaftlichen Tätigkeiten. Wenn nämlich jene Möglichkeit besteht, heißt dies, daß es möglich ist, daß alle Repräsentationen der Welt, die die naturwissenschaftlichen Systeme mittels des besten uns zur Verfügung stehenden Verfahrens liefern, und die Welt divergieren. Wenn dem so ist, warum soll dann die Existenz der physikalischen Außenwelt hier eine Ausnahme sein? Diese Frage ist rein metaphysischer Natur, wie ihre Lösung:

"Wenn wir hierbei nur ganz klar erkannte Prinzipien benutzen und alles in mathematischer Konsequenz daraus ableiten, und wenn dann das so Abgeleitete mit allen Naturerscheinungen genau übereinstimmt, so würden wir sicherlich Gott beleidigen, wenn wir die auf diese Weise ermittelten Ursachen der Dinge als falsch beargwöhnten und meinten, er habe uns so unvollkommen geschaffen, daß wir selbst bei dem richtigen Gebrauche unserer Vernunft irren." (Principia iii 43; Buchenau, S. 80) (44 $^{64}$

Es ist überhaupt nicht zu unterschätzen, wie genial es ist, daß Descartes darin nicht das Ende der Wissenschaft, sondern einen Leitfaden zu "neuen Reichtïmern", einen neuen Anfang der Philosophie gesehen hat, was in den Regulae für ihn nicht in Frage kam.

\section{Fazit}

\footnotetext{
64. "Et certe, si nullis principiis utamur nisi evidentissime perspectis, si nihil nisi per Mathematicas consequentias ex iis deducamus, \& interim illa quae sic ex ipsis deducemus, cum omnibus naturae phaenomenis accurate consentiant, injuriam Deo facere videremur, si causas rerum, hoc pacto a nobis inventas, falsas esse suspicaremur, tanquam si nos tam imperfectos genuisset, ut ratione nostra recte utendo fallamur."(AT VIII, S. 99) Siehe auch Principia, die letzten Paragraphen 206 und 207, AT VIII, S. 328-9
} 
Wie ich mehrmals in der Einleitung dieses Teils und im Fazit des ersten Kapitels angedeutet habe, geht es bei meiner Betrachtung des Problems des Skeptizismus bei Descartes in erster Linie nicht darum, eine Antwort auf die Motivationsfrage zu finden. Der Hauptanlaß und damit das Hauptinteresse dieser Betrachtungen war eigentlich die Frage, wie man mit dem Problem des Skeptizismus Descartes' umgehen kann oder soll. Die Motivationsfrage habe ich lediglich als ein Mittel benutzt, um zu zeigen, daß Descartes nicht auf das Problem des Skeptizismus gekommen ist, weil er falsche Voraussetzungen oder falsche Annahmen gemacht hat. Dafür ist er, wie wir gesehen haben, zu einsichtsvoll. Vergessen wir nicht, daß er selbst zu wissen behauptet, daß niemand mit gesundem Verstand die Existenz der Außenwelt in Frage stellen wird. Aber er hat trotzdem jenen Versuch gemacht.

Welche Konsequenz kann man aus der Betrachtung dieses Teils ziehen? Die einzige Konsequenz, die ich daraus ziehen möchte, ist die, daß man das Problem des Skeptizismus bei Descartes sowohl von seinen erkenntnistheoretischen als auch von seinen naturwissenschaftlichen Überlegungen trennen und als ein rein metaphysisches Problem behandeln muß. Die erste Meditation liefert eine unentbehrliche Grundlage zur Metaphysik, wie der Titel der Meditationes sagt.

Ich hoffe, daß meine Auseinandersetzung mit Williams und Mackie gezeigt hat, welche Probleme der erste Fall aufwirft. Hinsichtlich des zweiten Falls habe ich Buchdahl vor Augen. ${ }^{65}$ Obwohl ich im großen und ganzen seiner wissenschaftstheoretischen Analyse von Descartes' naturwissenschaftlichen Überlegungen zustimme, ist das, was ich bei ihm problematisch finde, die grundlegende Perspektive, von der aus er das Problem des Skeptizismus bei Descartes, oder anders ausgedrückt, seine Metaphysik, seine naturwissenschaftlichen Überlegungen und ihre Beziehungen zueinander betrachtet. Buchdahl geht nämlich davon aus, daß Descartes' Metaphysik in einem sehr engen Zusammenhang mit seinen naturwissenschaftlichen Überlegungen steht, und hat damit völlig Recht. Descartes hat selbst gesagt, daß die Metaphysik die Wurzel eines Baumes sei, dessen Stamm die Physik und dessen Zweige alle übrigen Wissenschaften seien. Aber das Problem liegt in der Frage, wie dies verstanden werden soll. Buchdahl interpretiert dieses Verhältnis folgendermaßen: ${ }^{66}$

"The logic of the programme of maximum elimination of error by means of a retrenchment of everything except 'ideas' has also carried in its train a second consequence for Descartes' ontology. The desired avoidance of 'erroneous judgements', so we have found, is again and again interpreted as the requirement that our comprehension of ideas should exclude not only all consideration of the purely 'sensory' aspects, but further (and more importantly), all

\footnotetext{
65. Siehe Buchdahl, Introduction und S. 155-180.

66. Wir haben oben auch gesehen, wie Buchdahl die Metaphysik und die Physik in einem anderen Zusammenhang miteinander in Verbindung gebracht hat.
} 
reference to 'external things'. Safety from error comes to be interpreted as withdrawal of the mind from the world 'outside' and of its attending solely to its own ideas which it possesses 'innately' and of itself. The problems that arise from this fateful development are as follows. No doubt, there is an external world endowed with sensory qualities, and comprehensible by the methods and investigations of science." (S. 155; Hervorhebung d. Verf.)

Wie wir hier sehen können, betrachtet Buchdahl das Problem des Skeptizismus bei Descartes als ein rein theoretisches Problem, das bei dem Aufbau eines naturwissenschaftlichen Systems einzig und allein durch eine grundlegende Annahme des Systems aufgeworfen wird. Deshalb kommt er zu dieser Ansicht:

"The problem is now whether it is possible to construct in an alternative way (by a process of 'reduplication') that external world of which the 'methodological doubt' seems for the moment to deprive us." (ebd.)

Dies ist die Behauptung, daß Descartes, da sich "Ideen" (als "basic inventory of the world") wegen der in dem ersten Zitat genannten Problematik als unzureichend für den Aufbau eines Systems (too partial, too narrow und too unstable) erweisen, Wege finden muß, auf denen dies kompensiert werden kann. Dies zwingt Descartes seiner Meinung nach dazu, einen anderen Faktor in sein System einzuführen. Dieser andere "Faktor", dies "metaphysical supplement" ist Gott.

Dies zeigt unmißverständlich, daß Buchdahl die Metaphysik bei Descartes eher als ein Element innerhalb eines naturwissenschaftlichen Systems behandelt. Dies aber halte ich für problematisch. Wie wir gesehen haben, steht die Metaphysik bei Descartes über oder unter der Physik, aber nicht innerhalb der Physik.

Wichtig ist vor allem, daß dieser Fehler kein Zufall ist, sondern ein Ergebnis der grundlegenden, aber sehr problematischen Perspektive, die Buchdahl einnimmt. Er vermittelt nämlich den Eindruck, als ob man mit der rechten Hand ein naturwissenschaftliches System aufbauen kann, indem man in der linken Hand "die Welt hält", so daß man ohne weiteres sehen kann, was man im System hinzufügen muß. Darüber hinaus vermittelt er den Eindruck, als ob wir diesen Prozeß nachprüfen können, indem wir die Welt und das System vergleichen, wobei wir wiederum die Welt zur Linken und das System zur Rechten haben. Obwohl dieses Bild in einem gewissen Sinne wahr ist, ist Buchdahls Betrachtungsweise meiner Meinung nach so schematisch, daß man an ihrer Richtigkeit zweifeln muß.

Abgesehen davon bin ich der Meinung, daß das Problem des Skeptizismus von Anfang an ein metaphysisches Problem ist, genauso wie seine Lösung metaphysisch ist. Es liefert Descartes nämlich die Grundlage zur Metaphysik. Wenn diese Konsequenz richtig ist, folgt daraus, daß man die Meditationes nicht als die erste Quelle zum Verständnis seiner Erkenntnistheorie und damit auch der Repräsentationstheorie benutzen darf, - oder nur, wenn man das Problem des 
Skeptizismus davon völlig abtrennt. Dies ist der Grund dafür, daß ich glaube, daß die Art und Weise, wie Wilson und Hatfield mit den Meditationes umgehen, die beste ist, aber nur dann, wenn das Problem des Skeptizismus bei Descartes irrelevant ist. Da ich aber das Problem des Skeptizismus für ernst und wichtig bei Descartes halte, ist die beste Art damit umzugehen entweder die von Moore oder die von Descartes. 


\section{Zweiter Teil: Das Problem des Skeptizismus bei Locke}

\section{Einleitung}

Während es fast selbstverständlich ist, Descartes in Verbindung mit dem Problem des Skeptizismus zu bringen, scheint dies für Locke nicht der Fall zu sein. Daß es im Essay drei Stellen gibt, ${ }^{1}$ an denen sich Locke mit dem Problem des Skeptizismus auseinanderzusetzen scheint, ändert daran nichts. Wenn man einfach aufgrund dieser Stellen Locke in Verbindung mit dem Problem des Skeptizismus bringen will, muß man wissen, daß dies Einwände hervorruft. Dabei geht es nicht einfach um die Frage, ob nicht aufgrund der geringen Anzahl jener Stellen die Annahme fragwürdig wird, daß Locke sich mit dem Skeptizismus auseinandergesetzt hat. Es geht vielmehr um den Einwand, daß Lockes Unternehmen im Essay nichts mit dem Skeptizismus zu tun hat, weil Lockes Programm kein Rechtfertigungsprogramm enthält. "He (Locke; d. Verf.) in facts accepts from the beginning that there are objects about which we acquire ideas and knowledge ... His enquiry into the original, certainty and extent of knowledge is descriptive, not justificatory" behauptet zum Beispiel Yolton. ${ }^{2}$ Vielleicht ist dies der Grund dafür, daß die Art und Weise, wie Locke das Problem des Skeptizismus behandelt, nicht den Eindruck vermittelt, daß er sich damit ernsthaft auseinandersetzt, sondern eher den Eindruck, daß er das Problem ignoriert, so, als würde er es nur erwähnen, um die Erwartung der Leser zu erfüllen, die aufgrund von Lockes ständiger Auseinandersetzung mit Descartes im Essay auch eine Behandlung des Skeptizismusproblems erwarten könnten.

Kann man unter diesen Umständen Locke sinnvollerweise in Verbindung mit dem Problem des Skeptizismus bringen? Selbst Mackie, der trotz der obigen Einwände das Problem des Skeptizismus bei Locke mit Rekurs auf seine Repräsentationstheorie behandelt, sagt am Ende:

"Reading the Essay as a whole, one certainly does not get the impression that the representative theory had anything like the importance for Locke himself that it has had for his critics from Berkeley onwards. It was something that he took pretty much for granted, rather than something that he was specially concerned to put forward, develop, and defend.' ${ }^{13}$

Vor dem Hintergrund dieses Bedenkens und der genannten Einwände möchte ich hier Locke in Verbindung mit dem Skeptizismus bringen. Deswegen ist es zunächst nötig darauf

\footnotetext{
1. IV.II.14., IV.IV.1-5. und IV.XI.1-8. Auf Stellen im Essay wird im Folgenden durch Angabe von Buch, Kapitel und Sektion verwiesen.

2. Yolton, Locke and the Compass of Human Understanding, S. 14. Vgl. Aaron, John Locke, S. 79.

${ }^{3}$. Mackie, Problems from Locke, S. 71.
} 
hinzuweisen, daß jene Bedenken und Einwände auf der Vorstellung beruhen, daß sich Locke, wenn er überhaupt etwas mit dem Problem des Skeptizismus hätte zu tun haben wollen, damit direkt beschäftigt hätte. Er hätte seine Position dazu klar und deutlich dargelegt, indem er direkt entweder dafür oder dagegen argumentiert hätte. Doch dies besagt nicht, daß es unmöglich ist, Locke sinnvoll in Verbindung mit dem Problem des Skeptizismus zu bringen. Dies ist sogar notwendig, um das gesamte Programm Lockes im Essay adäquat zu verstehen und zu bewerten. Dies zu zeigen, ist die Aufgabe dieses Teils. Dazu soll für folgende drei Thesen argumentiert werden.

Der erste Punkt ist der, daß es ein erklärungsbedürftiges Phänomen im Essay gibt, das nicht ohne weiteres nachvollziehbar ist, und zwar um so weniger, als man darauf beharrt, daß Lockes Programm ein rein beschreibendes ist. Der zweite Punkt ist der, daß die Diskussion über dieses Phänomen für die Interpretation des Essays von großer Bedeutung ist. Der letzte Punkt ist der, daß das Phänomen im Rekurs auf das Problem des Skeptizismus am besten verstanden werden kann. 


\section{Darlegung des Vorhabens}

\section{I. Ein erklärungsbedürftiges Phänomen (I)}

Mit dem bemerkenswerten Phänomen ist zuallererst Lockes Position gegenüber der Korpuskular-Theorie gemeint. Beginnen wir also mit dieser Frage: Wie steht Locke zur Korpuskular-Theorie, nach der alle physikalischen Gegenstände aus unbeobachtbar kleinen Partikeln in verschiedenen Weisen zusammengesetzt sind, wobei diese nur primäre Qualitäten besitzen? Auf diese Frage kann wie auf die Frage nach dem Problem des Skeptizismus bei Locke sofort mit der Gegenfrage reagiert werden, ob dies für die Interpretation des Essay eine sinnvolle Frage ist, ganz abgesehen von ihrer Wichtigkeit. Wie man aus seinem Brief an die Leser des Essay erfahren kann, scheint Lockes Ausgangsposition auf den ersten Blick dagegen zu sprechen. Er versteht sich nämlich weder als Naturwissenschaftler noch will er so verstanden werden. ${ }^{4}$ Er ist der Meinung, daß es auf naturwissenschaftlichem Gebiet genug fähige Leute gibt, etwa Boyle, Sydenham, Newton, so daß es viel vernünftiger sei, die naturwissenschaftlichen Untersuchungen ihnen zu überlassen. Was er im Essay vorhat, ist demzufolge nicht eine naturwissenschaftliche Arbeit, sondern etwas Anderes:

"This, therefore, being my Purpose to enquire into the Original, Certainty, and Extent of humane Knowledge; together, with the Grounds and Degrees of Belief, Opinion, and Assent"s

Dafür, so betont er, seien weder physikalische noch physio-psychologische Untersuchungen oder Spekulationen nötig, sondern allein die Untersuchung unserer kognitiven Fähigkeiten mittels der beschreibenden Methode.

Kann es unter diesen Umständen Raum für eine Diskussion von Lockes Position gegenüber der Korpuskular-Theorie geben? Diese Umstände müssen uns, so könnte man einwenden, nicht unbedingt daran hindern, nach Lockes Position zur Korpuskular-Theorie zu fragen. Versteht man unsere Frage demnach einfach als die Frage, welche Meinung Locke dazu hat, ist sie klar und deutlich zu beantworten. Er sagt an einigen Stellen des Essay unmißverständlich, daß die Korpuskular-Theorie die beste Hypothese liefere und vielleicht nicht einmal zu übertreffen sei. ${ }^{6}$ Können wir nun sagen, daß damit unsere Frage erledigt ist? Es sieht so aus. Laudan aber sieht dies nicht so. Er fragt sich nämlich, was es heißen soll, eine Hypothese, in diesem Fall die Korpuskular-Theorie, für die beste zu halten. Seiner Meinung nach wird man, wenn man sie für die beste Hypothese hält, weiter der Ansicht sein, daß sie dem Versuch der

\footnotetext{
${ }^{4}$. Vgl. Locke S. 9-10.

5. I.I.2.

${ }^{6}$. am deutlichsten in IV.III.16.
} 
Erklärung der Naturphänomene zugrunde gelegt werden muß. ${ }^{7}$ Daraus zieht er folgerichtig die Konsequenz, daß Locke der Ansicht sei, daß die Korpuskular-Theorie beim Versuch der Erklärung der Naturphänomene eine entscheidende Rolle spielen müsse, daß, mit anderen Worten, bei naturwissenschaftlichen Untersuchungen das sogenannte "hypothetisch-deduktive" Verfahren angewandt werden müsse: viele Naturphänomene zu beobachten, Hypothesen zur Erklärung der Phänomene im Rahmen der Korpuskular-Theorie zu bilden, und sie durch weitere Beobachtungen und Experimente nachzuprüfen und zu korrigieren.

Obwohl ich nicht behaupten will, daß der Vordersatz von Laudans Konditionalsatz den Hintersatz logisch impliziert, halte ich dennoch seine Behauptung für plausibel. Woran liegt es dann, daß Laudan trotz der Plausibilität seiner Position es für nötig befunden hat, sie zu betonen und darüber hinaus dafür zu argumentieren? Liegt es, wie er behauptet, daran, daß es einige Kommentatoren wie z.B. Yost und Yolton gibt, die seiner Meinung nach irrtümlicherweise das Gegenteil behaupten? Yolton behauptet nämlich folgendes: ${ }^{8}$

"There can be no question about Locke's acceptance of the corpuscular theory as an account of the nature of matter and as an explanation of the causation of perception. I can find no evidence that the account of the science of nature Locke gives recommended using the corpuscular hypothesis as a way of discovering new observable qualities of bodies. Nor did Locke's account urge us to use, or say that scientists were using, that hypothesis to explain all phenomena in the natural histories."

Nun ist zunächst die Frage, wer von beiden Recht hat. Es gibt keinen Zweifel (IV.III.16), daß Locke die Korpuskular-Theorie nicht nur für die beste Theorie hält, sondern auch von ihr zu dem von Yolton genannten Zweck im Essay Gebrauch macht. Andererseits ist es auch wahr, daß es eine Stelle (IV.XVI.12.) gibt, an der Locke sich zum hypothetisch-deduktiven Verfahren im Rahmen der Korpuskular-Theorie geäußert hat. Trotzdem geht es viel zu weit, wenn man wie Laudan daraus folgert, daß Locke für naturwissenschaftliche Untersuchungen das hypothetisch-deduktive Verfahren im Rahmen der Korpuskular-Theorie empfiehlt. Lockes Äußerung dazu hat nicht mehr als den Wert einer Nebenbemerkung. Sie ist die einzige dazu im ganzen Essay und beansprucht nicht mehr als eine Seite. Im Kontrast dazu muß man sehen, an wievielen Stellen Locke als die richtige Methode für naturwissenschaftliche Untersuchungen die Methode der Beschreibung von beobachtbaren Qualitäten empfiehlt. ${ }^{9}$

\footnotetext{
7. Vgl. Laudan, The Nature and Sources of Locke's Views on Hypotheses in Locke on Human Understanding, S. 150. Alexander schließt sich Laudan in dieser Hinsicht an. Vgl. Alexander, Ideas, Qualities and Corpuscles, S. 7-8.

8 . Yolton, S. 64.

9. Vgl.II.XXXI.8. Aus diesem Grund vergleicht Locke eine derartige Aufgabe sogar mit der mühevollen Herausgabe eines Lexikons von "a Natural History" (III.XI.24-25).
} 
Wenn dem so ist, stellt sich die Frage, warum sich Locke so verhält. Warum verhält er sich so unverständlich? Oder tut er dies nicht? Yolton sieht es nicht so. Er behauptet bezüglich der oben zitierten Stelle Folgendes:

"he (gemeint ist Laudan; d. Verf.) is not as clear as he might be about the difference between (a) accepting the corpuscular hypothesis, (b) recommending that hypothesis as a tool for empirical discovery."

Kann man (a) und (b) derart trennen? Dies fällt, wie gesagt, schwer. Ich vermute, daß dies auch Yolton so sieht. Sonst hätte er den Versuch unterlassen können, Lockes Verhalten mit einem historischen Rückgriff verständlich zu machen. Um Lockes Verhalten richtig zu verstehen, sei es, so behauptet Yolton, nicht nur hilfreich, sondern auch notwendig, es in Verbindung mit der Royal Society und ihrem allgemeinen Programm zu bringen ${ }^{10}$ Seiner Meinung nach sind viele Historiker der Naturwissenschaft zu sehr geneigt, die KorpuskularTheorie als einen wichtigen Bestandteil der Naturwissenschaft des 17. Jahrhunderts, insbesondere der Auffassungen der Royal Society, zu betrachten. Aber dies ist ein Irrtum (S.3-4). ${ }^{11}$ Die Royal Society war keine homogene Gruppe, und es war für die Mitglieder der Gruppe denkbar und möglich, die Korpuskular-Theorie zurückzuweisen (S. 8). Es gibt dennoch gemeinsame Ziele und Methoden, deren Ablehnung für alle Mitglieder der Gruppe undenkbar war. Es geht dabei darum "to enlarge the observational knowledge of nature by compiling natural histories of phenomena"(S. 4). Daraus zieht Yolton die Konsequenz, daß nicht die Korpuskular-Theorie und die hypothetisch-deduktive Methode, sondern gerade diese beschreibende Methode das ist, was Locke angezogen hat. Und dementsprechend formuliert Yolton das Projekt des Essays so:

"to show how the way of ideas could formulate and provide for the kind of observational knowledge of nature that his experimental friends were compiling." (S. 4)

Abgesehen von der Frage, ob Yoltons historische Erklärung richtig ist, ${ }^{12}$ kann man dennoch ohne weiteres sagen, daß sein historischer Rückgriff hinfällig ist. Es handelt sich hier nämlich nicht um die Frage, welche Meinung Locke zur Korpuskular-Theorie hat, sondern um die Frage, warum er sie nicht für naturwissenschaftliche Untersuchungen empfiehlt, obwohl er sie

\footnotetext{
${ }^{10}$. Es ist bekannt, daß Boyle, mit dem Locke Umgang hatte, ein Mitbegründer der Royal Society war, und daß Locke (und auch Sydenham) deren Mitglied war.

${ }^{11}$. Vgl. Yolton, ebd., insbesondere Kapitel II.

${ }^{12}$. Ayers vertritt eine andere Ansicht: "An Essay concerning Human Understanding was a late product of that amazing period in which the Aristotelian view of the natural world, under attack throughout the Renaissance, was finally overthrown and replaced by mechanistic corpuscularianism" Ayers, Locke, Bd I, S. 13.
} 
für die beste Hypothese hält. ${ }^{13}$ Dennoch schadet dieser Irrtum Yolton nicht, denn die Frage, die er damit eigentlich stellen wollte, ist eher die grundsätzliche, ob die Diskussion über Lockes Verhältnis zur Korpuskular-Theorie für die Interpretation des Essays hilfreich ist. Dies wäre der Fall, wenn Lockes Projekt, wie Yolton sagt, in der Tat von Anfang an einzig und allein darauf beschränkt war zu zeigen, wie "die Betrachtung der Vorstellungen" beobachtbare Erkenntnisse über die Natur liefern kann. Ist dies der Fall? Auf den ersten Blick scheint dem so zu sein.

Locke vertritt nachdrücklich die Meinung, daß Erkenntnis von beobachtbaren Qualitäten und die Fähigkeit, sie zu praktischen Zwecken zu verwenden, unabhängig von der Erkenntnis der Ursachen der beobachtbaren Qualitäten ist. Um mit seinem Beispiel zu sprechen, kann ein Maler nicht nur eine bessere Kenntnis der Farben als ein Physiker besitzen, sondern auch besser dazu in der Lage sein, sie erfolgreich zu einem praktischen Zweck zu verwenden. ${ }^{14}$ So konnte er wohl weiter auf die Idee kommen, daß es weder nötig noch hilfreich sei, sich auf eine physikalische Untersuchung der Mikrostruktur der Farben einzulassen, um Kenntnisse über die Farben zu erweitern. Diese Überlegungen konnte Locke machen, auch wenn er die Korpuskular-Theorie vertrat. Wenn dem so ist, haben wir hier einen typischen Fall, in dem (a) und (b) auseinandergehalten werden. Und in diesem Fall erweist sich die Diskussion darüber als irrelevant, welche Meinung der Maler über die Korpuskular-Theorie hat, geschweige denn, ob er sie für die beste hält.

Wie verständlich dieses Beispiel die Ausgangsposition und den Charakter des Lockeschen Projektes auch machen mag, so gibt es hier dennoch einen wesentlichen Unterschied. Wie sehr auch Lockes Formulierung seines Projektes an der oben zitierten Stelle (I.I.2) und seine Erklärung zur Anwendung der beschreibenden Methode jene Yoltonische Auffassung des Projektes von Locke zu bestärken scheint, so ist doch diese Auffassung irreführend und in einer wichtigen Hinsicht falsch. Warum dem so ist, kann folgendermaßen erklärt werden.

Hinsichtlich des in I.I.2. erwähnten Projektes geht Locke in der Tat davon aus, daß wir Erkenntnisse, Meinungen, und auch Phantasms, Notions, Species, oder Sonstiges in uns haben, wovon und womit wir im weitesten Sinne von "Denken" denken. ${ }^{15}$ Was er sich zur Aufgabe stellt, ist, die Wege zu beschreiben, auf denen wir einerseits solche Materialien des Denkens erwerben und aus denen wir andererseits Erkenntnisse und Meinungen gewinnen. Dieses Projekt ist ohne Zweifel ein analytisch-deskriptives Projekt. Aber es ist dennoch ein Irrtum zu glauben, daß das gesamte Projekt des Essays einzig und allein im analytischdeskriptiven Projekt besteht, so als würde dieses analytisch-deskriptive Projekt gleichsam als

\footnotetext{
${ }^{13}$. Ayers ist sogar der Meinung, daß Locke in Folge seines aktiven Interesse an der Medizin und der Korpuskular-Theorie unter dem Einfluß von Boyle und Sydenham seine Position gegen den Dogmatismus einnehmen und die Bedeutung von Erfahrung für Naturwissenschaften erkennen konnte. Vgl. Ayers. ebd.

${ }^{14}$. Vgl. II.VIII.2. und III.VI.24.

${ }^{15}$. Vgl. I.I.8.
} 
Selbstzweck durchgeführt. Wie Locke bereits in I.I.2. andeuten zu wollen scheint, ist dies nicht der Fall. Er glaubt nämlich, daß das analytisch-deskriptive Projekt einem anderen, nämlich dem kritischen Projekt dienen werde, eine generelle Grenze von Gegenstandsbereichen zu ziehen: zwischen dem, wovon Erkenntnis möglich ist, und dem, wovon Erkenntnis nicht möglich ist. Es geht darum:

"to search out the Bounds between Opinion and Knowledge". ${ }^{16}$

Wichtig ist aber dabei, daß auch dieses Projekt zusammen mit dem bereits genannten analytisch-deskriptiven Projekt nicht das gesamte Projekt des Essays erschöpft. Wenn dem so wäre, würde sein Projekt einfach darauf abzielen, dem Leser zu zeigen, mit welchen Gegenständen sie sich beschäftigen sollen. Die Antwort wäre natürlich diese: Mit den Gegenständen, von denen Erkenntnis möglich ist. Aber dies wäre unplausibel. Da Erkenntnis bei Locke Erkenntnis von Aussagen ist, deren Wahrheit entweder durch Intuition oder Demonstration (Deduktion) erkannt werden kann, ${ }^{17}$ sind die Gegenstandsbereiche, von denen die so ausgezeichnete Erkenntnis möglich ist, für Locke nur Mathematik und Ethik und decken zu wenig ab. Wir haben nämlich viel mehr mit solchen Gegenständen zu tun, zu denen wir zwar Zugang haben (diesen gewinnen wir nach Locke durch "sensitive knowledge of the existence of particular external Objects" (IV.II.14)), aber bei denen Erkenntnisse im so ausgezeichneten Sinne nicht möglich sind. Was die Ansicht darüber hinaus noch unplausibler macht, ist, daß wir nicht umhin können, mit jenen Gegenständen etwas zu tun zu haben.

$\mathrm{Da}$ Locke nicht auf eine solche Ungereimtheit verfällt, zeigt sich daran, daß die Frage, für die er sich am meisten interessiert und die er in seinem Projekt zuallerletzt $\mathrm{zu}$ beantworten versucht, eher die ist, wie wir uns zu Gegenständen verhalten sollen, von denen Erkenntnis im ausgezeichneten Sinne nicht möglich ist. Es geht ihm darum:

"(to; d. Verf.) examine by what Measures, in things, whereof we have no certain Knowledge, we ought to regulate our Assent, and moderate our Perswasions." ${ }^{118}$

So gesehen erlaubt die oben genannte generelle Grenze von Gegenstandsbereichen nur eine restriktive Antwort auf diese Frage. Sie besagt, daß es genau so hinfällig ist, in Bezug auf Gegenstände, von denen Erkenntnis im ausgezeichneten Sinne nicht möglich ist, Erkenntnis zu erwarten und zu suchen, wie sich zu beklagen, daß wir nicht in der Lage sind, solche Erkenntnis zu erwerben. Lockes Meinung nach besitzen wir nämlich auch Meinungen, die zwar nicht den Status der Erkenntnis im ausgezeichneten Sinne haben, aber notwendig und

\footnotetext{
${ }^{16}$. I.I.3.

${ }^{17}$. Vgl. IV.I. und II.

18 . I.I.3.
} 
ausreichend für die Zwecke unseres Alltags sind. ${ }^{19}$ Aber diese restriktive Antwort ist nur ein Teil von Lockes Antwort. Er ist nämlich fest davon überzeugt, daß es möglich ist, sehr viel mehr, verläßliche und nützliche Meinungen zu erwerben, wenn wir die richtige Methode dazu finden. Dies können wir tun, wenn wir zuvor unsere Erkenntnisfähigkeiten und ihre Funktionsweise erschöpfend erkannt haben (I.I.5-6). Dies zu zeigen, ist ein sehr wichtiges Ziel des Essays, und um dies zu zeigen, benötigt Locke auch eine kritische Überlegung darüber, welche Methode angemessen ist, und vor allem warum. Wenn dem so ist, darf und kann jene Yoltonische Darstellung des Projektes von Locke nicht im Sinne eines von vornherein gesetzten Ziels verstanden werden, sondern eher als die Konsequenz seiner kritischen Überlegung. Gerade hierin liegt der Grund dafür, daß die Diskussion von Lockes Position zur Korpuskular-Theorie Bedeutung für die Interpretation des Essays hat. Dies berechtigt uns, die folgende Frage zu stellen: Warum empfiehlt Locke für naturwissenschaftliche Untersuchungen nicht das hypothetisch-deduktive Verfahren im Rahmen der Korpuskular-Theorie, wenn er diese doch für die beste hält? Ist dies nicht merkwürdig? $?^{20}$

\footnotetext{
${ }^{19}$. Vgl. I.I.5 und IV.XI.10.

${ }^{20}$. Wie wir später sehen werden, rät Locke darüber hinaus vom hypothetisch-deduktiven Verfahren ab.
} 


\section{II. Ein neues Problem}

Während die Überlegungen im letzten Abschnitt die Frage nach Lockes Position zur Korpuskular-Theorie und damit auch die Zielsetzung dieses Teils sinnvoll erscheinen läßt, ergibt sich dennoch eine negative Auswirkung auf mein Vorhaben. Damit meine ich folgendes. Ich habe in der Einleitung erwähnt, daß es im Essay drei Stellen gibt, an denen sich Locke mit dem Problem des Skeptizismus auseinanderzusetzen scheint. Wir haben gesehen, daß Lockes Projekt nicht nur einen analytisch-deskriptiven, sondern auch einen kritischen Teil enthält. Wenn dem so ist, scheint es, da die drei Stellen im kritischen Teil auftreten, so zu sein, daß wir sie als ein Zeichen dafür verstehen müssen, daß Locke seine kritischen Überlegungen nicht nur in Bezug auf die Frage nach der Methode, sondern darüber hinaus auch in Bezug auf die Frage nach der Möglichkeit der Erkenntnis der physikalischen Außenwelt überhaupt anstellen wollte. Wenn dem so ist, scheint es weiter so zu sein, daß wir diese Auseinandersetzung als solche zur Kenntnis nehmen müssen. Gerade dies wirft für mein Vorhaben ein schwerwiegendes Problem auf. Besteht damit nämlich die Möglichkeit, Locke direkt in Verbindung mit dem Problem des Skeptizismus zu bringen, so kann man fragen, wozu ein Versuch dienen soll, ihn indirekt in Verbindung mit dem Problem des Skeptizismus zu bringen. Ist es nicht viel vernünftiger, das Thema des Skeptizismus bei Locke auf jene drei Stellen zu beziehen, und zur Erklärung von Lockes Position zur Korpuskular-Theorie andere Antworten zu suchen? Dieses Problem wird noch schwerwiegender, wenn man im Essay Argumente oder Gedankengänge finden kann, die uns nachvollziehen lassen, warum Locke vom hypothetisch-deduktiven Verfahren im Rahmen der Korpuskular-Theorie abrät. Aus diesem Grund will ich hier folgendermaßen verfahren.

Erstens werde ich versuchen, meine Behauptung in der Einleitung zu untermauern, daß die Stellen, an denen sich Locke mit dem Problem des Skeptizismus auseinanderzusetzen scheint, in Wirklichkeit nicht als Auseinandersetzung zu verstehen sind. Zweitens werde ich versuchen zu zeigen, daß es im Essay kein nachvollziehbares Argument dafür gibt, daß Locke vom hypothetisch-deduktiven Verfahren abrät. Drittens werde ich versuchen, das erklärungsbedürftige Phänomen mit Rekurs auf das Problem des Skeptizismus zu erklären. 


\section{Versuche der Lösung des neuen Problems}

\section{I. Übergang zu dem neuen Problem}

Wie gesagt gibt es im Essay drei Stellen (IV.II.14, IV.IV.1-5. und IV.XI.1-8.), an denen sich Locke mit dem Problem des Skeptizismus auseinanderzusetzen scheint. In IV.II.14. tritt das Problem des Skeptizismus im Zusammenhang mit dem Traumargument auf, in IV.IV. 1-5. im Zusammenhang mit der Repräsentationstheorie. IV.XI.1-8. ist eine Wiederaufnahme der beiden anderen Stellen. Ich werde die erste Stelle außer Acht lassen, da man Lockes Ausführungen dort kaum für eine echte Auseinandersetzung halten kann. Lockes Motivation liegt nämlich nicht darin, daß er im Traumargument einen Anlaß zum Skeptizismus gefunden und es deswegen für nötig gehalten hätte, das Problem des Skeptizismus zu lösen; vielmehr wollte Locke seine Auffassung zum Ausdruck bringen, daß jenes Problem absurd sei. Wenn Locke sich also mit dem Problem direkt und ernsthaft beschäftigt haben soll, muß es an der zweiten Stelle geschehen sein, und ein Teil dieser Stelle scheint eindeutig dafür zu sprechen:

" 'Tis evident, the Mind knows not Things immediately, but only by the intervention of the Ideas it has of them. Our Knowledge therefore is real, only so far as there is a conformity between our Ideas and the reality of Things. But what shall be here the Criterion? How shall the Mind, when it perceives nothing but its own Ideas, know that they agree with Things themselves?" (IV.IV.3) ${ }^{1}$

Mackie versteht Lockes Frage an dieser Stelle, woher wir wissen, ob Vorstellungen auf etwas referieren, als die universale skeptische Frage nach der Möglichkeit der Erkenntnis der physikalischen Außenwelt. Wenn man sie so versteht, liegt Lockes Motivation zur Auseinandersetzung mit dem Problem des Skeptizismus in der Repräsentationstheorie. Jene Frage beruht nämlich eindeutig und ausschließlich auf dem besonderen Status, den Locke den Vorstellungen zuschreibt: Diese sind die direkten Gegenstände der Wahrnehmung, die von physikalischen Gegenständen ontologisch distinkt sind und sich in dem wahrnehmenden Subjekt befinden. ${ }^{2}$ Wenn dem so ist, scheint es auf den ersten Blick so zu sein, daß man Lockes Auseinandersetzung mit dem Problem des Skeptizismus an dieser Stelle für ernsthaft halten muß. Aber ist die Frage, woher wir wissen, ob Vorstellungen auf etwas referieren, in der Tat die universale skeptische Frage? Ist es vielleicht nicht so, daß das Thema des

\footnotetext{
${ }^{1}$. Locke sagt in IV.I.1.: "the Mind, in all its Thoughts and Reasonings, hath no other immediate Object but its own Ideas"

2. Diesen Status der Vorstellungen will ich im folgenden kurz "den ontologischen Status (der Vorstellungen)" nennen.
} 
Skeptizismus bei Locke schon an der ersten Stelle, an der das Traumargument auftritt, erledigt ist, und daß er mit jener Frage auf etwas Anderes hinaus wollte? Im folgenden will ich versuchen diese Vermutung zu untermauern. Zu diesem Zweck werde ich drei repräsentative Stellen (II.VIII.1., II.XXX.2. und IV.IV.III.1.) "relativieren", an denen Locke die Repräsentationstheorie in einer Art und Weise zu vertreten scheint, in der sie das Problem des Skeptizismus aufwirft. Bevor ich aber darauf eingehe, will ich hier zunächst den Versuch machen, jene Frage Lockes zu "neutralisieren", da sie auf den ersten Blick eindeutig für Mackie zu sprechen scheint.

Erinnern wir uns daran, welchen Problemen die traditionelle Auffassung der Repräsentationstheorie ausgesetzt ist. Sie zeichnet sich dadurch aus, Vorstellungen den ontologischen Status zu verleihen, und sieht die Problematik der Repräsentationstheorie gerade in dem ontologischen Status der Vorstellungen, die uns von der physikalischen Außenwelt angeblich völlig "abschneiden". Dabei besteht aber das entscheidende Problem darin, daß sie nicht erklären kann, was unter jenem ontologischen Status verstanden werden soll. Die einzige Möglichkeit, ihn zu verstehen, besteht demnach darin, ihn von dem Standpunkt der skeptischen Konklusion aus zu verstehen, die dann aber unabhängig von dessen Verständnis vollzogen werden muß. Dies war der Grund dafür, daß ich die traditionelle Auffassung als Interpretation der Repräsentationstheorie für verfehlt erklärt habe. Ich habe keinen Zweifel daran, daß auch Mackie dieses Problem gesehen hat. Dies macht verständlich, daß er zuerst versucht hat, die Repräsentationstheorie ohne Bezugnahme auf das Problem des Skeptizismus verständlich zu machen. Aber trotz all dem teilt Mackie in einer wesentlichen und entscheidenden Hinsicht die traditionelle Auffassung. Aus welchen Gründen auch immer ist er nämlich davon überzeugt, daß man, wenn man die Repräsentationstheorie vertritt, zur Auseinandersetzung mit dem Problem des Skeptizismus gezwungen ist. Deshalb glaubt er, daß eine positive Antwort auf die Frage, ob die von ihm entwickelte Wahrnehmungstheorie als eine Repräsentationstheorie akzeptiert werden kann, einfach durch den Hinweis gegeben werden könne, daß sie den Anlaß zu dem Problem des Skeptizismus gebe. Ich glaube, daß nicht Lockes Formulierung im Zitat, sondern eher ein solcher Gedanke der entscheidende Grund dafür gewesen ist, daß er die Frage, woher wir wissen, ob Vorstellungen auf etwas referieren, als die universale skeptische Frage verstanden hat. Der beste Beleg dafür ist folgende Stelle:

"as it would not have arisen if he had been a direct realist (or even if he had held what Jackson calls a 'mixed view', and had been a direct realist about primary qualities only). (Hervorhebung d. Verf.) ${ }^{3}$

\footnotetext{
${ }^{3}$. Mackie, S. 40. Eigentlich tritt dieses Zitat im Zusammenhang mit einer anderen Stelle (IV.XI.1-2) auf.
} 
Dieser Schluß ist eindeutig zirkulär. Mackie setzt nämlich ohne weiteres voraus, daß die Frage, woher wir wissen, ob Vorstellungen auf etwas referieren, die universale skeptische Frage ist, und zieht daraus die Konsequenz, daß Locke den "mixed view" von Jackson nicht vertritt. Aber es ist durchaus möglich, daß Locke in Wirklichkeit den "mixed view" von Jackson vertritt. ${ }^{4}$ In diesem Fall steht die Möglichkeit offen, jene Frage nicht als die universale skeptische Frage $\mathrm{zu}$ verstehen. $\mathrm{Ob}$ also jene Frage als die universale skeptische Frage verstanden werden kann und soll, kann nicht einfach dadurch entschieden werden, ob Locke die Repräsentationstheorie vertritt, sondern vielmehr danach, wie er sie vertritt. Demgemäß will ich im Folgenden versuchen zu zeigen, daß Locke die Repräsentationstheorie genau in derselben Art vertritt, wie Descartes es tut, so daß jene Frage nicht als die universale skeptische Frage verstanden werden darf. ${ }^{5}$ Ich werde dies, wie gesagt, dadurch tun, daß ich drei repräsentative Stellen "relativiere", an denen Locke die Repräsentationstheorie in einer Art und Weise zu vertreten scheint, in der sie das Problem des Skeptizismus aufwirft.

\footnotetext{
${ }^{4}$. Vgl. Jackson, Locke's Version of Representative Perception, und, Lockes Distinction between Primary and Secondary Qualities in Locke and Berkeley.

${ }^{5}$. Dies macht es unvermeidlich, daß einige Teile dieses Abschnittes sich mit dem zweiten Kapitel des ersten Teils überschneiden.
} 


\section{II. Erster Versuch der Lösung des neuen Problems: Relativierung der Position Lockes im Essay, II.VIII.1.}

Die eine von den oben genannten drei Stellen ist folgende:

"CONCERNING the simple Ideas of Sensation 'tis to be considered, That whatsoever is so constituted in Nature, as to be able, by affecting our Senses, to cause any perception in the Mind, doth thereby produce in the Understanding a simple Idea" (II.VIII.1)

Dies ist der Beginn der Einführung der Unterscheidung von primären und sekundären Qualitäten. Hier geht Locke ohnehin von Vorstellungen aus und setzt eine kausale Beziehung zwischen Vorstellungen und ihren Ursachen voraus, wobei diese überhaupt nicht spezifiziert werden. Wenn man dies als Lockes Ausgangsposition versteht, kann es als der einfachste, aber entscheidende Beleg dafür gesehen werden, daß Lockes Repräsentationstheorie in sich von Beginn an den Anlaß zum Problem des Skeptizismus enthält. Damit scheint nämlich Locke hier einerseits Vorstellungen en bloc und andererseits ihre Ursachen en bloc zu unterscheiden. Aber tut er dies wirklich? Um diese Frage zu entscheiden, will ich eine allgemeine Betrachtung darüber anstellen, worin das analytisch-deskriptive Projekt Lockes besteht und wie er es durchführen will.

II. II. 1. Lockes Ausgangsposition im analytisch-deskriptiven Projekt

Bevor Locke auf sein Projekt eingeht, entschuldigt sich er bei den Lesern, daß er nicht umhin kann, sehr häufig von dem Terminus "idea" Gebrauch zu machen:

"It being that Term, which, I think, serves best to stand for whatsoever is the Object of the Understanding when a Man thinks, I have used it to express whatever is meant by Phantasm, Notion, Species, or whatever it is, which the Mind can be employ'd about in thinking; and I could not avoid frequently using it."

Was dies betrifft, so möchte ich betonen, daß Locke hier den Terminus "idea" als terminus technicus einführt, der sowohl all das bezeichnet, worüber wir denken, als auch alle Denkmaterialien. Obwohl Locke den Anwendungsbereich des Terminus "idea" bald auf Wahrnehmungsinhalte in direkten Wahrnehmungssituationen erweitert, ist es in Bezug auf sein

\footnotetext{
${ }^{6}$. I.I.8.
} 
analytisch-deskriptives Projekt vernünftig, unter dem Ausdruck "to think" im Zitat zunächst nur "Denken" zu verstehen.

Locke will zunächst zeigen, woher wir all diese Materialien des "Denkens" (die ich im Folgenden "Vorstellungen in uns" nennen will), nämlich bildliche Vorstellungen, Begriffe, Spezies etc. haben. Eine Teilantwort ist die Folgende:

"the first Capacity of Humane Intellect, is, That the mind is fitted to receive the Impressions made on it; either, through the Senses, by outward Objects; or by its own Operations, when it reflects on them" ${ }^{\text {7 }}$

Unabhängig von der Frage, ob es noch andere Quellen gibt, aus denen "Vorstellungen in uns" stammen, können wir Locke zumindest zugeben, daß viele "Vorstellungen in uns" die äußere und innere sinnliche Wahrnehmung als Ursprung haben.

Wie verhält sich aber mit "anderen Vorstellungen in uns"? Was diese Frage betrifft, ist es wichtig darauf aufmerksam zu machen, daß Locke mit seinem analytischen Projekt nicht darauf abzielt, den Ursprung von allen "Vorstellungen in uns" zu erklären. Er stellt eine bestimmte notwendige Bedingung dafür auf, daß sein Projekt erfolgreich ist. Sie besteht darin, allein mit Hilfe der "Vorstellungen" aus den oben genannten Quellen und des Vermögens unseres Verstandes zu erklären, wie solche "Vorstellungen in uns", die nicht direkt aus den oben genannten Quellen stammen, zustande gekommen sind: ${ }^{8}$

"This (Sensation und Reflexion; d. Verf.) is the first step a Man makes towards the Discovery of any thing, and the Groundwork, whereon to build all those Notions, which ever he shall have naturally in this World. All those sublime Thoughts, which towre above the Clouds, and reach as high as Heaven it self, take their Rise and Footing here: In all that great Extent wherein the mind wanders, in those remote Speculations, it may seem to be elevated with, it stirs not one jot beyond those Ideas, which Sense or Reflection, have offered for its Contemplation. ${ }^{\prime \theta}$

In diesem inhaltlichen Zusammenhang führt Locke die Unterscheidung von einfachen und komplexen Vorstellungen ein:

"The better to understand the Nature, Manner, and Extent of our Knowledge, one thing is carefully to be observed, concerning the Ideas we have; and that is, That some of them are simple, and some complex.

Though the Qualities that affect our Senses, are, in the things themselves, so united and blended, that there is no seperation, no distance between them; yet 'tis plain, the Ideas they

\footnotetext{
7. II.I.24.

${ }^{8}$. Vgl. I.II.1.

9. II.I.24.
} 
produce in the Mind, enter by the Senses simple and unmixed. .....: which being each in it self uncompounded, contains in it nothing but one uniform Appearance, or Conception in the mind, and is not distinguishable into different Ideas." ${ }^{\text {"10 }}$

Wenn z.B. ein Tisch vor mir steht, nehme ich mit meinen Augen eine bestimmte Farbe und Gestalt wahr. Dies ist aber nicht alles. Wichtiger ist, daß ich die beiden Qualitäten zugleich und als artverschieden, aber auch als einem und demselben Gegenstand zugehörig wahrnehme. Locke geht davon aus, daß in einer direkten Wahrnehmungssituation nicht nur einfache Vorstellungen, sondern auch komplexe Vorstellungen gegeben sind. ${ }^{11}$ Die beiden Qualitäten sind, obwohl sie durch ein und dasselbe Sinnesorgan wahrgenommen worden sind, so verschieden, wie zwei Qualitäten, die durch zwei verschiedene Sinnesorgane wahrgenommen werden, wie z.B. Farbe und Geruch. Locke führt damit die Einfachheit auf die Artverschiedenheit von Qualitäten zurück, die auf der eigentïmlichen Ausstattung unserer Sinnesorgane beruht. ${ }^{12}$ Daraus folgert Locke, daß uns keine einfachen Ideen von anderer Art zur Verfügung stehen. Dafür benötigen wir andere Sinne, die wir nicht haben. Was Locke mit seinem analytischen Projekt zunächst zeigen will, ist, wie "alle Vorstellungen in uns" allein aus einfachen Vorstellungen durch die Ausübung unseres Verstandesvermögens gewonnen werden. $^{13}$

\footnotetext{
${ }^{10}$. II.II.1.

${ }^{11}$. Dies muß betont werden, da es Kommentatoren gibt, die irrtümlicherweise die Unterscheidung von einfachen und komplexen Vorstellungen als die von Gegebenheit und Gemachtheit verstehen. Vgl. z.B. Aaron, S. 111 ff. In dieser Hinsicht ist es wichtig darauf hinzuweisen, daß die Gegebenheit der komplexen Ideen in direkten Wahrnehmungssituationen die notwendige Bedingung für die Möglichkeit der Abstraktion ist.

${ }^{12}$. Vgl. III.IV.10. Kambartel kritisiert an Locke, daß er keine ausreichende Analyse dessen durchgeführt habe, was "gegeben" ist: Er habe nämlich keinen Unterschied gemacht zwischen der "unberührten, unendlich mannigfaltigen Gegebenheit (Kants Gewühl der Empfindungen klingt hier unmittelbar an)" und der durch die Synthesis des Verstandes zur Einheit gebrachten Mannigfaltigkeit und Letztere als gegeben angenommen. Demnach nimmt Locke zuviel als gegeben an. Abgesehen davon, ob diese Kritik für berechtigt gehalten werden kann, ist darauf hinzuweisen, daß sie ausschließlich darauf beruht, Lockes Unterscheidung als Versuch der Abgrenzung von etwas, das gegeben ist, und etwas, das gemacht ist, aufzufassen. Dies ist aber ein Irrtum, wie wir gesehen haben. Vor allem muß für einen Autor wie Locke, der keinen Unterschied zwischen den unter genetischem Gesichtspunkt primären Daten und der Vorstellung von einem in der Zeit beständigen Gegenstand macht und Letztere als gegeben angenommen hat, die Frage nach der Abgrenzung von Gegebenem und Gemachtem eine einfache Frage sein. Folgerichtig glaubt Locke, daß es für uns einfach sei zu wissen, was in einer Wahrnehmungssituation gegeben ist. Er appelliert demgemäß einfach an unsere Beobachtung und Erfahrung. Lockes Unterscheidung von einfachen und komplexen Vorstellung wird entweder trivialisiert oder mißinterpretiert, wenn man sie in Verbindung mit jener Abgrenzung bringt. Vg. Kambartel, Erfahrung und Struktur, S. 24 ff. Aus demselben Grund kann ich auch Krügers Auseinandersetzung mit Kambartel und seinen Versuch, Locke zu retten, nicht unterstützen. Wenn wir nämlich, wie er vorschlägt, die Frage nach der Basis nicht durch ein psychologisierendes Postulat punktueller reiner Bewußtseinsinhalte, bloßer namenloser Sinnesdaten, belasten, sondern nach Wörtern der Basis fragen, wird die Frage nach jener Abgrenzung wiederum trivial, was für Locke in der Tat der Fall ist. Vgl. Krüger, Der Begriff des Empirismus, S. 35 ff.

${ }^{13}$. Hier ist es sehr wichtig, Vorstellungen als Materialien des Denkens einerseits und der Erkenntnisse und Meinungen andererseits auseinanderzuhalten. Wie Ayers richtig betont hat, ist der Empirismus, den Locke
} 
Ich will aus den bisherigen Überlegungen zwei Konsequenzen ziehen. Die erste Konsequenz ist die, daß man keinen besonderen Grund dafür erkennen kann, daß Locke den Terminus "idea" eingeführt hat. Er hätte auf ihn verzichten können. Die andere Konsequenz ist die, daß Lockes Ausgangsposition in seinem analytisch-deskriptiven Projekt die ist, daß wir direkt, durch sinnliche Wahrnehmungen, wissen, daß es physikalische Gegenstände gibt.

\section{II. 2. Die generelle Vorstellung der Substanz: \\ Relativierung von Lockes Position im Essay, II.VIII.1.}

Was man nach Locke unter der "generellen Vorstellung der Substanz" versteht und wie man zu dieser Vorstellung gekommen ist, kann man folgendermaßen darstellen.

Wie wir bereits gesehen haben, geht Locke davon aus, daß wir durch sinnliche Wahrnehmung direkt erkennen, daß es physikalische Gegenstände gibt, indem wir an physikalischen Gegenständen verschiedene Qualitäten wahrnehmen. Nun liegt es nahe zu fragen, worauf diese Qualitäten physikalischer Gegenstände beruhen, oder, um mit Locke zu sprechen, woher "they (die Qualitäten; d. Verf.) do result" (II.XXIII.I). Diese Frage, die zunächst harmlos aussieht, kann große Schwierigkeiten und Verwirrung bereiten. Dies ist der Fall, wenn man die Qualitäten als Bestandteile ("real Beings") auffaßt, aus denen physikalische Gegenstände bestehen. ${ }^{14}$ Damit bekommt die Frage einen metaphysischen Charakter und einen zusätzlichen Aspekt, nämlich den der Frage, wie die Qualitäten miteinander verbunden sind:

"They who first ran into the Notion of Accidents, as a sort of real Beings, that needed something to inhere in, were forced to find out the word Substance, to support them."(II.XIII.19)

Da man nicht weiß, was dieses "something" ist, sich aber nicht vorstellen kann, wie sonst die Qualitäten untereinander zusammenhängen können, nimmt man an, daß etwas hinter ihnen steht, das sie aufrecht erhält. Dieses etwas nennt man nach Locke "Substanz". Substanz ist also nichts anderes als "a supposition of he knows not what support of such qualities". ${ }^{15}$ Wenn

vertritt, ein "concept-empiricism", demzufolge alle Vorstellungen als Materialien aus Erfahrungen stammen, aber kein "knowledge-empiricism", demzufolge alle Erkenntnisse und Meinungen empirisch sind, also letzten Endes durch Erfahrung begründet werden. Wie wir in I.I.1. meiner Arbeit gesehen haben, gibt es nämlich Wahrheiten, die Lockes Meinung nach durch Intuition und Deduktion erkannt werden können. Vgl. Ayers. Bd I, S. 14-5.

14. Der Ausdruck "from which all its properties and qualities immediately flow" ist typisch für die traditionell-aristotelischen Scholastiker, die substanzielle Formen bei Aristoteles irrtümmlicherweise zur kausalen Erklärung von Qualitäten verwandt haben. Vgl. Alexander, I. 2., insbesondere S. 48-50.

15 . II.XXIII.2. 
dem so ist, folgt daraus, daß die Substanz prinzipiell nicht wahrnehmbar ist, da alles, was wir wahrnehmen können, nur als Qualität verstanden wird. Verwenden wir "Substanz" hier in dieser Bedeutung (SI).

Was diese Erklärung betrifft, so ist es fast überflüssig zu sagen, daß wir,- wenn wir fragen, wie ein Stück Gold die Qualitäten haben kann, die es hat,- nicht nach der (SI) fragen. Andererseits scheint sich, da die oben zitierte Stelle den Eindruck einer Kritik vermittelt, Locke von denjenigen aristotelischen Scholastikern zu distanzieren, die die (SI) vertreten. Dies läßt sich nicht bezweifeln, wenn wir berücksichtigen, daß Locke die Unterscheidung von primären und sekundären Qualitäten vertritt, die als Kritik an der aristotelisch-scholastischen Formtheorie verstanden werden soll. Demnach ist Lockes Antwort auf die Frage, wie ein Stück Gold beschaffen sein muß, um die Qualitäten haben zu können, die es hat, ein Verweis auf die innere Konstitution von Korpuskularen. Nennen wir dies im Gegensatz zu (SI) "(SII)". Hiermit sind wir auf die am Anfang dieses Abschnittes zitierte Eingangsrede zur Einführung der Unterscheidung von primären und sekundären Qualitäten (II. VIII. 1.) zurückgekommen, in der Locke von Vorstellungen ausgehend eine kausale Beziehung zwischen Vorstellungen und ihren Ursachen annimmt, wobei diese nicht spezifiziert werden.

Erinnern wir uns zunächst daran, daß die Einführung des Terminus "idea" keine besondere Aufmerksamkeit erregen konnte, weder zur Bezeichnung für "alle Vorstellungen in uns" noch zur Bezeichnung für Wahrnehmungsinhalte in direkten Wahrnehmungssituationen. Die einzige Motivation, die wir hier annehmen können, ist die, daß Locke damit auf die Gleichheit des Ursprungs von "allen Materialien des Denkens " und "Wahrnehmungsinhalten" aus inneren und äußeren Sinnen hinweisen wollte. Aufgrund der Einführung der Unterscheidung von primären und sekundären Qualitäten sieht die Situation nun aber etwas anders aus. Dadurch wird es nämlich möglich, daß Vorstellungen einen anderen Status bekommen. Wenn dem so ist, ist es fast überflüssig zu sagen, daß Lockes Einführung der Repräsentationstheorie in engem Zusammenhang mit der Einfuihrung der Unterscheidung von primären und sekundären Qualitäten steht. Demnach hängt die Frage, wie die vorher zitierte Stelle (II.VIII.1.) verstanden werden soll, davon ab, wie man einerseits die Unterscheidung von primären und sekundären Qualitäten und andererseits ihren Zusammenhang mit der Repräsentationstheorie versteht.

Eine Möglichkeit, die ich hier favorisiere, ist die, daß nur Vorstellungen von sekundären Qualitäten in direkten Wahrnehmungssituationen einen besonderen, nämlich ontologischen Status bekommen, während dies für Vorstellungen von primären Qualitäten nicht gilt. Diese Art und Weise, Lockes Unterscheidung von primären und sekundären Qualitäten zu verstehen, ist der mixed view von Jackson. Wenn man dazu neigt, eine Interpretation von der Art Jacksons für problematisch zu halten, liegt der Grund dafür m.E. vor allem darin, daß es sehr 
schwer vorstellbar ist, wie Vorstellungen von primären Qualitäten und von sekundären Qualitäten, die wir in direkten Wahrnehmungssituationen an ein und demselben Gegenstand wahrnehmen, verschiedenen Status haben können. Wenn man so denkt, ist es ein kleiner Schritt, folgende Position bezüglich des Zusammenhanges zwischen der Repräsentationstheorie und der Unterscheidung von primären und sekundären Qualitäten einzunehmen:

"If this is the distinction (die Unterscheidung von primären und sekundären Qualitäten; d. Verf.) Locke was trying to draw, it is clear in what way it presupposes a representative theory of perception. It is formulated in terms of a contrast between ideas in minds -here especially elements in the content of a present sensory perception-and intrinsic features of external material things. It is being assumed that the latter are causally responsible for the former, and hence that we can speak of powers, whose grounds are such intrinsic features, to produce those ideas, among other things."16

Wie sehr auch diese Erklärung den Zusammenhang zwischen der Repräsentationstheorie und der Unterscheidung von primären und sekundären Qualitäten bei Locke verständlich zu machen scheint, so ist sie doch nicht selbstverständlich. Warum nicht, kann gezeigt werden, wenn wir zwei Dinge auseinanderhalten. Es ist nämlich eine Sache zu sagen, daß die Unterscheidung von primären und sekundären Qualitäten bei Locke die Repräsentationstheorie voraussetzt. Es ist aber eine andere Sache zu sagen, daß die Unterscheidung von primären und sekundären Qualitäten bei Locke in der Terminologie der Repräsentationstheorie formuliert worden ist. Mackie setzt ohne weiteres voraus, daß das Erstere für Locke der Fall ist. Aber es ist auch möglich, daß das Letztere für Locke der Fall ist. Wenn dem so ist, kann die Frage, ob die Motivation Lockes, sich mit dem Problem des Skeptizismus zu beschäftigen, in der Repräsentationstheorie liegt, nicht einfach dadurch entschieden werden, daß man behauptet, daß die Unterscheidung von primären und sekundären Qualitäten die Repräsentationstheorie voraussetzt und daß Locke sie vertritt, sondern dadurch, daß man betrachtet, wie Locke sie vertritt. Demgemäß ist die entscheidende Frage die, ob Locke ausgehend von der Unterscheidung von primären und sekundären Qualitäten im Rahmen der Repräsentationstheorie weiter die Frage entwickelt, ob es möglich ist, daß die Vorstellungen von sekundären Qualitäten nicht auf den primären Qualitäten von physikalischen Gegenständen beruhen, in dem Sinne, daß auch die Vorstellungen von primären Qualitäten auf etwas beruhen, das über unsere Erkenntisfähigkeiten hinaus geht. Wenn dies der Fall wäre, so hielte Locke dadurch einerseits Vorstellungen en bloc und andererseits ihre Ursachen en bloc auseinander, und dies würde ihn auf das Problem des Skeptizismus führen. Dies würde aber nicht geschehen, wenn er die Repräsentationstheorie nur als Ausdruck der Unterscheidung von primären und sekundären Qualitäten sähe, wobei einerseits von

\footnotetext{
${ }^{16}$. Mackie, S. 16.
} 
vornherein überhaupt nicht in Frage stünde, daß es physikalische Gegenstände gibt, und andererseits vorausgesetzt wäre, daß diese - allein aus primären Qualitäten bestehenden Gegenstände Ursachen für die Wahrnehmungen von sekundären Qualitäten darstellen. Welche von diesen beiden Möglichkeiten der Fall ist, werden wir im nächsten Abschnitt untersuchen. 


\section{III. Zweiter Versuch der Lösung des neuen Problems}

II. III. 1. Weitere Überlegung zur generellen Vorstellung der Substanz: Bestätigung des Problems

Kehren wir zu unserer Betrachtung von der (SI) im letzten Abschnitt zurück. Obwohl Locke die Unterscheidung von primären und sekundären Qualitäten vertritt und dies als ein Beleg dafür verstanden werden kann, daß Locke nicht die (SI), sondern die (SII) vertritt, wenn es um die Frage geht, wie ein Gegenstand Qualitäten haben kann, so zögert Mackie doch in der Frage, ob sich Locke von der (SI) völlig distanziert. ${ }^{17}$ In der Tat kann man überall im Essay sehen, daß Locke von der (SI) Gebrauch macht. Vor allem kann man es, wie Mackie richtig behauptet, schwerlich für Ironie halten, wenn Locke sagt: "I confess, there is another Idea, which would be of general use for Mankind to have, as it is of general talk as if they had it; and that is the Idea of Substance, which we neither have, nor can have, by Sensation or Reflection.. If Nature took care to provide us any Ideas, we might well expect it should be such, as by our own Faculties we cannot procure to ourselves:" (I.IV.18). Wie erklärt sich dies?

Mackie findet eine Antwort darin, daß Locke genauso wie viele andere Philosophen zu sehr mit dem logisch-linguistischen Argument befaßt sei, das die (SI) einzuführen scheint: Der singuläre Terminus in einer prädikativen Aussage legt nämlich nahe, daß die Referenz des singulären Terminus' etwas von allen seinen Qualitäten Verschiedenes ist. ${ }^{18}$ Dies sei aber, so Mackie, nichts anderes als eine Täuschung. Wir können den singulären Terminus, falls sein Gebrauch uns irritieren oder zur Annahme von der (SI) bewegen sollte, dadurch eliminieren, daß wir ihn durch ein Bündel von Beschreibungen ersetzen.

In der Tat scheint ein Grund dafür, daß Locke die (SI) nicht so konsequent zurückweisen konnte, darin zu liegen, daß er glaubte, daß die übliche Art und Weise, singuläre prädikative Aussagen zu analysieren, uns dazu zwinge, die (SI) zu akzeptieren. Er sagt nämlich:

"These, and the like fashions of speaking intimate, that the Substance is supposed always something besides the Extension, Figure, Solidity.., or other observable Ideas, though we know not what it is."19

Trotzdem bin ich sehr skeptisch, ob dies der entscheidende Grund ist, wie Mackie behauptet. Die im letzten Abschnitt zitierte Stelle (II.XIII.19) zeigt unmißverständlich, daß Locke richtig gesehen hat, daß die (SI) eher auf einer falschen metaphysischen Annahme mit einer

\footnotetext{
17. Vgl. Mackie, S. 75.

${ }^{18}$. Vgl. Mackie, S. 77-79.

${ }^{19}$. II.XXIII.3.
} 
erkenntnistheoretischen Implikation beruht. Es ist dann sehr schwer vorstellbar, daß und wie allein die Struktur von singulären Aussagen Locke derart irritieren konnte. Vor allem wenn wir uns nicht in die Irre führen lassen, gibt es keinen Grund dafür, auf den Gebrauch von singulären Termini zu verzichten. Wir können sie weiter verwenden. Dieser Punkt ist wichtig, insbesondere weil Mackies Vorschlag keine Lösung des Problems sein kann. Er beruht auf derselben falschen metaphysischen Annahme, auf der die andere Alternative, nämlich die (SI), beruht. Kripke hat völlig Recht, wenn er sagt:

"They (die Philosophen; d. Verf.) have asked, are these objects behind the bundle of qualities, or is the object nothing but the bundle? Neither is the case; this table is wooden, brown, in the room, etc. It has all these properties and is not a thing without properties, behind them; but it should not therefore be identified with the set, or 'bundle' of its properties, nor with the subset of its essential properties. ${ }^{120}$

Worin liegt dann der Grund dafür, daß Locke die (SI) nicht so konsequent zurückweisen konnte? In Bezug auf das Vorhaben dieses Teils ist es eigentlich gleichgültig, ob Mackie Recht hat oder Kripke. Dies gilt auch von allen anderen möglichen Gründen, die Locke dafür haben mag. Es gibt aber einen Grund, der relevant sein könnte, und Locke scheint ihn anzuführen, wenn er sagt:

"So that if any one will examine himself concerning his Notion of pure Substance in general, he will find he has no other Idea of it at all, but only a Supposition of he knows not what support of such Qualities, which are capable of producing simple Ideas in us; which Qualities are commonly called Accidents. If any one should be asked, what is the subject wherein Colour or Weight inheres, he would have nothing to say, but the solid extended parts: And if he were demanded, what is it, that that Solidity and Extension inhere in, he would not be in a much better case, than the Indian before mentioned;who, saying that the World was supported by a great Elephant, was asked, what the Elephant rested on; to which his answer was, a great Tortoise: But being again pressed to know what gave support to the broad-back'd Tortoise, replied, something, he knew not what" (II.XXIII.2; Die letzte Hervorhebung d. Verf.).

Locke sagt hier folgendes:

(I) Wenn die aristotelisch-scholastische Auffassung der Akzidenzen als Bestandteile von physikalischen Gegenständen akzeptiert wird, tritt die Frage nach der (SI) auf;

(II) Diese Frage kann mit der Unterscheidung von primären und sekundären Qualitäten und auch mit (SII) beantwortet werden;

(III) Man kann dann weiter die Frage nach der Substanz bezüglich primärer Qualitäten

${ }^{20}$. Kripke, Naming and Necessity, S. 52. 
stellen;

(IV) Diese erneute Frage wirft wiederum große Probleme auf.

Dies ist die zweite der oben genannten drei Stellen. Stellen (II), (III) und (IV) Lockes eigene Gedankenentwicklung gegenüber (I) dar? Mackie zufolge ja. ${ }^{21}$ Wenn man so denkt, scheint es auf den ersten Blick so zu sein, daß man hier einen Beleg dafür finden kann, daß Locke weiter an der (SI) festhält. (III) und (IV) scheinen nämlich hinzudeuten, daß Locke die Unterscheidung von primären und sekundären Qualitäten und die (SII) nicht als Korrektur der aristotelisch-scholastischen Auffassung, sondern lediglich als eine Antwort auf die Frage nach der (SI) im Rahmen jener Auffassung versteht. (IV) ist eine natürliche Konsequenz daraus. Dieser Überlegung zufolge liegt dann der Grund dafür, daß Locke an der (SI) festhält, schlechthin darin, daß er jene aristotelisch-scholastische Auffassung akzeptiert. Daraus ergibt sich erstens, daß es ein Irrtum war, daß wir II.XIII.19. als Lockes Kritik an der aristotelischscholastischen Auffassung interpretiert haben, und zweitens, daß unsere Frage, warum Locke weiter an der (SI) festhält, hinfällig ist.

Wenn dem so ist, kann man darin die Möglichkeit finden zu erklären, warum Locke sich mit dem Problem des Skeptizismus beschäftigt. Es gibt nämlich wegen des metaphysischen Charakters von der (SI) keinen Grund anzunehmen, daß komplexe Vorstellungen von Individuen (SI)s als ihre Ursachen haben müssen. So führt dies zu der generellen skeptischen Frage. Gerade dies scheint Locke vor Augen zu haben, wenn er sagt:

"The Ideas, that our complex ones of Substances are made up of, and about which our Knowledge, concerning Substances, is most employ'd, are those of their secondary Qualities; which depending all (as has been shewn) upon the primary Qualities of their minute and insensible parts; $\mathrm{Or}$ if not upon them, upon something yet mote remote from our Comprehension" (IV.III.11; Hervorhebung d. Verf.)

Dies ist die letzte der oben genannten drei Stellen. So kann mein Ziel in diesem Teil von Anfang an als verfehlt erscheinen. Aus diesem Grund will ich versuchen zu zeigen, daß II.XXIII.2. und IV.III.11. anders verstanden werden können und müssen. Danach werde ich erklären, wie IV.IV.1-5., wo sich Locke in Rekurs auf die Frage nach der Referenz von Vorstellungen mit dem Problem des Skeptizismus auseinanderzusetzen scheint, verstanden werden muß.

II. III. 2. Relativierung von Lockes Position im Essay, II.XXIII.2.

${ }^{21}$. Vgl. Mackie, S. 81. 
Was II. XXIII.2. betrifft, bin ich der Meinung, daß Locke mit der Unterscheidung von primären und sekundären Qualitäten die Frage nach der (SI) nicht im Rahmen der aristotelisch-scholastischen Auffassung beantwortet, sondern eine kritische Korrektur dieser Auffassung vornimmt. In Folgendem will ich diese Auffassung zu rechtfertigen versuchen.

Wir haben oben Lockes auf der Unterscheidung von primären und sekundären Qualitäten beruhende Antwort auf die Frage nach der (SI) im Rahmen der aristotelisch-scholastischen Auffassung verbleibend verstanden. Dies lag einerseits daran, daß wir die erneute Frage nach der Substanz bezüglich der primären Qualitäten wörtlich genommen haben; andererseits hg dies an der Ratlosigkeit dieser erneuten Frage gegenüber in (IV). Wenn dem so ist, hängt die Entscheidung der Frage, ob Lockes auf der Unterscheidung von primären und sekundären Qualitäten beruhende Antwort auf die Frage nach der (SI) eine Korrektur der aristotelischscholastischen Auffassung als solcher ist, davon ab, wie (III) und (IV) verstanden werden. Deshalb will ich versuchen, eine andere Möglichkeit anzubieten, (III) und (IV) zu verstehen.

$\mathrm{Zu}$ diesem Zweck sollen zunächst zwei Stellen betrachtet werden, an denen Locke auf dasselbe Problem zurückzugreifen scheint:

"Let us compare then our complex Idea of an immaterial Spirit, with our complex Idea of Body, and see whether there be any more obscurity in one, than in the other, and in which most. Our Idea of Body, as I think, is an extended solid Substance, capable of communicating Motion by impulse: and our Idea of Soul, as an immaterial Spirit, is of a Substance that thinks, and has a power of exciting Motion in Body, by Will, or Thought. These, I think, are our complex Ideas of Soul and Body, as contra-distinguished;..." (II.XXIII.22.)

Anders ausgedrückt sagt Locke hier Folgendes:

(a) Es geht um die Frage, ob die Vorstellung der immateriellen Seele oder die des materiellen Körpers klarer ist;

(b) Der Vorstellung des Körpers zufolge ist der Körper eine ausgedehnte feste Substanz; ${ }^{22}$

(c) Der Vorstellung der Seele zufolge ist die Seele eine immaterielle denkende Substanz;

Lockes Antwort auf die Frage in (a) ist diese:

"If any one says, he knows not what 'tis thinks in him; he means he knows not what the substance is of that thinking thing: No more, say I, knows he what the substance is of that solid thing. Farther, if he says he knows not how he thinks; I answer, Neither knows he how he is extended; how the solid parts of Body are united, or cohere together to make Extension." (II.XXIII.23)

\footnotetext{
${ }^{22}$. Lassen wir andere Qualifikationen außer Acht.
} 
Mit anderen Worten:

(d) Wir sind, wenn es um die Frage nach der Substanz geht, in der gleichen schwierigen Lage, wenn es um den Körper geht, wie wenn es um die Seele geht;

(e) Wir sind in der gleichen schwierigen Lage, wenn wir zu erklären versuchen, wie die Seele denkt, wie wenn wir zu erklären versuchen, wie die festen Teilchen des Körpers miteinander verbunden sind, so daß sie die Extension bilden.

Wie können wir diese beiden Stellen und II.XXIII.2. aufeinander beziehen? Es stellt zunächst kein Problem, (b) als Lockes auf der Unterscheidung von primären und sekundären Qualitäten beruhende Antwort auf die Frage nach der (SI) in (II) aufzufassen. (d) zeigt eindeutig, daß Locke an der (SI) festhält. So scheint die erneute Frage nach der Substanz bezüglich von primären Qualitäten in (III) der Frage nach der (SI) des materiellen Körpers in (d) entsprechen zu müssen. Aber dem muß, wie gesagt, nicht so sein. Wenn es so erscheint, dann nur deswegen, weil man die erneute Frage nach de Substanz bezüglich von primären Qualitäten in (III) ohne weiteres als Frage nach der (SI) auffaßt. Meiner Meinung nach ist die richtige Lesart eher die, daß Locke damit die Frage in (e) meint. Warum, kann folgendermaßen erklärt werden.

Lassen wir zunächst (d) beiseite. Wie wir später sehen werden, kann (d) in einem ganz anderen Zusammenhang besser erklärt werden. Dann kann die erneute Frage nach der Substanz bezüglich von primären Qualitäten in (III) schlechthin der Frage in (e) entsprechen, nämlich der Frage: "how the solid parts of Body are united, or cohere together to make Extension." Die Formulierung dieser Frage, to make Extension, spricht dafür. Ayers glaubt ebenfalls, daß die erneute Frage in (III) nicht die Frage nach der (SI) sei:

"this last point (die erneute Frage in (III); d. Verf.) has nothing to do with the notion of a pure logical subject capable of being stripped in thought of every last property,...It is the sceptical demand for a more intelligible or explanatory account of matter's space-occupancy, in terms of what can be presented to sense and represented in imagination." 23

Ayers versteht die erneute Frage in (III) aber als eine skeptische Forderung nach einer klaren Erklärung zu "matter's space-occupancy, in terms of what can be presented to sense and represented in imagination". ${ }^{24} \mathrm{Er}$ glaubt, daß die auf (e) folgende Erklärung Lockes (insbesondere in II.XXIII.26) für seine Interpretation spreche. In der Tat äußert Locke dort

\footnotetext{
23. Ayers, Locke, Bd. II, S. 29. Diese Erklärung bezieht sich eigentlich auf Gassendi.

${ }^{24}$. Dieser Punkt ist sehr wichtig in Bezug auf die Frage nach Lockes Position zur Korpuskular-Theorie, von der in den nächsten Kapiteln die Rede sein wird.
} 
die folgende pessimistische Ansicht in Bezug auf die Möglichkeit jener Erklärung: "which seems to me as incomprehensible" (II.XXIII.24). So kommt Ayers zu der Konklusion:

"Locke thought that the question 'what is it?' is merely postponed by the best answer philosophers or scientists of the time could give, not because he thought that it would necessarily be postponed by any answer, but because he held... that the corpuscularian theory failed to capture the essence of what is there. ${ }^{125}$

Dies ist aber ein Irrtum. Obwohl ich mit Ayers darin einverstanden bin, daß Locke mit der erneuten Frage nach der Substanz bezüglich von primären Qualitäten in (III) nicht die Frage nach der (SI) meint, kann ich doch mit ihm nicht darin übereinstimmen, daß Locke damit die Forderung nach einer noch klareren Erklärung zu "matter's space-occupancy, in terms of what can be presented to sense and represented in imagination" meint. Der Irrtum beruht einerseits darauf, daß Ayers den gesamten Zusammenhang von (a)-(e) nicht genügend beachtet hat, und andererseits darauf, daß er dadurch daran gehindert worden ist, Lockes auf (e) folgende Erklärung richtig zu verstehen. Warum, kann folgendermaßen erklärt werden.

Worum geht es eigentlich in (a)-(e)? Es geht in (a) um die Frage, ob die Vorstellung der immateriellen Seele oder die des materiellen Körpers klarer ist. Locke gibt auf diese Frage drei Antworten. Die erste Antwort liegt in (b) und (c) vor, die zweite Antwort in (d) und die dritte Antwort in (e): allen zufolge sind beide Vorstellungen gleich klar oder unklar. Gemäß (b) und (c) beruht ihre gleiche Klarheit darauf, daß die Merkmale der beiden Substanzen in (b) und (c) dafür ausreichend sind, sie voneinander zu unterscheiden. Wie gesagt, ist (b) Lockes auf der Unterscheidung von primären und sekundären Qualitäten beruhende Antwort in (II). Gemäß (d) beruht ihre gleiche Unklarheit auf unserer Unkenntnis der Substanz im Rahmen der Aristotelischen Auffassung. (d) ist also ein deutliches Zeichen dafür, daß Locke in der Tat nach wie vor an der (SI) festhält. ${ }^{26}$ Worauf aber beruht ihre gleiche Unklarheit gemäß (e)? Lockes auf (e) folgende Erklärung gibt eine ausführliche Auskunft darüber. Wenn man nämlich sie vorsichtig liest, kann man ohne große Schwierigkeiten erkennen, daß es dort, anders als Ayers unterstellt, nur um eine Erklärung der Ursache der Kohärenz von Korpuskularen im Rahmen der Korpuskular-Theorie geht. Grob gesagt geht es darum, wie nicht mehr wahrnehmbar kleine Korpuskulare so miteinander verbunden sein können, daß sie einen wahrnehmbaren Gegenstand bilden. Lockes skeptische Ansicht bezieht sich demnach auf die Möglichkeit jener Erklärung, aber nicht auf die Korpuskular-Theorie als solche. So läßt sich die Ratlosigkeit in (IV) erklären. Es geht also um drei Antworten.

\footnotetext{
${ }^{25}$. Ayers, Bd. II. S. 37.

${ }^{26}$. Dies heißt aber noch nicht, daß die erneute Frage nach der Substanz bezüglich von primären Qualitäten die Frage nach der (SI) ist.
} 
Demnach liegt der Irrtum Ayers' darin, daß er Lockes auf (e) folgende Erklärung mißverstanden hat, indem er (d) und (e) nicht auseinanderhält. Dies hat zur Folge, daß er, obwohl er zwar zu Recht die erneute Frage nach der Substanz bezüglich von primären Qualitäten in (III) nicht als im Rahmen der aristotelischen Auffassung verbleibend verstanden hat, doch sie irrtïmlicherweise als eine Frage nach der Substanz in einem anderen Sinne verstanden hat, nämlich als eine Forderung nach einer noch über den Rahmen der Korpuskular-Theorie hinausgehenden klareren Erklärung zu "matter's space-occupancy, in terms of what can be presented to sense and represented in imagination" ist. Wie wir gesehen haben, ist nicht nur die Frage nach der (SI) im Rahmen der aristotelisch-scholastischen Auffassung, sondern auch die Frage nach der materiellen Substanz überhaupt durch Lockes auf der Unterscheidung von primären und sekundären Qualitäten beruhende Antwort grundsätzlich erledigt, die eine Korrektur jener Auffassung darstellt. ${ }^{27}$ Die erneute Frage nach der Substanz bezüglich von primären Qualitäten in (III) bzw. die Frage in (e) ist eine Frage, die Locke im Rahmen der Korpuskular-Theorie stellt. So bezieht sich seine skeptische Haltung jener Frage gegenüber nicht auf die Korpuskular-Theorie als solche. Sie kommt auch nicht daher, daß er die Möglichkeit offen läßt, daß physikalische Gegenstände über unsere Erkenntnisfähigkeit hinausgehen. ${ }^{28}$ Jene skeptische Haltung bezieht sich nur auf die Frage, ob wir unsere Konzeption von physikalischen Gegenständen so spezifizieren können, daß sie dazu beitragen kann, gegebene Phänomene zu erklären.

Warum hält Locke trotzdem weiter an der (SI) fest? Dies führt uns zu (d) zurück. (d) zeigt nämlich ohne Zweifel, daß Locke an der (SI) festhält. Eine Antwort kann man finden, wenn man berücksichtigt, worauf Locke mit (a)-(e) hinaus wollte. Es geht einzig und allein um die Frage in (a), nämlich die Frage, ob die Vorstellung der immateriellen Seele oder die des materiellen Körpers klarer ist. Und wir haben gesehen, wie er die Frage in (a) beantwortet. So vermute ich, daß Locke die (SI) als ein strategisches Mittel (in der Tat ein sehr gutes Mittel) gegen die dogmatischen Materialisten benutzt:

"I know that People, whose Thoughts are immersed in Matter, and have so subjected their Minds to their Senses, that they seldom reflect on anything beyond them, are apt to say, they cannot comprehend a thinking thing---: But I affirm, when they consider it well, they can no more comprehend an extended thing." (II.XXIII.22) ${ }^{29}$

\footnotetext{
${ }^{27}$. Warum Locke trotzdem an der (SI) festhält, kann und muß anders erklärt werden. Hierauf werden wir bald zurückkommen.

${ }^{28}$. IV.III. 11. ist die einzige Stelle, an der er jene Möglichkeit erwähnt.

${ }^{29}$. Wie große Mühe gibt sich Locke, Abstand von Dogmatikern aller Art zu halten! Siehe weiter II.XXXII.15-16. Vgl. IV.III.6.
} 
Diese Vermutung läßt sich bestätigen, wenn wir uns klar machen, wie Locke die dritte Antwort gegeben hat, nämlich indem er in seiner auf (e) folgenden Erklärung sich eher und nur zu der Unmöglichkeit äußert zu erklären, wie die Kohärenz von Korpuskularen zustande kommt. Da berührt er nicht einmal die Frage, ob es möglich ist zu erklären, wie die Seele denkt. So gibt er den Eindruck, daß er einfach voraussetzt, diese Möglichkeit bestehe nicht. Eine andere Bestätigung liegt darin, daß Locke, wenn er an vielen Stellen zuerst die (SI) erwähnt, obwohl es nur um physikalische Gegenstände geht, dies sofort durch die (SII) ersetzt. Folgende Stelle ist ein typisches Beispiel dafür:

"...the greatest part of the Ideas, that make our complex Idea of Gold, are Yellowness, great Weight..... etc. all united together in an unknown Substratum; all which Ideas,....., are not really in the Gold, considered barely in it self, though they depend on those real, and primary Qualities of its internal constitution" (II.XXIII.37)

\section{III. 3. Relativierung von Lockes' Position im Essay, IV.III.11.}

Was IV.III.11. betrifft, ist es wichtig, zuerst darauf hinzuweisen, daß sie nicht im Zusammenhang mit der Lockeschen Frage auftritt, ob die Ursache von Qualitäten die (SI) ist. Sie tritt eher einerseits auf im Zusammenhang mit der Frage nach der Möglichkeit der Erkenntnis von der (SII) als der Ursache von Qualitäten und andererseits im Zusammenhang mit der Frage, ob Erkenntnis von der (SII) zur Erweiterung der Erkenntnis von Relationen zwischen sekundären Qualitäten nützlich sei. In den darauf folgenden Absätzen versucht Locke zu zeigen, warum beides nicht der Fall ist. Da wir dies später ausführlich behandeln werden, will ich hier nicht darauf eingehen. Wichtig ist hier nur zu bemerken, daß Locke nirgends als Grund für seine Behauptung der Unmöglichkeit der Erkenntnis von sekundären Qualitäten die Möglichkeit angibt, daß die Ursache von sekundären Qualitäten über unsere Erkenntnisfähigkeit hinaus geht. So halte ich es für vernünftig, die Erwähnung dieser Möglichkeit in IV.III.11. als eine Übertreibung zu verstehen. Was für eine Übertreibung es ist, und warum Locke eine solche Übertreibung macht, ist eine für das Ziel dieses Teils wichtige Frage. Wir werden später eine Antwort darauf geben.

\section{Fazit}

So geben alle bisher betrachteten drei Stellen, nämlich II.VIII.1., II.XXIII.2. und IV.III.11., Locke keinen Anlaß, das Problem des Skeptizismus aufzuwerfen. Wie soll man dann IV.IV.1- 
4. verstehen, an der das Problem des Skeptizismus im Zusammenhang mit der Repräsentationstheorie aufzutreten scheint? Meine Antwort auf diese Frage ist folgende.

Die in IV.IV.1-4. aufgeworfene Frage nach der Referenz von einfachen Vorstellungen, ist nicht die skeptische Frage nach der Möglichkeit der Erkenntnis der physikalischen Außenwelt überhaupt. Diese skeptische Frage thematisiert Locke in IV.II.14, indem er sich mit dem Traumargument befaßt. Die Frage nach der Referenz bezieht sich nur auf einfache Vorstellungen von sekundären Qualitäten. ${ }^{30}$ Dies kann folgendermaßen erklärt werden.

Betrachten wir II.XXX.2., in dem sich Locke bereits mit der Frage nach der Referenz von einfachen Vorstellungen beschäftigt:

"Our simple Ideas are all real, all agree to the reality of things. Not that they are all of them the Images, or Representations of what does exist, the contrary whereof, in all but the primary Qualities of Bodies, hath been already shewed. But though Whiteness and Coldness are no more in Snow, than Pain is; yet those Ideas of Whiteness, and Coldness, Pain, etc. being in us the Effects of Powers in Things without us, ordained by our Maker, to produce in us such Sensations; they are real Ideas in us, whereby we distinguish the Qualities, that are really in things themselves. For these several Appearances, being designed to be the Marks, whereby we are to know, and distinguish Things, which we have to do with."

Ich will hier zunächst darauf aufmerksam machen, daß Locke die Frage nach der Referenz von einfachen Vorstellungen nicht einheitlich beantwortet. Er beantwortet die Frage nicht so: "simple ideas must be taken to correspond to their objects in regular and orderly ways, even if we are ignorant of the nature of those objects and of how they act on us", wie Ayers unterstellt. ${ }^{31}$ Wie wir im Zitat sehen können, hält er die Frage nach der Referenz von einfachen Vorstellungen von primären Qualitäten für kaum der Rede wert. Daß die (SII) die Ursache von Vorstellungen von sekundären Qualitäten ist, hält Locke auch für kaum der Rede wert. Locke antwortet nur auf die Frage nach der Referenz von einfachen Vorstellungen von sekundären Qualitäten in der von Ayers angegebenen Weise. In diesem Zusammenhang ist es wichtig darauf hinzuweisen, daß nicht die Frage nach der Referenz von einfachen Vorstellungen im allgemeinen, sondern nur die Frage nach der Referenz von einfachen Vorstellungen von sekundären Qualitäten wiederholt im Essay auftaucht. Warum? Der Grund ist einfach: Wie wir später sehen werden, ist Locke davon überzeugt, daß es unmöglich ist, die (SII) zu erkennen, die für einfache Vorstellungen von sekundären Qualitäten verantwortlich sind. Deshalb sind wir nach Locke gezwungen, fast ausschließlich mit Vorstellungen von

\footnotetext{
${ }^{30}$. Diese Frage darf aber nicht als die Frage verstanden werden, ob diese Vorstellungen überhaupt ihre Ursache in der physikalischen Welt haben. Gemeint ist eher die Frage, ob die Vorstellungen von sekundären Qualitäten, die die (SII) verursacht, eine verläßliche und objektive Basis für Erkenntnis von physikalischen Gegenständen abgeben.

${ }^{31}$. Ayers, Bd. I, S. 38.
} 
sekundären Qualitäten zu operieren, wenn es um die Erkenntnis von physikalischen Gegenständen geht, wie wir in IV.III.11. gesehen haben. Das Problem besteht aber dann in der Frage, was Vorstellungen von sekundären Qualitäten sein sollen. Können sie uns eine verläßliche und objektive Basis für die Erkenntnis von physikalischen Gegenständen liefern? Locke scheint, wie wir an der oben zitierten Stelle sehen können, davon überzeugt zu sein, daß dem so ist, und zwar aufgrund dessen, was Ayers angeführt hat. Aber gerade deswegen, weil diese Antwort nicht mehr als eine bloße Überzeugung ist, und, weil er davon überzeugt ist, daß es unmöglich ist, die (SII) zu erkennen, taucht die Frage nach der Referenz von einfachen Vorstellungen von sekundären Qualitäten wiederholt auf. Wie gesagt sieht die Situation aber in Bezug auf die Frage nach der Referenz von einfachen Vorstellungen von primären Qualitäten ganz anders aus. Die oben zitierte Stelle (II.XXX.2) ist nämlich die einzige Stelle, an der davon die Rede ist. So denke ich, daß die Frage nach der Referenz von Vorstellungen in IV.IV.2. nicht die skeptische Frage nach der Möglichkeit der Erkenntnis der physikalischen Außenwelt überhaupt ist, sondern eine zusammenfassende Wiederaufnahme der bereits mehrfach aufgeworfenen Frage nach der Referenz von einfachen Vorstellungen von sekundären Qualitäten. Und gerade deswegen kann sie nicht einfach als eine "pseudo-skeptische" Frage bezeichnet werden, anders als Ayers meint. Dies zeigt sich an der folgenden für Locke typischen Antwort:

"Thus the Idea of Whiteness, or Bitterness, as it is in the Mind, exactly answering that Power which is in any Body to produce it there, has all the real conformity it can, or ought to have, with Things without us. And this conformity between our simple Ideas, and the existence of Things, is sufficient for real Knowledge. ${ }^{162}$

${ }^{32}$. IV.IV.4. 


\section{Erklärungen des fraglichen Phänomens}

\section{I. Ayers' Erklärung}

Warum empfiehlt Locke nicht die hypothetisch-deduktive Methode im Rahmen der Korpuskular-Theorie, obwohl er diese für die beste Theorie hält und in seinem Projekt im Essay verwendet? Betrachten wir folgende Stelle:

"it being one thing to perceive, and know the Idea of White or Black, and quite another to examine what kind of particles they must be, and how ranged in the Superficies, to make any Object appear White or Black." (II.VIII.2)

kurz:

1) Erkenntnis von Vorstellungen ist von der Erkenntnis ihrer Ursachen unabhängig.

Wozu verpflichtet (1) Locke? Ayers gibt eine Antwort auf diese Frage. Das Problem dabei ist aber, daß sie, wenn sie richtig ist, mein Vorhaben als hinfällig erweist. Deshalb will ich mich in diesem Abschnitt mit Ayers auseinandersetzen. Diese Auseinandersetzung wird uns einen guten Ansatzpunkt liefern, mit dessen Hilfe wir zu den Überlegungen in den nächsten Abschnitten übergehen können. Bevor ich aber auf die Auseinandersetzung mit Ayers eingehe, will ich zuerst unsere bisherigen Überlegungen zusammenfassen. Dies ist nötig, da es in diesem Abschnitt letzten Endes darum geht, den grundsätzlichen Unterschied zwischen mir und Ayers in Bezug auf das Verhältnis zwischen Locke und Descartes darzustellen und demnach Ayers zu kritisieren.

Wie wir gesehen haben, vertrete ich die These, daß es keinen wesentlichen Unterschied zwischen Locke und Descartes in folgender Hinsicht gibt: Beide gehen davon aus, daß wir wissen, daß es physikalische Gegenstände gibt. Die Repräsentationstheorie ist nur ein Mittel zum Ausdruck der Unterscheidung von primären und sekundären Qualitäten. So impliziert diese Unterscheidung nicht den universalen Skeptizismus, daß physikalische Gegenstände über unsere Erkenntnisfähigkeit hinausgehen. Sie stellt nur eine Überlegung darüber dar, ob physikalische Gegenstände nur aus primären Qualitäten beschaffen sind. Die Frage, wie wir Vorstellungen interpretieren können und müssen, ist aber eine andere Sache, die nichts mit dem Problem des Skeptizismus zu tun hat. Diesbezüglich ist es, um Mißverständnisse zu vermeiden, wichtig zu betonen, daß meine Kritik an Mackie nicht darin besteht, daß seine Interpretation der Vorstellungen als intentionaler Gegenstände falsch wäre, sondern eher darin, 
daß er jene Frage und das Problem des Skeptizismus nicht auseinandergehalten hat. Anders verhält es sich mit Yolton. Obwohl er Mackie folgend Vorstellungen als intentionale Gegenstände auffaßt, hält er, anders als Mackie, jene Frage und das Problem des Skeptizismus auseinander. Dies tut er, indem er der Rede von Vorstellungen als intentionalen Gegenständen jede mögliche von physikalischen Gegenständen distinkte ontologische Implikation nimmt. Ich habe mich Yolton angeschlossen, Descartes und Locke eher als direkte Realisten zu verstehen. Ayers' Position ist eine ganz andere. Gehen wir nun auf Ayers ein.

\section{I. 1. Darstellung von Ayers' Erklärung}

Betrachten wir folgende Erklärung Ayers':

"The simple appearance (idea; d. Verf.) is taken by the mind as the sign of its unknown cause, but the mind has no choice in the matter since that is what a natural sign signifies. Speculations as to the intrinsic nature of its cause, whether true or false, are irrelevant to the signification of the idea or to its truth. Simple ideas do not, he (Locke; d. Verf.) claimed, 'become liable to any Imputation of Falsehood, if the Mind (as in most Men I believe it does) judges these Ideas to be in the Things themselves'(Essay, II.XXXII.14.; d. Verf.). For they are 'as real distinguishing characters, whether they be only constant Effects, or else exact Resemblances of something in the things themselves.'(Essay, II.XXXII.14.; d. Verf.). Locke wanted to say that we can distinguish things and have knowledge of their existence through sense-perception, but that no method of analysis of the ideas we form of them will bring us to knowledge of their underlying nature."'

\section{Mit anderen Worten:}

2) Alle einfachen Vorstellungen beruhen auf etwas, das wir nicht erkennen können;

3) Sie sind nur dessen Zeichen;

4) Spekulationen darüber, seien sie falsch oder wahr, sind irrelevant für die Bedeutung oder die Wahrheit von einfachen Vorstellungen;

5) Es gibt konstante kausale Beziehungen zwischen einfachen Vorstellungen und ihren Ursachen;

6) Einfache Vorstellungen können dazu beitragen, Dinge voneinander zu unterscheiden.

Wie wir in (2) sehen können und später näher betrachten werden, geht Locke Ayers zufolge von Vorstellungen aus, wobei ihre Ursachen nicht spezifiziert werden. So faßt Ayers

\footnotetext{
1. Ayers, Locke, Bd. I, S. 40. Ich glaube, daß dies ein Grund dafür ist, daß Ayers einen Vorzug des Essay so formuliert: "it (Essay; d. Verf.) sets out a version of anti-dogmatic realism constructed before the onset of the idealism or conceptualism which has dominated philosphy, in one form or another, for the last two centuries." (Bd I., S. 13.)
} 
Vorstellungen bei Locke nicht als intentionale Gegenstände, ${ }^{2}$ sondern als "blanc effects" in uns auf: Sie sind in physikalischer, ontologischer oder quasi lokalisierender Hinsicht Modifikationen in uns (S. 62). ${ }^{3}$ Gehen wir nun zu (4) über. (4) ist Ayers Interpretation von (1). ${ }^{4}$ Was Ayers mit "Bedeutung" oder "Wahrheit" von einfachen Vorstellungen in (4) meint, kann man mit Rekurs auf (5) verstehen. (6) ist eine Konsequenz aus (5). Dies meint Ayers mit "Zeichen" in (2).

Die Frage, die ich zur Diskussion stellen will, ist die, ob (4) eine richtige Interpretation von (1) ist. Vorgreifend läßt sich sagen, daß Ayers damit Locke eine absurde Position zuschreibt. Wenn man nämlich (2) vertritt, kann man nicht (4), sondern vielmehr (4') behaupten;

(4') Spekulationen über die Ursachen von Vorstellungen sind überhaupt irrelevant, da es unmöglich ist, sie zu erkennen.

(1) muß demnach anders verstanden werden.

Abgesehen davon, ob Ayers Recht hat, ist (4) als Interpretation für (1) der Grund dafür, daß Locke nicht das hypothetisch-deduktive Verfahren im Rahmen der Korpuskular-Theorie empfiehlt. So will ich im Folgenden versuchen, die Frage zu entscheiden, ob Locke in der Tat (4) vertritt. Dabei will zwei Punkte kritisch betrachten. Erstens: Ayers ist der Ansicht, daß (4) und Lockes Erklärung zur Unmöglichkeit der verbalen Definition von Worten für einfache Vorstellungen sich gegenseitig stützen. Dies scheint mir aber nicht der Fall zu sein. Der zweite Punkt ist dieser: Ayers glaubt, daß Locke beabsichtigt, eine radikal anticartesianische Position aufzubauen. Auch dies stimmt nicht.

III. I. 2. Qualitäten als dispositionale Eigenschaften

\footnotetext{
${ }^{2}$. Was Ayers' Argumente gegen Yoltons Interpretation der Vorstellungen als intentionaler Gegenstände bei Locke betrifft, siehe Ayers, Bd I, Kapitel 6. Was ich daran für problematisch halte, ist, daß Ayers dies tut, indem er Lockes vieldeutige Formulierung der Vorstellungen als "etwas in uns" oder als "direkte Gegenstände" wörtlich versteht, obwohl Yoltons Versuch gerade darin besteht, eine andere Interpretation anzubieten.

${ }^{3}$. Dies wirft das Problem des Skeptizismus auf. Hier werde ich aber das Thema des Skeptizismus beiseite lassen.

${ }^{4}$. Dies wird im Lauf dieses Abschnittes bestätigt werden. Vgl. Ayers, Bd. I, S. 41. Wir werden hierauf später zurückkommen.
} 
Ayers schickt dem obigen Zitat folgende Erklärung voraus:

"On Locke's account, .., the sensation or image is the idea of the colour, and his criterion for its simplicity is phenomenal, the limits of phenomenal discrimination: each simple idea, being in it self uncompounded, contains in it nothing but one uniform Appearance'. With phenomenal simplicity goes indefinability: the idea of a colour cannot be conveyed in words." (ebd.; die letzte Hervorhebung d. Verf.)

Kurz:

7) Worte für einfache Vorstellungen sind nicht verbal, sondern nur ostentativ definierbar;

8) Der Grund dafür liegt darin, daß die Einfachheit von einfachen Vorstellungen eine phänomenale Einfachheit ist.

So vertritt Ayers die folgende These:

"it seems central to his (Lockes; d. Verf.) official view that 'blue' has two employments: in the first instance it is the name or sign of an idea, while secondarily and derivatively it names whatever in the object causes the idea, and is therefore signified by it." (ebd. S. 207)

Mit anderen Worten:

9) Wir referieren mit Worten für einfache Vorstellungen in erster Linie auf die einfachen Vorstellungen und dann in einem sekundären und abgeleiteten Sinne auf ihre Ursachen.

Was (7) betrifft, gibt es in der Tat viele Stellen im Essay, die keinen Zweifel an (7) hinterlassen. Z.B. sagt Locke:

"The only way (Worte für einfache Vorstellungen zu erklären; d. Verf.) is, by applying to his Senses the proper Objekt; and so producing that Idea in him." (III.IV.11)

Wenn wir Lockes damit zusammenhängende Erklärungen betrachten, können wir ohne weiteres sehen, daß Locke dies auf (8) zurückführt. Eine von jenen Erklärungen wäre diese:

"And therefore the Cartesians very well distinguish between that Light which is the Cause of that Sensation in us, and the Idea which is produced in us by it, and is that which is properly Light." (III.IV.10; die letzte Hervorhebung d. Verf.)

Hat Ayers aber Recht damit, daraus (9) als Konsequenz zu ziehen? Wenn ja, dann referieren wir nach Locke mit dem Wort "Rot" in erster Linie auf die Vorstellung "Rot" und nur in einem 
sekundären und abgeleiteten Sinne auf ihre Ursache. Nehmen wir zunächst an, daß Ayers mit (9) Recht hat. Stellen wir uns dann folgende Situation vor. Vor mir und meinem Freund sind eine Studentenblume und ein Veilchen. Ich sage meinem Freund, daß die Farbe der Studentenblume gelb und die des Veilchens blau ist. Er stimmt mir zu. Kann dies allein aus (9) erklärt werden? Dies ist nur unter der Bedingung möglich, daß ich und mein Freund ein und dieselbe Vorstellung "Gelb" von der Studentenblume haben und ein und dieselbe Vorstellung "Blau" von dem Veilchen. Aber woher wissen wir dies? Es ist nämlich möglich, daß "the Idea, that a Violet produced in one Man's Mind by his Eyes, were the same that a Marigold produced in another Man's, and vice versa." (II.XXXII.15). Es scheint unmöglich zu sein nachzuprüfen, ob mein Freund und ich ein und dieselbe Vorstellung "Blau", z.B. von dem Veilchen, haben: "because one Man's Mind could not pass into another Man's Body, to perceive, what Appearances were produced by those Organs" (ebd.). Soll dies heißen, daß wir, nämlich ich und mein Freund, in diesem Fall aneinander vorbeireden? Nach (9) kann dies der Fall sein. Locke denkt aber nicht so: "Neither would it carry any Imputation of Falshood to our simple Ideas, if by the different Structure of our Organs, it were so ordered, That the same Object should produce in several Men's Minds different Ideas at the same time" (ebd.). Warum? Lockes Antwort ist diese:

"For all Things, that had the Texture of a Violet, producing constantly the Idea, which he called Blue; and those which had the Texture of a Marigold, producing constantly the Idea, which he as constantly called Yellow, whatever those Appearances were in his Mind; he would be able as regularly to distinguish Things for his Use by those Appearances, and understand, and signify those distinctions, marked by the Names Blue and Yellow, as if the Appearances, or Ideas in his Mind, received from those two Flowers, were exactly the same, with the Ideas in other Mens's Minds." (ebd.)

So scheint Locke der Meinung zu sein, daß wir, wenn wir z.B. das Wort "Blau" verwenden, damit nicht auf unsere eigene Vorstellung, sondern eher auf ihre Ursache referieren, die jene Vorstellungen hervorruft. Dies erklärt, daß wir, ich und mein Freund, über ein und denselben Gegenstand sprechen, wenn wir ein und denselben Namen verwenden. Entscheidend ist dabei nicht, daß wir von ein und demselben Gegenstand ein und dieselbe Vorstellung bekommen, sondern, daß zwischen der Vorstellung und dem Gegenstand eine konstante kausale Beziehung besteht.

Natürlich ist dies Ayers nicht unbekannt. ${ }^{5}$ Sehen wir, wie er jene Stelle interpretiert und bewertet. Ayers geht ohne weiteres davon aus, daß II.XXXII.14. (9) bestätigt. Ich will hier (9) in seiner Formulierung noch einmal zitieren:

\footnotetext{
${ }^{5}$. Er bezeichnet Lockes Überlegung zu jener Möglichkeit als "sophistisch". Sie ist es in der Tat. Dennoch ist zumindest klar, daß Lockes Überlegung nicht einfach dadurch als inkohärent nachgewiesen werden
} 
"it seems central to his (Lockes; d. Verf.) official view that 'blue' has two employments: in the first instance it is the name or sign of an idea, while secondarily and derivatively it names whatever in the object causes the idea, and is therefore signified by it." (ebd. S. 207)

Was die Stelle II.XXXII.15. betrifft, erkennt Ayers das Problem an, daß dies gegen seine These spricht:

"The argument for the unimpeachable 'truth' of simple ideas, however, was developed at one point (II.XXXII.15; d. Verf.) in what might seem a contrary direction" (S. 207; Hervorhebung d. Verf.)

Dieses Problem versucht Ayers zu beseitigen, indem er behauptet, daß Locke mit der Erklärung in II.XXXII.15. im ganzen und großen auf dasselbe hinaus wollte wie in II.XXXII.14. Nun bin ich darin mit Ayers völlig einverstanden, daß Lockes Tenor in II.XXXII.15. dasselbe ist wie in II.XXXII.14., wenn Ayers damit nur (5) und (6) meint:

5) Es gibt konstante kausale Beziehungen zwischen einfachen Vorstellungen und ihren Ursachen;

6) Einfache Vorstellungen können dazu beitragen, Dinge voneinander zu unterscheiden.

Ayers meint aber mehr, nämlich auch Folgendes:

"Still less was he (Locke; d. Verf.) suggesting that the use of 'blue' for objects is primary, and its use for ideas secondary and derivative....

There is in its context (II.XXXII. 15; d. Verf.) nothing particularly surprising about Locke's belief that the primary use of secondary-quality predicates is for sensations rather than things". (ebd. S. 209)

So kann ich Ayers' Erklärung von II.XXXII.15. nicht akzeptieren. Warum, will ich nun näher erklären.

Es ist zuerst sehr wichtig, darauf hinzuweisen, daß es Locke in II.XXXII. um die Wahrheit und Falschheit von Vorstellungen geht, wie der Titel von II.XXXII., nämlich "True and False Ideas", sagt. Am Beginn erklärt und betont Locke genauso wie Descartes in der dritten Meditation unmißverständlich, daß es eigentlich keinen Sinn hat, über Wahrheit oder Falschheit in Bezug auf Vorstellungen als solche zu sprechen:

kann, daß man, wie Ayers, Folgendes behauptet: "No difference in the phenomenal quality of the experience of such observers can be described or indicated in language. Contrary to hypothesis (Lockes; d. Verf.), therefore, no such difference exits." Ayers, Bd. I, S. 209. 
"For our Ideas, being nothing but bare Appearances or Perceptions in our Minds, cannot properly and simply in themselves be said to be true or false." (II.XXXII.1)

Descartes sagt dies so: ${ }^{6}$

"Was nun die Ideen anbetrifft, so können sie, wenn man sie nur an sich betrachtet.., nicht eigentlich falsch sein"(Buchenau, S. 29)

In diesem Sinne sind nicht nur einfache Vorstellungen, sondern alle Vorstellungen wahr. Trotzdem gibt es Locke zufolge eine Bedingung, unter der die Frage oder Diskussion über die Wahrheit oder Falschheit von Vorstellungen sinnvoll sein kann:

"Whenever the Mind refers any of its Ideas to any thing extraneous to them, they are then capable to be called true or false. Because the Mind in such a reference, makes a tacit Supposition of their Conformity to that Thing."(II.XXXII.4)

Descartes sagt zu diesem Thema Folgendes:

"Was nun die Ideen anbetrifft, so können sie, wenn man sie nur an sich betrachtet und sie nicht auf irgend etwas anderes bezieht, nicht eigentlich falsch sein"(ebd.; Hervorhebung d. Verf. $)^{8}$

Nun gibt es Locke zufolge zwei Gesichtspunkte, unter denen jene Annahme gemacht werden kann.

"When the Mind supposes any Idea it has, conformable to that in other Men's Minds called by the same common Name;....

When the Mind supposes any Idea it has in it self, to be conformable to some real Existence. (II.XXXII.5)

Der erste Gesichtspunkt ist dieser:

I) Eine Vorstellung, z.B. die, die ich mit dem Namen "Blau" verbinde, ist wahr, wenn sie mit der Vorstellung konform ist, die andere Menschen mit demselben Namen verbinden.

\footnotetext{
${ }^{6}$. Da es später um den Vergleich zwischen Locke und Descartes geht, zitiere ich hier auch Descartes.

7. "Iam quod ad ideas attinet, si solae in se spectentur,...,falsae esse non possunt." (AT VII. S.37)

${ }^{8}$. "Iam quod ad ideas attinet, si solae in se spectentur, nec ad aliud quid illas referam, false esse non possunt." (ebd.; Hervorhebung d. Verf.)
} 
Dies ist der zweite Gesichtspunkt:

II) Eine Vorstellung ist wahr, wenn sie etwas Realem entspricht.

Während Descartes seine Überlegung zur Wahrheit und Falschheit von Vorstellungen nur unter dem Gesichtspunkt von (II) durchführt, tut Locke dies unter beiden Gesichtspunkten (I) und (II). Abgesehen davon enthalten II.XXXII.14. und II.XXXII.15. Lockes Erklärung zur Wahrheit und Falschheit von einfachen Vorstellungen unter dem Gesichtspunkt von (II). In II.XXXII.14. sagt er, daß alle einfachen Vorstellungen wahr sind, da es eine konstante kausale Beziehungen zwischen verschiedenen einfachen Vorstellungen und ihren Ursachen gibt. Dies ist (5) in Ayers' Erklärung. Wenn II.XXXII.14. so als Antwort auf die Frage nach der Wahrheit von einfachen Vorstellungen verstanden wird, ist unklar, ob Lockes Erklärung zur Wahrheit von einfachen Vorstellungen unter dem Gesichtspunkt von (II) etwas mit dem Thema der Referenz von Worten zu tun haben kann. Dagegen könnte man vielleicht mit Rekurs auf II.XXXII.15. einen Einwand machen. II.XXXII.15. tritt nämlich genauso wie II.XXXII.14. im Zusammenhang mit der Frage nach der Wahrheit von einfachen Vorstellungen unter dem Gesichtspunkt von (II) auf. Dies könnte bedeuten, daß Locke der Meinung ist, daß die Erklärung zur Wahrheit von einfachen Vorstellungen unter dem Gesichtspunkt von (II) etwas mit dem Thema der Referenz von Worten zu tun hat. Wenn man so unbedingt das Thema der Referenz von Worten allgemein mit der Erklärung zur Wahrheit von einfachen Vorstellungen in Verbindung bringen will, scheint eher Lockes Erklärung in II.XXXII.15. als die in II.XXXII.14. als seine Grundposition darzustellen. Warum, kann folgendermaßen erklärt werden.

Es ist sehr wichtig, noch einmal zu betonen, daß die Diskussion der Wahrheit von einfachen Vorstellungen unter dem Gesichtspunkt von (II) es eigentlich nicht notwendig macht, das Thema der Referenz von Worten einzuführen. Es geht einfach nur um die Frage, ob einfachen Vorstellungen etwas in der Welt entspricht oder nicht. Die Situation sieht aber anders aus, wenn es um die Wahrheit von einfachen Vorstellungen unter dem Gesichtspunkt von (I) geht. Dann ist es unentbehrlich, auf die Referenz von Worten einzugehen. Die Frage der Wahrheit von einfachen Vorstellungen wird nämlich dadurch entschieden, ob z.B. die Vorstellung, die ich "Blau" nenne, mit der Vorstellung konform ist oder nicht, die andere Leute "Blau" nennen. Die Frage ist aber die, wie die Wahrheit von einfachen Vorstellungen unter dem Gesichtspunkt von (I) entschieden werden kann. In II.XXXII.9., in dem Locke dieses Thema behandelt, geht er ohne weiteres davon aus, daß wir ein und dieselbe Vorstellung von ein und demselben Gegenstand haben. So besteht die einzige Möglichkeit des Irrtums in der falschen Anwendung von Worten, daß ein Sprecher z.B. die Vorstellung "Blau" "Rot" nennt, während alle anderen Sprecher sie "Blau" nennen. Locke ist aber der Meinung, daß die Möglichkeit eines derartigen 
Irrtums sehr gering ist. Aber ist es nicht möglich, daß wir von ein und demselben Gegenstand nicht ein und dieselbe Vorstellung bekommen? In welcher Weise kann man in diesem Fall die Frage nach der Wahrheit entscheiden? Wie wir gesehen haben, greift Locke diese Fragen in II.XXXII.15. auf. Deshalb bin ich geneigt, diese Stelle als eine ergänzende Erklärung über die Wahrheit von einfachen Vorstellungen unter dem Gesichtspunkt von (I) zu betrachten, obwohl sie unter dem Gesichtspunkt von (II) auftritt.

Aus dieser Überlegung können wir folgende Konsequenz ziehen. Da die Diskussion der Wahrheit von einfachen Vorstellungen unter dem Gesichtspunkt von (II) es nicht nötig macht, das Thema der Referenz von Worten einzuführen, kann II.XXXII.14. nichts mit dem Thema der Referenz von Worten zu tun haben. Das Thema kann und muß nur in der Diskussion unter dem Gesichtspunkt von (I) auftreten. Wenn dem so ist, kann und muß man Lockes Position in Bezug auf das Thema der Referenz von Worten nur II.XXXII.15. entnehmen. Die beste Art, Lockes Erklärung in II.XXXII.15. ihrem Sinn gemäß klar und deutlich zu formulieren, kann man bei Kripke finden: Wir referieren mit dem Wort "Blau" auf die Ursache der Vorstellung von "Blau", wobei unsere eigene Vorstellung als ein Mittel benutzt wird, um die Referenz festzulegen. ${ }^{910}$

Abgesehen davon bin ich bereit, Ayers' Vorschlag zu akzeptieren, daß es sowohl in II.XXXII.15. als auch in II.XXXII.14. einfach nur darum geht, die Wahrheit von einfachen Vorstellungen mit Rekurs auf eine konstante kausale Beziehung zwischen Vorstellungen und ihren Ursachen zu erklären, aber, wie ich oben gesagt habe, nur unter der Bedingung, daß man II.XXXII.14. nicht auf das Thema der Referenz von Worten bezieht. Wie wir gesehen haben, akzeptiert aber Ayers diese Bedingung nicht. Warum? Davon abgesehen glaube ich nicht, daß Ayers meine obige Interpretation akzeptiert. Warum? All dies kann folgendermaßen erklärt werden.

Es ist meiner Meinung nach kein Zufall, daß in Ayers' Diskussion nicht einfach von der Frage nach der Referenz, sondern eher von der Frage nach dem Vorrang die Rede ist. nämlich von der Frage, ob wir z.B. mit dem Wort "Blau" in erster Linie auf die Vorstellung "Blau" und in sekundärem und abgeleitetem Sinn auf ihre Ursache referieren oder umgekehrt. Dies ist sehr merkwürdig. Aber es gibt einen Grund dafür. Wie wir gesehen haben, formuliert Ayers, um noch einmal zu zitieren, das Problem in II.XXXII.15. so:

\footnotetext{
9 . Vgl. Kripke, Naming and Necessity, S. 139-140 und dessen Fußnote 71.

${ }^{10}$. Gegen diese Erklärung scheint auf den ersten Blick zu sprechen, daß Locke unseren Gebrauch von generellen Termini als abuse of words kritisiert, wenn sie auf reale Essenzen referieren sollen. Aber wie wir später sehen werden, beruht diese Kritik weder darauf, daß er physikalische Eigenschaft als dispositionale Eigenschaft auffaßt, noch darauf, daß er der Meinung ist, daß wir Worte nur sinnvoll anwenden können, wenn wir sie in Verbindung mit Vorstellungen gebrauchen, die uns bekannt sind. Sie beruht auf seiner Annahme, daß es nicht möglich ist, reale Essenzen zu erkennen.
} 
"The argument for the unimpeachable 'truth' of simple ideas, however, was developed at one point (II.XXXII.15; d. Verf.) in what might seem a contrary direction" (S. 207; Hervorhebung d. Verf.)

Trotzdem glaube ich nicht, daß Ayers wirklich so denkt. Damit meine ich folgendes. Er weiß nämlich genau, daß die Kripkesche Auffassung von II.XXXII.15. nicht darauf abzielt, daß wir mit dem Wort "Blau" in erster Linie auf die Ursache der Vorstellung und dann in sekundärem und abgeleitetem Sinn auf die Vorstellung referieren, sondern darauf, daß wir damit nur auf die Ursache referieren, wobei die Vorstellung als Mittel benutzt wird, um die Referenz festzulegen. Sie ist nicht eine alternative Antwort auf die Frage nach dem Vorrang. Daß Ayers diesen Punkt nicht übersehen hat, zeigt sich an dieser Stelle:

"(On that argument) the two uses of 'blue' are indeed systematically connected, but its primary use is for publicly observable objects, surfaces, light and so forth, while it is its use in characterising visual sensations which is secondary" (ebd. S. 208; Hervorhebung d. Verf.)

Die Frage nach dem Vorrang ist also hinfällig. Warum zieht sich bei Ayers trotzdem die Frage nach dem Vorrang durch? Ayers könnte vielleicht auf Locke zurïckgreifen. Wie wir gesehen haben, sagt Locke:

"And therefore the Cartesians very well distinguish between that Light which is the Cause of that Sensation in us, and the Idea which is produced in us by it, and is that which is properly Light." (III.IV.10; die letzte Hervorhebung d. Verf.)

Ich glaube aber nicht, daß Ayers nicht weiß, was er hier tut. Was Lockes Erklärung betrifft, ist nicht entscheidend, daß Locke behauptet, daß wir mit dem Wort "Licht" in erster Linie auf die Vorstellung referieren. Entscheidend ist nur, daß er anerkennt, daß wir auch auf ihre Ursache referieren, wenn auch in sekundärem Sinne. Warum ist nur dies entscheidend? Die Antwort finden wir, wenn wir fragen, was man darunter verstehen soll, daß auf die Ursache in sekundärem und abgeleitetem Sinn referiert wird. Die einzige Möglichkeit, dies verständlich zu machen, ist nach wie vor die Kripkesche Auffassung. Sie ist die einzige, die beidem, nämlich Worten und Vorstellungen, ihre je eigene Aufgabe zuschreiben kann. So ist nur wichtig, ob beides, die Vorstellung und ihre Ursache, ins Spiel kommt, aber nicht, was den Vorrang hat. Um es noch einmal zu sagen: Ich glaube nicht, daß Ayers dies übersehen hat. So vermute ich, daß er, wenn sich trotzdem die Frage nach dem Vorrang bei ihm durchzieht, dies nicht ohne Absicht tut. Was die Absicht ist, kann sich zeigen, wenn wir fragen, was man darunter verstehen soll, daß auf eine Ursache in sekundärem und abgeleitetem Sinn referiert wird. Die einzige Möglichkeit, dies anders zu verstehen, ist die, daß wir mit dem Wort nur auf die 
Vorstellung referieren, wobei die Rede vom Referieren auf die Ursache "in sekundärem und abgeleitetem Sinn" und letzten Endes die Rede von der Ursache irrelevant wird. In der Tat interpretiert Ayers Locke in dieser Richtung mit (4):

(4) Spekulationen über die Ursache, seien sie falsch oder wahr, sind irrelevant für die Bedeutung oder die Wahrheit von einfachen Vorstellungen.

Damit kann man den Grund dafür, daß Ayers nicht einfach die Frage nach der Referenz, sondern auch die Frage nach dem Vorrang behandelt, folgendermaßen erklären. Wie wir gesehen haben, tritt das Thema des Vorranges bei Locke häufig auf. Dies spricht aber nicht gegen die Kripkesche Auffassung, daß er immer beides, Vorstellung und ihre Ursache, in Bezug auf das Thema der Referenz ins Spiel bringt. So kann Ayers Locke nicht in jener Richtung interpretieren, ohne den Vorrang der Vorstellung übermäßig zu betonen.

Abgesehen davon faßt Ayers damit alle Qualitäten bei Locke als rein dispositionale Eigenschaft auf. ${ }^{11}$ Wenn man so alle Qualitäten als dispositionale Eigenschaften mit ontologischer Priorität auffaßt, dann gilt, um mit Mackie zu sprechen, daß

" this would undermine the distinction between powers or dispositions and the internal constitution from which they arise, and so would leave us no reason tying substance-names to the latter" (S. 98)

Wie Mackie hier richtig andeutet, werden in diesem Fall nicht nur die Spekulation über die Ursachen von einfachen Vorstellungen im Rahmen der Unterscheidung von primären und sekundären Qualitäten, sondern alle Spekulationen darüber in Bezug auf Bedeutung und Wahrheit irrelevant erscheinen, gleich ob sie wahr sind oder falsch. Wenn dem so ist, liegt der Grund dafür, daß Locke uns davon abrät, die Ursachen mit Hilfe des hypothetisch-deduktiven Verfahrens im Rahmen der Korpuskular-Theorie zu untersuchen, nicht darin, daß er glaubt, daß dies unmöglich sei, sondern eher darin, daß er glaubt, daß die Untersuchung als solche, gleich ob sie wahr oder falsch ist, in Bezug auf Wahrheit und Bedeutung von einfachen Vorstellungen irrelevant sei. Demnach ist es m.E. kein Zufall, daß Ayers in seiner Erklärung ausgerechnet die folgende Stelle zitiert hat-"Nor do they (einfache Vorstellungen; d. Verf.) become liable to any Imputation of Falsehood, if the Mind (as in most Men I believe it does) judges these Ideas to be in the Things themselves" (II.XXXII.14; Hervorhebung d. Verf.). Diese Stelle ist nämlich fast die einzige Stelle, die den Eindruck (aber nur dann, wenn sie isoliert gelesen wird) vermitteln kann, als wollte er die Unterscheidung von primären und sekundären Qualitäten bloß darstellen.

\footnotetext{
${ }^{11}$. Vgl. Ayers, Bd. I, S. 42.
} 
Warum all dies? Wie ich zu Beginn dieses Abschnittes erwähnt habe, tendiert Ayers sehr stark dazu, Lockes und Descartes' Position als unversöhnbar zu stellen. Natürlich gibt es viele Themen, in Bezug auf welche die beiden Autoren entgegengesetzte Positionen einnehmen. Aber sie sind zumindest nicht hinsichtlich der Unterscheidung von primären und sekundären Qualitäten verschiedener Auffassung. Im nächsten Abschnitt will ich zeigen, daß Ayers in diesem Punkt Unrecht hat.

\section{I. 3. Locke versus oder cum Descartes: Kritik an Ayers}

Ayers vertritt die These, Lockes Unterscheidung von einfachen und komplexen Vorstellungen sei "tailor-made for a confrontation with Descartes" (S. 38). Wenn Ayers damit nur meint, daß es einen Unterschied zwischen Lockes Unterscheidung von einfachen und komplexen Vorstellungen und Descartes' entsprechender Unterscheidung gibt, hat er Recht. ${ }^{12}$ Es ist fast überflüssig zu sagen, daß Lockes Unterscheidung von einfachen und komplexen Vorstellungen in der Tat mit Descartes' Unterscheidung nicht identisch ist. Nach Lockes Unterscheidung gehören alle Vorstellungen von sekundären Qualitäten zu der Kategorie der einfachen Vorstellung, während nach Descartes' Unterscheidung nur die Vorstellungen von primären Qualitäten zu jener Kategorie gehören. Aber Ayers meint damit mehr, nämlich eine wahre "Konfrontation" im wahren Sinne des Wortes. Warum soll dies aber eine Konfrontation bedeuten? Er führt dies darauf zurück, daß alle einfachen Vorstellungen sowohl von primären Qualitäten als auch von sekundären Qualitäten bei Locke wahr sind, während bei Descartes die Vorstellungen von sekundären Qualitäten nach Ayers als "liable to falsity" gesehen werden. Zunächst ist dann die Frage, wo Descartes so etwas behauptet. Ayers' Antwort ist diese:

"In the Meditations (besonders in der dritten Meditation AT VII. S. 43 f.; d. Verf.) he linked the possibility of such an idea's ( Vorstellungen von sekundären Qualitäten; d. Verf.) being 'materially' false with the possibility that (as he supposed to be the case with the idea of cold) it represents a mere privation, or nothing, as something real and positve. ... Descartes' position (...) seems to have been that, given that cold is a privation, the sensory idea of cold can only be false." (S. 39)

\footnotetext{
${ }^{12}$. Obwohl Descartes, wie wir in unserer Betrachtung über die Regulae gesehen haben, Vorstellungen dort als "einfach" bezeichnet, ist mir keine Stelle außer der fraglichen in der ersten Meditation bei Descartes bekannt, wo er die Vorstellungen von sekundären Qualitäten als "komplex" bezeichnet. Seine typische Charakterisierung der Vorstellungen von sekundären Qualitäten ist "dunkel und nicht-deutlich" (Siehe z.B. AT VII. S. 43). Vielleicht ist dies der Grund dafür, daß Ayers, was die Vorstellungen von sekundären Qualitäten betrifft, nur dies sagt: "ideas of colours, tastes,.., were taken by Descartes to exemplify composition". (Bd. I, S. 39; Hervorhebung d. Verf.)
} 
Diese Interpretation von Ayers ist aber verfehlt. Es ist wahr, daß Descartes in der dritten Meditation den Terminus 'falsitas materialis" mit Bezug auf Vorstellungen einführt. Es ist auch wahr, daß er dabei die aristotelisch-scholastische Erklärung der Ursachen der beiden entgegengesetzten Vorstellungen, nämlich "Kälte" und "Wärme", einführt. Ihr zufolge wird die Ursache der Vorstellung "Wärme" eines Gegenstandes dadurch erklärt, daß in dem Gegenstand "Wärme" als qualitas realis vorliegt, während die Ursache der Vorstellung durch Rekurs auf eine privatio caloris erklärt wird. Aber es ist ein Irrtum, wenn man wie Ayers annimmt, dies wäre Descartes' eigene Position:

"No doubt because of the argument of the Meditations, Locke opened his chapter on primary and secondary qualities with the topic of ideas of privations, such as the ideas of cold, darkness, black and rest." (ebd. S. 41)

Descartes benutzt aber die aristotelische Erklärung nur als Beispiel, um deutlich zu machen, was er mit falsitas materialis von Vorstellungen meint. Was Descartes sagen will, ist nur, daß eine Vorstellung falsa materialis ist, "cum non rem tamquam rem representant". Die Frage, welche von den beiden Vorstellungen "Kälte" und "Wärme" aus einer privatio realitatis materialis entsteht, ist an sich und als solche kein Thema für Descartes. Dies liegt nicht daran, daß er sich nicht in der Lage sieht, jene Frage zu entscheiden, sondern eher daran, daß er eigentlich jene aristotelisch-scholastische Erklärung zurückweist (dies tut Locke genauso wie Descartes). So läßt er dort nicht nur jene Frage offen, sondern auch die Möglichkeit, daß beide Vorstellungen falsae materiales sind.

Abgesehen davon ist nicht $\mathrm{zu}$ leugnen, daß alle einfachen Vorstellungen von sekundären Qualitäten bei Descartes falsae materiales sind, wie wir bald sehen werden. Gerät er damit in Konflikt mit Locke? Dies ist nicht der Fall. Worauf Descartes damit hinaus wollte, ist nur, daß physikalischen Gegenständen nur primäre Qualitäten zukommen, nicht aber, daß die Vorstellungen von sekundären Qualitäten keine objektive Basis haben. Gerade dies sagt er unmißverständlich in der sechsten Meditation:

"Und zweifelos schließe ich daraus, daß ich verschiedenartige Farben, Töne, Gerüche, Geschmäcke,...und dergleichen empfinde, mit Recht, daß in den Körpern, von denen mir diese verschiedenartigen Wahrnehmungen der Sinne zukommen, gewisse Verschiedenartigkeiten vorhanden sind, die jenen entsprechen, wenngleich sie ihnen freilich nicht ähnlich sind."(Buchenau, S. 70) ${ }^{13}$

So meint Descartes, wenn er die Vorstellungen von sekundären Qualitäten als falsae materiales erklärt, damit nicht, daß sie uns keine objektive Basis für die Unterscheidung von

\footnotetext{
${ }^{13}$. "Et certe, ex eo quod valde diversos sentiam colores, sonos, odores, sapores...\& similia, recte concludo, aliquas esse in corporibus, a quibus variae istae sensuum perceptiones adveniunt, varietates iis respondentes, etiamsi forte iis non similes" (AT VII, S. 81)
} 
Gegenständen liefern können, sondern nur, daß sie als solche nicht in physikalischen Gegenständen liegen. In den Principia (i.66-71, AT VIII S. 32-6) gibt Descartes dieselbe Erklärung. Es gibt demnach keine Veränderung in Descartes' Erklärung zwischen den Meditationes und Principia, anders als Ayers behauptet:

"In the Principles of Philosophy (I 66-71, AT VIII S. 32-6; d. Verf.), however, he set aside the argument from the possibility of privative causes" (S. 39)

Es ist völlig unverständlich, wie man aus jener Stellen in den Principia diese Konsequenz ziehen kann:

"(Descartes; d. Verf.) in effect allowed for two sorts of 'obscure and confused' ideas of a colour: if we cautiously judge that the external cause of our sensation is unknown, then we avoid error; but if (as it is natural and normal for us to do from childhood) we rashly judge that what is in the object is qualitatively like the sensation, then our judgement is erroneous. The implication is that there are two possible sensory ideas of colour-in-the-object, one materially true and the other materially false." (S. 39-40)

So gesehen ist Descartes ohne Bedenken bereit, Lockes Behauptung zu akzeptieren, daß alle einfachen Vorstellungen von sekundären Qualitäten wahr sind, wenn damit nur gemeint ist, daß sie eine objektive Basis für die Unterscheidung von Gegenständen liefern können. Dies ist der Fall, wie (5) und (6) zeigen. So behauptet Locke auch nicht, daß alle einfachen Vorstellungen von sekundären Qualitäten in dem Sinne wahr sind, daß sie als solche in physikalischen Gegenständen liegen. Dies ist nur der Fall für Vorstellungen von primären Qualitäten.

Man muß auch den Zusammenhang berücksichtigen, in dem Descartes sagt, daß die Vorstellungen von sekundären Qualitäten uns leichter zum Irrtum führen. Damit meint er nämlich nicht, daß unsere Wahrnehmungen von sekundären Qualitäten im Gegensatz zu unseren Wahrnehmungen von primären Qualitäten uns leichter täuschen. Um zu sehen, daß dies nicht der Fall ist, genügt es, einen Blick auf das Beispiel zu werfen, das Descartes wählt, um zu erklären, daß unsere Wahrnehmungen uns leicht täuschen (AT VII, S 76). Im Turmbeispiel geht es um die Wahrnehmung einer primären Qualität. Warum dieses Beispiel? Dies liegt daran, daß unsere Wahrnehmungen von sekundären Qualitäten viel weniger als unsere Wahrnehmungen von primären Qualitäten uns zu Irrtum führen. Die blaue Farbe eines Turms z.B. sieht nicht rot aus, wenn wir ihn aus der Ferne wahrnehmen, während seine viereckige Figur rund aussehen kann, wenn wir ihn aus der Ferne wahrnehmen. So sind wir sehr daran gewöhnt, daß die Wahrnehmungen von sekundären Qualitäten (mehr als die Wahrnehmungen von primären Qualitäten) verläßlich sind. Deswegen sind wir nach Descartes geneigt zu glauben, daß die physikalischen Gegenstände in Wirklichkeit so beschaffen sind, wie sie uns 
aufgrund der Wahrnehmung sekundärer Qualitäten erscheinen, obwohl ihnen eigentlich nur primäre Qualitäten zukommen. In diesem Zusammenhang muß jene Behauptung Descartes' verstanden werden. Eine andere Möglichkeit, sie zu verstehen, liefert Locke selbst. Wie wir an obigem Zitat aus der sechsten Meditation gesehen haben, ist auch Descartes der Meinung, daß die Wahrnehmungen von sekundären Qualitäten eine objektive Basis für die Unterscheidung von Gegenständen liefern. Wenn aber Locke in (6) behauptet, daß die Vorstellungen von einfachen Vorstellungen dazu beitragen können, Gegenstände voneinander zu unterscheiden, sagt er dies nicht ohne Einschränkung. (6) besagt genauer betrachtet nur, daß die Vorstellungen von sekundären Qualitäten zwar eine verläßliche und objektive Basis für die Unterscheidung von physikalischen Gegenständen abgeben, aber nur für das Alltagsleben:

"Not knowing therefore what number of Particles, nor what Motion of them is fit to produce any precise degree of Whiteness, we cannot demonstrate the certain Equality of any two degrees of Whiteness, because we have no certain Standard to measure them by, nor Means to distinguish every the least real difference, the only help we have being from our Senses, which in this point fail us. But where the difference is so great, as to produce in the Mind clearly distinct Ideas, whose differences can be perfectly retained, there these Ideas of Colours, as we see in different kinds, as Blue and Red, are as capable of Demonstration, as Ideas of Number and Extension."(IV.II.13)

So kann und muß man sagen, daß Descartes und Locke darüber keine Meinungsverschiedenheit hinsichtlich (5) und (6) haben.

Abgesehen davon hat Ayers zumindest Recht, daß nicht die Unterscheidung von primären und sekundären Qualitäten, sondern die Unterscheidung von einfachen und komplexen Vorstellungen die entscheidende Rolle bei Locke spielt. Womit er Unrecht hat, ist nur, daß er darin "a fundamental difference of view over the nature of what ties thought to reality" sehen zu können glaubt. Wenn dem so ist, hat die Frage einen Sinn, warum Locke dies glaubt, anders als Descartes. Warum empfiehlt Locke nicht das hypothetisch-deduktive Verfahren im Rahmen der Korpuskular-Theorie, obwohl er wie Descartes diese für die beste Theorie hält und deswegen im Essay durchgängig anwendet? Die Konsequenz aus unserer bisherigen Überlegung ist die, daß (1), falls dies Lockes Antwort ist, nicht als (4) interpretiert werden darf:

(1) Erkenntnis von Vorstellungen ist von der Erkenntnis ihrer Ursachen unabhängig;

(4) Spekulationen über die Ursachen, seien sie falsch oder wahr, sind irrelevant für die Bedeutung oder die Wahrheit von einfachen Vorstellungen.

Auf die Frage, worauf Locke dann mit (1) hinaus wollte, werden wir im Fazit dieses Teils zurückkommen. 
Bevor ich diesen Abschnitt abschließe, will ich jene Konsequenz durch eine allgemeine Überlegung noch einmal bestätigen, die ich am Ende des letzten Kapitels angestellt habe.

Man darf nämlich nicht übersehen, daß nicht die Frage nach der Referenz von einfachen Vorstellungen allgemein, sondern nur die Frage nach der Referenz von Vorstellungen von sekundären Qualitäten wiederholt im Essay gestellt wird. ${ }^{14}$ Warum? Wenn man Ayers folgend annimmt, daß Locke (4) vertritt, ist dieses Phänomen nicht zu erklären. Man kann es nur so erklären, daß Locke zwar die (SII) im Rahmen der Unterscheidung von primären und sekundären Qualitäten als die Ursache von Vorstellungen von sekundären Qualitäten versteht, aber davon überzeugt ist, daß es unmöglich ist, die (SII) zu erkennen. So ist nicht (4), sondern (4') Lockes Position:

(4') Spekulationen über die Ursachen von Vorstellungen sind überhaupt irrelevant, da es unmöglich ist, sie zu erkennen.

Daher sind wir nach Locke gezwungen, fast nur mit sekundären Qualitäten zu operieren, wenn es um die Erkenntnis von physikalischen Gegenständen geht. Wir operieren nämlich mit Vorstellungen der sekundären Qualitäten nicht deswegen, weil Erkenntnis von ihnen als dispositionale Eigenschaften unabhängig von der Erkenntnis ihrer Ursachen ist, sondern weil es unmöglich ist, die (SII) zu erkennen. Mit anderen Worten: Wenn nämlich Locke die Spekulation über die Ursachen von Vorstellungen von sekundären Qualitäten für irrelevant hält, liegt dies nicht daran, daß sie wirklich generell irrelevant ist, noch darin, daß er glaubt, daß die Korpuskular-Theorie als "at best higly probable" (Ayers, ebd. S. 41) "failed to capture the essence of what is there" (Ayers, Bd II. S. 37). Es liegt eher daran, daß er, obwohl er sie generell für richtig hält, dennoch daran zweifelt, daß man daraus spezifizische Theorien aufbauen kann, mit deren Hilfe gegebene Phänomenen erklärt werden können. Dies werden wir in den nächsten Abschnitten näher sehen.

\footnotetext{
${ }^{14}$. Ironischerweise scheint Ayers selbst dies dadurch zu untermauern, daß er die Frage nach dem Vorrang unter dem Titel "Private language and secondary qualities" (Hervorhebung d. Verf.) behandelt.
} 


\title{
III. II. Pragmatische Überlegungen zu dem erklärungsbedürftigen Phänomen
}

\author{
III. II. 1. Lockes pragmatische Erklärung
}

Warum empfiehlt Locke nicht das hypothetisch-deduktive Verfahren im Rahmen der Korpuskular- Theorie, obwohl er diese für die beste Theorie hält? Kann man diese Frage einfach dadurch beantworten, indem man (1) so interpretiert, daß die Erkenntnis von der (SII) zu praktischen Zwecken untauglich sei? Locke scheint dies zu meinen, wenn $\mathrm{er} \mathrm{sagt}^{15}$ :

"A Painter or Dyer, who never enquired into their causes, hath the Ideas of White and Black, and other Colours, as clearly, perfectly, and distinctly in his Understanding, and perhaps more distinctly than the Philosophers..." (II.VIII.2)

Die Antwort auf jene Frage ist dennoch "Nein". Es bleibt nämlich die Möglichkeit offen, daß die Erkenntnis von der (SII) viel mehr als die Erkenntnis von beobachtbaren Qualitäten dazu beiträgt, unser praktisches Leben zu verbessern. Locke benötigt also ein Argument für seine Behauptung. Und er hat ein Argument dafür:

"The complex Ideas, that our Names of the Species of Substances properly stand for, are Collections of such Qualities, as have been observed to co-exist in an unknown Substratum which we call Substance; but what other Qualities necessarily co-exist with such Combinations, we cannot certainly know, unless we can discover their natural dependence; ...in all their secondary Qualities, we can discover no connexion at all, ....1. Because we know not the real Constitutions of Substances, on which each secondary Quality particularly depends. 2. Did we know that, it would serve us only for experimental (not universal) Knowledge; and reach with certainty no farther, than that bare instance. Because our Understandings can discover no conceivable connexion between any secondary Quality, and any modification whatsoever of any of the primary ones." ${ }^{\text {16 }}$ (IV.VI.7.; Hervorhebung d. Verf.)

Lassen wir den ersten Punkt im Zitat zunächst beiseite. Locke sieht demnach den Grund dafür, daß die Erkenntnis von der (SII) für unser Alltagsleben nicht von Nutzen sein kann, darin, daß sie nicht zur Erkenntnis von Relationen zwischen beobachtbaren sekundären Qualitäten beitragen kann. Locke hat hierin völlig Recht. Keine Erkenntnis von der (SII) kann dazu

\footnotetext{
${ }^{15}$. In der Tat äußert er einen solchen Gedanken in II.XXIII.12.: "if by the help of such Microscopical Eyes, (if I may so call them,) a Man could penetrate farther than ordinary into the secret Composition, and radical Texture of Bodies, he would not make any great advantage by the change, if such an acute Sight would not serve to conduct him to the Market and Exchange', Obwohl der Vergleich des Gebrauches der Mikroskopie mit mikroskopischen Augen verfehlt ist (Dafür entschuldigt sich Locke in II.XXIII.13.), so ist doch wichtig, daß wir hier zumindest sehen können, warum er von der Suche nach der (SII) abrät.

${ }^{16}$. Vgl. IV.III.11-13 und IV.VI.14.
} 
beitragen. Aber dies heißt nicht, daß die Erkenntnis von der (SII) nicht praktischen Zwecken dienen kann. Zu erklären, warum dies so ist, ist keine schwierige Aufgabe.

Nehmen wir an, daß wir einen Gegenstand an einem Berg gefunden haben. ${ }^{17}$ Unabhängig von der Entscheidung der Frage, ob wir den Versuch machen, die (SII) des Gegenstandes herauszufinden, steht es uns völlig frei zu entscheiden, ob wir dem Gegenstand einen Namen geben oder nicht, und ob wir ihm einen Eigennamen oder einen generellen Namen geben. Die beiden Fälle lassen sich dadurch unterscheiden, daß wir im ersten Fall eine Verknüpfung zwischen dem Gegenstand und dem Namen herstellen, während wir im zweiten Fall eine Verknüpfung zwischen dem Namen und einer bestimmten Art von Gegenstand herstellen. Das letztere geschieht einfach dadurch, daß wir voraussetzen, daß es viele andere Dinge (mindestens noch ein anderes Ding) in der Welt gibt, die zusammen mit ihm eine Art bilden. In diesem Fall ist die (SII) die reale Essenz der betreffenden Art. Nennen wir sie in diesem Fall "(RI)". Die Frage, ob eine solche Voraussetzung wahr ist, kann nur empirisch entschieden werden. Wenn sie wahr ist, ist die (SII) eine (RI). Wenn dies nicht der Fall ist, dann nicht. Nehmen wir an, daß wir dem Gegenstand den generellen Namen "Gold" gegeben haben. Wenn dies so ist, wird unsere Vorstellung von der Suche nach der (RI) und dem Zusammenhang zwischen ihr und den Eigenschaften, mit denen wir den generellen Terminus verbinden, um mit Kripke zu sprechen, folgendermaßen aussehen:

"A priori, all we can say is that it is an empirical matter whether the characteristics originally associated with the kind apply to its members universally, or even ever, and whether they are in fact jointly sufficient for membership in the kind."18

Nehmen wir weiter an, daß wir den Versuch gemacht haben, die (SII) des Gegenstandes herauszufinden, und sie auch entdeckt haben. Dann werden wir die (SII) für die (RI) einer natürlichen Art namens "Gold" halten. Dann werden wir, um zu entscheiden, ob ein Gegenstand derselben Art ist oder nicht, die (SII) dieses Gegenstandes daraufhin überprüfen, ob sie mit der (RI) identisch ist. Wenn ja, nennen wir ihn "Gold", wenn nicht, dann nicht. Dies ist der Grund dafür, daß wir, wenn die (SII) nicht mit der (RI) identisch ist, einen Gegenstand nicht "Gold" nennen, auch wenn er alle identifizierenden Merkmale besitzt, die wir dem Gold gewöhnlich zuschreiben und mittels derer wir es zunächst identifizierten. Dies ist auch der Grund dafür, daß wir, wenn die (SII) identisch mit der (RI) ist, den Gegenstand "Gold" nennen, auch wenn er keine von den oben genannten Eigenschaften besitzt. So gesehen zielt die Suche nach realen Essenzen vor allem darauf ab, ein sicheres Identitätskriterium für die Zugehörigkeit eines Gegenstandes $\mathrm{zu}$ der betreffenden Art $\mathrm{zu}$ finden, damit alle

\footnotetext{
17. Um unsere Betrachtung einfach zu halten, nehmen wir an, daß er nur aus einer Art von Stoff besteht.

${ }^{18}$. Kripke, S. 137
} 
Schwierigkeiten beseitigt werden, die wir bekommen, wenn wir nur von nominalen Essenzen ausgehen.

Dies ist noch nicht alles. Wenn die (RI) des Goldes identifiziert wird, benutzen wir sie auch als Basis, um zu erklären, welche von den Eigenschaften, die wir anfangs als identifizierende Merkmale benutzt haben, sich an der (RI) ergeben, welche nicht und warum, und welche anderen Eigenschaften sich aus der (RI) ergeben. Wenn dem so ist, scheint es so zu sein, daß Locke sich über die Rolle von der (RI) als Basis der Erklärung nicht im klaren ist. Dabei geht es überhaupt nicht um die Erkenntnis von Relationen zwischen sekundären Qualitäten, sondern um die Erkenntnis von Relationen von der (RI) und den sekundären Qualitäten (wenn dabei von den sekundären Qualitäten die Rede sein soll). Wenn wir die Eigenschaften eines Dreieckes untersuchen, untersuchen wir nicht Relationen zwischen Eigenschaften, die ein Dreieck hat, sondern Relationen zwischen dem Dreieck und seinen Eigenschaften.

$\mathrm{Daß}$ Locke sich nicht nur über die Rolle der (RI) als Basis der Erklärung, sondern auch als Identitätskriterium nicht im klaren ist, zeigt sich, wenn wir seine Erklärung der "adäquaten" oder "vollkommenen Vorstellung" in II.XXXI. betrachten. In II.XXXI.3. nennt Locke die Vorstellung des Dreieckes "adäquat", und der Grund dafür liegt darin, daß sie die (RI) ist. Dies läßt vermuten, daß Locke als Kriterium für die Adäquatheit bzw. "perfectness" einer Vorstellung die Antwort auf die Frage behandelt, ob sie die (RI) als Identitätskriterium repräsentiert. Wenn wir aber seine Erklärung darüber weiter verfolgen, warum alle Vorstellungen von Substanzen "unvollkommen" oder "nicht-adäquat" sind, so finden wir den Grund nicht darin, daß sie nicht die (RI) als Identitätskriterien repräsentieren, sondern darin, daß wir ihre Eigenschaften nicht vollständig erkannt haben. Wenn dies aber in der Tat das Kriterium für die Vollkommenheit einer Vorstellung sein soll, ist es überflüssig zu sagen, daß nicht nur alle Vorstellungen von Substanzen (auch wenn ihre (RI)s identifiziert worden sind), sondern auch alle Vorstellungen von geometrischen Figuren unvollkommen oder nicht adäquat sind.

Trotz alledem scheint die Frage, ob und welchen Fehler Locke damit begangen hat, in Bezug auf mein Vorhaben irrelevant zu sein. Es geht hier nämlich in erster Linie nur um die Frage, ob Locke ein Argument dafür hat, von der Suche nach der (SII) abzuraten. Und er hat ein Argument dafür. Heißt dies nicht, daß das Thema damit erledigt ist, unabhängig davon, ob das Argument richtig ist oder nicht? In der Tat. Deshalb muß es eine andere und bessere Möglichkeit geben zu erklären, worauf Locke eigentlich mit jener oben zitierten Stelle (IV.VI.7) hinaus wollte. Da ich eine solche Erklärung am Ende dieses Kapitels anbieten werde, will ich im Folgenden als Vorbereitung dazu Frage stellen, ob Locke der Suche nach der (SII) deswegen abrät, weil er in der Tat, wie wir gesehen haben, glaubt, daß die Erkenntnis der (SII) keinen 
praktischen Nutzen habe. Ich bin mit Yost einer Meinung, daß es sehr schwer vorstellbar ist, daß Locke dies glaubt. ${ }^{19}$

III. II. 2. Locke gegen seine eigene pragmatische Erklärung

Daß Locke von der Suche nach der (SII) deswegen abrät, weil er in der Tat glaubt, daß deren Erkenntnis ohne Nutzen sei, wird zweifelhaft, wenn wir einerseits betrachten, worin Lockes Argumente gegen die traditionelle Formtheorie liegen, und andererseits, wie gewiß er sich der Schwierigkeiten bewußt ist, denen wir ausgesetzt sind, wenn wir aufgrund mangelnder Erkenntnis von der (RI) nur von nominalen Essenzen ausgehen. Aus all dem folgt, daß sich Locke auch bewußt ist, welche Vorteile die Erkenntnis der (RI) mit sich bringt. Abgesehen davon zeigt seine Kritik an der Formtheorie vor allem, daß Locke sich über die beiden Rollen der (RI) im klaren ist. Sie weist nämlich zwei Aspekte auf: Der eine Aspekt ist der, daß substanzielle Formen keine Identitätskriterien von (RI)s sind. Der andere Aspekt ist der, daß sie nicht wie die (RI) Basis der Erklärung von Eigenschaften sind.

III. II. 2. 1. Lockes Kritik an der Formtheorie: (RI) als Basis der Erklärung

Betrachten wir zunächst Lockes Erklärung von realen Essenzen;

"it may not be amiss to consider the several significations of the Word Essence.

"First, Essence may be taken for the very being of any thing, whereby it is, what it is. And thus the real internal, but generally in Substances, unknown Constitution of Things, whereon their discoverable Qualities depend, may be called their Essence. This is the proper original signification of the Word, as is evident from the formation of it; Essentia, in its primary notation signifying properly Being. And in this sense it is still used, when we speak of the Essence of particular things, without giving them any Name. ${ }^{20}$

Diese Erklärung ist nicht neu. Wenn wir an einem Gegenstand (z.B. einem Stück Gold) viele verschiedene Qualitäten wahrnehmen, nehmen wir an, daß es aus Korpuskularen mit einer inneren Struktur besteht, von denen sie abhängig sind. Dieser Komplex von Korpuskularen mit einer inneren Struktur ist die (SII), und Locke setzt die (SII) mit der Essenz im ursprünglichen Sinne des Wortes gleich, so daß er "Essenz" und "Seiendes" für synonym hält.

\footnotetext{
${ }^{19}$. Vgl. Yost, S. 122-123.

${ }^{20}$. III.III.15.
} 
Lockes Argument gegen die traditionelle Formtheorie als Erklärung von Eigenschaften ist Folgendes. Wenn die substanziellen Formen reale Essenzen wären, müßte es möglich sein, aus ihnen durch deduktive Verfahren auf neue Eigenschaften der Einzelgegenstände der betreffenden Art zu schließen. ${ }^{21}$ Dies ist aber nicht möglich, da man keinen notwendigen Zusammenhang unter Eigenschaften identifizieren kann. Hierauf beruht Lockes Kritik an den Scholastikern, daß sie irrtümlicherweise glaubten, daß es zur Erweiterung der Erkenntnis über die Einzelgegenstände beitrage, sie in species und genera einzuteilen, und apriorische Überlegungen über ihre Beziehungen untereinander anzustellen. ${ }^{22}$ Was daraus bestenfalls folgt, sind triviale Wahrheiten, und schlimmstenfalls verbale Streitigkeiten. Obwohl Locke dies hier mit dem Beispiel einer geometrischen Figur erklärt, setzt er voraus, daß die Erkenntnis der (RI) die Erkenntnis von Eigenschaften erweitern werde. Wenn dem so ist, folgt unmittelbar, daß die Erkenntnis der (RI) sehr nützlich ist. Dies Vorstellung von der (RI) bezieht sich nicht nur auf geometrische Figuren, sondern auch auf physikalische Gegenstände. Locke sagt:

"I doubt not but if we discover the Figure, Size, Texture, and Motion of the minute Constituent parts of any two Bodies, we should know without Trial several of their Operations one upon another, as we do now the Properties of a Square, or a Triangle. Did we know the Mechanical affections of the Particles of Rhubarb, Hemlock, Opium, and a Man, .....we should be able to tell before Hand, that Rhubarb will purge, Hemlock kill, and Opium make a Man sleep... The dissolving of Silver in aqua fortis, and Gold in aqua Regia, and not vice versa, would be then, perhaps, no more difficult to know, than it is to a Smith to understand, why the turning of one Key will open a Lock, and not the turning of another.' ${ }^{23}$

\footnotetext{
${ }^{21}$. Vgl. II.XXXI.5. und 6.

${ }^{22}$. Vgl. III.VIII.2.

${ }^{23}$ IV.III. 25.
} 
III. II. 2. 2. Lockes Kritik an der Formtheorie: (RI) als Identitätskriterium

Lockes Erklärung der nominalen Essenz ist Folgende:

"Secondly, The Learning and Disputes of the Schools, having been much busied about Genus and Species, the Word Essence has almost lost its primary signification; and instead of the real Constitution of things, has been almost wholly applied to the artificial Constitution of Genus and Species. 'Tis true, there is ordinarily supposed a real Constitution of the sorts of Things; and 'tis past doubt, there must be some real Constitution, on which any Collection of simple Ideas co-existing, must depend. But it being evident, that Things are ranked under Names into sorts or Species, only as they agree to certain abstract Ideas, to which we have annexed those Names, the Essence of each Genus, or Sort, comes to be nothing but that abstract Idea, which the General, or Sortal (...) Name stands for. And this we shall find to be that, which the Word Essence imports, in its most familiar use. These two sorts of Essences, I suppose, may not unfitly be termed, the one the Real, the other the Nominal Essence."(III.III.15)

Obwohl das im letzten Abschnitt behandelte Argument Lockes zeigt, daß substanzielle Formen keine (RI)s sind, scheint dies doch nicht die Möglichkeit auszuschließen, daß die Klassifikation von Gegenständen nach substanziellen Formen als Identitätskriterien (die nach Locke durch Angabe einer bestimmten präzisen Anzahl von Eigenschaften genau definiert sind) ${ }^{24}$ mit der Klassifikation nach (RI)s identisch ist. Und Locke kann dies nicht einfach dadurch ausschließen, daß er die Möglichkeit des Gegenteils andeutet. ${ }^{25}$ Besondere Schwierigkeiten bereitet es Locke dabei, daß er nicht an die Möglichkeit glaubt, (RI)s (bzw. (SII)s) zu identifizieren. ${ }^{26}$ Aber wie Locke richtig gesehen hat, besteht die Möglichkeit, zu zeigen, daß die Klassifikation von Gegenständen nach substanziellen Formen und die Klassifikation nach (RI)s divergiert, nicht einzig und allein darin, (RI)s zu ermitteln. Eine andere Möglichkeit kommt in den Blick, wenn wir einerseits Lockes Erklärung zu generellen sortalen Termini von natürlichen Arten betrachten und andererseits sehen, wie er davon ausgehend gegen die Formtheorie argumentiert. Dies wird letzten Endes zeigen, daß Locke weiß, welchen Schwierigkeiten wir aufgrund des Mangels an Erkenntnis von (RI)s ausgesetzt sind.

Eine wichtige Frage, die Locke im dritten Buch des Essays thematisiert, ist die, wie erklärt werden kann, daß wir über generelle Termini verfügen. "All Things, that exist," sind "Particulars" (III.III.1). Generelle Termini unterscheiden sich von Eigennamen dadurch, daß sie weder zur Bezeichnung eines Einzelgegenstandes verwendet werden, noch zur Bezeichnung einer Vielzahl von Gegenständen. Sie bezeichnen vielmehr Sorten von Einzelgegenständen.

\footnotetext{
${ }^{24}$. Vgl. III.III.17., III.VI.17., 19., und 27., und III.X.14.

${ }^{25}$. Vgl. z.B. III.III.13., III.IX.21. und III.X.21.

${ }^{26}$. Auf diesen Punkt werden wir später zurückkommen.
} 
Wie kann, fragt Locke, ein Terminus, der selbst einzeln ist, generell werden? Dies führt Locke auf die Idee, daß es etwas geben müsse, das als Brücke zwischen Einzelgegenständen und generellen Termini dient. Dies sind komplexe abstrakte Ideen: ${ }^{27}$ Ein Terminus wird dadurch generell, daß er als Symbol für eine komplexe abstrakte Idee (ein Bündel von beobachtbaren Eigenschaften) verwandt wird, und diese wird von uns durch Abstraktion aus gemeinsamen Eigenschaften von verschiedenen Einzelgegenständen gebildet. ${ }^{28}$ Die so gebildeten abstrakten Ideen werden wiederum als Kriterien dafür verwendet, ob wir Einzelgegenstände mit dem betreffenden generellen Namen bezeichnen dürfen oder nicht. Daraus folgert Locke, daß species und genera bei den traditionellen Scholastikern nichts anderes als die abstrakten Ideen sind: "to be of any Species, and to have a right to the name of that Species, is all one" (III.III.12). Wir werden nun überlegen, wie er davon ausgehend gegen die Formtheorie argumentiert.

Locke vertritt folgende Thesen:

(1) Die Bedeutung eines generellen Terminus ist eine komplexe abstrakte Idee (Ein Bündel von beobachtbaren Eigenschaften); ${ }^{29}$

(2) Die komplexe abstrakte Idee, die ein Sprecher mit einem generellen Terminus verbindet, wird von ihm selbst erzeugt. ${ }^{30}$

(2) folgt nach Locke aus (3):

(3) Es gibt viele Fälle, in denen verschiedene Sprecher ein und denselben generellen Terminus mit verschiedenen komplexen abstrakten Ideen verbinden. ${ }^{31}$

Außerdem vertritt Locke weiter folgende beiden Thesen:

(4) Ein Sprecher hält die komplexe abstrakte Idee, die er mit einem generellen Terminus verbindet, für die notwendige und hinreichende Bedingung der Zugehörigkeit eines Einzelgegenstandes zu der betreffenden Art: ${ }^{32}$

(5) Die Frage nach der Zugehörigkeit eines Einzelgegenstandes zu einer Art ist von der Frage abhängig, mit welcher abstrakten Idee ein Sprecher den Terminus verbindet. ${ }^{33}$

\footnotetext{
${ }^{27}$. Es geht hier nur um komplexe abstrakte Ideen von stofflichen Substanzen.

28. Ich will hier nicht darauf eingehen, ob dies richtig ist oder nicht und was als "abstrakte" Idee verstanden werden kann und soll.

${ }^{29}$. Vgl. III. II.2.

${ }^{30}$. Vgl. II.XXX.3, III.II.3. und III.II.8.

${ }^{31}$. Vgl. III.III.14, III.VI.31 und III.IX.17.

${ }^{32}$. Vgl. III.VI.30. und 38.

${ }^{33}$. Vgl. III.III.12-14. und 18., III.VI.26-27. und IV.IV.8-9.
} 
(3) ist wahr. Wie steht es aber mit (4)? Um diese Frage zu entscheiden, greifen wir ein Beispiel Lockes auf. Ein Kind äußert angesichts des gelben strahlenden Schwanzes eines Pfaus "Gold". Vielleicht haben seine Eltern ihm früher ein Stïck Gold gezeigt und es "Gold" genannt. Was zeigt das Beispiel? Es zeigt, obwohl Locke es nicht explizit auf den Punkt gebracht hat, zunächst, daß das Kind den Terminus "Gold" als generellen Terminus verwendet. Andererseits zeigt es nach Locke, daß es den Terminus nur mit den beiden Eigenschaften, die es selbst aus dem Stück Gold abstrahiert hat, verbunden hat. Dies könnte bedeuten, daß (2) zutreffend ist. Es zeigt weiter, daß es den Terminus synonym mit einem Bündel von Ausdrücken für Eigenschaften verwendet, mit denen es ihn in Verbindung bringt. Wenn dies alles wäre, würde daraus folgen, daß (4) wahr ist. Aber dies ist nicht alles, denn die Eltern reagieren in bestimmter Weise, wenn das Kind den Schwanz "Gold" nennt. Wie reagieren die Eltern? Sie würden, wenn Locke Recht hat, etwa sagen, "Ah, Du verwendest den Terminus "Gold" so! Aber wir verwenden ihn anders." Würden sie wirklich aber so reagieren? Ich denke nicht. Man könnte einwenden, daß damit Locke zu Unrecht eine absurde Position zugeschrieben werde. Obwohl dieser Vorwurf unberechtigt ist, ${ }^{34}$ wollen wir die Geschichte weiter so entwickeln, daß Lockes Position sinnvoller erscheint.

Wie würden die Eltern reagieren? Sie würden dem Kind sagen, daß der Pfauenschwanz kein Gold sei. Sie würden ihm vielleicht einige weitere Eigenschaften von Gold zeigen oder erklären, die es den Unterschied zwischen Gold und dem Pfauenschwanz erkennen lassen können. Das Kind lernt dadurch, daß nicht alles, was gelb ist und glänzt, Gold ist:

"because many of the simple Ideas that make up our specifick Ideas of Substances, are Powers, which lie not obvious to our Senses in the Things as they ordinarily appear; therefore, in the signification of our Names of Substances, some part of the signification will be better made known, by enumerating those simple Ideas, than in shewing the Substance it self. ${ }^{135}$

Nun wird Locke sagen, daß damit nichts gegen seine Behauptung gesagt ist, daß wir den Terminus "Gold" synonym mit einem Bündel von Ausdrücken für Eigenschaften verwenden. Das Kind wird zwar den generellen Terminus "Gold" nicht mehr synonym mit dem Bündel der beiden Eigenschafts-Ausdrücke "gelb sein" und "glänzen", aber synonym mit dem Bündel der bisherigen Eigenschaftsausdrücke und derjenigen Eigenschafts-Termini gebrauchen, die es von seinen Eltern zusätzlich gelernt hat. Dies hätte Folgen. Da nämlich immer die Möglichkeit bestünde, daß wir aneinander vorbeireden, auch wenn wir ein und denselben Terminus verwenden, müssen wir immer darauf achten, ob wir den Ausdruck mit Bezug auf dasselbe Bündel von Eigenschaften verwenden. Aber dies tun wir normalerweise nicht. Wenn ich mich

\footnotetext{
${ }^{34}$. Vgl. III.II.8., III.VI.21., 27. und 38., und III.IX.13.

${ }^{35}$. III.XI.22.
} 
nicht irre, kümmern wir uns in normalen Gesprächen sehr selten darum und glauben dennoch, daß wir nicht aneinander vorbei reden. Wie erklärt sich das? Locke hat eine Erklärung für dieses Phänomen, die auf den ersten Blick sehr überzeugend zu sein scheint:

"Most Men, wanting either Time, Inclination, or Industry enough for this, even to some tolerable degree, content themselves with some few obvious, and outward appearances of Things, thereby readily to distinguish and sort them for the common Affairs of Life: And so, without farther examination, give them names, or take up the Names already in use".(Hervorhebung d. Verf.) ${ }^{36}$

Dies verstehe ich folgendermaßen. Obwohl es uns allen frei steht, eigene komplexe abstrakte Ideen für die betreffenden generellen Termini zu bilden, tun wir es (vielleicht aus den von Locke genannten Gründen) dennoch nicht immer, sondern sogar sehr selten. Zunächst nämlich lernen wir eine gemeinsame Sprache. Dies hindert uns daran, aneinander vorbei zu reden, wenn wir einen generellen Terminus verwenden. Heißt dies, daß Locke mit (4) Recht hat? Um diese Frage besser beantworten zu können, betrachten wir ein anderes Beispiel Lockes. Er ist sehr zuversichtlich, daß wir, wenn wir den Ring an seinem Finger sehen, ihn als "Gold" bezeichnen würden. ${ }^{37}$ Ich habe daran keinen Zweifel. Woran liegt dies?

Nach Locke liegt es daran, daß wir gelernt haben, daß Gold etwas ist, das die Eigenschaften F, $\mathrm{G}$ und $\mathrm{H}$ besitzt, und daß der Ring sie besitzt. Hier bemerken wir die Wirkung des Erwerbs einer gemeinsamen Sprache, nämlich, daß nicht ich allein, sondern wir alle es "Gold" nennen. Aber hat Locke Recht damit? Ich denke nicht.

Nehmen wir z.B. die Situation, daß wir auf der Straße ein Ding gefunden haben, das die oben genannten Eigenschaften besitzt. Werden wir es Gold" nennen? Ich glaube, daß niemand von uns behaupten würde, daß es Gold sei, nur weil es die Eigenschaften zeigt, von denen wir gelernt haben, daß Gold sie besitzt, es sei denn, daß wir wissen, daß jene Eigenschaften wesentliche Eigenschaften des Goldes sind.

Dies zeigt, daß der Grund dafür, daß wir Lockes Ring als "Gold" bezeichnen, nicht darin liegt, daß es die erwähnten drei Eigenschaften hat. Woran liegt er dann? Er liegt einfach darin, daß wir bisher erfahren haben, daß die meisten Ringe aus Gold sind.

Gehen wir zu dem Beispiel zurück. Was würden wir tun, um zu entscheiden, ob der Gegenstand, den wir auf der Straße gefunden haben, Gold ist oder nicht? Wir würden es zu einem Experten bringen. Dagegen hat Locke etwas zu sagen. Er behauptet nämlich, daß die Situation dadurch nicht verändert werde, da die Experten untereinander darüber streiten,

\footnotetext{
${ }^{36}$. III.VI.30. Lockes Ausdruck dafür ist "Common Idea" in II.XXXI.6., Vgl. III.II.4. und 9., III.IX.3., 8 und 15., und "Common Acceptance of the Language" in III.II.8.

${ }^{37}$. Locke benutzt dieses Beispiel eigentlich in einem anderen Zusammenhang. Aber dies macht hier keinen Unterschied. Vgl. II.XXXI.7.
} 
welche Eigenschaften ein Ding besitzen muß, um "Gold" genannt werden zu können. ${ }^{38}$ Demnach können ihre Entscheidungen verschieden ausfallen, oder sie könnten sich des Urteils enthalten. Wenn sie ihre Entscheidungen treffen, heißt dies, daß ihre Kriterien für die Entscheidung in nichts anderem bestehen als in den Eigenschaften, die sie mit dem Terminus "Gold" verbunden haben. Dies zeigt, daß sie nichts anderes als nominale Essenzen sind. Dies ist mit (5) gemeint. Wenn die Experten sich aber nicht in der Lage sehen, eine Entscheidung zu treffen, heißt dies, daß jene Eigenschaften keine realen Essenzen sind. So besteht Lockes Argument gegen die Formtheorie im Nachweis der Unmöglichkeit, bestimmte und präzise Angabe von Eigenschaften als Identitätskriterien anzugeben. Diesen Punkt können wir folgendermaßen präzisieren.

Mit (2) meint Locke nicht einfach, daß die generellen Termini und die abstrakten Ideen nichts anderes als menschliche Erzeugnisse seien. Dies wäre selbstverständlich. Er unterscheidet richtig zwei Komponenten, nämlich eine sprachliche und eine nicht-sprachliche, und ist der Ansicht, daß es eine nicht-sprachliche Komponente gibt, die unserem Gebrauch von generellen sortalen Termini zugrunde liegt. Komplexe abstrakte Ideen werden nämlich durch Abstraktion aus gemeinsamen Eigenschaften verschiedener Einzelgegenstände gebildet. Aber dies heißt nicht, daß die Entscheidung der Frage, welche und wieviele Eigenschaften jeder von uns mit dem Terminus "Gold" verbindet, völlig nach unserem Belieben getroffen werden kann, obwohl Locke dies prinzipiell anerkennt und wiederholt zu betonen scheint. Der wichtige Punkt von (2) liegt eher darin, daß wir nicht in der Lage sind, eine präzise Anzahl von Eigenschaften für einen generellen Terminus zu bestimmen, derart daß keine Möglichkeit besteht, daß die oben angeführte Geschichte weiter geführt werden kann. Dies ist der Grund dafür, daß Locke alle Termini von natürlichen Arten "imperfect" nennt. ${ }^{39}$

Wenn unsere bisherige Betrachtung stimmt, zeigt sie, daß sich Locke der Schwierigkeiten völlig bewußt ist, denen wir ausgesetzt sind, wenn wir mangels Erkenntnis der (RI)s (bzw. der (SII)) nur über sekundäre Qualitäten als Identitätskriterien verfügen (Locke setzt dies voraus). Dies heißt, anders formuliert, daß wir alle diese Schwierigkeiten beseitigen können, wenn wir Erkenntnis der (RI)s besäßen. Diese Meinung äußert Locke in der Tat an vielen Stellen im Essay.

\section{III. Das erklärungsbedürftige Phänomen (II)}

Wenn sich Locke, wie wir gesehen haben, nicht nur über die beiden Rollen der (RI), sondern auch über den praktischen Nutzen ihrer Erkenntnis im klaren ist, kann der Grund dafür, daß Locke von der Suche nach der (RI) abrät, nicht darin liegen, daß er glaubt, daß ihre

\footnotetext{
${ }^{38}$. Vgl. III.IX.8., 13 und 15.

${ }^{39}$. unter der Voraussetzung, daß wir die (RI) nicht identifizieren können.
} 
Erkenntnis keinen praktischen Nutzen hat. Wie wir gesehen haben, ist das Gegenteil der Fall. Worin liegt dann der Grund? Auf diese Frage antwortet Yost, daß Locke nicht glaubt, daß es möglich sei, die Mikrostruktur physikalischer Gegenstände mittels des hypothetischdeduktiven Verfahrens im Rahmen der Korpuskular-Theorie zu identifizieren:

"It therefore seems extremely likely to me that if Locke had believed it possible to get probable knowledge of specific sub-microscopic mechanisms-specific enough to permit one to "read off" the hitherto unknown powers of observable things-he frequently would have urged investigators to seek it." ${ }^{\text {H0 }}$

In der Tat gibt es viele Stellen im Essay, an denen Locke behauptet, daß es nicht möglich sei, die Mikrostruktur herauszufinden. Wenn dem so ist, führt dies zu einer weiteren Frage: Warum glaubt Locke dies? Ich glaube, daß man dafür weder eine Erklärung noch ein Argument im Essay finden kann. Sonst hätte Mackie auf diese Frage nicht folgendermaßen zu antworten versucht:

"Looking back after nearly three centuries of scientific advance, we can easily see where Locke was mistaken about theses issues. Chemists and physicists have achieved the sort of detailed knowledge of microstructure of which Locke despaired, and they have achieved it not, in the main, by devising more powerful microscopes but by fraiming and testing detailed hypotheses, a method whose power and value Locke did not realize. ${ }^{.11}$

Dies ist eine Vermutung, aber eine richtige. Wenn Locke, wie Mackie vermutet, zu der Meinung gekommen ist, daß es nicht möglich sei, die Mikrostruktur zu erkennen, weil er sich nicht vorstellen konnte, wie dies möglich sei, ist dies nachvollziehbar. Nicht nachvollziehbar aber ist, wie ein Autor, der sich weder als Naturwissenschaftler versteht noch so verstanden werden will, seine Gedanken so nachdrücklich vertreten kann, daß er die dritte Art der Erkenntnis, nämlich die Erkenntnis der materiellen Substanzen, als die der Ko-Existenz, oder notwendigen Verbindung von ausschließlich beobachtbaren Eigenschaften definiert. ${ }^{42}$ Dies ist alles andere als trivial. Warum tut Locke dies?

Man könnte vielleicht einwenden, daß es Locke nicht darauf ankam, seine Position so extrem zuzuspitzen. Die richtige Lesart wäre demnach eher diese: Locke verneint nicht die Möglichkeit der Erkenntnis der (RI). Seine Absicht ist nur die, darzustellen, was seiner Meinung nach bei dem damaligen Zustand der Erkenntnis getan werden sollte, um die praktischen Lebensumstände zu verbessern. ${ }^{43}$ Obwohl ich glaube, daß dieses Thema durch

\footnotetext{
${ }^{40}$. Yost, S. 127.

${ }^{41}$. Mackie, S. 101. Vgl. auch S. 97-98.

${ }^{42}$. Vgl. IV.I.2.

${ }^{43}$. IV.XII.11-12. kann dafür ein Beleg sein.
} 
meine Auseinandersetzung mit Yolton bereits erledigt ist, will ich hier doch noch einen anderen Beleg dafür liefern, daß Locke in der Tat die stärkere These vertritt, nämlich die, daß es nicht einfach nur von dem damaligen Zustand der Erkenntnis aus, sondern überhaupt unmöglich ist, Erkenntnis der (RI) zu erwerben. Dies zeigt sich deutlich, wenn wir betrachten, warum er den Versuch kritisiert, mit generellen Termini auf reale Essenzen zu referieren. 


\section{IV. Lockes Kritik an dem Versuch, mit generellen Termini auf reale Essenzen zu referieren}

Locke hat erkannt, daß wir generelle Termini mit der Absicht gebrauchen, auf reale Essenzen von natürlichen Arten zu referieren. Er sieht den Grund dafür darin, daß wir so die Möglichkeit ausschließen können, aneinander vorbei zu reden: "To avoid this (aneinander vorbei zu reden; v. Verf.) therefore, they have supposed a real Essence belonging to every Species,..." ${ }^{4}$ Dies ist aber eine Verwechslung von Mittel und Zweck. Wenn unsere Verwendung von generellen Termini die Möglichkeit des Mißverständnisses ausschließt, ist dies nicht der Zweck, sondern vielmehr eine Konsequenz aus jenem Gebrauch. Die Möglichkeit, uns aneinander vorbei zu reden, besteht nämlich nur dann, wenn wir, wie Locke es von uns fordert, generelle Termini bloß synonym mit Ausdrücken für Bündel von Eigenschaften verwenden. Aber wir verwenden sie nicht in dieser Weise. Es ist zwar wahr, daß wir einen generellen Terminus, z.B. "Gold", immer mit Bezug auf eine Eigenschaft oder ein Bündel von Eigenschaften verwenden. Aber dies heißt nicht, daß wir es für synonym mit einem Ausdruck für ein Bündel von Eigenschaften halten. Wie Kripke richtig sagt, benutzen wir die Eigenschaften nur, um die Referenz festzulegen, während wir mit dem Terminus auf die reale Essenz zu referieren beabsichtigen.

Obwohl Locke erkannt hat, daß wir generelle sortale Termini mit der Absicht verwenden, auf reale Essenzen zu referieren, und daß damit die Möglichkeit ausgeschlossen ist, aneinander vorbei zu reden, so verwirft er doch diese Art und Weise des Gebrauchs der Termini als Mißbrauch. Worin liegt der Grund dafür? Liegt der Grund einfach darin, daß Menschen beim damaligen Stand der Erkenntnis noch keine realen Essenzen erkannt haben? Wenn dies der Grund wäre, würde der letzte Grund darin liegen, daß in diesem Fall alle generellen Termini Locke zufolge sinnlos sein würden, da wir sie mit etwas verbinden, das wir nicht kennen, wie Mackie behauptet. ${ }^{45}$ Aber dies ist ein Irrtum. Warum dies so ist, kann folgendermaßen gezeigt werden.

Es ist wichtig darauf aufmerksam zu machen, daß Locke zu Recht zweierlei unterscheidet. Es ist eine Sache, wie wir die Referenz eines generellen Terminus festlegen, und es ist eine andere Sache, worauf wir mit dem Terminus referieren. ${ }^{46}$ Wenn wir einen generellen Terminus mit Ausdrücken von Eigenschaften (z.B. "F" und "G" ) verbinden, referieren wir damit nach Locke nicht auf die beiden Eigenschaften, sondern auf die physikalischen Gegenstände, die die beiden Eigenschaften besitzen. ${ }^{47}$ Dies ist der Grund dafür, daß alle generellen Termini von Substanzen

\footnotetext{
${ }^{44}$. III.VI.49. Vgl. III.X.17-19.

45. Vgl. Mackie, S. 98.

46. Vgl. II.XXXI.6-8.

${ }^{47}$. Dies tun wir einerseits, indem wir ihn mit Ausdrücken von Eigenschaften festlegen, und andererseits, indem wir eine Annahme machen, die Locke auch macht: "Nature makes many particular Things, which
} 
unvollkommen sind, denn es ist möglich, weitere, sogar unendlich viele Eigenschaften der Gegenstände zu identifizieren. Dies zeigt, daß Locke die Möglichkeit zugibt, einen generellen Terminus mit der Absicht zu verwenden, auf etwas zu referieren, das noch nicht vollständig erkannt worden ist. Daraus folgt, daß er nicht der Ansicht ist, daß generelle Termini einfach sinnlos werden, wenn wir sie mit der Absicht gebrauchen, auf die (RI) zu referieren, ohne in der Lage zu sein, die (RI) zu erkennen. Wenn dem so ist, ist Locke nicht berechtigt, daran zu kritisieren, daß wir einen Terminus mit der Absicht verwenden, auf reale Essenzen zu referieren, es sei denn, er glaubt, daß es unmöglich sei, die (SII) bzw. die (RI) zu erkennen. So ist es auch in der Tat. Dies zeigt sich daran, daß er letzten Endes nominale Essenzen von natürlichen Arten für notwendige Bedingungen dafür hält, von realen Essenzen von natürlichen Arten zu sprechen. ${ }^{48}$ Dies bedeutet nichts anderes als die Verneinung der Möglichkeit der Erkenntnis von realen Essenzen überhaupt. ${ }^{49}$

Was dies betrifft, kann man sagen, daß Locke mit seiner Kritik Recht hat, wenn gezeigt werden kann, daß es nicht möglich ist, die (SII) bzw. die (RI) zu erkennen. Wenn dies gezeigt wird, werden wir darauf verzichten, generelle Termini mit der Absicht zu verwenden, auf die (RI) zu referieren. Die Frage, ob wir die (SII) bzw. die (RI) erkennen können oder nicht, ist aber eine empirische Frage.

\section{Fazit}

Wir haben diesen Teil über Locke mit der Beobachtung begonnen, daß Locke die Suche nach der (SII) bzw. der (RI) mit Hilfe des hypothetisch-deduktiven Verfahrens im Rahmen der Korpuskular-Theorie nicht empfiehlt und von ihr abrät. Dies ist deshalb bemerkenswert, weil er die Theorie nicht nur für die Beste hält, sondern auch deswegen, weil er davon Gebrauch macht. Wir haben deshalb hier den Versuch gemacht zu verstehen, warum Locke zu jener Theorie Stellung nimmt. Fassen wir zuerst unsere Ergebnisse zusammen.

Das erste Ergebnis unserer Überlegungen besagt, daß Locke nicht die These vertritt, daß die Erkenntnis von Vorstellungen von ihren Ursachen in dem Sinne unabhängig ist, daß für die Wahrheit oder die Bedeutung von einfachen Vorstellungen die Erkenntnis ihrer Ursachen irrelevant ist. Daß diese Interpretation von Ayers sehr problematisch ist, habe ich in Auseinandersetzung mit Ayers gezeigt. Wenn dem so ist, ergibt sich die Frage, worauf Locke

\footnotetext{
do agree one with another, in many sensible Qualities, and probably too, in their internal frame and Constitution" (III.VI.36.)

${ }^{48}$. Vgl. III.VI.6.

${ }^{49}$. Dies ist keine Verneinung von (RI) bzw. (SII). Deshalb kann dies nicht für Ayers sprechen.
} 
mit der Behauptung hinaus wollte, daß Erkenntnis von Vorstellungen von ihren Ursachen unabhängig ist. Diese Frage haben wir offen gelassen.

Das zweite Ergebnis besagt, daß Locke kein pragmatisches Argument dafür hat, uns von dem hypothetisch-deduktiven Verfahren abzuraten. Obwohl es ein paar Stellen im Essay gibt, an denen er dafür zu argumentieren scheint, daß Erkenntnis von der (SII) bzw. der (RI) keinen praktischen Nutzen habe, sprechen doch seine Ausführungen zu (SII) bzw. (RI) eindeutig dafür, daß das Gegenteil der Fall ist.

Das letzte Ergebnis ist daher, daß der eigentliche Grund dafür einzig und allein darin liegt, daß Locke glaubt, daß es nicht möglich sei, die (SII) bzw. die (RI) zu identifizieren.

Nun besteht das Problem dabei, wie schon gesagt, weder darin, daß Locke glaubt, daß es nicht möglich sei, die (SII) bzw. die (RI) herauszufinden, noch darin, daß er kein Argument dafür hat. All dies ist nachvollziehbar. Das Problem besteht auch nicht darin, daß er versucht, einen anderen möglichen Weg zu finden, das eigene Leben besser zu führen. Sein auf der Unterscheidung von einfachen und komplexen Vorstellungen beruhender Kompositionalismus ist ein Ergebnis dieses Versuchs. Dies ist auch richtig, es sei denn, daß man wie Ayers einen Konflikt zwischen Descartes und Locke sieht. Abgesehen von Meinungsverschiedenheiten zwischen beiden bezüglich anderer Themen gibt es, wie gesagt, keine Meinungsverschiedenheit zwischen ihnen hinsichtlich der Akzeptanz der Unterscheidung von primären und sekundären Qualitäten, und auch in der Hinsicht, daß die naturwissenschaftliche Untersuchung im Rahmen dieser Unterscheidung die Form des hypothetisch-deduktiven Verfahrens annehmen wird. ${ }^{50}$ Diesbezüglich liegt der einzige Unterschied zwischen den beiden nur darin, daß Descartes optimistisch hinsichtlich der Möglichkeit ist, die (SII) bzw. die (RI) mittels des hypothetischdeduktiven Verfahrens herauszufinden, während dies für Locke nicht der Fall ist. So ist der Kompositionalismus auch Locke zufolge nur die zweitbeste Lösung, aber die einzig realisierbare. Ein Problem entsteht aber daraus, daß Locke ohne irgendein Argument seine Position so nachdrücklich vertritt. Wie kann er überall im Essay behaupten, daß es nicht möglich sei, die (SII) bzw. die (RI) zu erkennen, obwohl er sich weder als Naturwissenschaftler versteht noch so verstanden werden will? Dies war das zweite erklärungsbedürftige Phänomen.

Kann man dieses Phänomen einfach ignorieren? Wenn man dies tut, muß man bereit sein, alle Behauptungen Lockes zu ignorieren, daß Erkenntnis von Vorstellungen von der Erkenntnis ihrer Ursachen unabhängig sei, daß Erkenntnis von ihren Ursachen keinen praktischen Nutzen habe. Kann man all dies einfach ignorieren? Ich denke nicht. Dafür sind all diese Behauptungen zu zahlreich und zu stark. Wie kann und soll man dann verstehen, warum Locke solche Behauptungen gemacht hat? Wir können eine Antwort mit Rekurs auf Lockes Erklärung der

${ }^{50}$. Vgl. VI.XVI.12. 
Motivation geben, sich im Essay mit der Restriktionsfrage zu beschäftigen. Seine Antwort ist folgende:

"This was that which gave the first Rise to this Essay concerning the Understanding. For I thought that the first Step towards satisfying several Enquiries, the Mind of Man was very apt to run into, was, to take a Survey of our own Understandings, examine our own Powers, and see to what Things they were adapted. Till that was done I suspected we began at the wrong end, and in vain sought for Satisfaction in a quiet and secure Possession of Truths, that most concern'd us, whilst we let loose our Thoughts into the vast Ocean of Being, as if all that boundless Extent, were the natural, and undoubted Possession of our Understanding, wherein there was nothing exempt from its Decisions, or that escaped its Comprehension. Thus Men, extending their Enquiries beyond their Capacities, and letting their Thoughts wander into those depths, where they can find no sure Footing; 'tis no Wonder, that they raise Questions, and multiply Disputes, which never coming to any clear Resolution, are proper only to continue and increase their Doubts, and to confirm them at last in Perfect Scepticism. ${ }^{151}$ (Hervorhebung d. Verf.)

Worauf ich aufmerksam machen will, ist folgendes. Locke ist der Ansicht, daß die Beschäftigung mit Gegenständen, die über unsere Erkenntisfähigkeit hinaus gehen, uns in einen "perfect Scepticism" verfallen läßt. So sieht er den größten Verdienst seiner Beschäftigung mit der Restriktionsfrage darin, daß sie uns daran hindern kann, in den "perfect Skepticism" zu verfallen, aber nicht deswegen, weil der Skeptizismus dadurch widerlegt wird, sondern deswegen, weil wir dadurch davon abgehalten werden, uns mit Gegenständen zu beschäftigen, die über unsere Erkenntnisfähigkeit hinausgehen. Daraus ergibt sich eindeutig, daß Locke, wenn er uns von dem hypothetisch-deduktiven Verfahren im Rahmen der KorpuskularTheorie abhält, indem er behauptet, daß es unmöglich sei, die (SII) bez. die (RI) zu erkennen, dies aus Gründen tat, daß die naturwissenschaftliche Untersuchung mit dem Verfahren im Rahmen der Korpuskular-Theorie uns in den "perfect Scepticism" verfallen läßt. Dies ist aber sehr merkwürdig. Warum bringt Locke, obwohl seine Beschäftigung mit der Restriktionsfrage Fälle von Erkenntnis voraussetzt, das Problem des Skeptizismus wieder in Verbindung? Sie hat nämlich nichts mit dem Problem des Skeptizismus zu tun. Wie ist denn Locke überhaupt zu der Auffassung gekommen, nämlich zu der Auffassung, daß wir in den "perfect Scepticism" verfallen, wenn wir uns mit Gegenständen beschäftigen, die über unsere Erkenntnisfähigkeit hinausgehen? Diese Auffassung ist nicht nachvollziehbar. Wie kann mein Wissen, daß ich zwei Hände habe, dadurch ins Zweifel gezogen werden, daß ich mich mit Gegenständen beschäftige, die über unsere Erkenntnismöglichkeit hinausgehen? Um mit der KorpuskularTheorie zu sprechen: Warum soll die naturwissenschaftliche Untersuchung mittels des hypothetisch-deduktiven Verfahrens im Rahmen der Korpuskular-Theorie uns in den "perfect

\footnotetext{
${ }^{51}$. I.I.7.
} 
Scepticism" verfallen lassen? Die einzige Möglichkeit, eine Antwort auf diese Frage zu geben, besteht darin anzunehmen, daß Locke, aus welchen Gründen auch immer, Descartes als Beispiel dafür gesehen hat. Es ist fast überflüssig zu sagen, daß Locke die Regulae gut kennt, in denen nur von der Restriktionsfrage, die Locke im Essay aufgenommen hat, die Rede ist. Das Problem des Skeptizismus tritt erst nach den Regulae auf. Wenn ich mich nicht irre, hat Locke den Anlaß für Descartes, sich mit dem Skeptizismus zu beschäftigen und letzten Endes in einen "perfect Scepticism" zu verfallen, darin gesehen, daß Descartes Erkenntnis im strengsten Sinne (intuitive oder deduktive) in Bezug auf Gegenstände zu erwerben versucht hat, von denen Locke es für unmöglich hält. ${ }^{52}$ Damit hat Locke Descartes' Projekt in den Meditationes genauso wie Williams verstanden, nämlich als den Versuch, eine "absolute conception" (die er oben im Zitat als die Suche nach "perfect Knowledge" bezeichnet hat) zu entwickeln. Andererseits soll Locke den Ansatz dazu in dem hypothetisch-deduktiven Verfahren im Rahmen der Korpuskular-Theorie, das Descartes empfohlen hat, gesehen haben. ${ }^{53}$ Locke hat geglaubt, daß das beste Mittel dagegen, in den "perfect" Scepticism" zu verfallen, eher darin liege, den Weg zum Skeptizismus von vornherein zu versperren. Diese Position sehe ich in seiner Stellungnahme zum hypothetisch-deduktiven Verfahren im Rahmen der Korpuskular-Theorie. Die naturwissenschaftliche Untersuchung mittels jenes Verfahrens als die Suche nach (SII) bzw. (RI) enthält ihm zufolge nämlich die Gefahr, in einen "perfect Scepticism" zu verfallen. In diesem Zusammenhang halte ich es nicht für Zufall, daß Locke, wenn es von Erkenntnis der (SII) bzw. der (RI) die Rede ist, immer Ausdrücke wie "perfect Knowledge" verwendet oder metaphysische Themen "Erkenntnis von Seele, Gott usw." einführt. ${ }^{54}$ Demgemäß versucht er uns mit allen möglichen Mitteln von dem Versuch abzuhalten, die (SII) bzw. die (RI) zu erkennen, und zwar nicht weil er erkannt hätte, daß dies nicht möglich ist, sondern allein aus dem oben genannten Grund. Seine wiederholte Behauptung, daß es unmöglich sei, die (SII) bzw. die (RI) zu erkennen, ist nur ein strategisches Mittel, um uns von einem entsprechenden Versuch abzuhalten. Seine Behauptung, daß dies keinen praktischen Nutzen habe, selbst wenn es möglich wäre, die (SII) bzw. die (RI) zu erkennen, ist nur ein zusätzliches strategisches Mittel und seine Behauptung, daß Erkenntnis von Vorstellungen von der Erkenntnis ihrer Ursachen unabhängig sei, ebenfalls.

Wenn meine Überlegung richtig ist, kann man sagen, daß Locke sich zwar nicht offensichtlich mit dem Problem des Skeptizismus beschäftigt hat. Aber bewußt oder unbewußt hatte Locke das Descartes' Problem des Skeptizismus vor Augen, während er den Essay schrieb. Er hätte sich alle jene Ausführungen sparen können, wenn er lediglich das begrenzte Ziel gehabt hätte zu zeigen, wie wir Erkenntnis von beobachtbaren Qualitäten mittels der beschreibenden

\footnotetext{
52. So hat auch Locke Descartes' Problem des Skeptizismus mißverstanden.

53. Was Lockes Kritik an Descartes' in dieser Hinsicht betrifft, siehe Aaron, S. 9-10.

${ }^{54}$. Siehe II.XXIII.12. und Vgl. IV.III.6.
} 
Methode erwerben und erweitern können. Alle jene Ausführungen klingen wie Moores "Ich habe zwei Hände". 
Erwähnte Literatur

A. Werke von Descartes und Locke

Descartes, René:

OEuvres de Descartes, publiées par Ch. Adam et P. Tannery, Paris, 1897-1913

Briefe (1629-1650), Übers. v. Fritz Baumgart, Köln und Krefeld: Staufen Verlag, 1949

Meditationen, Übers. v. Artur Buchenau, Hamburg: Felix Meiner Verlag, 1915

Die Prinzipien der Philosophie, Übers. v. Artur Buchenau, Hamburg: Felix Meiner Verlag, 8. Aufl., 1992

Regeln, Revidiert, übersetzt und hrsg. von Heinrich Springmeyer, Lüder Gäbe und Hans Günter Zekl, Hamburg: Felix Meiner Verlag, 1973

Die Welt oder Abhandlung über das Licht, Nachwort und Übers. v. Günther Matthias Tripp, Weinheim: VCH, Acta humaniora, 1989

Locke, John:

An Essay concerning Human Understanding, Hrsg. v. P.H. Nidditch, Oxford: Clarendon Press, 1975

B. Weitere Literatur

1. Bücher

Aaron, R.I., John Locke, Oxford: Clarendon Press, 1937

Alexander, P., Ideas, Qualities and Corpuscles, Cambridge: Cambridge University Press, 1985

Ayers, M., Locke, Volume I und II, London und New York: Routledge, 1991

Beck, L.J., The Method of Descartes: A Study of the Reguale, Oxford: Clarendon Press, 1952

Bennett, J.F., Lockes, Berkeley, Hume: Central Themes, Oxford: 1971

Buchdahl, G., Metaphysics and The Philosophy of Science, Oxford: Basil Blackwell, 1961 
Clarke, D.M., Descartes' Philosophy of Science, Manchester: Manchester University Press, 1982

Curley, E.M., Descartes Aainst the Skeptics, Oxford: Basil Blackwell, 1978

Frankfurt, H.G., Demons, Dreamers, and Madmen: The defense of reason in Descartes's "Meditations", Indianapolis: Bobbs-Merrill, 1970

Kambartel, F., Erfahrung und Struktur. Bausteine zu einer Kritik des Empirismus und Formalismus, Frankfurt: Suhrkamp Verlag, 1976

Kripke, S., Naming and Necessity, Oxford: Basil Blackwell, 1972

Krüger, L., Der Begriff des Empirismus, Berlin, New York: Walter de Gruyter, 1973

Mackie, J.L., Problems from Locke, Oxford: Clarendon Press, 1976

Perler, Dominik, Repräsentation bei Descartes, Frankfurt am Main: Vittorio Klostermann, 1996

Popkin, R.H., The History of Scepticism from Erasmus to Spinoza, Berkeley etc.: University of California Press, 1979

Sextus Empiricus, Grundriss der pyrrhonischen Skepsis, Einleitung und Übersetzung v. Malte Hossenfelder, Frankfurt: Suhrkamp, 1968

Smith, N.K., Studies in the Cartesian Philosophy, New York: Russell \& Russell, 1962

Stroud, B., The Significance of Philosophical Scepticism, Oxford: Clarendon Press, 1984

Unger, P., Ignorance, Oxford: Clarendon Press, 1975

Williams, B., Descartes: The Project of Pure Enquiry, Penguin Books, 1978

Wilson, M.D., Descartes, London, Henley and Boston: Routledge \& Kegan Paul, 1978

Yolton, J.W., Locke and the Compass of Human Understanding, Cambridge: Cambridge University Press, 1970

ders., Perceptual Acquaintance from Descartes to Reid, Oxford: Basil Blackwell, 1984

\section{Aufsätze}

Ayer, A.J., Cogito, ergo sum, in: Analysis, Vol. 14, 1953-1954

Ayers, M., Ideas of Power and Substance, in: Locke on Human Understanding, Hrsg. v. I.C. Tippton, Oxford: University Press, 1977

Carnap, R., Empiricism, Semantics and Ontology, Supplement A, in: ders., Meaning and Necessity, 2. Aufl., Chicago, 1958

Clarke, T., The Legacy of Skepticism, in: The Journal of Philosophy, Volume LXIX, 1972

Garber, D., Science and Certainty, in: Descartes; Critical and Interpretive Essays, Hersg. v. Michael Hooker, Baltimore and London: John Hopkins University Press, 1978 
Hatfield, G., Reason, Nature, and God in Descartes, in: Essays on the Philosophy and Science of Rene Descartes, Hrsg. v. Stephen Voss, New York and Oxford: Oxford University Press, 1993

ders.: Science, Certainty, and Descartes, in: PSA, 1988

Jackson, R., Locke's Version of Representative Perception, in: Locke on Human Understanding, 1977

ders., Locke's Distinction between Primary and Secondary Qualities, in: Locke on Human Understanding, 1977

Laudan, L., The Nature and Sources of Locke's Views on Hypotheses, in: Locke on Human Understanding, 1977

Moore, G.E., Proof of an External World, in: ders., Philosophical Papers, London: George Allen \& Unwin Ltd, 1959

ders., A Defense of Common Sense, in: ders., Philosophical Papers, 1959

ders., Certainty, in: ders., Philosophical Papers, 1959

Ryle, G., John Locke on the Human Understanding, in: Locke and Berkeley, Hrsg. v. Martin und Armstrong, London: Macmillan

Sepper, D. L., Ingenium, Memory Art, and the Unity of Imaginative Knowing in the Early Descartes, in: Essays on the Philosophy and Science of René Descartes, 1993

Striker, G., The Ten Tropes of Aenesidemus, in: The Skeptical Tradition, Hersg. v. Myles Burnyeat, Berkeley etc.: University of California Press, 1983

Williams, B., Deciding to believe, in: ders., Problems of the Self, Cambridge, 1973

ders., Descartes's Use of Skepticim, in: The Skeptical Tradition, 1983

Yost Jr., R.M., Locke's Rejection of Hypotheses about Sub-Microscopic Events, in: Journal of the History of Ideas, XII, 1951 